\title{
THE ORUANUI ERUPTION: \\ INSIGHTS INTO THE GENERATION AND DYNAMICS OF THE WORLD'S YOUNGEST SUPERERUPTION
}

\author{
Aidan S.R. Allan
}

A thesis submitted to Victoria University of Wellington

in fulfilment of the requirements for the degree of Doctor of Philosophy in Geology

Victoria University of Wellington

Wellington, New Zealand 


\section{ABSTRACT}

This work investigates the pre- and syn-eruptive magmatic processes that culminated in the world's youngest supereruption - the $\sim 25.4 \mathrm{ka}, 530 \mathrm{~km}^{3}$ Oruanui eruption from Taupo volcano, New Zealand - from the perspective of crystals contained in single parcels of frozen magma (pumice). The eruption is unusual in its variety of magmatic compositions. About $98-99 \%$ by mass of the juvenile material is high- $\mathrm{SiO}_{2}$ rhyolite (HSR; $>74 \mathrm{wt} \% \mathrm{SiO}_{2}$ ), with lesser volumes of tholeiitic and calc-alkaline mafic magmas (total 3-5 km³ basaltic andesite to andesite: 53-63\% $\mathrm{SiO}_{2}$ ), low-silica rhyolite (LSR: 0.1-0.5 km³; $<74 \mathrm{wt} \% \mathrm{SiO}_{2}$ ) and a 'foreign' biotite-bearing rhyolite from an adjacent magma source $\left(0.03 \mathrm{~km}^{3} ; \sim 74 \mathrm{wt} \% \mathrm{SiO}_{2}\right)$. Detailed textural and chemical data from amphibole, plagioclase, and orthopyroxene are placed within the context of an established time-stratigraphic, volcanological and petrographic framework, of unrivalled detail globally for an eruption of this age and magnitude. Other previously published information from zircon and quartz is also incorporated. This unique contextual information is used to constrain observations and inferences regarding the processes that moved the Oruanui magma from a largely uneruptible crystal-rich progenitor at depth (where an eruption was possible), to a highly eruptible melt-rich magma at shallow crustal levels (where eruption was inevitable).

A thermally and compositionally stratified crystal mush body, with an upper $\mathrm{SiO}_{2}$-saturated and quartz bearing cap at $\sim 3.5 \mathrm{~km}$ depth and quartz-free roots extended down to at least $\sim 10 \mathrm{~km}$. This inference is made on three bases. 1) That the quartz cores contain trapped melt that is more evolved than the melt component of the immediately pre-eruptive magma body, indicating their growth within mush from a more evolved interstitial melt. 2) The majority of plagioclase, amphibole, and orthopyroxene cores, in contrast to quartz have compositions that indicate growth from less evolved melts than that encountered in the final melt-dominant magma body. 3) Barometric estimates from amphibole core compositions indicate derivation from a range of depths $(\sim 3.5$ to $10 \mathrm{~km})$.

The spatial and temporal transitions from mush to melt-dominant magma body are recorded in the textural and compositional zonations within the crystal phases. Crystals from all levels of the zoned mush body were entrained during the melt extraction process resulting in a diversity of crystal compositions being brought together in the melt-dominant magma body. Textural disequilibrium features in the cores of orthopyroxene and plagioclase crystals reflect their temporary departure from stability during the accompanying significant decompression (recorded in the amphibole model pressures). Counterpart chemical signatures, reflecting this partial orthopyroxene and plagioclase dissolution, are recorded in the amphiboles which show no textural evidence for destabilisation during ascent. Crystal chemical and textural zonation in the rim growths of the plagioclase, orthopyroxene, and amphibole record further crystallisation 
in the accumulating melt-dominant magma body, and reflect cooling and compositional evolution of the body towards its final pre-eruptive conditions. The timing of growth of the melt dominant magma body is constrained by Fe-Mg diffusion modelling of key boundaries in orthopyroxene crystals. Accumulation of this body began only $\sim 1600$ years and peaked at 230 years prior to the eruption, as vast volumes of melt and entrained crystals were drained from the mush body and began to accumulate at shallower levels ( $\sim 3.5$ to $6.0 \mathrm{~km}$ depth). Within the thin, sill-like melt-dominant magma body, significant heat loss drove vigorous convection. Textural and chemical zonation patterns within the rim-zones of plagioclase, orthopyroxene and amphibole, inferred to have grown solely in the melt-dominant magma body, depict a secular cooling and melt evolution trends towards final uniform thermal $\left(\sim 770^{\circ} \mathrm{C}\right)$ and compositional conditions inferred for the HSR magma.

Despite the rapid accumulation of a vast volume of crystal-poor HSR magma at shallow crustal levels, the apparent gas-saturated nature of that magma, and vigorous convection within the melt-dominant magma body itself, the chronologies from HSR orthopyroxene imply that the magma underwent a period of stasis of about 60 years. The presence of $3-16 \mathrm{wt} \%$ of 'foreign' biotite-bearing juvenile pumices in the early Oruanui fall deposits (phases 1 and 2) show that coincident with the onset of the Oruanui eruption, magma was transported laterally in a dike from an adjacent independent magma system 10-15 km to the NNE to intersect the active Oruanui conduit. Consideration of the tectonic stress orientations associated with this lateral transport imply that an external tectonic influence through a major rifting event was a critical factor in the initiation of the Oruanui eruption. Only the presence of the foreign magma, and linkages to detailed field-based and geochemical constraints enables the tectonic influence to be identified. During the eruption itself, minor quantities of Oruanui LSR magma were erupted, and with a crystal cargo, reflecting derivation from deeper (mostly $>6 \mathrm{~km})$, hotter $\left(\sim 820^{\circ} \mathrm{C}\right)$ sources in the crystal mush roots to the system. Comparisons of LSR crystal compositions with cores to many HSR crystals for plagioclase, orthopyroxene and amphibole imply that the LSR magma was derived from pockets in the mush zone ruptured during escalation of the eruption vigour during phase 3. The LSR and its crystals are inferred to be closely similar in their characteristics to the feedstock magma that generated the melt-dominant body and evolved through subsequent cooling and fractionation to form the HSR.

In overall terms, the evidence from the crystal phases demonstrates that a super-sized rhyolite magma body can be physically created in a geologically very short period of time. The compositional textures and data for all the mineral phases, both previously published and newly presented in this work, yield a consistent story of extraordinarily rapid extraction of LSR melt and entrained crystals into a rapidly evolving and cooling HSR body. When coupled with field constraints these data establish a central role for extensional tectonics in regulating the pre-and syn-eruptive processes and their timings in the Oruanui system. 


\section{Acknowledgements}

The conclusion of this thesis marks the end of a very rich and rewarding 10 years at Victoria (I know -10 years!). During that time I've had the pleasure to be surrounded by some wonderful people who have been extremely generous with their time, knowledge, expertise, guidance and friendship. It is not possible for me to name you all and I will forget people, but you know who you are, so thank you.

To my supervisors: Colin Wilson - the enthusiasm and passion you have for your science has been infectious, and at times, hilarious. Thank you for the time and effort you have poured into this work, your encouragement, and not least, for trusting me with your baby. The day I taught you something new about the Oruanui is the day I knew I was on the right track. Marc-Alban Millet - your offers to read and edit material consistently outpaced my ability to produce it! I'm very grateful for the expertise you've brought and appreciated the regular 'all good?'s from the other side of the globe. Dan Morgan - my unofficial supervisor - your input in the final year and half of this thesis resulted substantial gains and the realisation of some truly exciting results.

This research has been made possible from funding provided by the Marsden Fund of the Royal Society of New Zealand, and a Bright Futures Top Achiever Doctoral Scholarship administered by the Tertiary Education Commission.

Many people have generously shared their expertise and offered invaluable scientific advice along the way - Richard Wysoczanski, Monica Handler, Euan Smith, John Townend and James Muirhead are thanked in particular. Special mention must also go to John Creech for the invaluable EPMA training and Marc-Alban for guidance during whole-rock chemistry and mass spectrometry.

George Cooper - from Cork, to Spiffy Wednesdays, from late night Leo marathons in San Fran, to discussing the finer points of the conceptual crystal mush model and its applicability to homogeneous crystal-poor rhyolites in extensional tectonic settings - throughout this $\mathrm{PhD}$ you've helped ensure that a good laugh has never been far away - 'Thanks Jan'.

To the SGEES crew past and present - Katy Chamberlain, Condor(Man), Ben Hines, Simon (Dmitri) Barker, Melissa, Alexa, James, George (Jorgé, I have your latté) Cooper, Katie Collins, Matt Ryan, 'The Beer Poms' Shaun and Selwyn (I'm over it guys, honestly), Jenni, Loretta, Bella, Denise, Kylie, Kim, Martin, Thor, and many, many more - thanks for making the last several years so much fun.

To my family: Mum and Dad (Carol and Rodney Allan), my brother Hamish, and my Nana Mac (Lorraine McIntyre) - thank you for love and support throughout my career as a professional student.

To my gorgeous children, Mica and Eddie: I love you both.

And Julene - as one long journey to comes to a close I'm looking forward to our journey ahead together. You've provided me with moments of encouragement, and empathy, calm rational advice, and moments of hard-ass-take-no-prisoners-just-get-shit-done, all in perfect balance and delivered with expert timing, to get me across the line. Thank you for everything. I love you. 


\section{Table of Contents}

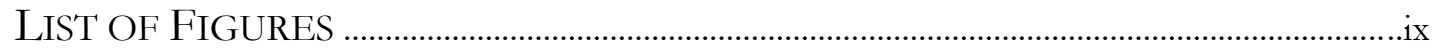

LIST OF TABLES ...........................................................................................................

PUBLICATIONS ARISING FROM THIS THESIS .......................................................................

1. INTRODUCTION

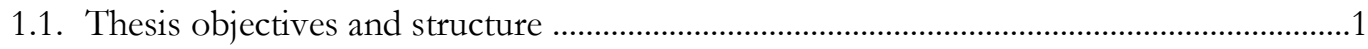

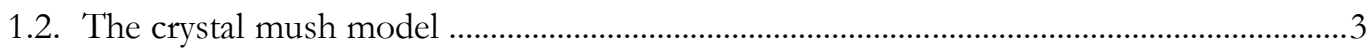

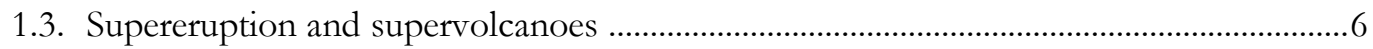

1.4. New Zealand's Taupo Volcanic Zone ………………....................................................

1.4.1. Background to silicic volcanism at Taupo .............................................................

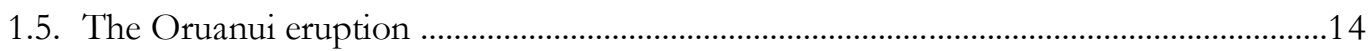

1.5.1. Stratigraphy of the Oruanui eruption deposits ..........................................................14

1.5.2. Key results from previous geochemical studies of the Oruanui eruption deposits

2. THE INVISIBLE HAND: TECTONIC TRIGGERING AND MODULATION OF A RHYOLITIC SUPERERUPTION

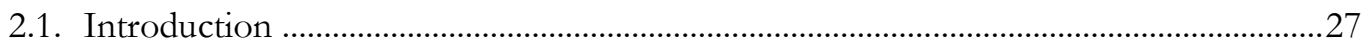

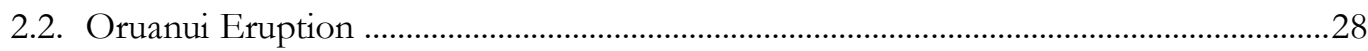

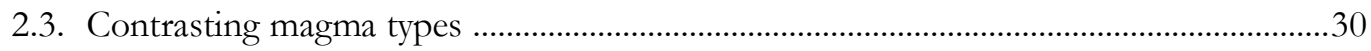

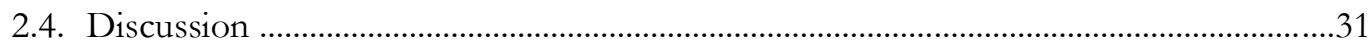

2.4.1. How and why did the magmas interact? ....................................................................31

2.4.2. How do you (prematurely) stop a supereruption? ......................................................34

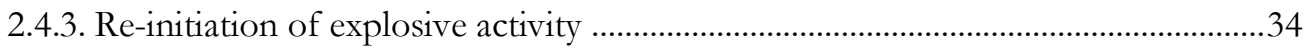

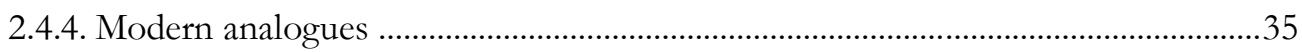

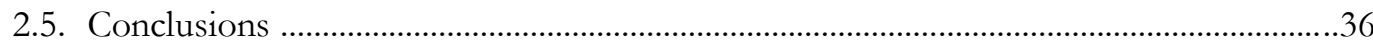

3. FROM MUSH TO ERUPTION IN CENTURIES: ASSEMBLY OF THE SUPERSIZED ORUANUI MAGMA BODY

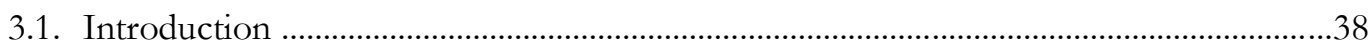

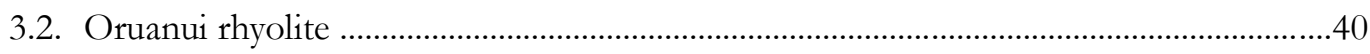

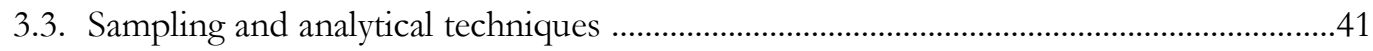

3.4. Crystal textural characteristics and analytical approaches ...............................................42

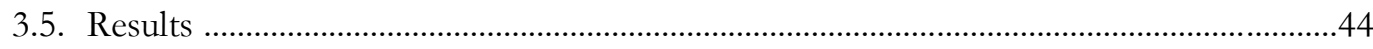

3.5.1. Major element compositions of orthopyroxene and amphibole ...............................44

3.5.2. Amphibole trace element chemistry and pressure estimates .....................................46

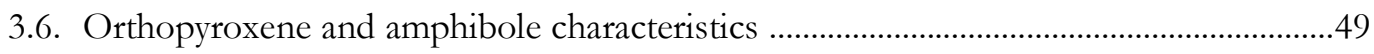

3.6.1. Compositional groupings of Oruanui orthopyroxene and amphibole ..................49

3.6.2. Origins of textural features in Oruanui orthopyroxene ...........................................50

3.6.3. Origins of the inflections in amphibole trace element chemistry ……………........51

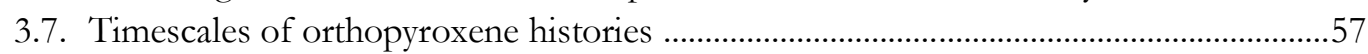

3.8. Modelling of $\mathrm{Fe}-\mathrm{Mg}$ interdiffusion in orthopyroxene ....................................................59

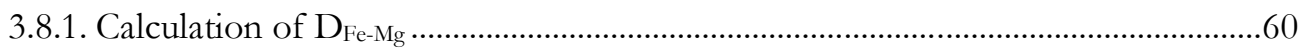

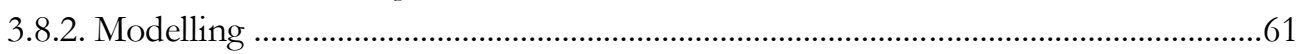

3.9. Implications of Fe- $\mathrm{Mg}$ diffusion timescales in Oruanui orthopyroxene ........................68 
4. FROM DIVERSITY TO UNIFORMITY: ORIGINS OF THE UNZONED ORUANUI MAGMA FROM A STRATIFIED CRYSTAL-RICH RESERVOIR

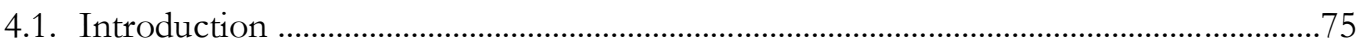

4.1.1. The nature and generation of large silicic magma bodies .......................................75

4.1.2. The crystal archive as a record of processes in crystal-poor ignimbrites...............76

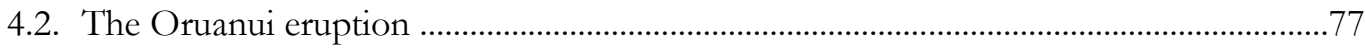

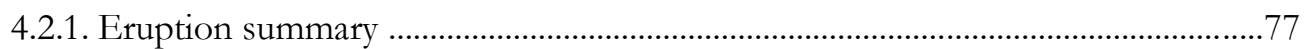

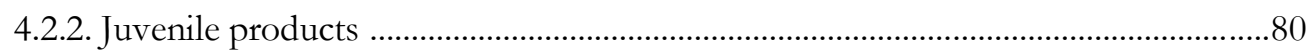

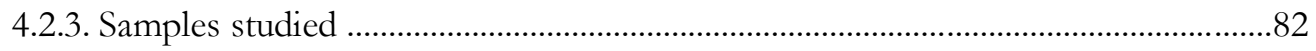

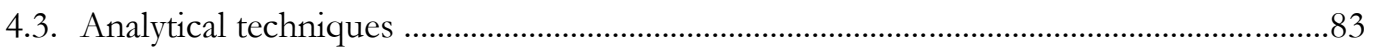

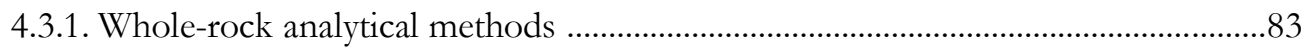

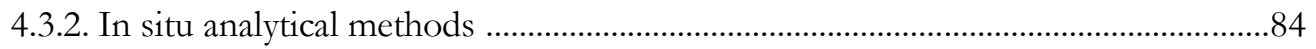

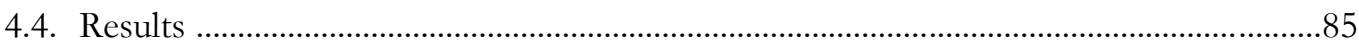

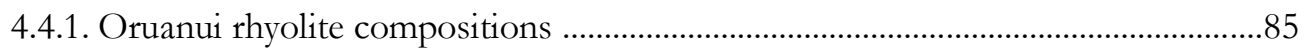

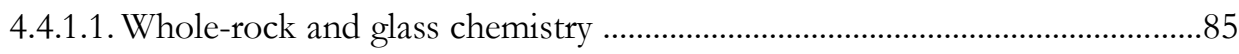

4.4.1.2. Textural linkages between crystal phases in the HSR ....................................90

4.4.1.3. Compositional characteristics of the HSR and LSR crystals .........................94

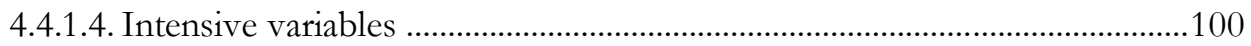

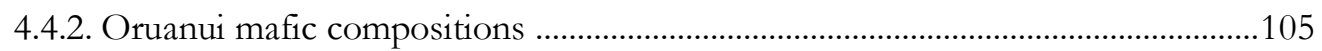

4.4.2.1. Textural characterisation of mafic clasts from thin sections .......................105

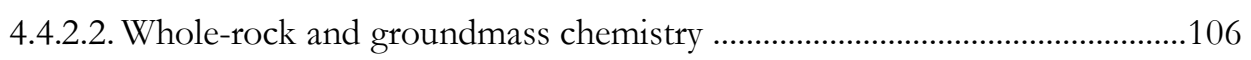

4.4.2.3. Compositional characteristics of mafic crystals .............................................108

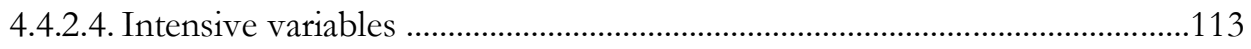

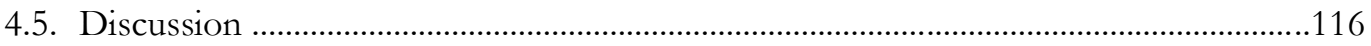

4.5.1. Absence of zonation in the Oruanui HSR magma body ......................................116

4.5.2. Generation of the Oruanui melt-dominant magma body .....................................118

4.5.2.1. A revised (tweaked) model for the generation of the melt-dominant magma

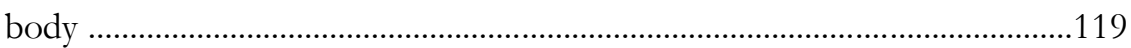

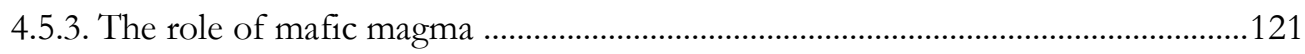

4.5.4. Timescales of processes in the Oruanui system ....................................................124

4.5.4.1. Fe-Mg diffusion timescales from orthopyroxene .........................................124

4.5.4.2. Fe-Ti diffusion timescales from magnetite ...................................................124

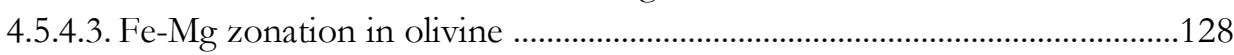

4.5.4.4. A cascade of timescales inferred from the Oruanui crystal archive ..........128

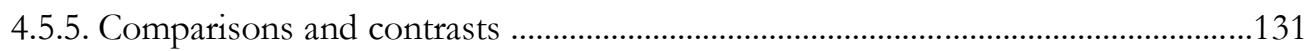

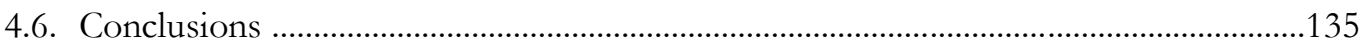

5. INTENSIVE PARAMETERS IN SILICIC MAGMAS: AN EXTENDED DISCUSSION

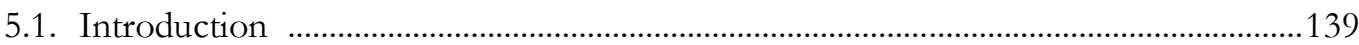

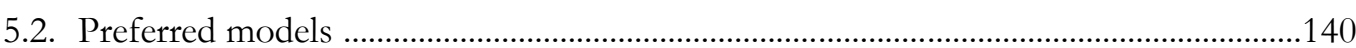

5.2.1. Fe-Ti oxide thermometry ……………………………....................................... 140

5.2.2. Amphibole-based thermometry and barometry ……………………………….....148

5.2.2.1. The pressure-sensitive Al-Tschermak exchange ............................................149

5.2.2.2. Fluctuations in apparent pressure in single crystals ......................................150

5.2.3. Plagioclase-melt and orthopyroxene-melt thermometry ………………………...154

5.2.4. Volatile saturation pressures ............................................................................157

5.3. Models investigated, but not relied on ........................................................................ 


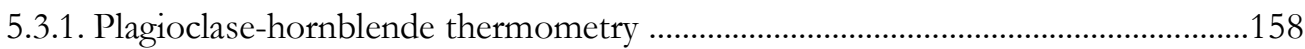

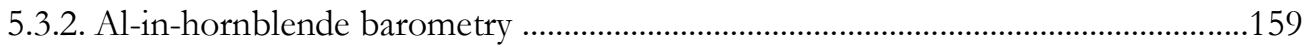

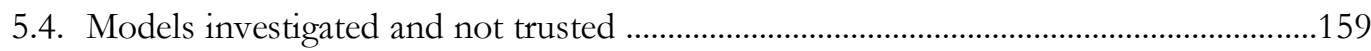

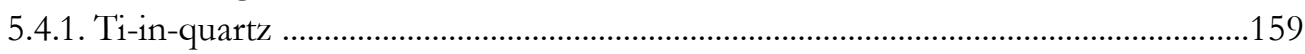

\section{SYNTHESIS AND CONCLUSIONS}

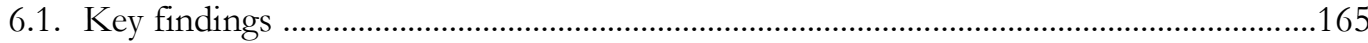

6.1.1. What determines the precise moment a large silicic eruption begins? .................165

6.1.2. Was the Oruanui magma extracted from a crystal-mush source? ..........................168

6.1.3. Over what timescales did the Oruanui melt-dominant magma body accumulate?

6.1.4. What are the controls on determining whether a magma body is zoned versus unzoned?

6.1.5. To what extent are the Oruanui crystals inherited from older sources, versus grown in situ within the melt-dominant magma body?

6.1.6. What information about magma intensive parameters can be reliably inferred?

6.2. Suggestions for future studies

7. REFERENCES

8. APPENDIX 1 - ANALTYICAL TECHNIQUES

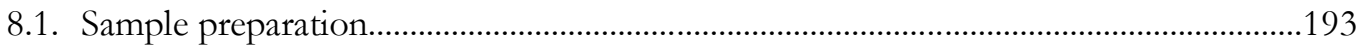

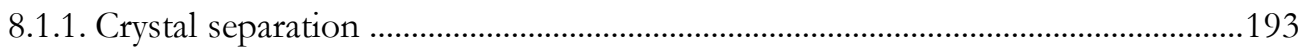

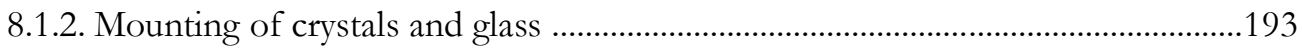

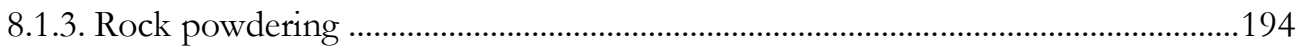

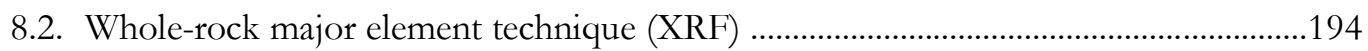

8.3. Whole-rock trace element technique (solution ICP-MS) ………………………….........197

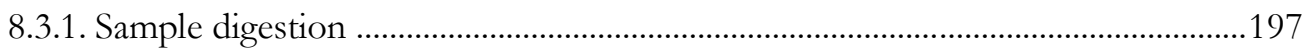

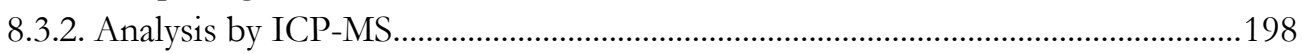

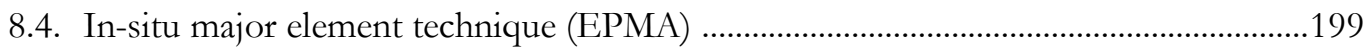

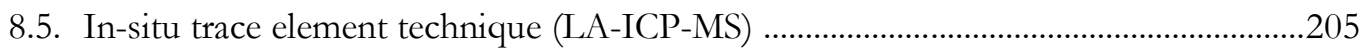

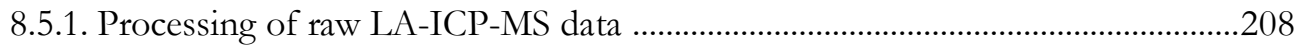

9. ELECTRONIC APPENDICES - DVD

- supplementary data files from published works

- full datasets for whole-rock and in-situ geochemical analyses 


\section{List of Figures}

Figure 1.1 Schematic representation of the crystal mush model .......................................................

Figure 1.2 Location map showing the plate boundary and caldera systems of the TVZ .............8

Figure 1.3 TVZ cumulative erupted volumes through time ...........................................................

Figure 1.4 Taupo erupted volumes versus age relationships ......................................................11

Figure 1.5 Zircon age spectra of Oruanui-type and NE dome-type magmas ................................12

Figure 1.6 Pre- and post-Oruanui compositional relationships at Taupo .......................................13

Figure 1.7 Photo of reworked Oruanui unit 1 ash deposits …………………………………........16

Figure 1.8 Outline timing and erupted volumes of the Oruanui ...................................................17

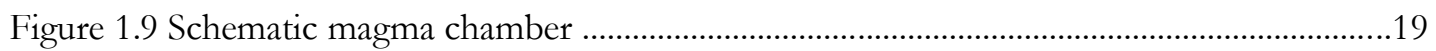

Figure 1.10 Stratigraphic log of proximal Oruanui deposits showing abundance of foreign

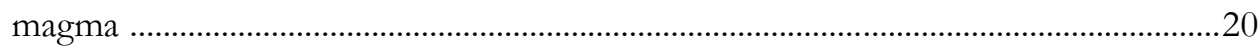

Figure 1.11 Whole-rock composition versus stratigraphic height of the Oruanui ........................21

Figure 2.1 Volcanic and geological features of the Taupo/Maroa area ..........................................29

Figure 2.2 Selected major element compositional data for whole-rock, plagioclase and glass from

Oruanui biotite-free and biotite-bearing rhyolites

Figure 2.3 Trace elements and estimated apparent pressures and temperatures of amphibole crystals in Oruanui and NE dome magmas...................................................................32

Figure 2.4 Scaled cross section through the Oruanui and NE dome magmatic systems .............33

Figure 3.1 Backscattered electron (BSE) images showing key textural features in Oruanui orthopyroxene and amphibole

Figure 3.2 Stacked histograms showing the distribution of enstatite and $\mathrm{Al}^{\mathrm{IV}}$ content in the Oruanui HSR and LSR orthopyroxenes and amphiboles, respectively

Figure 3.3 In situ trace element compositions and apparent pressures of amphiboles from Oruanui rhyolitic clasts

Figure 3.4 Mean composition of orthopyroxene rims normalised to mean amphibole rims in HSR pumices.

Figure 3.5 Modelled Oruanui decompression path $\left(\mathrm{P}-\mathrm{T}-\mathrm{H}_{2} \mathrm{O}\right)$ and schematic phase relations between orthopyroxene and amphibole.

Figure 3.6 WDS-element map of a representative orthopyroxene crystal from a high-SiO

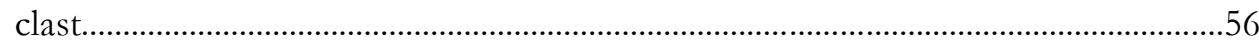

Figure 3.7 BSE image and plots showing the relationship between greyscale intensity and $\mathrm{Fe}-\mathrm{Mg}$ content and the differences in $\mathrm{Fe}-\mathrm{Mg}$ zoning characteristics across the orthopyroxene $a$ - versus $c$-axis 58

Figure 3.8 Contoured $\mathrm{x}-\mathrm{y}$ plots showing the effects of temperature and $\mathrm{fO}_{2}$ on modelled $\mathrm{Fe}-\mathrm{Mg}$ diffusion ages

Figure 3.9 Summary of Fe-Mg diffusion ages for the main core-rim boundary in orthopyroxenes from high- $\mathrm{SiO}_{2}$ rhyolite clasts.

Figure 3.10 Summary of Fe-Mg diffusion ages for streaky, discontinuous zonation boundaries in orthopyroxenes from high- $\mathrm{SiO}_{2}$ rhyolite clasts

Figure 3.11 Summary of Fe-Mg diffusion ages for growth zones in orthopyroxenes from high$\mathrm{SiO}_{2}$ rhyolite clasts.

Figure 4.1 Key volcano-tectonic features of the Taupo-Maroa area .79 
Figure 4.2 Selected whole-rock analytical data from Oruanui rhyolites versus eruption phase.

Figure 4.3 Major element data glass data for HSR and LSR pumice matrix glass........................87

Figure $4.4 \mathrm{Ti}$ versus $\mathrm{Rb} / \mathrm{Sr}$ of quartz melt inclusions versus HSR groundmass glass.................89

Figure 4.5 Ti versus $\mathrm{Rb} / \mathrm{Sr}$ of LSR plagioclase melt inclusions and selvedges versus

HSR groundmass.

Figure 4.6 Pictorial summary of textural and zonation characteristics of HSR

orthopyroxene. .91

Figure 4.7 Pictorial summary of textural and zonation characteristics of HSR plagioclase.......92

Figure 4.8 Examples of quartz zonation under cathodoluminescence (CL)...............................93

Figure 4.9 Plagioclase major element data from HSR and LSR clasts .........................................95

Figure 4.10 Plagioclase trace element data from HSR and LSR clasts ........................................95

Figure 4.11 Orthopyroxene major element data from HSR and LSR clasts...................................96

Figure 4.12 Orthopyroxene trace element data from HSR and LSR clasts .................................96

Figure 4.13 Amphibole major element data from HSR and LSR clasts .......................................98

Figure 4.14 Amphibole trace element and apparent pressure data from HSR and LSR clasts...

Figure 4.15 Summary of preferred thermometric models applied to HSR and LSR samples..103

Figure 4.16 Summary of preferred barometric models applied to HSR and LSR samples.......104

Figure 4.17 Selected whole-rock analytical data for Oruanui mafic clasts. ...106

Figure 4.18 Major element compositional comparison between crystals from Oruanui mafic versus felsic clasts

Figure 4.19 Textural features in BSE images of mafic plagioclase linked to variations and distinctive trends in $\mathrm{FeOt}$ versus An content

Figure 4.20 Plagioclase trace element data from mafic clasts..

Figure 4.21 Orthopyroxene trace element data from tholeiitic mafic clasts..

Figure 4.22 Amphibole trace element data from mafic clast.

Figure $4.23 \mathrm{Fe}$-Ti oxide and two-pyroxene thermometry of mafic samples. 115

Figure 4.24 Comparison of plagioclase compositions for early- versus late-erupted, and easterlyversus westerly-vented, HSR pumices.

Figure 4.25 $\mathrm{Ti}$ versus $\mathrm{Rb} / \mathrm{Sr}$ of rhyolitic glasses and mafic clasts (whole-rock) with binary mixing model

Figure 4.26 Whole-rock analytical data and apparent mixing trajectories for Oruanui mafic and felsic clasts.

Figure 4.27 Examples of zoned magnetite in BSE images from mafic clasts . .125

Figure 4.28 Relationship between greyscale intensity (BSE) and major element composition in magnetite.

Figure 4.29 Example of a Fe-Ti diffusion modelling in magnetite.

Figure 4.30 Summary figure of timescales of Oruanui processes from pre-eruptive to syneruptive.

Figure 4.31 Scaled cross section of the Oruanui magmatic system immediately before (and during) eruption.

Figure 5.1 Summary of preferred thermometric models applied to HSR and LSR samples.....143

Figure 5.2 Summary of preferred barometric models applied to HSR and LSR samples. 144

Figure 5.3 Comparison between the results of two Fe-Ti oxide thermometry and oxybarometry models (Ghiorso and Evans, 2008 versus Sauerzapf et al. 2008)

Figure 5.4 Modelled aTiO2 versus oxygen fugacity $(\Delta \mathrm{NNO})$ from Fe-Ti oxide modelling.....148 
Figure 5.5 Pressure- and temperature-sensitive atomic exchange mechanisms in HSR amphiboles

Figure 5.6 Comparison between amphibole P- and T-sensitive atomic exchange reactions with the amphibole thermobarometric results

Figure 5.7 WDS-element maps of selected amphibole crystals from Oruanui HSR clasts........154

Figure 5.8 Matrix glass major element compositions from HSR and LSR clasts..........................155

Figure 5.9 Effect of melt-H2O input on orthopyroxene-melt and plagioclase-melt

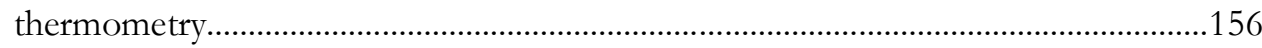

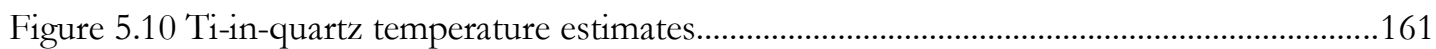

Figure 5.11 Ti-in-quartz pressure estimates ..............................................................................162

Figure 6.1 Schematic summary of the mush extraction and homogenisation of the melt dominant magma body

Figure 6.2 Schematic summary of the origins of the HSR crystal cargo.

Figure Al Summary of XRF data for the BCR-2 and JR-1 rock standards ..................................195

Figure A2 Summary of the ICP-MS data for the international rock standards ............................204

Figure A3 Summary of data for the BHVO-2G, BCR-2G, and ATHO-G glass standards......207

Figure A4 Annotated screen-shot of the Iolite data reduction software.........................................210

Figure A5 Annotated screen-shot the Iolite software illustrating the 'spline' function................210

Figure A6 Time-resolved signal from laser ablation analyses compromised by accidental ablation of contaminant phases.

Figure A7 REE data for normal orthopyroxene versus orthopyroxene contaminated by a LREE-rich phase 


\section{List of Tables}

Table 4.1 Summary of new and existing datasets integrated in this work........................................78

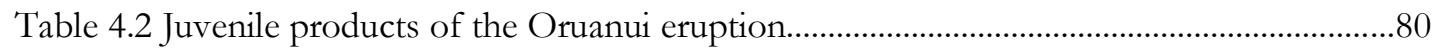

Table 4.3 Representative whole-rock major and trace element compositions of rhyolitic

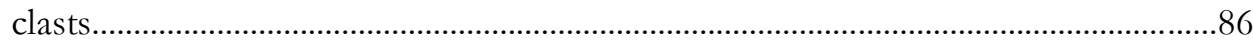

Table 4.4 Mean major element glass chemistry for rhyolitic pumices and fall deposits................88

Table 4.5 Summary of estimates for final pre-eruptive HSR and LSR temperatures....................101

Table 4.6 Summary of barometric estimates for the HSR and LSR magmas................................101

Table 4.7 Summary of $\mathrm{fO}_{2}$ and melt $\mathrm{H}_{2} \mathrm{O}$ estimates for HSR and LSR magmas........................102

Table 4.8 Representative whole-rock major and trace element compositions of mafic

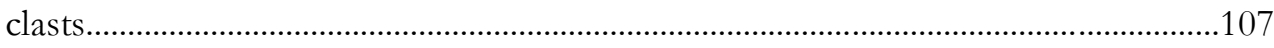

Table 5.1 Summary of the perceived reliability of models for magma intensive variables.........140

Table 5.2 Summary of estimates for final pre-eruptive HSR temperature conditions.................141

Table 5.3 Summary of barometric estimates for the HSR melt-dominant magma body............141

Table 5.4 Summary of estimates for oxygen fugacity of the pre-eruptive HSR magma..............142

Table 5.5 Summary of estimates of melt H2O content in the HSR magma body ........................142

Table 5.6 Summary of modelled a $\mathrm{TiO} 2$ liquid values....................................................................142

Table A1 XRF data for the JR-1, BCR-2, and BHVO-2 rock standards.......................................196

Table A2 Preferred elemental compositions of rock powder standards........................................200

Table A3 Summary of ICP-MS data acquired for international rock standards............................201

Table A4 My preferred values for the JR-1 rhyolite standard........................................................202

Table A5 Summary of EPMA data for glass and mineral standards...........................................203

Table A6 Preferred elemental compositions of glass standards.....................................................206

Table A7 Summary of data acquired on international glass standards............................................209 


\section{Publications arising from this thesis}

\section{JOURNAL ARTICLES}

Allan ASR, Wilson CJN, Millet M-A, Wysoczanski RJ (2012) The invisible hand: tectonic triggering and modulation of a rhyolitic supereruption. Geology 40:563-566

Allan ASR, Morgan DJ, Wilson CJN, Millet M-A (2013) From mush to eruption in centuries: assembly of the super-sized Oruanui magma body. Contributions to Mineralogy and Petrology 166:143-164

Charlier BLA, Morgan DJ, Wilson CJN, Wooden JL, Allan ASR, Baker JA (2012) Lithium concentration gradients in feldspar and quartz record the final minutes of magma ascent in an explosive supereruption. Earth Planet Sci Lett 319-320:218-227

Vandergoes MJ, Hogg AG, Lowe DJ, Newnham RM, Denton GH, Southon J, Barrell DJA, Wilson CJN, McGlone MS, Allan ASR, Almond PC, Petchey F, Dabell K, Dieffenbacher-Krall AC, Blaauw M (2013) A revised age for the Kawakawa/Oruanui tephra, a key marker for the last Glacial Maximum in New Zealand. Quat Sci Rev doi:10:1016/j.quascirev.2012.11.006

Wilson CJN, Seward TM, Allan ASR, Charlier BLA, Bello L (2012) A comment on: 'TitaniQ under pressure: the effect of pressure and temperature on the solubility of Ti in quartz', by Jay B. Thomas, E. Bruce Watson, Frank S. Spear, Philip T. Shemella, Saroj K. Nayak and Antonio Lanzirotti. Contrib Mineral Petrol 164:359-368

\section{CONFERENCE ABSTRACTS}

Allan ASR, Baker JA, Wysoczanski RJ, Carter L, Wilson CJN (2009) Melt compositions from deep ocean tephras provide new insights into the magmatic evolution of Taupo Volcanic Zone, New Zealand. Paper number T21A-1790. Poster presented at the AGU Fall Meeting, 14-18th December 2009, San Francisco, CA, USA.

Allan ASR, Wilson CJN, Baker JA (2010) Crystal-specific investigations of the earliest phases of the $27 \mathrm{ka}$ Oruanui supereruption. Oral presentation given at the GeoNZ 2010 Conference, 21-24th November 2010, The University of Auckland, Auckland, New Zealand.

Allan ASR, Wilson CJN, Millet M-A, Wysoczanski RJ (2011) Magmatic variety through tectonic modulation of the $27 \mathrm{ka}$ Oruanui eruption, Taupo, New Zealand. Poster presentation given at Goldschmidt 2011 conference in Prague, Czech Republic.

Allan ASR, Morgan DJ, Wilson CJN, Millet M-A (2012) From mush to eruption in 1000 years: rapid assembly of the super-sized Oruanui magma body. Poster to be presented at AGU Fall Meeting 3-7th December 2012, San Francisco, CA, USA.

Morgan DJ, Allan ASR, Charlier BLA, Wilson CJN (2012) Determining pre- and syn-eruptive timescales by diffusion methods: case studies from the Oruanui super-eruption. To be presented at AGU Fall Meeting 3-7th December 2012, San Francisco, CA, USA. 
Wilson CJN, Seward TM, Charlier BLA, Bello L, Allan ASR (2009) A critical assessment of the validity of temperature and pressure estimates from Ti concentrations in quartz in two large silicic eruption deposits. Abstract V43A-2356, Poster presented at the AGU Fall Meeting, 13-17 December 2010, San Francisco, CA, USA.

Wilson CJN, Allan ASR, Barker SJ, Morgan DJ, Charlier BLA, Baker JA, Wooden JL (2012) Taupo in time and space: dymanics of a breathing caldera volcano. Oral presentation to be presented at AGU Fall Meeting 3-7th December 2012, San Francisco, CA, USA. 


\section{Introduction}

\subsection{THESIS OBJECTIVES AND OUTLINE}

This work is focussed on identifying the processes that culminated in the eruption of the world's youngest supereruption, the $\sim 25.4 \mathrm{ka}$ Oruanui eruption $\left(530 \mathrm{~km}^{3} \mathrm{magma}\right)$ from Taupo volcano, New Zealand. These processes are approached by utilising the detailed chemical and textural information recorded in the main mineral phases, themselves extracted from individual pumices that are afforded unique stratigraphic and temporal controls. The research presented here builds on and benefits enormously from the contextual information provided by a number of published works, but in particular the detailed, field-focussed volcanological constraints from Wilson (2001), and the works of Sutton (1995) and Wilson et al. (2006) that established the bulk geochemical characteristics of the Oruanui eruption products.

The central purpose of this thesis is to establish how and why the Oruanui eruption occurred, and the timescales over which the processes responsible operated. Some of the key questions that drive this research are as follows:

- What determines the precise moment when an eruption begins?

- Does the Oruanui crystal-poor rhyolite follow the popular paradigm of being extracted from a crystal-rich mush source?

- Over what timescale did the Oruanui melt-dominant magma body accumulate?

- What are the controls on determining whether a melt-dominant magma body is zoned or unzoned?

- To what extent are the Oruanui crystals inherited from older sources, versus grown in situ within the melt-dominant magma body that erupted?

- What information about magma intensive parameters can be reliably inferred from the products of volcanic eruptions?

These specific questions, and many others, are addressed within six interrelated chapters, structured around the central theme of understanding the dynamics of the generation, assembly and evacuation of a large crystal-poor rhyolite magma body. Chapters 2 and 3 have been published as Allan et al. (2012) and (2013), respectively, and Chapter 4 is written in a style suitable for publication. Although many of these chapters serve as self-contained studies, each chapter progressively builds on the information from the preceding chapters, 
forming a coherent single thesis. The only changes in the thesis to the published works are for the sake of consistency and styling (e.g., references to relevant supplementary information). The eruption ages discussed in Chapter 2 (Allan et al. 2012) have since been superseded by newer data, with the age of the Oruanui eruption having been shifted from $\sim 27.1 \mathrm{ka}$ (Lowe et al. 2008) downwards to $\sim 25.4 \mathrm{ka}$ (Vandergoes et al. 2013), as well as some of the other units mentioned throughout this thesis (e.g., Okaia, Poihipi/Rubbish Tip Domes; Lowe et al. 2013). The slightly older ages are retained in Chapter 2 for consistency with the published paper, but none of the resultant age changes alter any of the conclusions drawn by this research. The more recently published ages are used in the remaining chapters and discussions.

Chapter 1 introduces some of the broader contextual positioning of this research. Current notions of how large silicic eruptions are made possible and their derivation from crystalrich mush bodies are explored. I also identify some of the knowledge gaps that this research aims to address. This chapter introduces the Oruanui case study and outlines the key stratigraphic, volcanological and geochemical features that were established by previous workers and around which my research is built.

Chapter 2 begins with the Oruanui melt-dominant body held in its final position in the shallow crust, and then asks the question: 'What was it that caused the magma to erupt when it did?' The relationships between newly discovered juvenile biotite-bearing rhyolite pumices and the volumetrically dominant (and biotite-free) Oruanui rhyolite are explored from geochemical, petrological and field-based perspectives to shed light on the processes that initiated and controlled the early phases of the Oruanui eruption.

Chapter 3 takes a step back in time to before the formation of the melt-dominant magma body. Key overarching textural and compositional features of Oruanui orthopyroxene and amphibole crystals are linked to the extraction of melt and crystals from the mush source region and the accumulation of the magma in its final pre-eruptive position. Fe-Mg diffusion modelling of key zonation boundaries in the orthopyroxenes are used to constrain the timescale over which the Oruanui magma transitioned from a largely uneruptible crystal mush, to a highly eruptible crystal-poor rhyolite at shallow crustal levels. 
Chapter 4 integrates textural and compositional information from all of the major crystal phases and incorporates new and existing datasets to establish a unifying scenario for the development of the Oruanui melt-dominant magma body. The role of Oruanui mafic magmas in remobilising the crustal mush and the timing of their interactions with the Oruanui rhyolites are explored. In recognition that deposits with strongly contrasting zonation characteristics (from whole-rock to intra-crystal scales) may potentially be generated by a broadly similar mush-extraction process, notions of what may cause a magma chamber to be compositionally zoned versus unzoned are explored.

Chapter $\mathbf{5}$ forms an extended discussion around the some of the key models available for constraining intensive variables (temperature, pressure and oxygen fugacity) in silicic magmatic systems. The discussion is centred on recent exchanges in the literature that have openly questioned the veracity of some of the more widely applied thermometers and thermobarometers, in particular, Fe-Ti oxides (Ghiorso and Gualda 2013 versus Evans and Bachmann 2013) and Ti-in-quartz (Wilson et al. 2012 versus Thomas and Watson 2012).

Chapter 6 integrates the primary findings of this research, re-visiting some of the key research questions raised at the outset, and identifying some opportunities for future research.

\subsection{THE CRYSTAL MUSH MODEL}

The crystal mush model is a useful theoretical concept in igneous petrology that revolutionised conventional thinking about how large volumes of silicic (dacitic to rhyolitic) magma are generated and stored at upper crustal levels as substantial bodies of evolved, eruptible magma. Petrological and geochemical observations have led to the recognition that the evolution of most (but certainly not all) voluminous silicic magmas are dominated by fractional crystallisation processes with varying, but generally subordinate, contributions from melting of pre-existing crustal lithologies (e.g., Hildreth 1981; Michael 1983; Cameron 1984; Miller and Mittlefehldt 1984; Bacon and Druitt 1988; Bachmann et al. 2007a). While this relationship holds as a generalised view one might justifiably question whether petrological and geochemical data used to define these relationships (e.g., radiogenic isotopes, incompatible trace elements) would be able to identify significant contributions from re-melting of a pre-existing plutonic body. Regardless, establishing a 
viable physical model that supported the strong geochemical evidence for crystal-liquid separation, however, proved problematic (e.g. Hildreth 1979; Michael 1983; Hildreth and Michael 1983; Cameron 1984). From an early stage, separation of crystals from liquid via gravitational settling was recognised as too slow and inefficient (e.g., Shaw 1965) to account for crystal-liquid segregation of the magnitude implied, and within the timescales inferred (Michael 1983; Cameron 1984).

The conceptual crystal mush model took the traditional model, controlled by gravitational settling of crystals and prolonged cooling, and turned it on its head (see Hildreth 2004, Bachmann and Bergantz 2004 for overviews). Rather than separating the crystals from the liquid, the crystal mush model, shown schematically in Figure 1.1, focuses on separating the liquid from the crystals. From this concept, the substantive history of melt evolution and crystallisation is envisaged to occur in large batholithic bodies of overall intermediate composition (andesite-dacite). While crystallinity in these batholith-scale bodies of intermediate magma is 'low' $(<45 \%)$, crystals are kept in 'chaotic suspension' and both melt and crystals can circulate relatively freely due to convective stirring. Although the bulk volume of the magma remains broadly intermediate in composition, large degrees of crystallisation act to drive the interstitial melt compositions towards high $\mathrm{SiO}_{2}$ rhyolite compositions. Once the crystallinity of the magma crosses a critical threshold of $>45-60 \%$ crystals (Marsh 1981; Brophy 1991) the magma becomes rheologically locked. There is an assumed crystal fraction window (typically reported as 45-65\% crystals by volume) within which efficient separation of crystals from interstitial high-SiO 2 liquid can occur (Bachmann and Bergantz 2004). Within this window the crystal framework is still relatively permeable and can allow large amounts of liquid to percolate through it. Large volumes of evolved melt are then envisaged to accumulate as the liquid is expelled from the mush via compaction of the crystal pile from crystal microsettling (Bachmann and Bergantz 2004). More recent expansions of the crystal mush model have posited that rheologically locked mush bodies can be rejuvenated when ascending mafic magmas pond at their base, transferring heat and volatiles (i.e. 'gas sparging' or mafic 'wind') into the overlying mush to initiate re-melting and over-pressurisation (see Bachmann and Bergantz 2006 for overview). This particular aspect of the mush model has been used to explain the remobilisation and eruption of very large volumes of crystal-rich silicic magma such as the Fish Canyon Tuff (Bachmann et al. 2002; Bachmann and Bergantz 2003) and crystal-rich ignimbrites erupted from the La Pacana caldera system, Chile (Lindsay et al. 2001). 
(a)

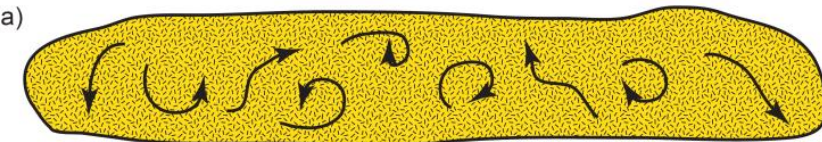

$<45 \%$ crystals. Convection leds to dynamic stirring of crystals and melt.

(b)

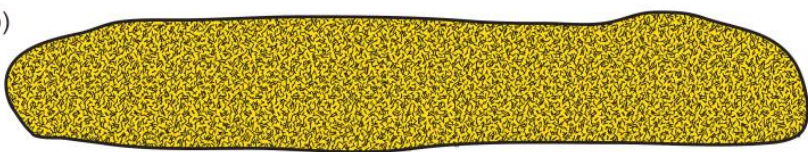

$>45$ to $50 \%$ crystals. Rheological lock-up. Convection stops. Crystal framework is still permeable. Melt extraction begins via compaction and crystal microsettling.

(c)

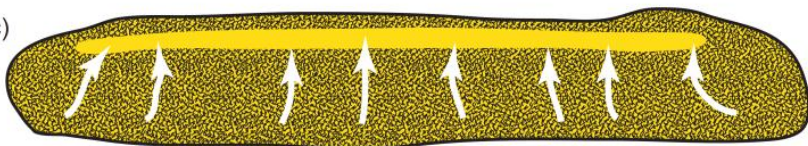

Expulsion of liquid generates a melt-rich rhyolitic lens above a crystalline residue and below a solidification front

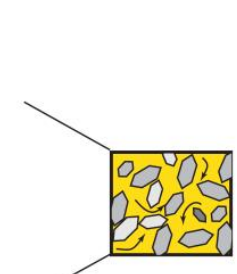
dominate (i.e. fractional crystallisation) governing the composition of the magma that will ultimately be erupted.

Compatible elements sequestered in minerals, incompatible elements enriched in the interstitia melt.

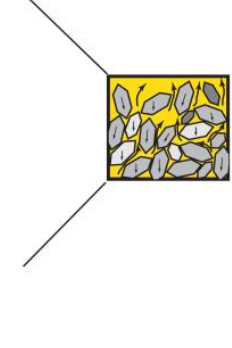

Physical processes dominate governing the timescales of assembly and storage of the ultimately be erupted. magma that will

Figure 1.1. Schematic representation of the crystal mush model in which batholith-scale bodies of crystal-rich intermediate magma with highly silicic interstitial melt, can generate voluminous evolved melt-dominant magma bodies that give rise to supereruptions. Figure modified from Bachmann and Bergantz 2004.

Implicit to the current thinking around the crystal mush model is that processes operating within a large silicic magmatic system can be viewed along two contrasting timeframes (e.g. Wilson and Charlier 2009). The first is associated with the operation of longer-term processes, such as fractional crystallisation and assimilation, through which the magma(s) evolve and acquire their compositional characteristics. The second, shorter-term timescales correspond to the processes that determine the physical transition from a largely uneruptible mush body into large volumes of eruptible melt-rich magma. It is these latter processes that bear the most immediate relevance in establishing how and when a large silicic (super-) eruption may occur.

Identifying the processes that govern this important transition, however, is not straightforward, and crystal-rich magmas have generally received more attention in this regard than their crystal-poor counterparts. Many crystal-rich magmas are inferred to have origins in a physical rejuvenation and/or remobilisation of the crystal mush by mafic injection or underplating (Bachmann and Bergantz 2006; Pistone et al. 2013). This process is generally recognised from widespread up-temperature signals in crystal rims (e.g., high- 
$\mathrm{Al}$ amphibole rims of the Fish Canyon Tuff; Bachmann and Dungan 2002). In contrast, the timescales associated with the physical extraction of crystal-poor rhyolites from their antecedent crystal mushes are not readily apparent or widely documented. This lack of documentation is, in part, because it is not yet clear if that melt extraction process is recorded in any tangible manner in the crystals or deposits themselves. Numerical models are inherently limited by the processes assumed by the modeller to drive the crystal-liquid separation. These processes have traditionally invoked passive internal mechanisms that suggest timescales that vary by orders of magnitude, and that may be much longer than suggested by other lines of evidence. For example, Bachmann and Bergantz (2004) calculate that accumulation of a $>500 \mathrm{~km}^{3}$ melt-rich magma body through processes of hindered crystal settling and compaction would take on the order of $10^{4}-10^{5}$ years.

The dynamic processes associated with modest-scale systems are reasonably well understood (e.g. Crater Lake, Bacon and Druitt 1988). However, many issues arise, such as that outlined in the preceding paragraph, when these ideas are extended to much larger volumes of evolved melts that are associated with some of the largest explosive eruptions documented. Many questions then arise as to how so-called 'supereruptions' (see section 1.3) are made possible. Do 'super-sized' bodies of magma require proportionally longer periods of time to assemble (as exemplified in models put forth by Smith [1979] and Shaw [1985], and reiterated by Reid [2008]), with otherwise normal processes carried to extreme volumetric excess? Or rather, do the processes involved simply act more efficiently or to a greater intensity? These questions are central to the approach adopted in this thesis work

\subsection{SUPERERUPTIONS AND SUPERVOLCANOES}

Within the last decade the terms 'supereruption' and 'supervolcano' have been introduced in order to describe the largest explosive volcanic eruptions and their source volcanoes (e.g. Rampino and Self 1992; Mason et al. 2004). Supereruptions are defined as those that disgorge $>10^{15} \mathrm{~kg}$ (or $450 \mathrm{~km}^{3}$ ) of magma, equivalent to $\sim 1000 \mathrm{~km}^{3}$ of pyroclastic material (Mason et al. 2004; Sparks et al. 2005; Miller and Wark 2008). Such vast volumes of material are difficult to comprehend, in part because the volumes associated with some of the largest eruptions in recent times, and those which most people would consider to be large volcanic eruptions (e.g. Mt. St. Helens, 1980; Mt. Pinatubo, 1991), are 2 to 3 orders of magnitude less than these. To give these volumes some perspective, $1000 \mathrm{~km}^{3}$ of 
pyroclastic material spread evenly across the entire surface area of New Zealand's North Island would equate to a $\sim 8.5 \mathrm{~m}$ thick blanket of pumice and ash.

It is fairly apparent that were a supereruption to occur tomorrow there would be immediate and long-lasting devastation, loss of life, destruction of social infrastructure and long-term climatic effects arising from loading the stratosphere with sulphur-rich gases (Rampino and Self 1993; Sparks et al. 2005; Self 2006). Supereruptions themselves only occur globally at intervals of roughly 250,000 years during the Quaternary (Mason et al. 2004), but their source volcanoes (labelled as 'supervolcanoes' from their largest eruptions) almost inevitably will produce numerous other eruptions of varying sizes at much shorter time intervals. Knowledge of the past and, potentially, future behaviour of supervolcanoes is therefore of considerable global interest from societal and economic perspectives.

Four out of the ten global supereruptions during the Quaternary have occurred from New Zealand volcanoes (Wilson et al. 2009), making New Zealand an ideal setting to study the generation and dynamics of these large eruptions.

\subsection{TAupo Volcanic Zone}

New Zealand's Taupo Volcanic Zone (TVZ) is an active continental rifted-arc, the southernmost expression of the Tonga-Kermadec subduction system (Cole and Lewis 1981; Cole 1990; Gamble et al. 1996) (Figure 1.2). Comprehensive reviews of the Taupo Volcanic Zone from structural, stratigraphic, geochemical and petrological perspectives are found in Cole et al. (1995), Wilson et al. (1995, 2009), Houghton et al. (1995), and Rowland et al. (2010). The region is characterised by its unusually high heat flux (e.g. Bibby et al. 1995; Hochstein 1995), and longitudinal segmentation into andesite-dominated regions in the south and north versus a central region dominated by rhyolitic volcanism (Figure 1.2). For the last $\sim 1.6 \mathrm{Ma}$ this $125 \times 60 \mathrm{~km}$ central portion of TVZ has been the world's most productive and frequently erupting site of rhyolitic volcanism (Houghton et al. 1995; Wilson et al. 1995 2009). The unusually high proportion of erupted rhyolite compared to less evolved compositions (>95\%; Wilson et al. 1995) and the high long-term average rates of rhyolite production $\left(0.28 \mathrm{~m}^{3} / \mathrm{s}\right.$; Wilson et al. 1995) are undoubtedly a consequence of the exceptionally high heat flux beneath the central portion of the TVZ. There is, however, no consensus as to why that heat flux should be so high with diverse and disputed explanations ranging from crustal fusion and plastic deformation (Hochstein 1995), to mantle upwelling and decompression (Reyners 2013). 

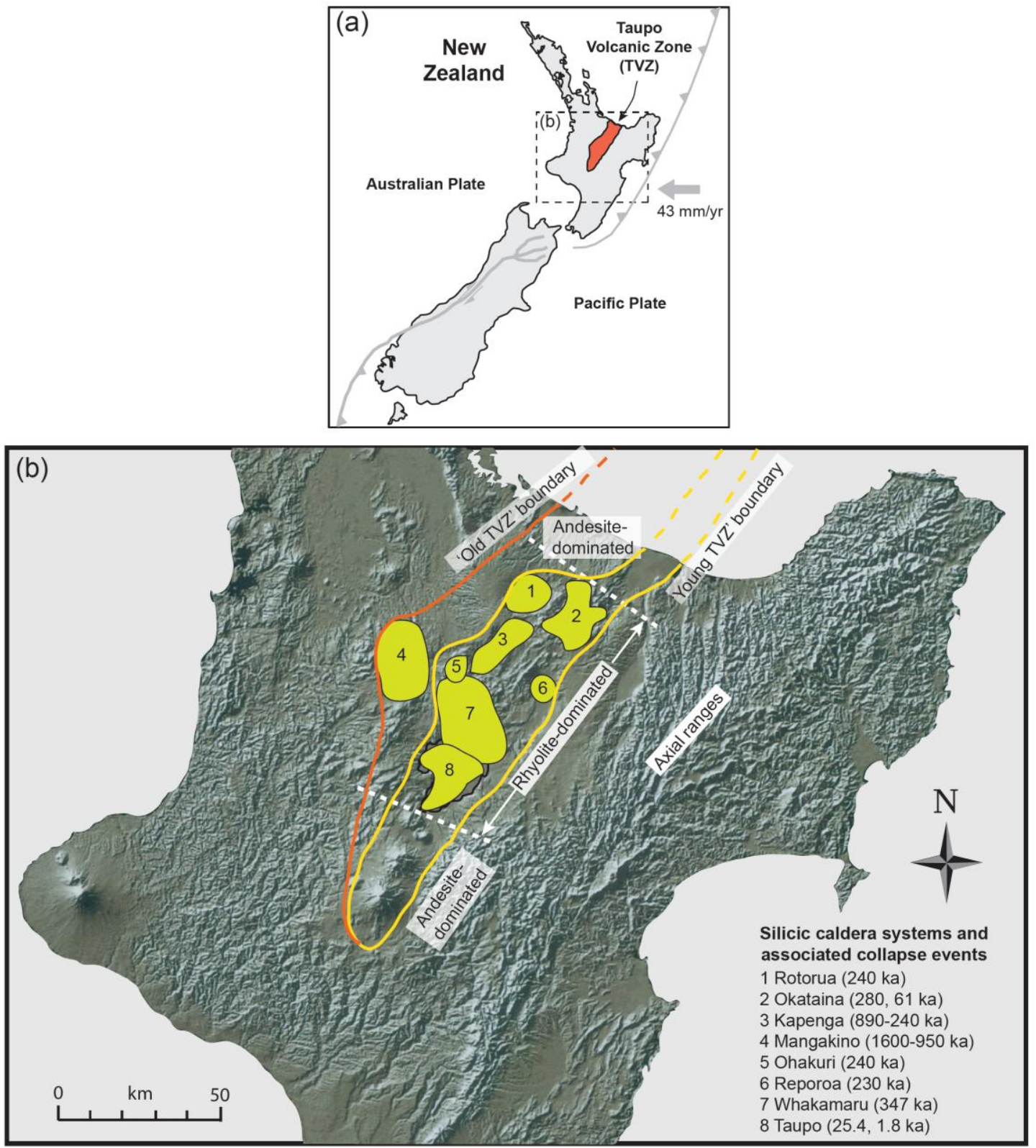

Figure 1.2. (a) Tectonic setting of the New Zealand landmass and the Taupo Volcanic Zone (TVZ) relative to the Pacific-Australian plate boundary. (b) Map of selected volcanic features of the TVZ, highlighting the 8 known centres of caldera collapse throughout the last 1.6 Ma. Note the longitudinal segmentation into andesite-dominated regions in the north and south, versus the rhyolite-dominated central region. Caldera outlines are from Wilson et al. (2009). Boundaries of the 'old' and 'young' TVZ are from Wilson et al. (1995). Digital elevation model developed by Rob Davies. C GeographX June 2000 .

Of the 8 caldera systems so far identified within the central TVZ, only two are considered active: Okataina in the north and Taupo in the south (Figure 1.2). Both caldera systems developed or have been extensively modified partly or wholly in the last $\sim 61 \mathrm{kyr}$. The two volcanoes contrast in their magnitude-frequency relationships during this time period with Okataina having generated eruptions in the $1-20 \mathrm{~km}^{3}$ range whereas Taupo has produced 
silicic eruptions of volumes ranging over five orders of magnitude, from $\sim 0.01 \mathrm{~km}^{3}$ deposits comparable in size to those collectively discharged in the 1995-1996 eruptions at Ruapehu up to the $530 \mathrm{~km}^{3}$ Oruanui supereruption (Wilson et al. 2009). In particular, over the last $\sim 61 \mathrm{kyr}$, the high frequency of eruptions of all sizes at Taupo means that the deposits of smaller precursor and subsequent eruptions are preserved in amongst the deposits of the climactic supereruption, a feature that enables studies of this monster event to be placed in the context of 'normal' background volcanic activity.

As a measure of its productivity, the TVZ has hosted four of the ten Quaternary supereruptions worldwide (Figure 1.3). The two oldest examples were sourced from Mangakino volcanic centre at $\sim 1.2 \mathrm{Ma}$ (Ongatiti, $\sim 500 \mathrm{~km}^{3}$ magma) and $\sim 1.0 \mathrm{Ma}$ (Kidnappers, $\sim 1200 \mathrm{~km}^{3}$ ). At $\sim 350 \mathrm{ka}$ a close-spaced sequence of colossal eruptions formed the Whakamaru group of ignimbrites (Wilson et al. 2009) together with its coeval Rangitawa Tephra, with a magma volume of at least $1500 \mathrm{~km}^{3}$ (Matthews et al. 2012a, b). The Oruanui eruption, the subject of this thesis, is world's youngest supereruption and occurred from Taupo volcano at $25.4 \pm 0.3 \mathrm{ka}$ (Vandergoes et al. 2013).

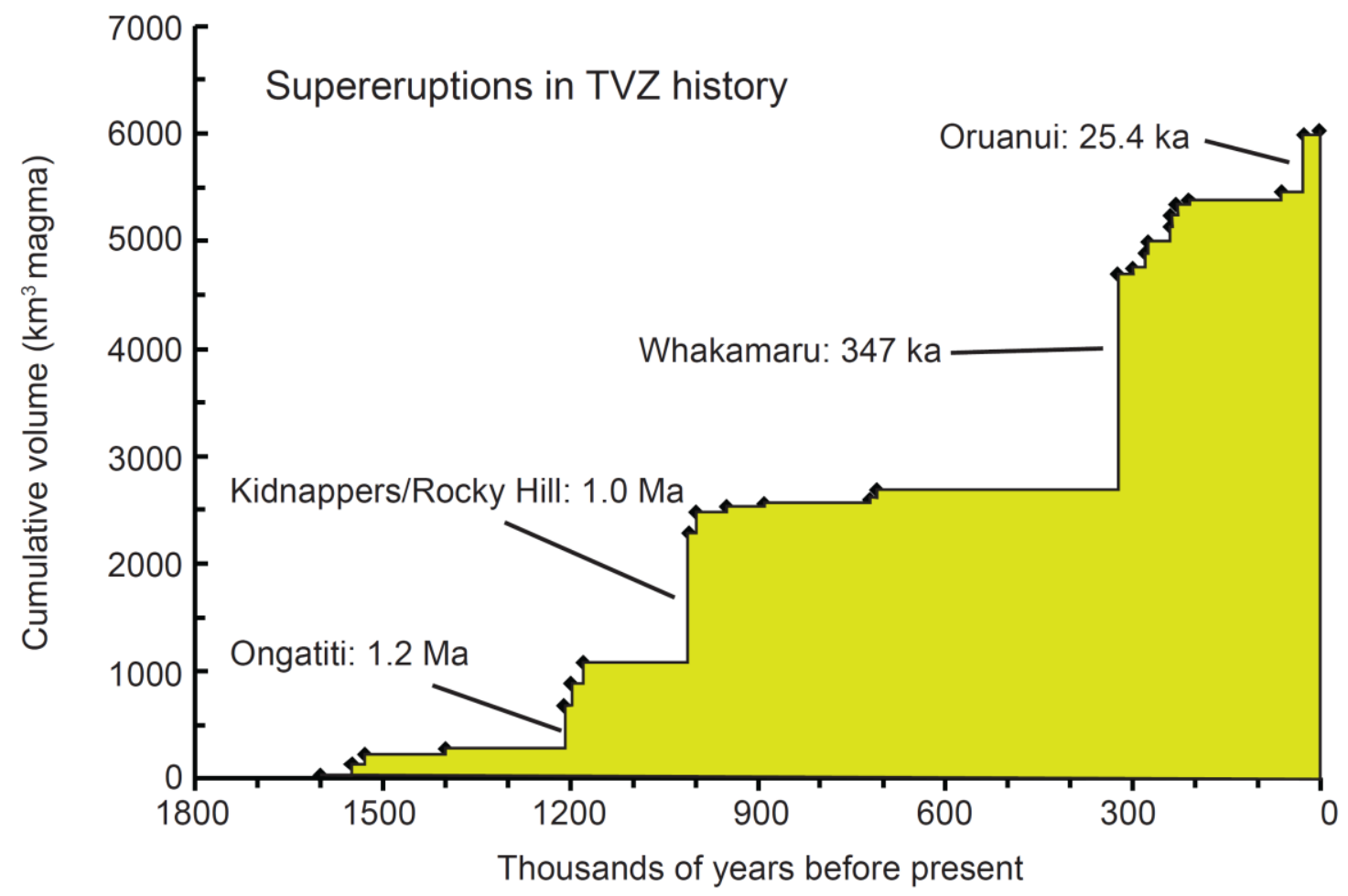

Figure 1.3. Cumulative erupted magma volume versus time for large ignimbrite-forming eruptions from the TVZ. Modified from Wilson et al. (2009). 
In the case of the Oruanui, this relative youth means that the deposits are comparatively well preserved, and in general have been less affected by erosion and burial from the products of later volcanism than elsewhere. The post-61 ka eruptive sequence at Taupo is relatively well constrained and comprises abundant silicic eruption products of volumes varying from $\sim 10^{-2} \mathrm{~km}^{3}$ to $\sim 10^{2} \mathrm{~km}^{3}$ (Wilson et al. 2009). The high frequency of the snapshots of silicic volcanism at Taupo is unique worldwide and affords some uniquely constrained perspectives on silicic volcanism associated with the lead-in to the climactic Oruanui eruption, and the subsequent recovery (e.g. Charlier et al. 2005; Wilson and Charlier 2009).

\subsubsection{Background to silicic volcanism at Taupo volcano}

Since $61 \mathrm{ka}$ three silicic caldera systems have been active across the whole of TVZ, with 43 eruptions from Taupo/Maroa, 25 from Okataina and 1 from Kapenga (Wilson et al. 2009). Although clusters of the major vent sites from Maroa and Taupo are geographically discrete, scattered rhyolite domes occur in the region between the two systems and the boundary between them is arbitrarily positioned (Wilson et al. 1986). All volcanism associated with the Taupo volcanic centre post-dates the $349 \mathrm{ka}$ Whakamaru eruption (Houghton et al. 1995; Leonard et al. 2010). Relatively little is known, however, about volcanism in the $\sim 340-65 \mathrm{ka}$ period due to limited exposure of the deposits and associated radiometric age constraints (Houghton et al. 1991; Brown 1994; Leonard 2003). In contrast, records from Taupo that post-date the regionally extensive marker horizon associated with the $\sim 61$ ka Rotoiti eruption from Okataina caldera are more complete, and volume, source and age relationships of the deposits are relatively well constrained (e.g. Wilson et al. 2009) (Figure 1.4) .

Previous studies have established that for at least $\sim 20 \mathrm{kyr}$ prior to the Oruanui eruption at $25.4 \mathrm{ka}$, two contrasting silicic volcanic systems operated beneath Taupo, erupting two distinctive magma-types from vents distributed over an area of $\sim 20 \times 20 \mathrm{~km}$ (Sutton 1995; Sutton et al. 1995 2000; Wilson et al. 2006 2009; Wilson \& Charlier 2009). The first of these magma-types, the Oruanui-type magmas, are recognised on the basis of closely similar mineralogy, crystal contents, and ${ }^{87} \mathrm{Sr} /{ }^{86} \mathrm{Sr}$ compositions to that of the magma discharged in the Oruanui eruption itself. Temperature estimates for these magmas are also similar to that inferred for the Oruanui $\left(\sim 760^{\circ} \mathrm{C}\right)$ although their slightly lower whole rock $\mathrm{SiO}_{2}$ and $\mathrm{Rb} / \mathrm{Sr}$ values indicate the magmas were slightly less evolved. Radiometric dating 


\section{Eruption volume, $\mathbf{k m}^{\mathbf{3}}$}

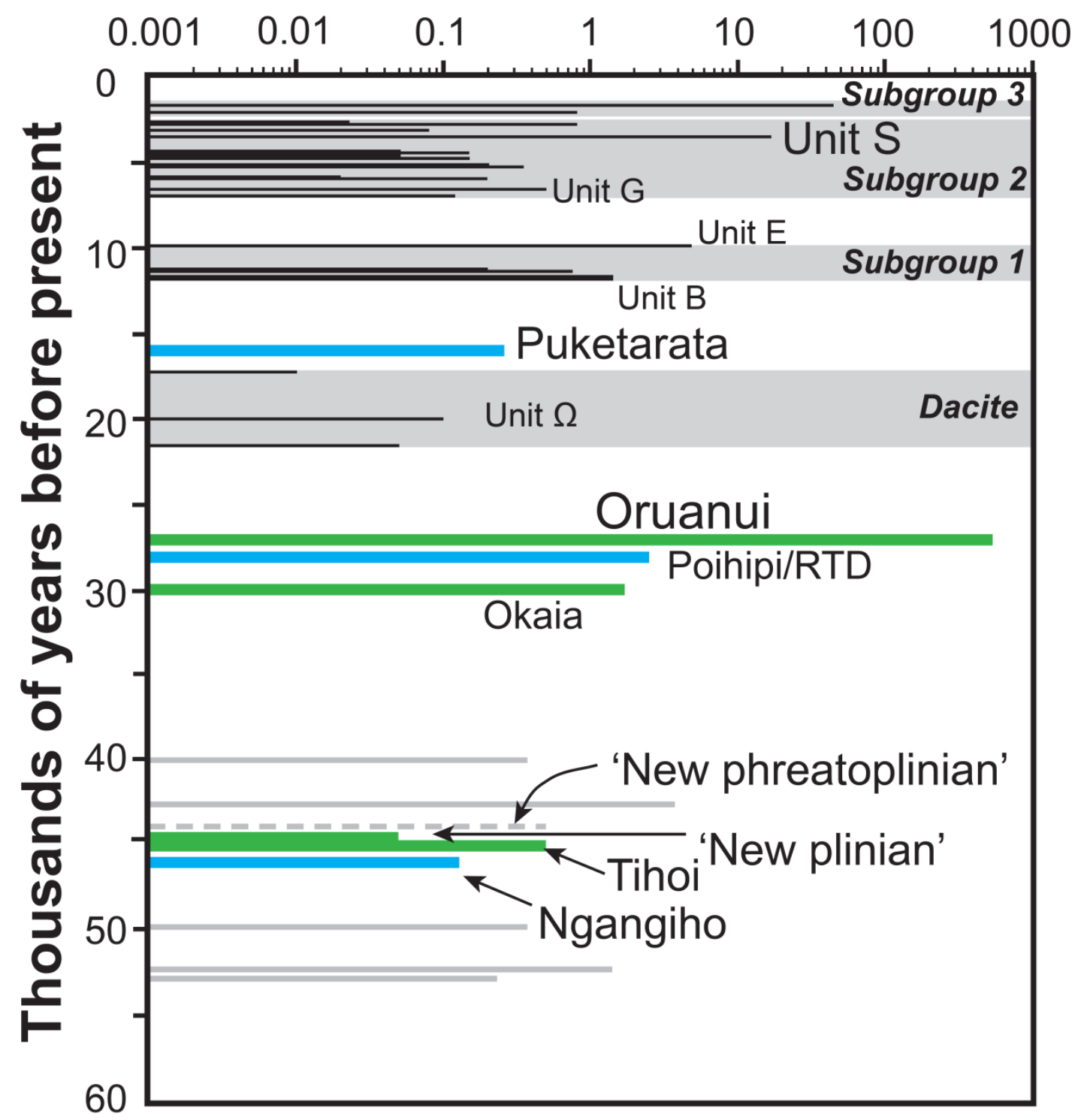

Figure 1.4. A plot highlighting the time versus erupted volumes of silicic magmas erupted from and around Taupo volcano since $60 \mathrm{ka}$. Green lines represent the Oruanui and Oruanui-type magmas, blue are the NE dome-type magmas and black are the post-Oruanui Taupo magmas. The grey lines in the pre-Orunaui period are for magmas unrelated to the Taupo/Oruanui or NE dome systems and that have not yet been studied in detail. Modified from Wilson et al. (2006).

of magmatic zircons (using $\mathrm{U} / \mathrm{Th}$ disequilibrium techniques) has identified a characteristic bimodal zircon age spectra recorded in the Oruanui-type magmas with a common 'old' peak of zircon crystallisation centred on $\sim 95 \mathrm{ka}$ and a younger near-eruption aged peak typically 5 to $20 \mathrm{kyr}$ before eruption (Charlier et al. 2005; Wilson and Charlier 2009) (Fig. 1.5). Compositional and zircon age data has been used to suggest the Oruanui-type magmas 


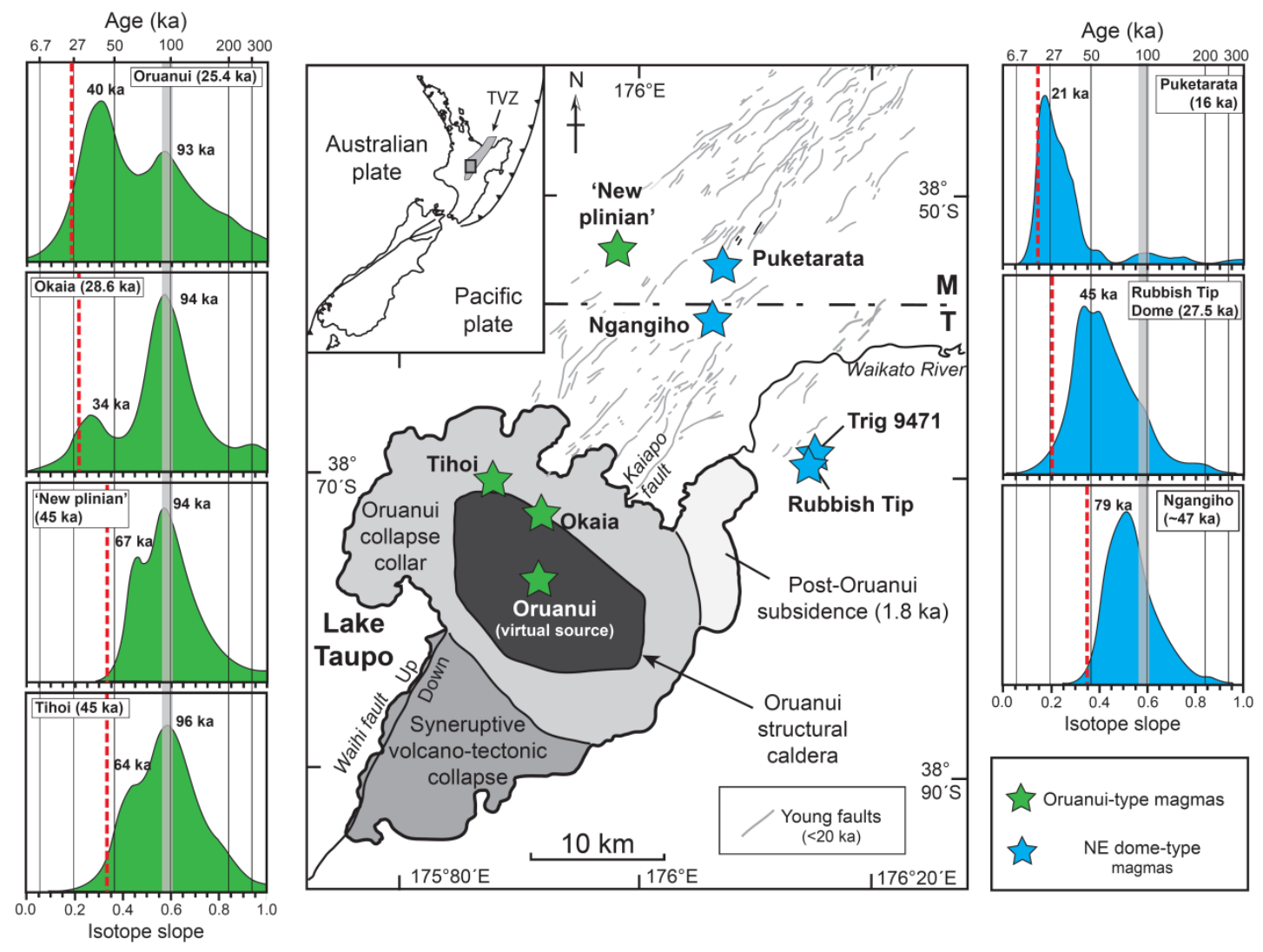

Figure 1.5 Summary of the U/Th zircon age spectra (after Wilson and Charlier 2009) from eruption products of two nearby and contemporaneously active silicic volcanic systems: the Taupo/Oruanui system (green) and NE dome (biotite-bearing) system. The position of the coloured stars marks the approximate vent sites for the eruptions. The Oruanui and its pre-cursor eruptions share a common older peak of zircons with a peak crystallisation age around $95 \mathrm{ka}$. Modified from Wilson and Charlier (2009).

represent precursor leaks from the Oruanui magma source (Charlier et al. 2005; Wilson et al. 2006; Wilson and Charlier 2009), whereby single bodies of crystal-poor melt were expelled from a common source/crystal mush zone (the source of the common $\sim 95 \mathrm{ka}$ peak in zircon ages), shortly before eruption and containing both newly grown phenocrysts and antecrysts entrained from the mush below. This model is tested for consistency with the other main mineral phases in Chapters 3 and 4. Three documented eruptions of Oruanui-type magma occurred in the lead up to the climactic Oruanui eruption at $25.4 \mathrm{ka}$ (Tihoi, $45 \mathrm{ka}, 0.5 \mathrm{~km}^{3}$; 'New Plinian', $\sim 45 \mathrm{ka}, 0.05 \mathrm{~km}^{3}$, Okaia, $28.6 \mathrm{ka}, 1.5 \mathrm{~km}^{3}$ : Wilson and Charlier 2009 with Okaia age from Lowe et al. 2013) (Figure1.4).

The second magma type, referred to as the NE dome-type, differs in that it represents more crystalline (12-23\% crystals), lower temperature (although overlapping with the Oruanuitype; $730-780^{\circ} \mathrm{C}$ ), biotite-bearing rhyolite magmas with lower ${ }^{87} \mathrm{Sr} /{ }^{86} \mathrm{Sr}$ values. Eruption of these magmas was typically took the form of passive dome effusion although significant 
volumes of explosively erupted pumice and ash deposits are documented for some units (e.g. Poihipi Tephra: Vucetich and Howorth 1976). Zircon age spectra of the NE dome-type magmas contrast with the Oruanui-type magmas, recording only a single peak in zircon crystallisation, between 5 to $30 \mathrm{kyr}$ before eruption (Figure 1.5). Two NE dome-type deposits pre-date the Oruanui event (Ngangiho, $\sim 47 \mathrm{ka}, 0.15 \mathrm{~km}^{3}$; and RTD/Poihipi Tephra, $27.5 \mathrm{ka}, 1.5 \mathrm{~km}^{3}$ ) with a single unit post-dating the Oruanui (Puketarata, $16.5 \mathrm{ka}, 0.14 \mathrm{~km}^{3}$ ) (Brooker et al. 1993; Wilson and Charlier 2009) (Figure 1.4).

Following the climactic Oruanui eruption at $25.4 \mathrm{ka}$ (discussed in detail below) the magmatic system beneath Taupo was re-organised. All of the 28 post-Oruanui eruptions from Taupo volcano (labelled Units $\psi, \Omega$, and A... to Z) are chemically and isotopically distinct from the Oruanui magma (Sutton et al. 1995 2000), despite having been erupted from vents which largely overlap the Oruanui structural caldera (Figure 1.6).

Compositional differences between groups of these eruptions allow further sub-division into four temporally clustered compositional groups: a dacitic group (Units $\psi, \Omega$ and A), group 1 rhyolites (B-E), group 2 rhyolites (F-W) and group 3 rhyolites $(\mathrm{X}-\mathrm{Z})$ (Sutton et al. 2000) (Figure 1.6).
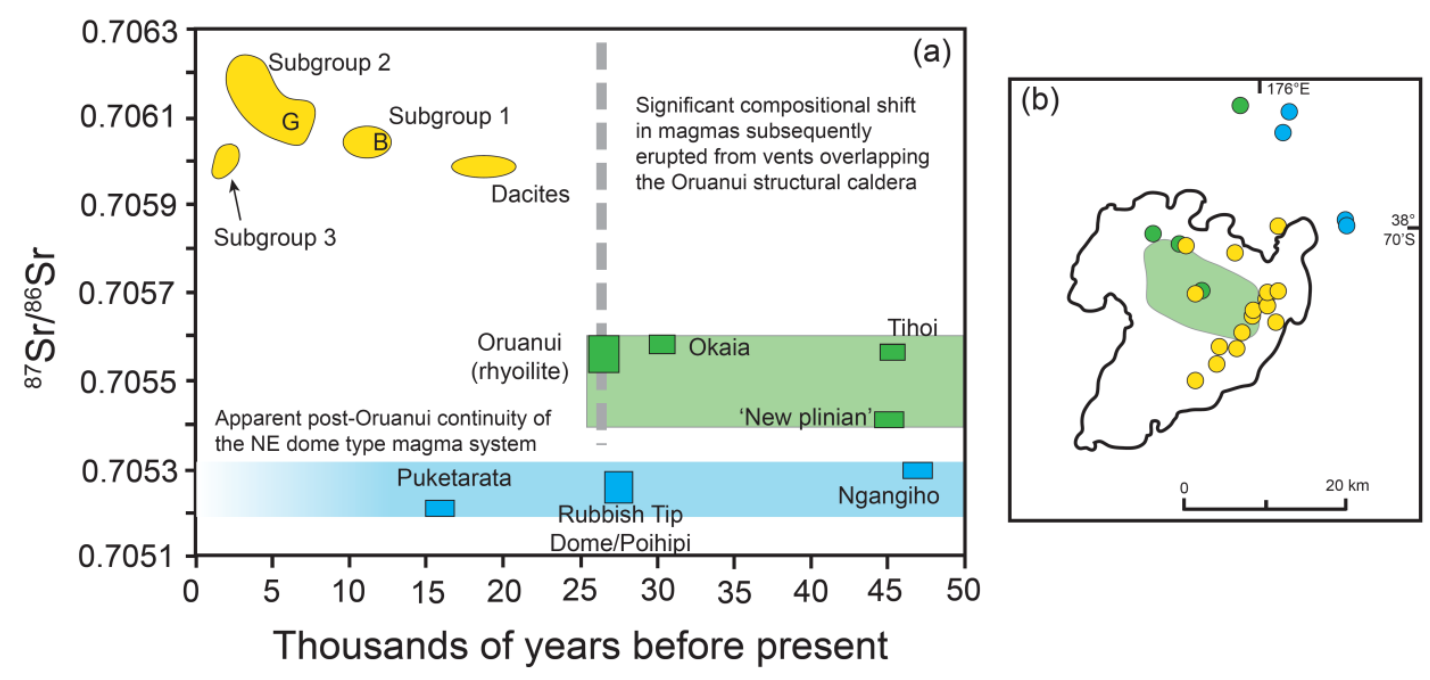

Figure 1.6. Temporal, compositional and spatial relationships between groups of erupted pre- and postOruanui magmas at and around Taupo volcano in the last $\sim 47 \mathrm{kyr}$. The green group represents the Oruanui and Oruanui-type magmas (after Sutton et al. 1995), and the blue correspond to the NE dome-type magmas, a sub-group of biotite-bearing rhyolite magmas associated with dome formation. The yellow group represent the post-Oruanui succession of eruptive from within the modern Lake Taupo, themselves sub-divided into 4 groups based on temporal and compositional clustering. Figure drafted from data in Sutton (1995) and Sutton et al. (1995). 
When compositional data for the post-Oruanui Taupo eruptives are plotted on Harker diagrams (for examples, see Sutton et al. 2000) it is noticeable that none of these groups define compositional trends that fall on trajectories to the Oruanui magma compositions. This has been interpreted to suggest that the substantial melt-dominant Oruanui magma body was completely drained of any significant quantity of melt by the time that postOruanui activity had resumed (Sutton et al. 1995, 2000). Available SIMS U/Th zircon age data for two post-Oruanui units (Unit B, $11.8 \mathrm{ka}, 0.5 \mathrm{~km}^{3}$; Unit G, $6.65 \mathrm{ka}, 0.2 \mathrm{~km}^{3}$ ) reveals two subordinate peaks in zircon crystallisation corresponding to the $\sim 95 \mathrm{ka}$ peak common to the Oruanui-type magmas and a $\sim 40 \mathrm{ka}$ peak recorded in the Oruanui zircons, as well as a near-eruption age peak (Charlier et al. 2005; Wilson and Charlier 2009). These data suggest that although no 'Oruanui melt' was involved in the generation of the younger Taupo magmas, crystal inheritance pathways remained open and a component of Oruanui crystals may be present in these younger magmas.

\subsection{THE 25.4 KA ORUANUI SUPERERUPTION}

The $25.4 \mathrm{ka}$ Oruanui eruption from Taupo volcano is the world's youngest supereruption and the second largest eruption globally within the last $\sim 100 \mathrm{kyr}$. Previous workers on the Oruanui eruption deposits have produced detailed reconstructions of the eruptive stratigraphy and established their broad chemical and isotopic characteristics. These studies form the framework upon which this thesis is built and offer a context unrivalled in detail within which to place the crystal-specific geochemical investigations undertaken during this research. The major findings of these earlier studies and their significance to the current research are summarised in the following sections.

\subsubsection{Stratigraphy of the Oruanui eruption deposits}

Early studies of the Oruanui stratigraphy resulted in the division of the deposits into 6 members (Self and Sparks 1978; Self 1983; Self and Healy 1987). Wilson (2001) later revised and updated these earlier efforts, presenting a more detailed and laterally consistent eruptive stratigraphy. In all, Wilson (2001) divided the eruption into 10 phases of activity on the basis of layering in the fall deposits. Pyroclastic density current (PDC) deposits were generated throughout the eruption as evidenced by interbedding relationships with the 10 
fall units. The energy of these PDCs, as measured by the maximum extent of laterally emplaced deposits, increased as the eruption progressed, reaching peak distances of $\sim 90$ $\mathrm{km}$ from source during phase 8 , then markedly decreased, such that most of the thicknesses of proximal ignimbrite $<20 \mathrm{~km}$ from the edge of the caldera are inferred to be from phases 9 and 10. Outcrops of thick, monotonous proximal ignimbrite were placed into the context of the eruptive sequence by Wilson (2001) on the basis of interbedding relationships with the fall deposits. These correlations were further facilitated by the presence of distinctive stratigraphic horizons, and in particular 'spikes' in the abundance of (typically ash-grade) juvenile mafic material in the deposits of phases 3 plus 4, 7 and 9 . Layering within the deposits and local- to regional-scale re-working at some unit boundaries demonstrate that the eruption was spasmodic and punctuated by periods of inactivity. Wilson (2001) inferred the eruption lasted for several months, with at least one hiatus in activity on the order of weeks to months (between phases 1 and 2; Fig 1.7). Shorter breaks in explosive activity, ranging from minutes to hours, punctuated some of the later eruption phases whereas some the transition between some phases was continuous with no recognisable break in activity (Figure 1.8). These hiatuses in activity, particularly the significant time-break between phases 1 and 2 after only trivial volumes magma $\left(\sim 0.3 \mathrm{~km}^{3}\right)$ had been erupted, are intriguing, and difficult to reconcile with existing notions of how and why large silicic eruptions are triggered. New data introduced in Chapter 2 of this thesis explores the processes operating during the opening phases of the Oruanui eruption and specifically addresses the question of how this time break was made possible.

An outline timing and volume history of the different phases of the eruption has been constructed by Wilson (2001) and this is adopted in this thesis (Figure 1.8).

Inferences from maximum pumice and lithic clast sizes in the early eruption deposits enabled Wilson (2001) to constrain the approximate positions of the vent openings during phases $1-4$. These early stages saw shifting vent positions. During phases 1 and 2 activity was confined to the northern margin of the modern Lake Taupo, however the onset of phase 3 was marked by the unzipping of an elongate NNE-SSW trending vent structure down the eastern margin of the modern lake, with subsequent phase 4 activity focused on a more westerly vent near the centre of the modern lake. Vent positions for the later phases are unable to be identified (although all occurred within the modern Lake Taupo) due to the scouring and partial-to-complete removal of the proximal phase 5-10 fall 


\section{Phase 2 \& 3 flows}

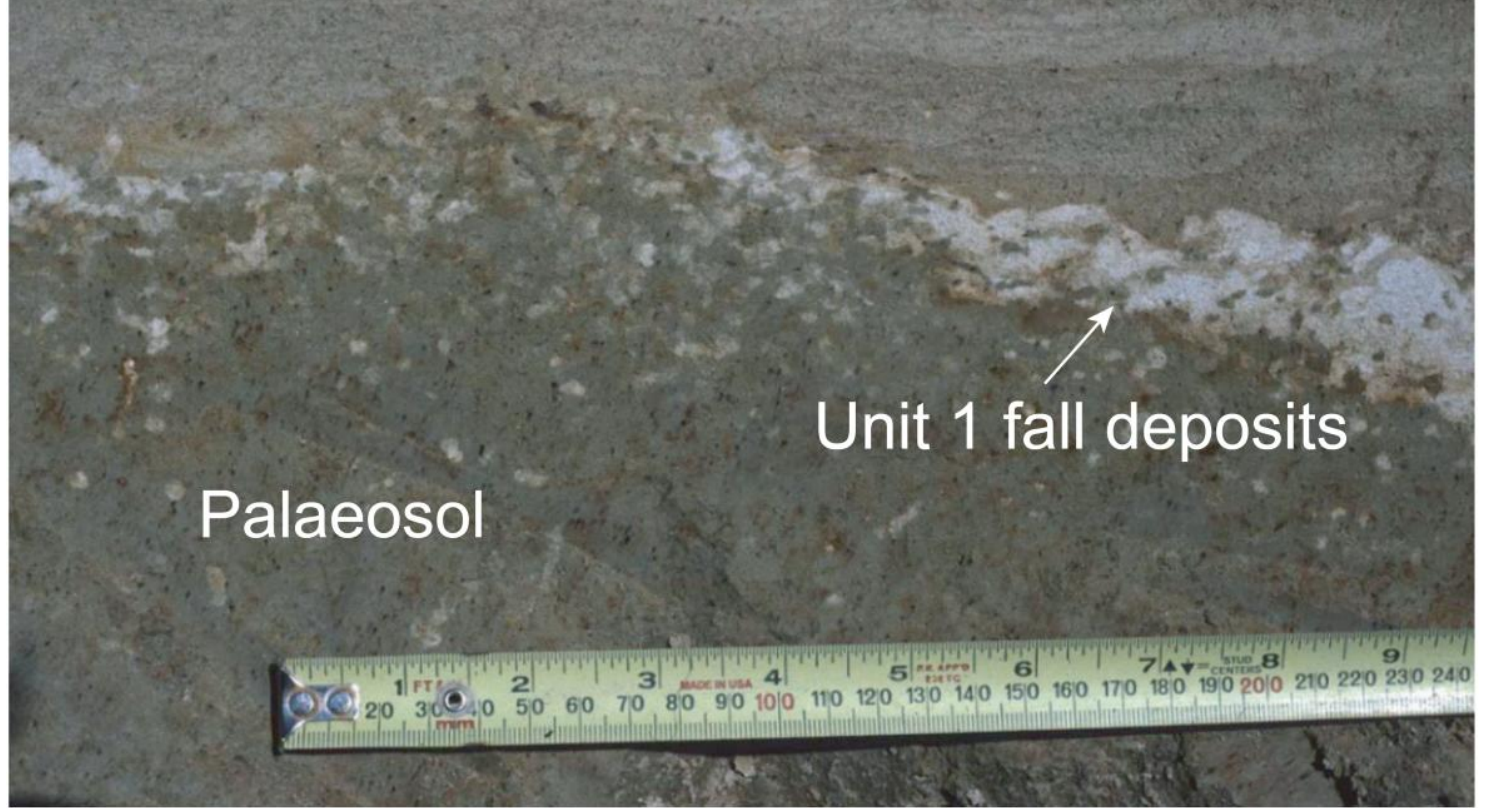

Figure 1.7. A photograph showing the reworked deposits of Oruanui fall unit 1. Phase 1 ash has been reworked and bioturbated into the underlying palaeosol prior to the arrival of phase 2 ash. On the basis of the reworking and/or partial to complete removal by erosion of the phase 1 deposits across many localities, Wilson (2001) inferred that a time break of several weeks to months separated phases 1 and 2. Photo courtesy of CJN Wilson.

deposits during later ignimbrite emplacement. Occasionally, however, field relationships provide qualitative constraints on the vent locations for later phases. For example, exposures of the Oruanui deposits at the Punatakahi scoria quarry (loc. 2288, $4.6 \mathrm{~km} \mathrm{NW}$ of Taupo township) show that the phase 3 deposits have been planed off by the incoming phase 7 ignimbrite flows from the west, implying a more westerly source (vent site) during phase 7 . The major collapse and establishment of the Oruanui caldera to its maximum extent is inferred, from lithic lag breccias, to have occurred during the climactic phase 10.

The established detailed internal stratigraphy of the Oruanui eruption deposits allows for strategic sampling of the quenched eruption deposits investigated in this thesis.

Observations from crystal-specific studies, such as changes in the depth or composition of the magma being tapped by the eruption, to be confidently linked to specific times in the progression of the eruption. Similarly, the first order constraints on the vent sites of different phases allows magma erupted from different geographic domains within the meltdominant Oruanui magma body to be targeted and lateral variations in magma and crystal 
compositions to be assessed (e.g. the eastern sourced phase 3 versus the westerly sourced phase 7).
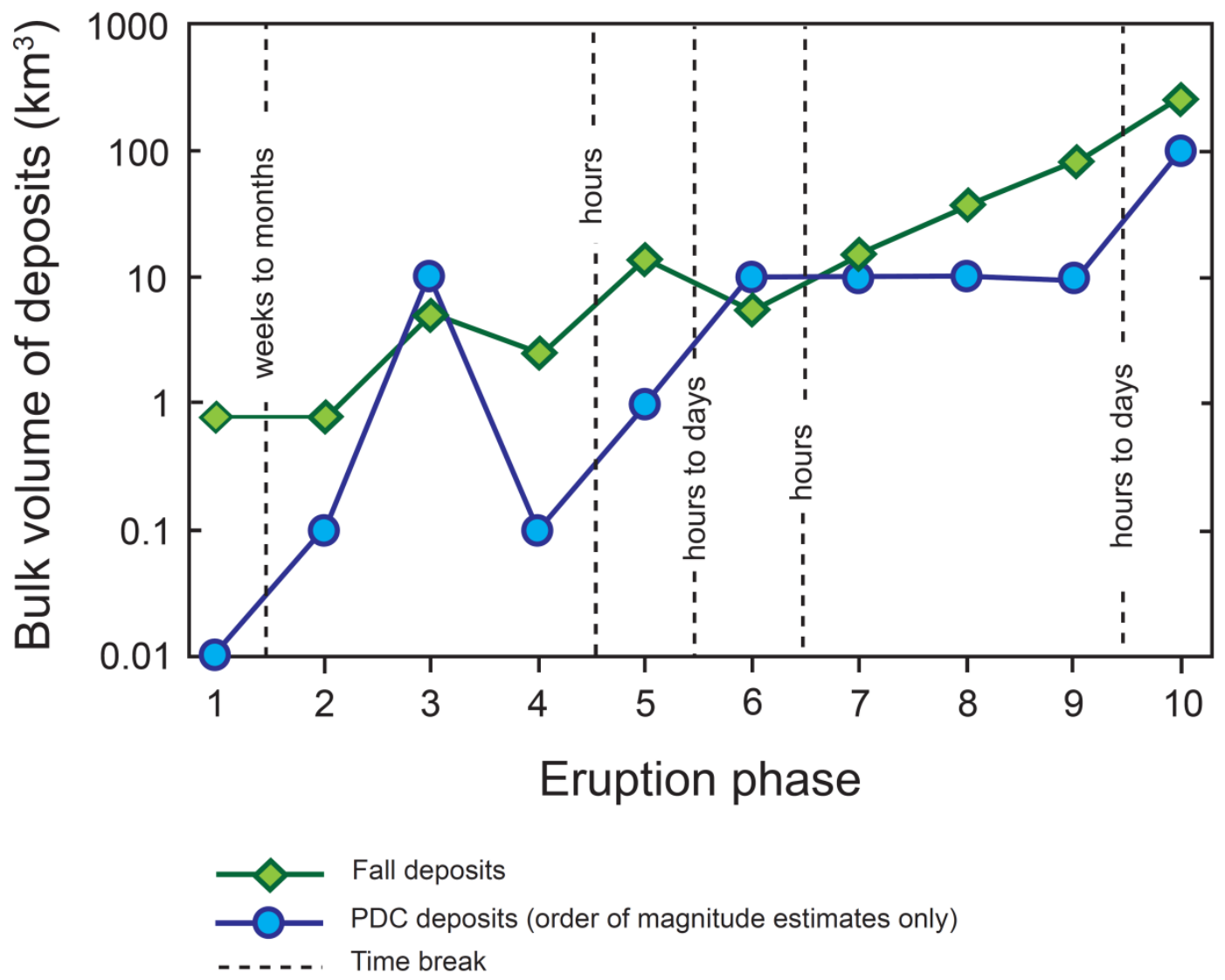

Figure 1.8. Approximate bulk volume of eruption deposits versus eruption phase, annotated to show significant hiatuses in explosive activity. The figure is plotted from data in Wilson (2001). Note: Wilson (2001) emphasises that phase 10 of the eruption is a 'catch-all' for the latest portion of the eruption where a lack of internal stratigraphy precludes further subdivision.

\subsubsection{Key results from previous geochemical investigations of the Oruanui eruption} deposits

Previous studies have established the broad geochemical, isotopic and petrological characteristics of the Oruanui eruption deposits and identified some of the contributing sources (e.g. Sutton 1995; Sutton et al. 1995 2000; Charlier et al. 2005 2008; Liu et al. 2006; Wilson et al. 2006; Wilson and Charlier 2009). The key findings from these studies, which inform the targeted crystal-specific investigations in this thesis, are summarised below.

Note, in the discussions below and throughout this thesis I adopt the phrase 'melt- 
dominant magma body', in line with the usage in Hildreth and Wilson (2007), to represent the melt-rich portion of the magma chamber that ultimately erupts (see Figure 1.9).

(1) Chemical and isotopic data from single pumice clasts have identified three broadly defined juvenile components to the Oruanui magma (as outlined in Wilson et al. 2006).

a. The first, and volumetrically dominant (>99\%), component is represented by white, highly vesicular rhyolitic pumice. Further subdivision of the rhyolites is possible based on whole rock compositional data. The dominant rhyolite type has whole rock $\mathrm{SiO}_{2}$ contents of $74-76 \mathrm{wt} \%$ with an assemblage consisting of plagioclase $>$ orthopyroxene $>$ quart $>$ hornblende $>$ magnetite $>$ ilmenite with trace amounts of apatite and zircon. A low- $-\mathrm{SiO}_{2}$ endmember (71.8 to 74 $\mathrm{wt}^{0} \%$ ) has been identified as a minor (but unquantified) component in the deposits of phase 3 and 6 . Hand sample specimens of this low $\mathrm{SiO}_{2}$ rhyolite end-member are similar in appearance to the dominant rhyolite but can be discerned by their higher proportion of hornblende (especially relative to orthopyroxene) and lesser abundance of quartz. A third rhyolite subgroup was suggested by Wilson et al. (2006) in recognition of a component of evolved rhyolite pumices with slightly (but noticeably) higher whole-rock $\mathrm{MgO}$ contents compared to the dominant rhyolite group.

b. The second component is represented by scoriaceous juvenile mafic clasts (strictly speaking, basaltic-andesite to high-Si andesite). Although they vary in abundance (mostly as ash-grade material) from $\sim 0.1$ to $4 \mathrm{wt} \%$, these mafic clasts are present at all stratigraphic levels of the deposits (Wilson 2001) and a total erupted volume of $\sim 5 \mathrm{~km}^{3}$ is inferred. They are inferred to be juvenile on the basis of cauliform or crenulated chilled margins, liquid-liquid contacts between them and local rinds of rhyolite pumice, quench crystallisation textures, and sparse micro-inclusions of vesicular rhyolitic glass (Wilson et al. 2006). At least two mafic magmas of contrasting lineages (one tholeiitic, the other calc-alkaline) have been identified (Sutton 1995; Wilson et al. 2006).

c. The final component is represented by very rare grey streaky pumices $\left(\mathrm{SiO}_{2}\right.$ contents of 60.9 to $73.7 \mathrm{wt} \%$ ). Analytical data for these pumices define a mixing trend between evolved (but somewhat $\mathrm{MgO}$-enriched) Oruanui rhyolite pumices and the least evolved calc-alkaline mafic compositions, indicating an origin through mechanical mixing of the high-Mg Oruanui rhyolite and one of the mafic magmas (Wilson et al. 2006). 
During this research previously unrecognised biotite-bearing rhyolite pumices were found in amongst the volumetrically dominant (and biotite-free) Oruanui pumices in the proximal phase 1 and 2 deposits. These biotite-bearing pumices are generally more crystalline ( $\sim 15-20 \%$ crystals), quartz- and hornblende-rich, and denser than the 'normal' Oruanui pumices (Figure 1.10). The origins of the biotite-bearing rhyolite magma, and significance of its presence in the early Oruanui deposits, are explored in Chapter 2 of this thesis.

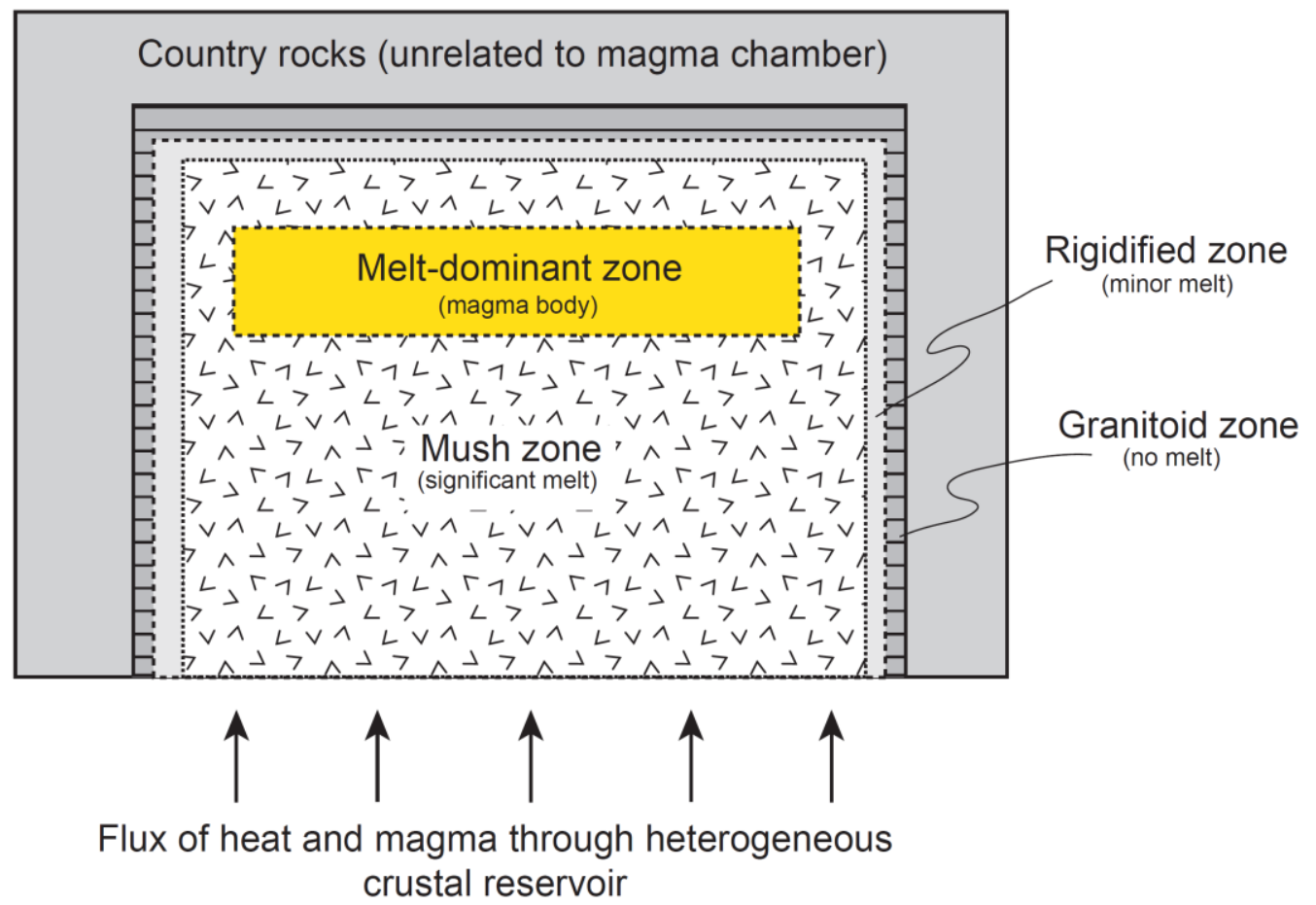

Figure 1.9. A schematic definition sketch of a silicic magma chamber. This figure, redrafted from Figure 17 of Hildreth and Wilson (2007), was used by them to help distinguish between key apects of areas of a magma chamber, only some of which may erupt. The term 'melt-dominant magma body' is used throughout this thesis in accordance with the definition of Hildreth and Wilson (2007), corresponding to the melt-rich portion of the magma chamber that represents the vast bulk of the erupted material. In this definition the 'mush zone' comes under the umbrella of the magma chamber.

(2) Non-systematic zonation of the Oruanui magma chamber. Major and trace element data from single Oruanui pumice clasts, when plotted eruption phase (i.e. stratigraphic height), do not reveal any discernible trends (Figure 1.11: Wilson et al. 2006).

Therefore, despite the existence of significant chemical variability in the Oruanui magma chamber, there was no systematic (stratified) compositional zonation at the time of eruption. These observations contrast with, for example, those from the Bishop Tuff supereruption from Long Valley caldera, USA, where the earliest erupted 


\section{Locality 2751 stratigraphic log}

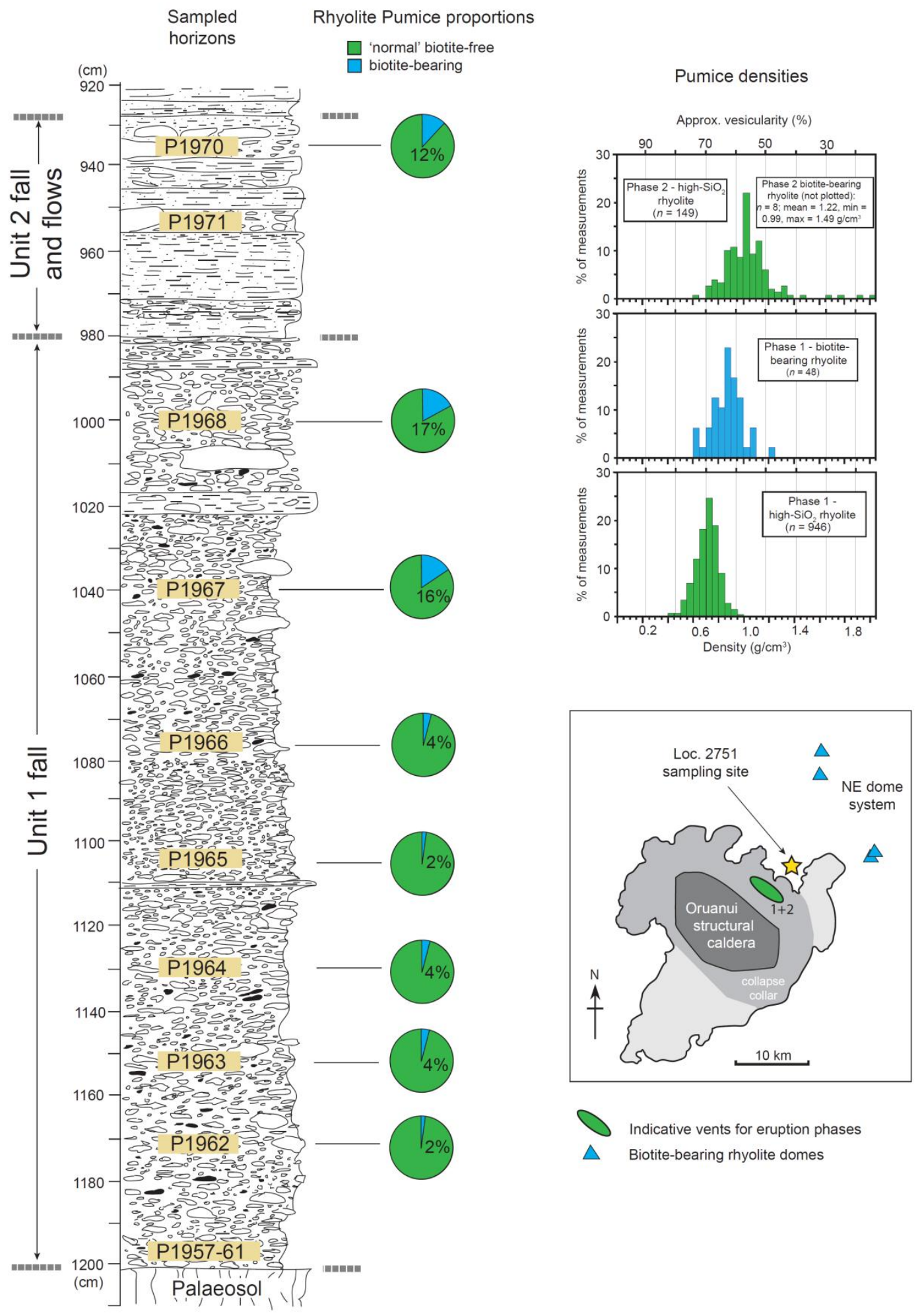

Figure 1.10. Stratigraphic log through proximal exposures of the early Oruanui deposits from locality 2751 of wilson (2001; see map). Systematic sampling through the section resulted in the discovery of juvenile biotite-bearing rhyolite pumices. These biotite-bearing pumices are generally denser and more crystalline ( $\sim 15-25 \%$ crystals) than the biotite-free clasts. The origin and significance of these biotitebearing rhyolite pumices are explored in Chapter 2. The stratigraphic log is based on the unpublished field notes of CJN Wilson. Density measurements were made following the method established by Houghton and Wilson (1989). The phase 1 and 2 vent envelope is shown in the in set map is from Wilson (2001). 
compositions are the most evolved and where less evolved and more crystal-rich compositions become more prominent as the eruption progressed (Hildreth 1979; Hildreth and Wilson 2007). The lack of systematic zonation suggests the Oruanui magma chamber was vigorously stirred at some stage before the eruption.

The claim that the Oruanui melt-dominant magma body was unzoned at the time of eruption is revisited in Chapter 4. Particular emphasis is placed on the new insights that can be gained by examining detailed textural and compositional information recorded in the crystals, combined with the stratigraphic and temporal control afforded by the Wilson (2001) eruption stratigraphy. Those findings progress to a discussion around the pre-eruptive processes and/or conditions that may determined the preservation versus destruction of compositional gradients in the melt-dominant magma body.
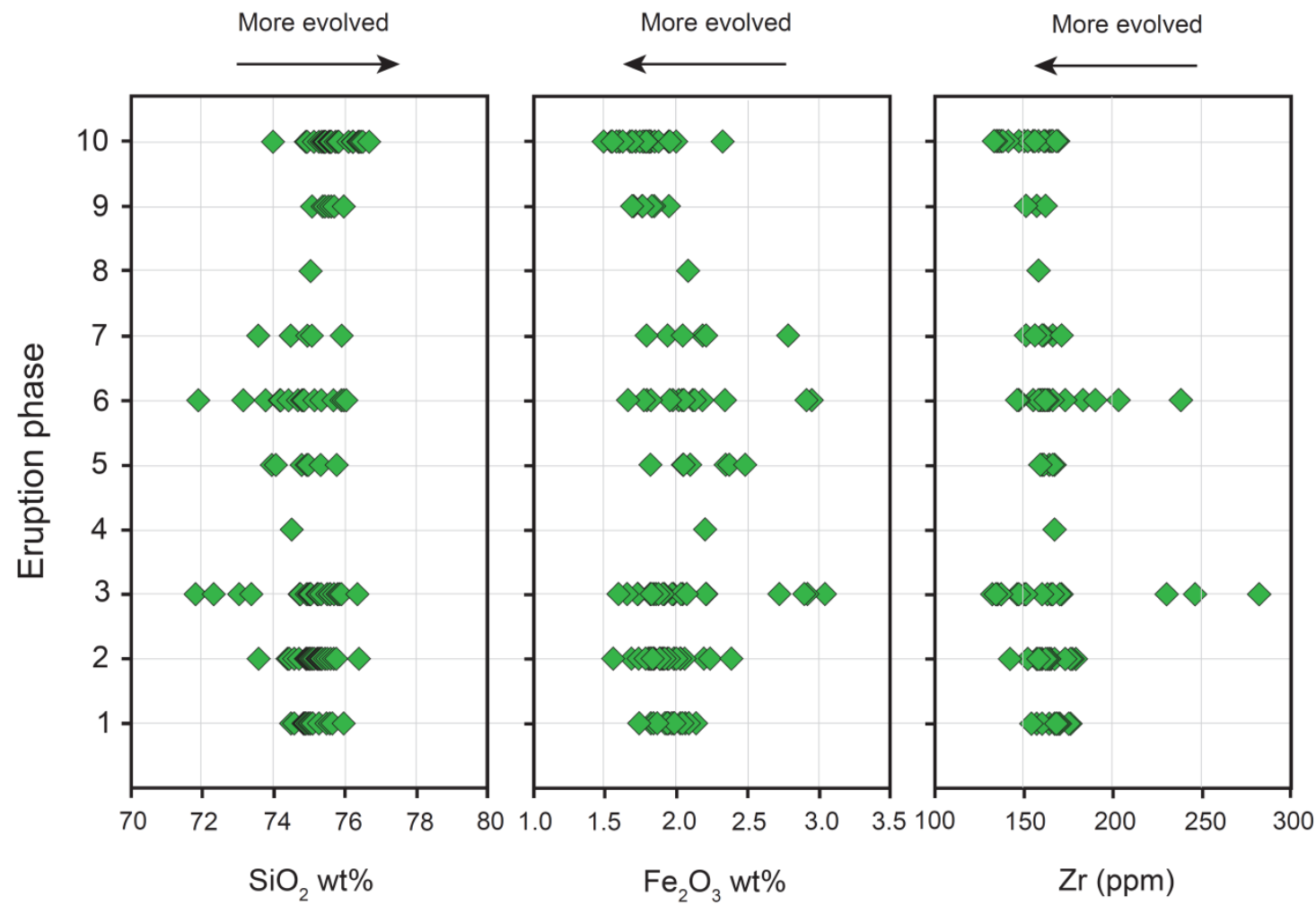

Figure 1.11. Selected whole-rock analytical data for Oruanui rhyolitic pumice clasts versus eruption phase (i.e., stratigraphic height). Despite significant compositional variation within the Oruanui rhyolites, the variability is not systematic with respect to stratigraphic height, indicating the Oruanui melt-dominant magma body was not zoned at the time eruption occurred. Modified from Wilson et al. (2006). 
(3) Wilson et al. (2006) demonstrated that the most evolved of the Oruanui rhyolite compositions he encountered ( $\mathrm{WR} \mathrm{SiO}_{2}=76.7 \mathrm{wt} \%$ ) could be theoretically generated from the least evolved rhyolite (WR SiO2 $=71.8 \mathrm{wt} \%$ ) after $\sim 28 \%$ Rayleigh fractional crystallisation of the observed phenocrysts phases.

The relationship between the high- $\mathrm{SiO}_{2}$ rhyolite and low- $\mathrm{SiO}_{2}$ rhyolite end-members, including whether they represent a single compositional continuum or distinct magma bodies, are explored throughout Chapters 3 and 4.

(4) Several magmas encountered and interacted with the growing Oruanui magma body, contributing crystals and melt, right up to the eruption. This conclusion is reached through several lines of evidence.

a. EPMA analysis of minerals extracted from individual Oruanui pumice clasts show that a number of crystals have non-equilibrium compositions for the host pumice from which they were extracted. To a first order, these non-equilibrium crystal compositions reflect growth in hotter and/or less evolved melts.

Extensive new datasets for the main mineral phases are presented and discussed in Chapters 3 and 4, with particular emphasis on the records of crystal cores and interior domains (earlier growth) versus the outermost crystal rims (final growth before eruption).

b. Juvenile clasts with mafic compositions (typically ash sized and rarely to lapilli or block sized) are present throughout the eruption deposits, but with prominent spikes in abundance during phases 3+4, 7 and 9 (Wilson 2001). Previous chemical and isotopic characterisation of the mafic clasts recognised that at least two mafic magmas with different lineages (one calc-alkaline and one tholeiitic) encountered and interacted with the main rhyolite body (Sutton 1995; Wilson et al. 2006). Reconnaissance data for minerals in these mafic clasts show exchange of crystals occurred between the mafic and rhyolitic magmas (Sutton 1995). On the basis of textural ('mushy' vs 'fresh' groundmass) and compositional differences between the two mafic magmas it has been inferred that the tholeiitic mafic magma stagnated at the base of the rhyolite body for some time prior to eruption (perhaps initiating stirring) whereas the calc-alkaline mafic magma ascended from depth and erupted with the rhyolite without stalling (Wilson et al. 2006).

New whole-rock and mineral chemistry data for the Oruanui mafic magmas are presented and discussed in Chapter 4. The inheritance of crystals from the 
Oruanui rhyolites, the timing of mafic-felsic interactions and the possibility the the mafic magmas triggered the onset of the eruption are explored.

c. Previous thermobarometric applications have estimated the final magmatic temperature of the voluminous evolved Oruanui rhyolite at $\sim 760^{\circ} \mathrm{C}(\mathrm{Fe}-\mathrm{Ti}$ oxide thermometry, Sutton 1995; Wilson et al. 2006). The melt-dominant magma body is inferred to have been stored at pressures equivalent to between $\sim 4$ and $8 \mathrm{~km}$ depth (94 to $188 \mathrm{MPa}$; Liu et al. 2006), on basis of volatile contents in quartz-hosted melt inclusions, and the inference of gas-saturated conditions (Liu et al. 2006; Wilson et al. 2012).

Estimates of magma intensive variables for the Oruanui rhyolites are revisited here in Chapters 4 and 5. Recently calibrated thermobarometric formulations applied to amphibole compositions (Ridolfi et al. 2010) provide new insights, particularly as to the pressures/depths associated with the low-SiO ${ }_{2}$ rhyolite magma for which no previous constraints are available. In light of recent controversies played out in the literature regarding the validity of some widely applied mineral thermometers and barometers, Chapter 5 comprises an extended discussion around some of the intricacies of the dark arts of thermobarometry.

d. U/Th age spectra for Oruanui zircons (and those of pre-cursor Oruanui-type magmas) reveal that a significant proportion of these zircons are inherited from an earlier magmatic history (Charlier et al. 2005; Wilson and Charlier 2009). These data have been used to put forward a model whereby the melt-dominant bodies for the Oruanui-type magmas assembled rapidly $(<3000 \mathrm{yr}$ for the Oruanui) as melts were expelled from a common crystal mush/source zone, entraining a significant component of older crystals (Wilson and Charlier 2009). Rare zircons that plot on the ${ }^{238} \mathrm{U} /{ }^{232} \mathrm{Th}-{ }^{230} \mathrm{Th} /{ }^{232} \mathrm{Th}$ equiline (i.e. are $\geq \sim 300$ ka) imply significant disaggregation/melting of greywacke basement rocks and/or Quaternary silicic volcanic deposits may also have occurred (see also Charlier et al. 2010). Charlier et al. (2005) determined a 'crystallisation age' for the major phases in the Oruanui rhyolites of $33+18 /-16 \mathrm{ka}$. This age was based upon on a 5-point 'isochron' modelled through ${ }^{238} \mathrm{U} /{ }^{232} \mathrm{Th}-{ }^{230} \mathrm{Th} /{ }^{232} \mathrm{Th}$ data from analyses of bulk crystal separates of plagioclase, hornblende, orthopyroxene, magnetite and the host pumice from which they were extracted. Importantly, despite the large associated uncertainties, this age 
determination establishes that the majority of crystals in the Oruanui magma are from young crystallisation that post-dates the $\sim 95 \mathrm{ka}$ peak common to the Oruanui-type magmas.

The rapid timescales (<3000 years) for the assembly of the Oruanui meltdominant magma body suggested by the zircon age spectra, and the overall extraction-from-mush model put forward by Wilson and Charlier (2009), are tested for consistency with the information recorded by the other crystal phases. Timing of the melt extraction event, especially, is addressed in Chapter 3 from a different perspective offered by $\mathrm{Fe}-\mathrm{Mg}$ diffusion in orthopyroxenes.

e. Conspicuous feldspars with blue-grey cores are present in rhyolitic pumices at all levels of the eruption deposits and comprise $\sim 1 \mathrm{~km}^{3}$ of the total erupted volume. Detailed major element traverses and novel in situ analysis of ${ }^{87} \mathrm{Sr} /{ }^{86} \mathrm{Sr}$ from zoned crystal domains revealed a complex history for these grains (Charlier et al. 2008). This history involved initial growth in a broadly intermediate composition plutonic body (rounded cores), followed by dissolution and growth within a radiogenic melt thought to be derived from melting of greywacke basement (inner overgrowth regions), and finally continued growth and evolution in the Oruanui melt-dominant magma body (outer overgrowths and rims: Charlier et al. 2008). Involvement of melting of crustal protoliths is implicated also in other magmas at Taupo as has already been shown for the immediate post-Oruanui dacite (Charlier et al. 2010). The blue-grey cored feldspars were specifically targeted for interrogation by Charlier et al. (2008) because they were conspicuous and unusual. The work in this thesis focuses in contrast on the characterisation and documentation of the numerically dominant 'normal' clear plagioclase, although additional data are also presented from the blue-grey cored crystals. Textural and compositional characteristics of the 'rhyolitic' plagioclase presented in Chapter 4 show many parallels with the results and conclusions of Charlier et al. 2008.

f. Liu et al. (2006) measured trace and volatile elements in quartz-hosted melt inclusions in high- $\mathrm{SiO}_{2}$ rhyolite Oruanui pumices. They noted a minor proportion of the melt inclusions, corresponding to those trapped in irregular shaped and dark CL quartz cores, had compositions indicating derivation from a Ba-compatible source. They reported that the trend was indicative of the presence of sanidine but no sanidine has ever been reported in the Oruanui 
eruption products. On the basis that the Oruanui caldera overlaps with the footprint of the earlier Whakamaru caldera (Figure 1.2), Liu et al. (2006) explored the possibility that the Ba-compatible melt may record incorporation of plutonic materials associated with the older sanindine-bearing (Bacompatible) Whakamaru system. The zircon age data available at the time of the Liu et al. (2006) publication (i.e. Charlier et al. 2005) and subsequent zircon $\mathrm{U}-\mathrm{Pb}$ age datasets acquired since then on a post-Oruanui dacite vented from inside the Oruanui caldera (Unit Omega, Charlier et al. 2010), are indicative of a significant inheritance of 'Whakamaru-age' zircons and are therefore supportive of this notion.

These previous field-focussed, petrological and geochemical studies provide a contextual standpoint for the crystal-specific investigations in this thesis that is unrivalled for an eruption of this magnitude and age. The subsequent chapters build from this established framework to piece together the story of the world's youngest supereruption from the final minutes in which eruption was triggered, to the centuries and millennia over which the magma was generated and assembled. 


\title{
2. The invisible hand: tectonic triggering and modulation of a rhyolitic supereruption
}

\begin{abstract}
Identifying the processes that initiate and control large explosive eruptions on time-scales of human interest is challenging. We present evidence for syneruptive, subsurface interactions between rhyolite magmas derived from distinctive sources that reflect tectonic processes starting, then temporarily stopping, the $27 \mathrm{ka}$ Oruanui supereruption $\left(530 \mathrm{~km}^{3}\right.$ magma, Taupo, New Zealand). Subordinate (3\%-16\%) biotite-bearing pumice lapilli occur in fall deposits from phases 1 and 2 (of 10) amongst the biotite-free 'normal' pumices in the Oruanui deposits. The biotite-bearing magma is sourced to an independent magmatic system 10-15 km NE of Taupo. Lateral migration of the biotite-bearing magma was initiated during a rifting episode that also triggered the Oruanui eruption. Limited physical mingling indicates the biotite-bearing and Oruanui biotite-free magmas interacted in the conduit simultaneously with eruption. After phase 1, a time break of months elapsed before phase 2 explosive activity resumed from the same vent, again with intermixed biotite-bearing magma. A rift-related tectonic event, with its accompanying stress change, is inferred to have initiated diking from NE to SW, transporting biotite-bearing magma and triggering the Oruanui eruption. Stress relaxation following the rifting event terminated phase 1 before a tectonic event caused renewed diking and activity in phase 2 . Tectonics may trigger large silicic eruptions through rupturing of shallow crustal magma chambers and lateral magma transport, especially in extensional regimes, without necessarily leaving any discernible geological imprint. Only the presence of a 'foreign' magma in the Oruanui deposits allows the tectonic control to be identified.
\end{abstract}

\subsection{INTRODUCTION}

How do large explosive (super-) eruptions start? Are they the inevitable culmination of factors such as gas-saturation and over-pressure (e.g. Blake 1984), or can other controls be discerned? Gaining an accurate perspective on what happens to control explosive eruptions on human-relevant time-scales, in particular identifying the trigger of a supereruption, is a significant challenge. Direct observations are impossible, and 
information on eruption timings and processes must be gained from field studies (Wilson 2008). Petrological studies of eruption products yield information about growth and evolution of large magma bodies on geological timescales. However, neither approach can necessarily show why a particular eruption started at a particular moment, due to the limits of the geological record.

What if an eruption trigger leaves no discernible imprint on the geological record? External forcing of magma chamber rupture, by tectonic processes for example, may not leave any tangible record of the triggering process. While historic links between eruption onsets and seismicity are known (e.g. Manga and Brodsky 2006), the question remains, how might one discern from the geological record whether an eruption was tectonically triggered? Tectonic processes may also be a key to understanding what controls syneruptive propagation of dikes (e.g. Bursik et al. 2003) and the vigor of magma withdrawal once an eruption has begun (e.g. Costa et al. 2011). Few theoretical models that invoke internal (magmatic) eruption triggers (e.g., over-pressure and gas-saturation - Blake 1984) can explain the dynamic stop-start nature of activity inferred for some supereruptions (e.g., Oruanui, Huckleberry Ridge Tuff: Wilson 2001, 2008) which may instead reflect external controls.

Here, crystal and glass compositional data are coupled with field observations to document the opening stages of the Oruanui supereruption. We identify syneruptive interactions between compositionally contrasting magmas derived from geographically separate magmatic systems. The fortuitous presence of these coeval, independent systems and involvement of a 'foreign' magma in the Oruanui eruption permits the recognition of rifting-related processes in controlling the onset and modulating the vigor of a supereruption.

\subsection{ORUANUI ERUPTION}

The $27 \mathrm{ka}$ Oruanui eruption (Taupo, New Zealand; Figure 2.1) discharged $\sim 530 \mathrm{~km} 3$ of moderate-to high-silica rhyolite during a prolonged, episodic eruption (Wilson, 2001; Wilson et al. 2006). Ten phases of activity occurred during which comparable volumes of pyroclastic fall and density current deposits were generated. Sampling through thick proximal exposures of the phase 1 and 2 fall deposits (each representing $\sim 0.3 \mathrm{~km} 3$ of magma from the $\sim 530 \mathrm{~km}^{3}$ total for the eruption; Wilson 2001) has identified distinctive juvenile crystal-richer biotite-bearing rhyolite pumices among the volumetrically dominant 
(and biotite-free: Wilson et al. 2006) Oruanui pumices. The former are also more quartzand hornblende-rich compared to the biotite-free Oruanui pumices (Electronic Appendix, Table DR1). The biotite-bearing pumices comprise 3\% of the 16-32 $\mathrm{mm}$ size fraction of the phase 1 deposits, including the very first erupted material, with an increase to $\sim 16 \%$ in the upper third of the deposit. The biotite-bearing pumices occur at several horizons in the phase 2 deposits but their abundance $(12 \%)$ has only been quantified at one level. The estimated volume of biotite-bearing magma is minor $(\sim 0.03 \mathrm{~km} 3)$ when compared with the volume of biotite-free Oruanui magma.

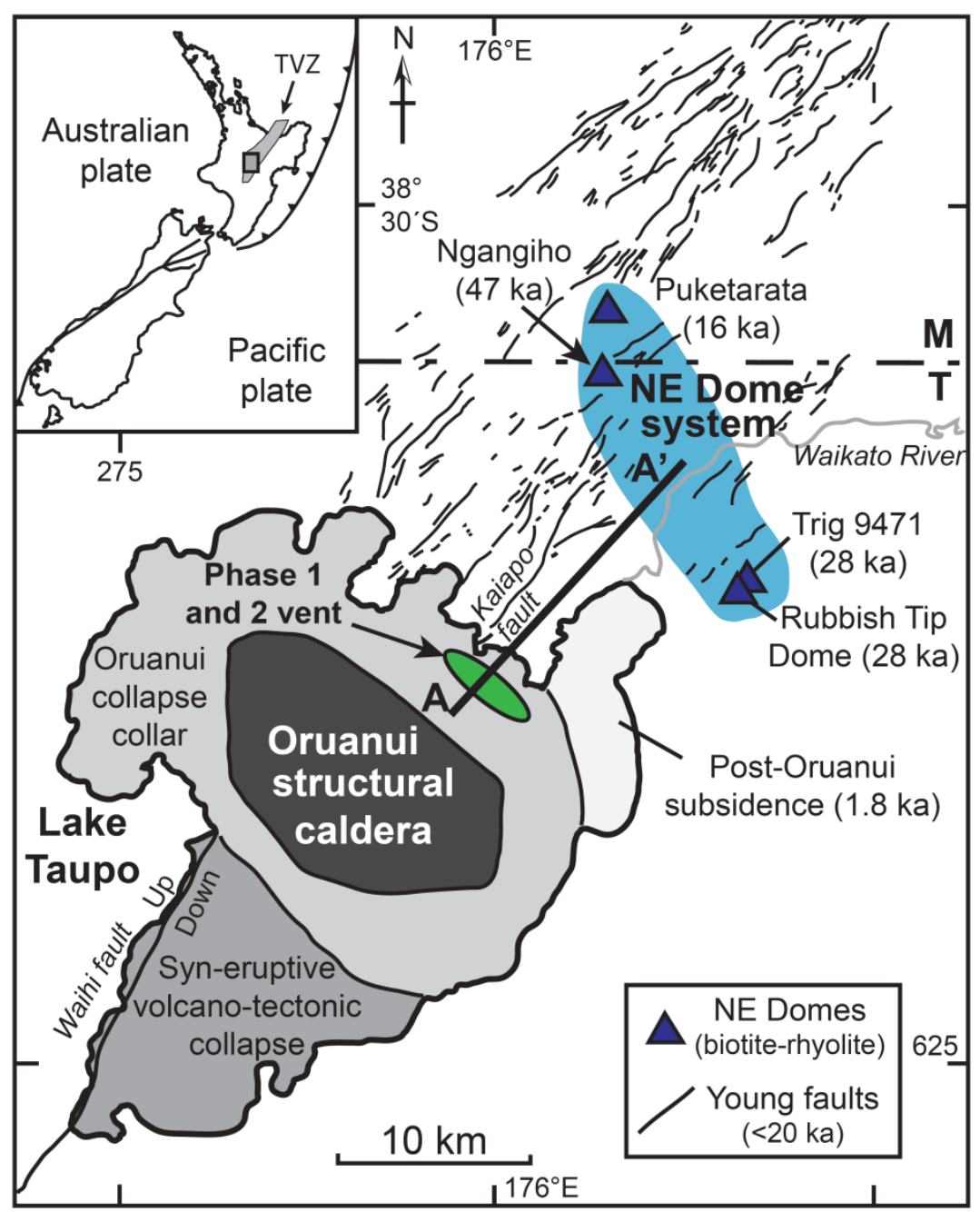

Figure 2.1. Key volcano-tectonic features of the Taupo-Maroa area, located in the central North Island, New Zealand (inset: TVZ - Taupo Volcanic Zone). Caldera structure and vent envelope for phase 1 and 2 of the Oruanui eruption are from Wilson (2001). The NE-SW alignment of 'young' faults (ruptures $<20$ k.y. old) highlight the axis of regional extension in the modern TVZ. Dashed line marks the boundary between Taupo (T) and Maroa (M) volcanoes (Sutton et al. 1995). The stippled gray region encompasses the NE Dome magmatic system and associated biotite-rhyolite domes (triangles - after Sutton et al., 1995). Eruption ages are from Wilson and Charlier (2009). The line labeled A to A' marks the line of section in Figure 2.4. Modified from Wilson and Charlier (2009). 


\subsection{CONTRASTING MAGMA TYPES}

Fresh, biotite-free and biotite-bearing pumices (5-12 cm long) were sampled from the phase 1 and 2 fall deposits (see Appendix 1 for analytical techniques and Electronic Appendices for representative data). Despite their obvious mineralogical contrasts, major and trace element compositions of single biotite-bearing and biotite-free pumices are broadly similar. However, the biotite-bearing pumices have distinctively lower concentrations of high field strength elements, particularly $\mathrm{Zr}$ and Hf, although a few biotite-bearing pumices plot close to, or within the field of, data for the biotite-free pumices (Figure 2.2a). Pumice glass major element chemistry more clearly highlights the compositional differences (Figure 2.2b). Glass from the biotite-free pumices defines a compositional grouping that is essentially homogenous within analytical uncertainty. Glass fragments separated from individual biotite-bearing pumices, however, show more diversity; some clasts show unimodal patterns, others bimodal and one comprised a spectrum of compositions between the two groups. Glasses from the unimodal clasts are characterized by higher $\mathrm{K}_{2} \mathrm{O}$, and lower $\mathrm{FeO}, \mathrm{CaO}, \mathrm{TiO}_{2}$ and $\mathrm{MgO}$ contents when
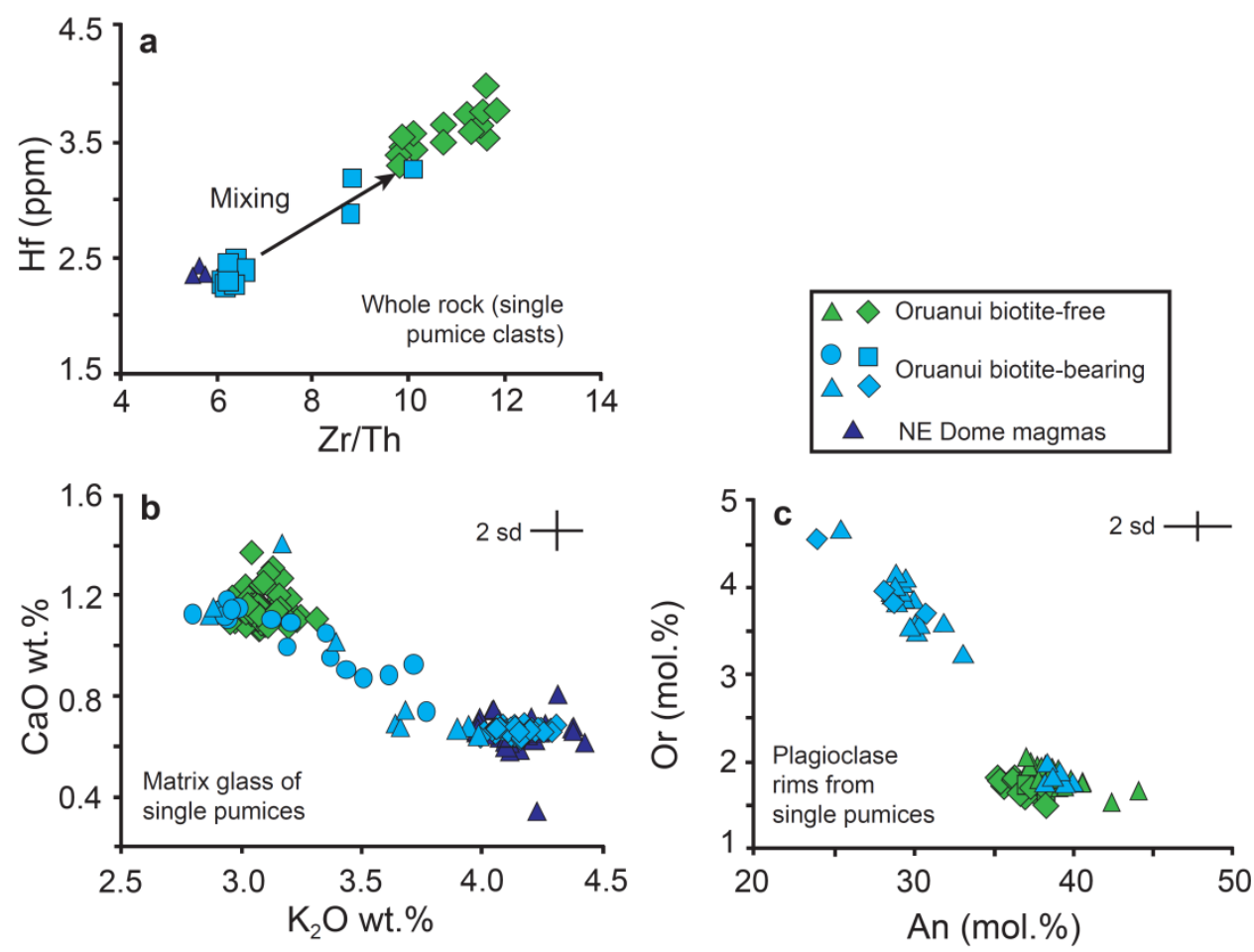

Figure 2.2. Mixing between the Oruanui biotite-bearing and biotite-free magmas is evident at the whole rock (a), single pumice (b) and single-crystal scales (c). The Oruanui biotite-bearing magma shows close compositional affinities with the NE Dome type magmas (28 ka dome used as example). Each symbol type in (b) and (c) represents data from a single pumice clast. $2 \mathrm{sd}-2$ standard deviations. 
compared to the biotite-free compositional group. In the bimodal clasts, one of the compositional groups matches that of the unimodal biotite-bearing pumices while the other matches that of the biotite-free Oruanui clasts.

Plagioclase rim compositions from the two Oruanui pumice types also form distinctive groups. Those from the biotite-bearing pumices are generally offset to lower anorthite and higher orthoclase values than rims from the biotite-free pumices (Figure 2.2c). However, six of the analyzed plagioclase crystals from one biotite-bearing clast (which also shows two compositional populations in the matrix glass) have rim compositions matching those of the biotite-free group.

Biotite-bearing crystal-rich magma was also erupted nearby to Taupo at 28 ka, only $\sim 1$ k.y. prior to the Oruanui to generate the Poihipi Tephra and co-erupted Rubbish Tip and Trig 9471 domes (Sutton et al. 1995; Wilson and Charlier 2009; Figure 2.1). These eruptives represent part of the NE Dome magma type of Sutton et al. (1995), and their whole rock trace-element and glass major-element compositions are indistinguishable from the dominant compositional groups from the Oruanui biotite-bearing pumices (Figure 2.2a and 2.2b). Trace-element fingerprinting of amphibole crystals confirms the similarities between the Oruanui biotite-bearing and the NE Dome-type magmas (Figure 2.3). Although there is some overlap, many amphiboles from the Oruanui biotite-bearing pumices display chemical signatures that are matched by the NE Dome samples but which differ to those from the biotite-free Oruanui pumices. For example, a number of amphiboles from the biotite-bearing pumices have concentrations of $\mathrm{Ni}$ and $\mathrm{Zr}$ that are about a factor of 10 higher and a factor of 3 lower, respectively, than the amphiboles in the biotite-free pumices at broadly similar Sr levels (Figures 2.3a and 2.3b). These characteristic enrichments and depletions in these elements are also observed in amphiboles from the NE Dome samples. The NE Dome system is, however, an independent entity to the Oruanui system, despite its close geographic proximity and coeval existence, with contrasting chemical, mineralogical and isotopic characteristics, and zircon crystallization histories (Sutton et al. 1995; Wilson and Charlier 2009).

\subsection{DisCUSSION}

\subsubsection{How and Why Did the Magmas Interact?}

When the amphibole trace-element data are plotted alongside pressure and temperature estimates from the same crystals (Figure $2.3 \mathrm{c}$ and $2.3 \mathrm{~d}$ ) it is apparent that the two magma 

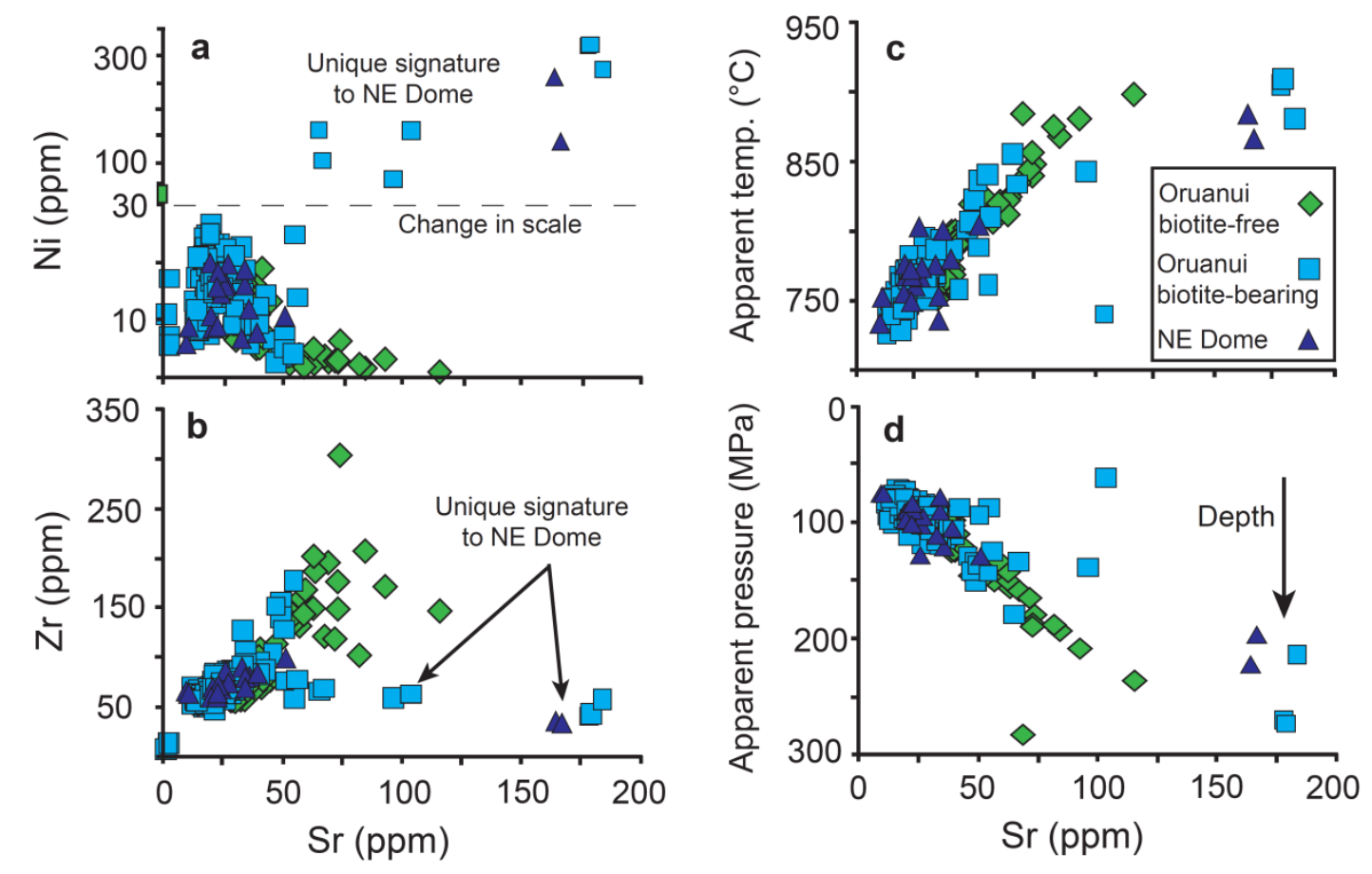

Figure 2.3. Trace elements (determined by laser ablation ICP-MS) and estimated apparent pressures and temperatures (after Ridolfi et al. 2010) of amphibole crystals in Oruanui and NE Dome magmas.

bodies (biotite-bearing and biotite-free) overlapped considerably in their storage and growth depths in the crust, yet have independent chemical signatures. Vertical pre-eruptive juxtaposition of the two contrasting magmas is therefore implausible and we infer that the magma bodies were horizontally separated. Compositional similarities at whole-rock to single crystal scales (Figures 2.2 and 2.3) link the biotite-bearing Oruanui magma to the NE Dome system and suggest that the horizontal separation of the pre-eruptive magma bodies was $\sim 10-15 \mathrm{~km}$, based on the surface footprints of the Oruanui caldera and NE Dome eruptive vents (Wilson and Charlier 2009; Figure 2.1). Trends in whole rock trace-element data (Figure 2.2a) and the bimodality of pumice matrix-glass and plagioclase rim compositions (Figure 2.2b and 2.2c) in some biotite pumices are consistent with subsurface mingling between the two magmas. Importantly, this exchange was uni-directional, that is, crystal and melt compositions corresponding to the biotite-free Oruanui magma are found in some biotite-bearing pumices but never the reverse. We interpret these relationships to indicate that the (foreign) biotite-bearing magma encountered the Oruanui magma in the conduit en route to the surface just prior to fragmentation. The geochemical data corroborate field observations of clast sizes in the fall deposits that the maximum clast sizes (pumices and lithics) consistently diminish away from the northeastern Lake Taupo 
area (CJNW, unpublished data), indicating eruption from the same vent, as opposed to simultaneous eruption from geographically separated vents.

We infer that the two magmas met through transport of the biotite-bearing magma in a dike that propagated SW to intersect the Oruanui conduit immediately prior to or from the earliest stages of the eruption (Figure 2.4), and hence that both lateral magma transport and initiation of the Oruanui eruption were accompanied by a rifting-related event. The density structure of the crust north of Taupo (Robinson et al. 1981) would favor lateral transport of magma where any reduction in the minimum principal horizontal stress through rifting-related processes would cause mild overpressure and drive magma sideways, rather than to the surface (Lister 1990). The area northeast of Taupo is intensively faulted, and the Kaiapo Fault (Figure 2.1) was a clean scarp against which Oruanui ignimbrite was banked in later eruptive phases. Surface displacement on this fault thus may have accompanied diking. Evidence for other syn-eruptive fault movements is, however, buried by the Oruanui ignimbrite or obscured by post-eruption collapse and regional faulting.

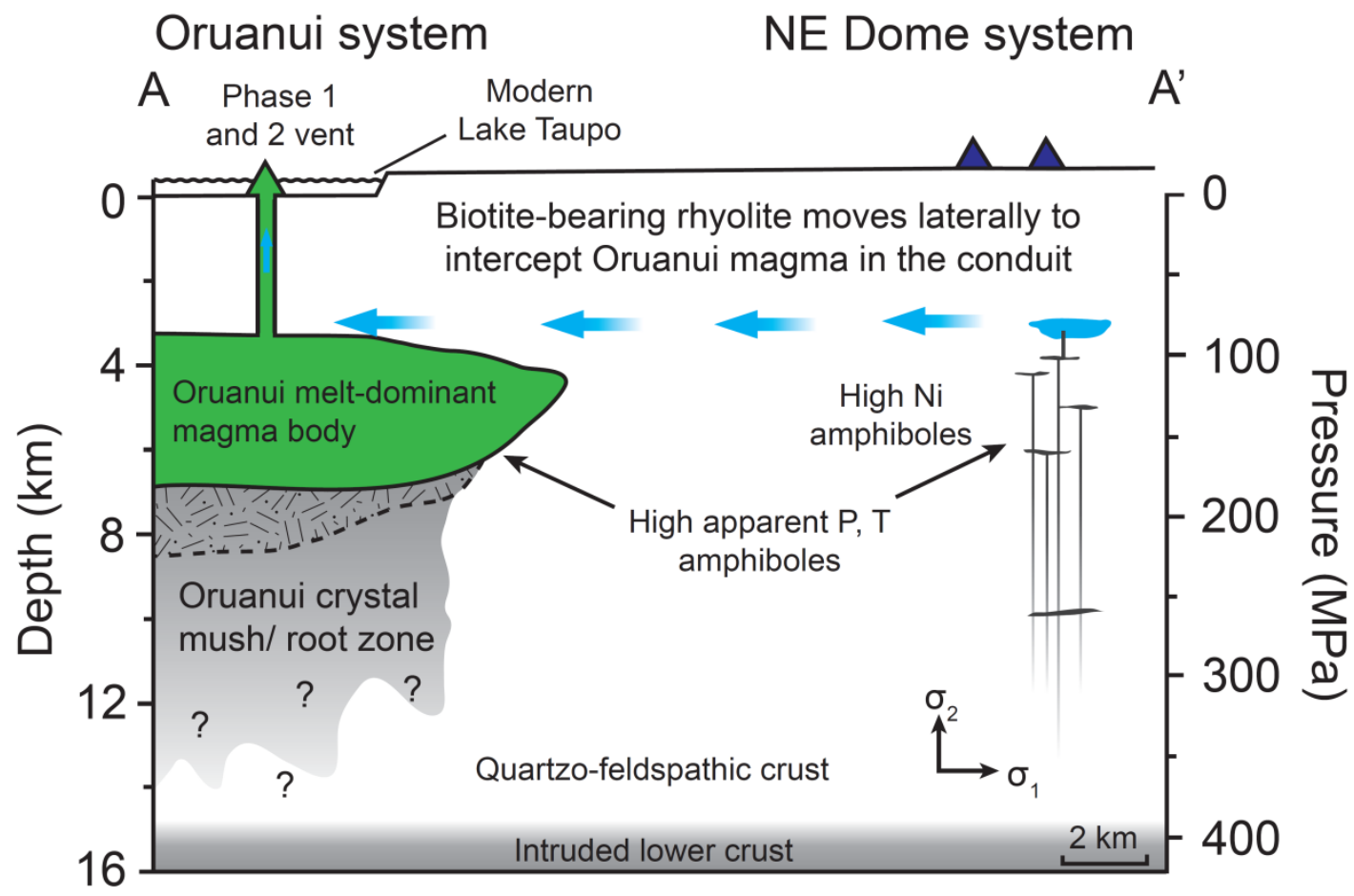

Figure 2.4. Scaled cross-section through the Oruanui and NE Dome magmatic systems immediately prior to, and during the opening phases of the Oruanui eruption at $27 \mathrm{ka}$. Subsurface dimensions of magma bodies, root zones/source regions and depth of crustal horizons are constrained by thermobarometry (Liu et al. 2006; Wilson et al. 2006; this study) and geophysical data (e.g., Harrison and White 2006). Orientation of regional principle stress axes $(\sigma 1, \sigma 2)$ are indicated, while $\sigma 3$ is out of the page. $\mathrm{P}-$ pressure, $\mathrm{T}-$ temperature. See text for discussion. 


\subsubsection{How Do You (Prematurely) Stop a Supereruption?}

Phase 1 of the Oruanui eruption stopped after the withdrawal of $<0.1 \%$ of the total magma volume. The succeeding time break lasted of the order of months, based on the degrees of reworking, bioturbation or removal of the phase 1 deposits before deposition of phase 2 tephra (Wilson 2001). Why did the eruption stop? During phase 1 and at the time of this shutdown $\sim 530 \mathrm{~km}^{3}$ of crystal-poor rhyolite magma was present at $\sim 4-8 \mathrm{~km}$ depths beneath Taupo. The magma was gas-saturated and, based on the crystallization trends observed in trace and volatile element concentrations in quartz-hosted melt inclusions (Liu et al., 2006), had been so and hence highly eruptible for some time. These features should mean that if a rift-related event triggered the eruption, a run-away escalation in eruptive intensity would be favored as long as the magma pressure is high enough to keep the vent open (e.g., Costa et al. 2011). The fact that high eruption rates did not result until later in the eruption is thus puzzling. The minor volume of magma erupted during phase 1 and absence of lithic-rich deposits preclude vent, or early-caldera, collapse as a mechanism for stopping the eruption. Similarly the trivial volumes we infer for the biotite-bearing magma suggest it is equally unlikely that influx of this comparatively gas-poor foreign magma somehow 'choked' the Oruanui conduit.

If rifting-related tectonic processes can initiate a large eruption or lateral transport of magma by diking by reducing the horizontal minimum principal stress ( $\sigma 3$ ) above a magma chamber, do they also have the potential to prematurely shutdown an eruption by clamping and unclamping faults that control magma exiting the chamber? Costa et al. (2011) suggested that crustal extension combined with magma chamber overpressure can result in high eruption rates of $>1010 \mathrm{~kg} / \mathrm{s}$, using phase 3 of the Oruanui eruption as one example. However, the cessation of explosive activity after phase 1, despite the available volumes of gas-saturated magma and evidence that rifting-related processes initially accompanied opening of the chamber, suggests an alternative scenario. We suggest that the stress drop (in the range 1-10 MPa: e.g., Bursik et al. 2003; Allmann and Shearer 2009) associated with the dike emplacement and any surface (normal) faulting served to temporarily clamp shut the vent structure above the Oruanui chamber.

\subsubsection{Re-Initiation of Explosive Activity}

Phase 2 explosive activity from the same vent as phase 1 also saw an influx of biotitebearing magma, indicating renewed diking in response, we infer, to another rifting-related 
event. A minority of pumices (of both types) from the phase 2 deposits are denser than their phase 1 counterparts and occasionally microlite-bearing, indicating that they had undergone partial degassing in the conduit and possibly formed a small dome extrusion during the intervening time break (Wilson 2001). In parallel fashion to modern magmatically-assisted rifting (see below for examples) we suggest that the time break between phases 1 and 2 saw recovery of the magma chamber pressures and regional stress states to the point where another rifting event and vent opening occurred. In the rejuvenated eruption, run-away activity then occurred into phase 3 , accompanied by a spike in the abundance of deeply-derived juvenile mafic material (Wilson 2001; Wilson et al. 2006), which may indicate that rifting processes and accompanying deep-derived magma insurgence caused destabilization of the whole Oruanui magma chamber (cf. Costa et al. 2011).

\subsubsection{Modern Analogues}

A tectonic and temporal analogue to the Oruanui events is seen in rifting processes in the Afar, Ethiopia from 2005 onwards (Belachew et al. 2011, for overview). Observations there yield three results that have close parallels with Oruanui geologic evidence despite contrasts in the magma properties. First, there is a spacing of 1-9 months between individual episodes of coupled rifting/dike intrusion events, comparable to the Oruanui time break between phases 1 and 2. Second, the on-off nature of the rifting/diking process is tectonically controlled by changes in the stress regime. While magma overpressure is important in controlling magma transport in dikes (Lister 1990), gross overpressure of the magma bodies alone in the absence of rifting processes would result in eruption of the magmas directly above their sources with little or no lateral migration. There is a delicate interplay between magma driving pressure and tectonic stress relief accompanying faulting that encourages the lateral magma migration (Lister 1990; Bursik et al. 2003). Third, dike emplacement led to eruption in only 3 of 14 events and at locations removed from the magma source. Thus, movement of magma initiated by rifting need not result in either eruption or a vent location above where the magma was stored.

A second, tectonic and magmatic analogue is seen in the emplacement of the $10-15 \mathrm{~km}$ long rhyolite dike in association with the $\sim 1350 \mathrm{CE}$ sequence of eruptions at the MonoInyo system (e.g., Reches and Fink 1988). Here, lateral movement of crystal-poor rhyolite magma is inferred to have accompanied (and in turn been influenced by) rupture on 
adjacent faults (Bursik et al. 2003). At the southern extent of the dike, the crystal-poor rhyolite encountered and mixed with a crystal-rich rhyolite derived from an independent, Long Valley source and the two were co-erupted from aligned vents (Sampson and Cameron 1987). The Mono-Inyo sequence differs from the Oruanui in the presence of multiple vents, but otherwise amply demonstrates the feasibility of lateral transport of rhyolite at shallow depths in the crust.

\subsection{CONCLUSIONS}

Our data suggest that rifting processes triggered the onset and controlled the timing of the world's youngest supereruption. We infer that tectonics also played a subtle, and largely invisible, role in modulating the shut-down of the Oruanui eruption after its first phase and controlling a hiatus in explosive activity of some months. We suggest that, particularly in extensional settings, lateral (as opposed to vertical) mixing of different magmas at shallow levels may be an under-recognized process. If tectonic processes have the potential not only to initiate a large explosive eruption, but also to prematurely suppress or stop the eruption altogether, being able to accurately declare when a large explosive eruption has truly ended may be a significant challenge. 


\section{From mush to eruption in centuries: assembly of the super-sized Oruanui magma body}

\section{Abstract}

The magmatic systems that give rise to voluminous crystal-poor rhyolite magma bodies can be considered to operate on two contrasting timescales: those governed by longer-term processes by which a magma acquires its chemical and isotopic characteristics (e.g. fractional crystallisation and assimilation), and those operating at shorter timescales during the physical accumulation of the melt-dominant magma body that finally erupts. We explore the compositional and textural relationships between amphibole and orthopyroxene crystals from the $25.4 \mathrm{ka}, 530 \mathrm{~km}^{3}$ (magma) Oruanui eruption products (Taupo volcano, New Zealand) to investigate how processes related to the physical assembly of the pre-eruptive magma body are represented in the crystal record. Over $90 \%$ of orthopyroxenes from the volumetrically dominant high- $\mathrm{SiO}_{2}(>74 \mathrm{wt} \%)$ rhyolite pumices record textural evidence for a significant disequilibrium event (partial dissolution \pm resorption of cores and interiors) prior to the growth of 40-500 $\mu \mathrm{m}$ thick rim zones. This dissolution/regrowth history of orthopyroxene is recorded in the chemistry of cocrystallising amphiboles as a prominent inflection in the concentrations of $\mathrm{Mn}$ and $\mathrm{Zn}$, two elements notably enriched in orthopyroxene relative to amphibole. Textural and chemical features, linked with in-situ thermobarometric estimates, indicate that a major decompression event preceded the formation of the melt-dominant body. The decompression event is inferred to represent the extraction of large volumes of melt plus crystals from the Oruanui crystal mush/source zone at pressures of 140 to $300 \mathrm{MPa}$ ( 6$12 \mathrm{~km}$ depth). Orthopyroxene underwent partial dissolution during ascent before restabilising in the melt-dominant magma body at pressures of $90-140 \mathrm{MPa}(\sim 3.5$ to $6 \mathrm{~km})$. We model Fe-Mg diffusion across the core-rim boundaries along the crystallographic $a$ or $b$-axes to constrain the timing of this decompression event, which marked establishment of the melt-dominant magma body. Maximum modelled ages indicate that this event did not begin until $\sim 1600$ years before eruption, consistent with constraints from zircon model-age spectra. Once extraction began it underwent run-away acceleration with a peak extraction age of $\sim 230$ years, followed by an apparent period of stasis of $\sim 60$ years prior to eruption. The rapidity of the extraction and accumulation processes implies the involvement of a 
dynamic driving force which, in the rifted continental arc setting of the Taupo Volcanic Zone, seems likely to be represented by magma-assisted extensional tectonic processes.

\subsection{INTRODUCTION}

Deciphering the processes associated with the build-up to large silicic eruptions offers many challenges from petrological and volcanological perspectives. Among the most contentious issues is determining over what timescales voluminous melt-dominant magma bodies, particularly those of extreme size that give rise to supereruptions $\left(>\sim 450 \mathrm{~km}^{3}\right.$ of magma: Self 2006; Miller and Wark 2008), accumulate at the shallow crustal levels from which they erupt. The presence of such bodies raises major questions about the nature of the holding chambers, how they can be contained for long enough to accumulate to such large sizes, and what might be the controls on when the eruptions initiate (e.g. Jellinek and DePaolo 2003; Annen 2009; Karlstrom et al. 2010). Central to debates here is the distinction between two aspects of silicic magmatic systems. The first is the longevity of the magmatic system that generated the silicic magmas by various 'chemical' processes, such as fractional crystallisation and assimilation, gauged by such parameters as the timing and composition of precursor events (e.g. Metz and Mahood 1985, 1991; Stix et al. 1988; Rowe et al. 2007) and age determinations from accessory mineral phases such as zircon or allanite (e.g. Brown and Fletcher 1999; Bindeman et al. 2001; Vazquez and Reid 2004; Charlier et al. 2005; Simon and Reid 2005; Bachmann et al. 2007; Wilson and Charlier 2009; Folkes et al. 2011). The second aspect is the timescale over which the erupted bodies themselves form, that is, the physical accumulation of a melt-dominant body. That the two timescales are disconnected is apparent from consideration of crystal-specific age determinations, where the discrimination between crystals grown in the melt-dominant body itself, versus those inherited from the longer-lived parental magmatic system, versus those incorporated from older, unrelated sources is often challenging (Hildreth 2004; Charlier et al. 2005; Simon and Reid 2005; Wilson and Charlier 2009).

An important contribution to the debate on the generation and accumulation of large volumes of silicic magma has been the 'crystal mush model' (Hildreth 2004; Bachmann and Bergantz 2004, 2008 for overviews). With this model came the linked recognition that large silicic magma systems can operate on two widely divergent timescales, corresponding to those outlined above. The substantive part of a magma's history, during which much of its 
chemical compositional characteristics are acquired, is envisaged to occur within large(batholith) scale bodies of crystal-rich ( $>45-60 \%$ crystals) magma of broadly intermediate bulk composition and highly silicic interstitial melt. Such bodies may occasionally erupt (the 'monotonous intermediates' of Hildreth 1981; e.g. Bachmann et al. 2002; Christiansen 2005) but most evolved crystal-poor rhyolites are inferred to have been extracted from the mush zone and accumulated at shallower levels prior to eruption.

The timing of the physical extraction and establishment of large bodies of crystal poor rhyolite is thus a central question. It is not always clear how these processes might be reflected in the crystal record, and what physical and temporal constraints might be applied. Where such constraints have been available (e.g. Wolff and Ramos 2003; Wilson and Charlier 2009) they have been made on the basis of compositional or radiometric age data combined with field constraints. Numerical models provide some important insights (e.g. Bachmann and Bergantz 2004; Huber et al. 2011) but the results of such approaches are necessarily governed by the process(es) assumed to drive the crystal-liquid separation. Traditionally these processes have been confined to the small-scale internal dynamics of crystal settling and compaction of the crystal pile (Bachmann and Bergantz 2008). Although more difficult to model, external forces, such as those related to extensional tectonics in rifted-arc settings, are very likely to exert a significant influence on the rate and dynamics of crystal-melt segregation in silicic mush-like bodies. Constraining the timescales of subsurface processes operating during the lead-in to an eruption can also be addressed by modelling elemental diffusion in crystals (e.g. Martin et al. 2008; Kahl et al. 2011; Matthews et al. 2012; Saunders et al. 2012). In order for this approach to yield meaningful estimates the boundaries targeted for diffusion modelling need to be clearly related to a particular process (or processes) and consideration of the sources and magnitude of uncertainties of diffusion modelled ages is essential (Chakraborty 2008; Costa and Morgan 2010).

At Taupo volcano, New Zealand, the temporal disconnect between the longevity of a large silicic magmatic system and the physical assembly of related crystal-poor rhyolite bodies was highlighted by Wilson and Charlier (2009) by noting the contrasting U/Th model-age spectra of zircons from the $25.4 \mathrm{ka}$ Oruanui supereruption and a smaller precursor eruption (Okaia, $28.6 \mathrm{ka}$; Lowe et al. 2013) erupted from a geographically coincident vent. By implication, the erupted $530 \mathrm{~km}^{3}$ Oruanui magma body was inferred by them to 
have assembled only after the Okaia event, constraining the physical assembly of the Oruanui magma body to a period of $<\sim 3000$ years.

Here we present data from the two major ferromagnesian phases (orthopyroxene and amphibole) in the Oruanui deposits. Although these phases occur in all Oruanui rhyolite samples at various abundances, the orthopyroxene shows textural features inferred to represent a period of significant disequilibrium, not experienced by the amphiboles, before returning to growth. Textural observations and chemical data are linked with thermobarometric information to identify a commonality of process that led to the generation of these features, accompanying establishment of the Oruanui melt-dominant magma body. Using the zonation features in orthopyroxene crystals, we assess their modification by Fe-Mg interdiffusion in order to determine the associated timescales.

\subsection{ORUANUI RHYOLITE}

During the $25.4 \pm 0.2 \mathrm{ka}$ Oruanui eruption, $\sim 530 \mathrm{~km}^{3}$ of magma was disgorged during a complex phreatomagmatic eruption that is inferred to have in total lasted several months (Wilson 2001; eruption age estimate from Vandergoes et al. 2013). Ten phases of activity are inferred on the basis of layering in the fall deposits, and recognition of key stratigraphic horizons allows a detailed internal stratigraphy of the eruption products to be established (Wilson 2001). Over 99\% of erupted clasts are rhyolitic, with whole rock (WR) $\mathrm{SiO}_{2}$ values ranging from 71.8 to $76.7 \mathrm{wt} \%$ and the majority falling between 74 and $76 \mathrm{wt} \%$. (Wilson et al. 2006). The remaining material $(<1 \%)$ is represented by more mafic compositions. Specifically, these consist of juvenile basaltic-andesite to andesite mafic clasts (WR $\mathrm{SiO}_{2}$ 52.3-63.3 wt\%) and exceedingly rare streaky grey pumices ( $\mathrm{WR} \mathrm{SiO}_{2}$ 61.0-74.7 $\mathrm{wt}^{\mathrm{0}} \%$ ). Juvenile mafic clasts are identified to come from two separate lineages, one calc-alkaline and the other tholeiitic, while the streaky pumices represent mechanical mixing of the felsic and calc-alkaline mafic magmas (Wilson et al. 2006).

Our focus in this paper is solely on the rhyolitic magma and we use the terms high-SiO rbyolite to refer to pumices with whole rock $\mathrm{SiO}_{2}$ content $>74 \mathrm{wt} \%$ and low-SiO${ }_{2}$ rbyolite for those $<74 \mathrm{wt} \%$. The high $-\mathrm{SiO}_{2}$ rhyolite has the assemblage plagioclase $>$ quartz $>$ orthopyroxene $>$ hornblende $>$ magnetite $>$ ilmenite with trace amounts of zircon and apatite. In comparison the low- $\mathrm{SiO}_{2}$ rhyolite clasts are quartz-free and hornblende dominates the ferromagnesian assemblage over orthopyroxene (see Table 4 of Wilson et al. 
2006). The involvement of at least two other volumetrically minor $(<0.5 \%)$ rhyolite subgroups has also been recognised; biotite-bearing pumices which represent magma from a nearby separate magmatic system that was syn-eruptively vented with Oruanui eruption phases 1 and 2 (Allan et al. 2012), and high-Mg rhyolite pumices reported in Wilson et al. (2006), which reflected mixing between the evolved rhyolite and more mafic compositions. Due to their late-stage origins and minor volumes neither of these subgroups are considered further here.

\subsection{SAMPLING AND ANALYTICAL TECHNIQUES}

High- $\mathrm{SiO}_{2}$ rhyolite pumices ( 7 to $45 \mathrm{~cm}$ across) were collected from a range of stratigraphic horizons representing the early (phases 1-3), mid (phase 7) and late (phase 10) erupted magma. The low- $\mathrm{SiO}_{2}$ rhyolite represents a much smaller volume of magma that so far has only been found in any significant abundance (at the 1-10\% level in lapilli clasts) in the deposits of phases 3 and 6 (Sutton 1995; Wilson et al. 2006). On the basis of volume estimates for the ten phases of the eruption (Table 1 of Wilson, 2001), the erupted volume of the low- $\mathrm{SiO}_{2}$ rhyolite is estimated to amount to no more than $\sim 0.5 \mathrm{~km}^{3}$ (magma), or $<$ $1 \%$ of the total erupted volume. To recover more low- $\mathrm{SiO}_{2}$ rhyolite, we sampled the phase 3 deposits at the Hinemaiaia Dam section in Lake Taupo Forest (loc. 1086 of Wilson, 2001). In hand sample the low- $\mathrm{SiO}_{2}$ rhyolite pumices are very similar in appearance (colour, crystallinity, density) to the high- $\mathrm{SiO}_{2}$ clasts but can be distinguished on the basis of having amphibole in greater abundance than orthopyroxene (Wilson et al., 2006). Four low- $\mathrm{SiO}_{2}$ rhyolite pumices, with whole rock $\mathrm{SiO}_{2}$ values ranging from $70.8 \mathrm{wt} \%$ to 72.6 $\mathrm{wt} \%$ were used for our crystal-specific investigations here.

Pumice clasts were cleaned to remove any adhering matrix, soaked overnight in distilled water and then oven dried at $110^{\circ} \mathrm{C}$ for 24 to 48 hours. Clasts were split in half with one fraction used for whole rock chemistry and the remainder used for crystal specific analysis. Whole rock major element compositions (Electronic Appendix Table S1) were determined by XRF by Spectrachem Analytical (CRL Energy LTD, Wellington, New Zealand) to confirm characterisation into high- and low-SiO 2 rhyolite clasts.

Sample splits allocated for crystal specific investigations were gently crushed using an agate mortar and pestle to liberate crystals. Amphibole and orthopyroxene were handpicked from the 0.5 to $1.0 \mathrm{~mm}$ fraction then mounted in epoxy resin, polished and analysed by 
electron probe microanalysis (EPMA) and laser ablation (LA) ICP-MS at Victoria University of Wellington. Major element compositions were determined using a JEOL JXA-8230 EPMA equipped with five wavelength dispersive (WDS) spectrometers. Analyses were conducted at $15 \mathrm{kV}$ and $12 \mathrm{nA}$ under a focused $(\sim 1 \mu \mathrm{m})$ electron beam and concentrations of the unknowns calculated using the ZAF correction method. Analyses of the Engels' amphibole and Johnstown hypersthene standards were interspersed among sample amphibole and orthopyroxene to monitor for spectrometer drift (Electronic Appendix Table S2). High resolution backscattered electron (BSE) images of each crystal were taken to investigate crystal zonation and mark the location of individual analyses so that the exact sites could be re-analysed for trace element content by LA-ICP-MS.

In-situ trace element compositions of amphibole and orthopyroxene were determined using a New Wave 193 nm (deep UV) laser ablation system coupled to an Agilent 7500CS ICPMS. The isotopes ${ }^{43} \mathrm{Ca}$ (for amphibole) and ${ }^{29} \mathrm{Si}$ (for orthopyroxene) were employed as internal standards during laser ablation analyses with the concentrations of $\mathrm{CaO}$ and $\mathrm{SiO}_{2}$ having previously been determined by EPMA. The value of adopting of Ca over $\mathrm{Si}$ as an internal standard for the amphibole analyses is discussed during presentation of our amphibole trace element data. The USGS basaltic glass standard BHVO-2G was used as the calibration standard. Tuning and optimization of signal sensitivity and stability was achieved by rastering across the BHVO-2G standard and adjusting the inflow of ultra-pure He gas. Data were acquired during $60 \mathrm{~s}$ acquisitions (+ $60 \mathrm{~s}$ backgrounds) under a static, circular laser beam of $35 \mu \mathrm{m}$ diameter pulsed at $5 \mathrm{~Hz}$. Data were reduced using the Iolite software package using the trace element (Internal Standard) data reduction scheme (Hellstrom et al. 2008). Care was taken to screen each analysis and remove any data compromised by the incidental ablation of inclusions beneath the polished surface. The USGS basaltic glass standard BCR-2G was run as a secondary standard to inform estimates of precision and accuracy of the LA-ICP-MS data. Data for this standard appears in the Table S3 of the Electronic Appendix.

\subsection{CRYSTAL TEXTURAL CHARACTERISTICS AND ANALYTICAL APPROACHES}

An integral part of this study is the recognition and interpretation of textural features seen in the orthopyroxene and amphibole crystals, coupled with in-situ chemical analyses to show compositional variations and BSE imaging to quantify compositional gradients. In 
BSE images the orthopyroxenes characteristically show darker (more Mg-rich) inner parts that are rich in melt and mineral inclusions which are then overgrown by lighter (more Ferich) inclusion-poor rim zones ranging between $40 \mu \mathrm{m}$ and $500 \mu \mathrm{m}$ thick (Figure 3.1). In contrast, the amphiboles show no such visible core-rim textural relationships, although occasional gradients in composition are visible under BSE imaging. This amphibole compositional zonation is more complexly related to the back-scattering intensity than in the orthopyroxenes. Sometimes the intensity reflects $\mathrm{Fe}-\mathrm{Mg}$ variations, but in other instances $\mathrm{Si}-\mathrm{Al}$ variations appear to exert more influence. In the most evolved pumices encountered (those with $>76.5 \mathrm{wt} \% \mathrm{SiO}_{2}$ ) many amphiboles appear to have undergone late-stage resorption (Figure 3.1). This resorption is not evident in any of the pumice clasts with $<76.5 \mathrm{wt}^{\%} \% \mathrm{SiO}_{2}$.

\section{Orthopyroxene}
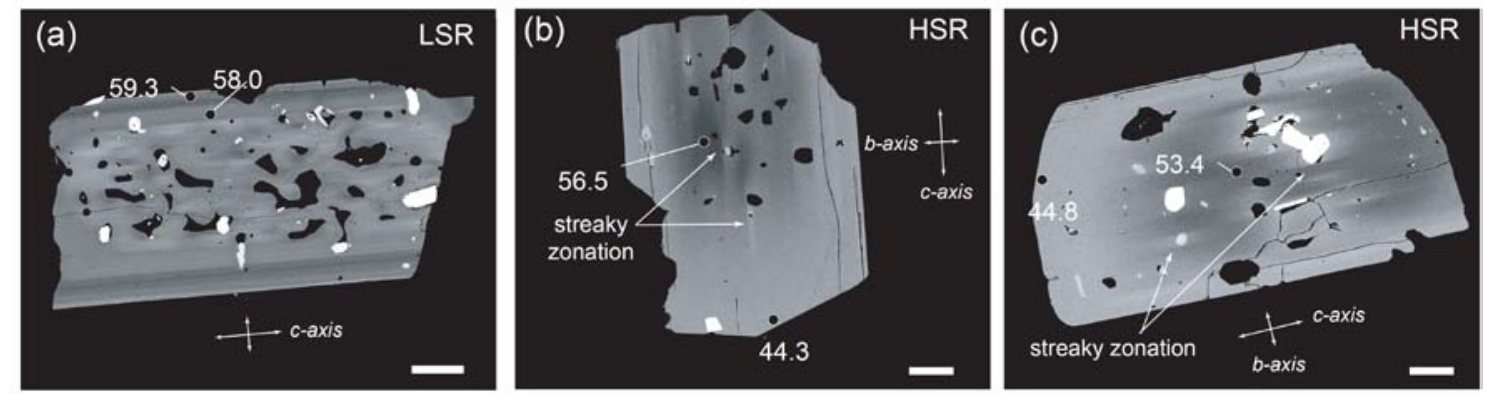

\section{Amphibole}
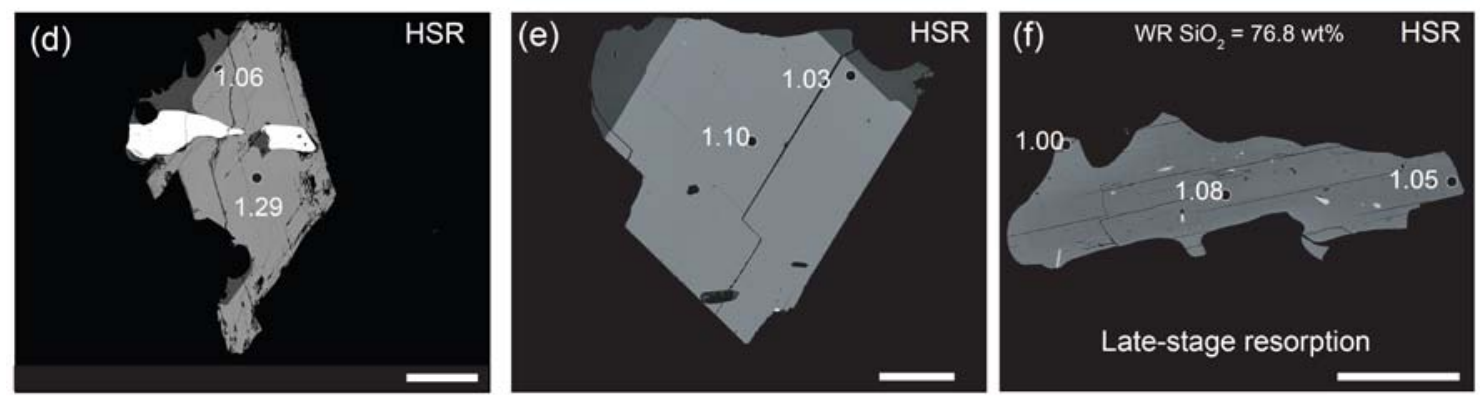

Figure 3.1. Back-scattered electron (BSE) images illustrating some of the key textural features of orthopyroxenes (a-c) and amphiboles (d-f) from Oruanui rhyolite pumices. Filled black circles highlight spot analyses by electron probe microanalysis (EPMA), labelled here to show the En and $\mathrm{Al}^{\mathrm{IV}}$ content of the orthopyroxenes and amphiboles, respectively. Panel a, from a low-SiO 2 rhyolite clast, shows partial dissolution and recrystallisation of orthopyroxene in the core, surrounded by a rim zone of fine (10-20 $\mu \mathrm{m})$ oscillatory zones towards the crystal rim, similar to the 'type- $A$ ' orthopyroxene of Tomiya and Takahashi (2005). Panels b and c are examples from high- $\mathrm{SiO}_{2}$ rhyolite clasts that show an inferred progression and 'ripening' of the type of texture shown in panel a following development of a 40-500 $\mu \mathrm{m}$ rim zone (grading out to $\mathrm{En}_{46 \pm 2}$ ) in the growing and cooling melt-dominant magma body. In these examples melt (black) and mineral (white = magnetite and ilmenite, grey = apatite) inclusions are common in the cores and interiors of the crystals and less abundant in the rim zones. Streaky, discontinuous zoning elongated parallel to the $c$-axis commonly extends outwards from these mineral and melt inclusions. Amphiboles affected by late-stage resorption, such as in panel $\mathrm{f}$, are restricted to the most evolved clasts with WR $\mathrm{SiO}_{2}>76.5 \mathrm{wt} \%$. The white scale bar in each image is $100 \mu \mathrm{m}$. 
A methodical approach was undertaken during analysis to ensure that at least the inferred oldest and youngest parts of each crystal were analysed. Compositional zonations of crystals evident from BSE images were used to constrain the crystal stratigraphy and infer the earliest crystallising (oldest) portion of the crystal (referred to here as 'cores'). The outermost crystal rims, where they are coincident with a glass selvedge and consistent with crystal zonation, are taken to represent the final crystal growth stage within the meltdominant magma body prior to eruption. Any other prominent zones inward from the outermost rims, but inferred to be younger than the crystal cores, were also analysed here to ensure complete coverage of the compositional range within single crystals and are here referred to as crystal 'interiors'.

\subsection{RESULTS}

\subsubsection{Major element compositions of orthopyroxene and amphibole}

Key features of the major element compositions of amphibole and orthopyroxene from high- and low- $\mathrm{SiO}_{2}$ rhyolite pumices are summarised in Figure 3.2 and the full dataset can be found in Tables S4 to S11 of the Electronic Appendix. In high-SiO ${ }_{2}$ rhyolite clasts the enstatite (En) content of orthopyroxene cores and interiors (Figure 3.2a) cover a considerable range, varying from $\mathrm{En}_{42.4}$ to $\mathrm{En}_{64.5}$. There is, however, a broad mode of compositions centred on $\mathrm{En}_{51.5 \pm 2}$. In contrast, compositions of the outermost orthopyroxene rims collapse down into a relatively restricted and, in general, more Fe-rich range in which $93 \%$ of analyses fall between $\mathrm{En}_{44}$ and $\mathrm{En}_{48}$. Those outermost orthopyroxene rims that fall outside this restricted window coincide in composition with the modal compositions of the cores and interiors. Major element analyses of amphibole from high-SiO $\mathrm{S}_{2}$ rhyolites (Figure 3.2b) show a broadly similar, if less pronounced, pattern to that observed in the orthopyroxene. The cores and interiors zones return a large range of $\mathrm{Al}^{\mathrm{IV}}$ values $(0.90$ to 1.73 ) whereas the outermost rims of amphibole from high-SiO rhyolite clasts occupy a more restricted compositional range with $\mathrm{Al}^{\mathrm{IV}}$ varying from 0.99 to 1.48. Both the cores plus interiors population and the outermost rims are bimodal, with values centred on a main peak at $\mathrm{Al}^{\mathrm{IV}} \sim 1.10$ and a secondary peak at $\mathrm{Al}^{\mathrm{IV}} \sim 1.35$. This secondary peak is more strongly represented in the cores plus interiors population.

In the low- $\mathrm{SiO}_{2}$ rhyolite clasts the major element compositions of orthopyroxene (Figure 3.2c) do not show the systematic differences between cores plus interiors and outermost 
Orthopyroxene
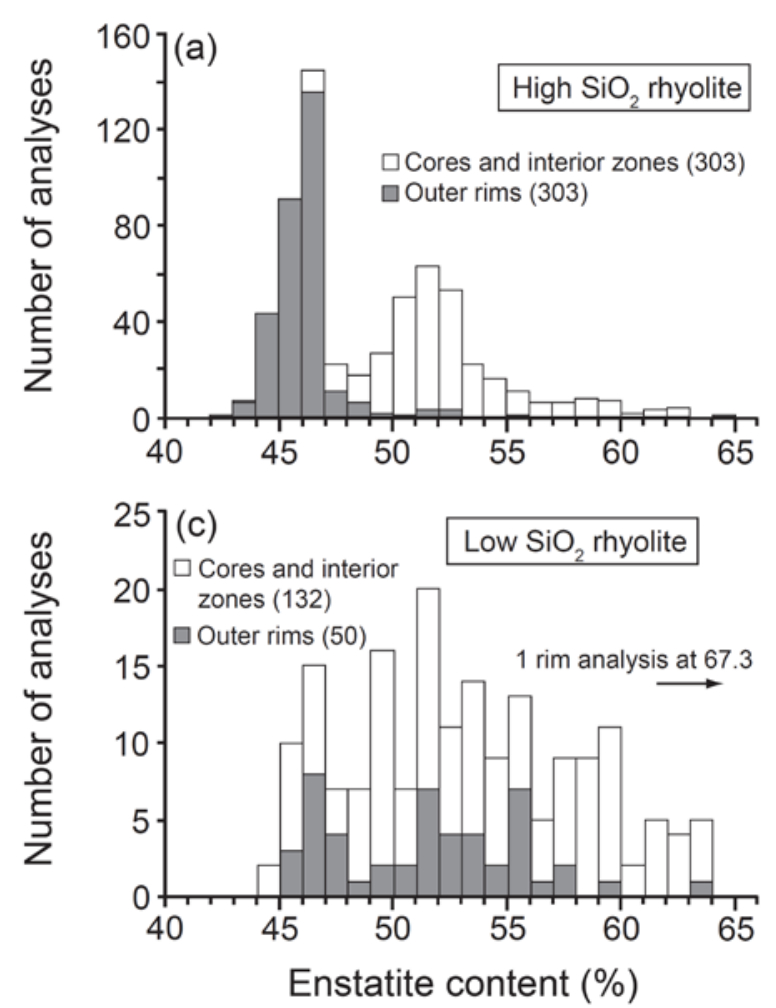

\section{Amphibole}
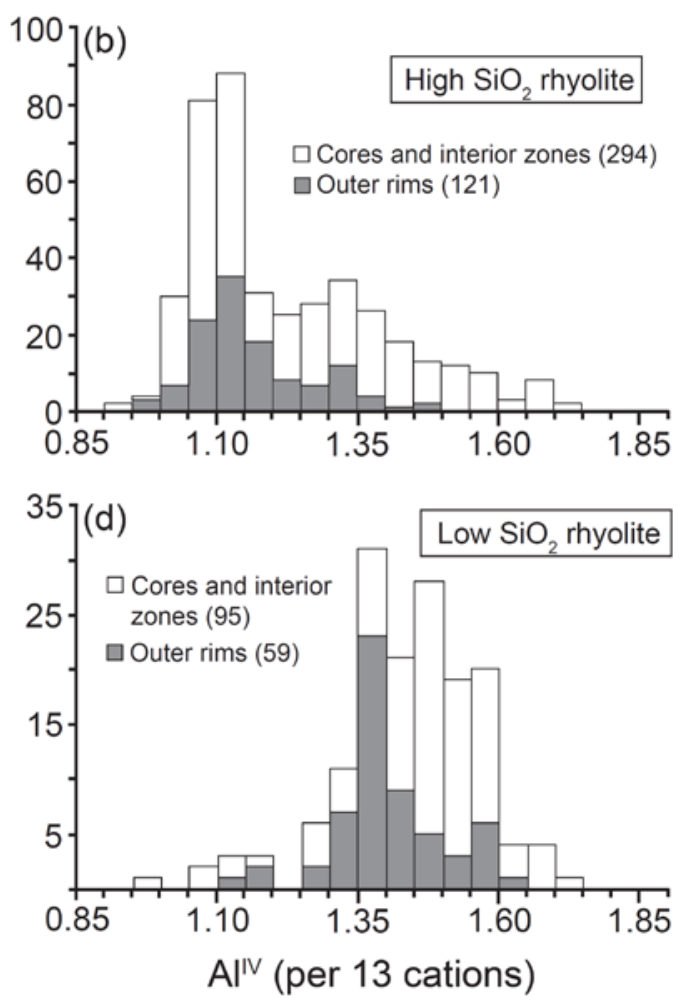

Figure 3.2. Stacked histograms showing compositional relationships between cores plus interior zones and the outermost rims for Oruanui orthopyroxene and amphibole crystals. Panels a and b show crystals from high- $\mathrm{SiO}_{2}$ rhyolite clasts (whole rock $\mathrm{WR} \mathrm{SiO}_{2}>74 \mathrm{wt} \%$ ) and panels c and d show crystals from low- $\mathrm{SiO}_{2}$ clasts $(<74 \mathrm{wt} \%)$. Numbers in brackets correspond to the number of individual EPMA spot analyses for the data plotted. For the high-SiO 2 rhyolite crystals (panels a and b) the cores and interiors of both minerals exhibit a wide range of compositions compared to the relatively tight clustering of the majority of outermost rims. Orthopyroxenes from low- $\mathrm{SiO}_{2}$ rhyolite clasts (c) display a wide range of compositions with no clear modes whereas the amphibole cores plus interiors and outer rims (d) have modal values of $\mathrm{Al}^{\mathrm{IV}}$ broadly similar to a subordinate peak from the high- $\mathrm{SiO}_{2}$ rhyolite amphiboles.

rims that is evident in grains from the high- $\mathrm{SiO}_{2}$ clasts. Although orthopyroxene from the low- $\mathrm{SiO}_{2}$ rhyolite exhibit a nearly identical range of enstatite values, they lack a clearly defined modal composition. Orthopyroxene compositional data from each of the four low$\mathrm{SiO}_{2}$ rhyolite clasts exhibits a near identical range of crystal compositions (Table S9, Electronic Appendix). Data from the outermost rims of orthopyroxene from low-SiO rhyolite samples identify three apparent minor peaks centred on $\mathrm{En}_{47}, \mathrm{En}_{52}$ and $\mathrm{En}_{55}$. Although it is questionable whether these represent statistically significant compositional populations (especially given the smaller sample size), we note the first two of these peaks correspond well with the modal compositions from the orthopyroxene in the high- $\mathrm{SiO}_{2}$ rhyolite clasts. 
Amphibole cores and interiors from the low- $\mathrm{SiO}_{2}$ rhyolite clasts (Figure 3.2d) have a broad mode of compositions between $\mathrm{Al}^{\mathrm{IV}} 1.25$ and 1.75. The outermost rims have a more defined mode centred on $\mathrm{Al}^{\mathrm{IV}} \sim 1.35$ which corresponds to the secondary peak seen in the high-SiO $\mathrm{S}_{2}$ rhyolite clasts for both the outermost rims and the cores plus interiors.

\subsubsection{Amphibole trace element chemistry and pressure estimates}

The comprehensive trace element dataset for amphibole and orthopyroxene can be found in the Electronic Appendix and key features of the in-situ trace element data for Oruanui amphiboles are summarised in Fig 3. Notably, there is a prominent inflection in $\mathrm{Zn}$ and Mn concentrations when plotted against $\mathrm{Eu} / \mathrm{Eu}^{*}$ in the amphiboles (Figures 3.3a and 3.3b). The amphibole $\mathrm{Eu} / \mathrm{Eu}^{*}$ ratio is used here as a qualitative measure of the degree of evolution of the melt from which the crystals grew, with the higher $\mathrm{Eu} / \mathrm{Eu}^{*}$ values indicating growth from less-evolved melt and vice versa. The concentrations of $\mathrm{Zn}$ and $\mathrm{Mn}$ in the amphiboles increase together from $\mathrm{Eu} / \mathrm{Eu}^{*}$ values of $\sim 0.8$ to 0.42 . At $\mathrm{Eu} / \mathrm{Eu}^{*}=$ 0.42 , there is a hinge point beyond which the abundance of these elements decreases as the melt continues towards more evolved compositions. These inflections are recorded in all Oruanui samples (earliest through to latest erupted) and seem to indicate that at some stage in the history as recorded by the amphiboles there was a significant and chamber-wide change in the chemistry of the melt.

The in-situ trace element signatures from laser ablation analyses can also be paired with estimates of apparent crystallisation pressure based on the major element composition from the earlier EPMA analyses from the same spots using the formulation of Ridolfi et al. (2010) (Figures 3.3c to 3.3e). When this is done there is an approximately linear positive relationship ( $\mathrm{R}^{2}$ of 0.83 ) between the apparent pressure and $\mathrm{Eu} / \mathrm{Eu}^{*}$ in the amphiboles. Taken at face value, this implies that the most evolved melt compositions were at the shallowest levels of the chamber ( $90 \mathrm{MPa})$. For this relationship to be 'real', and not the result of an analytical or modal artefact, two aspects are important to consider further.

First, we discuss and present our barometric estimates and their associated uncertainties from the Ridolfi et al. (2010) model as they are generated by that model. The absolute model values may be subject to greater variability, particularly if the host melt undergoes significant shifts in chemistry. For example, elevated $\mathrm{Al}$ concentrations within thin zones of single amphiboles may reflect localised increases in $\mathrm{Al}$ availability owing to feldspar 

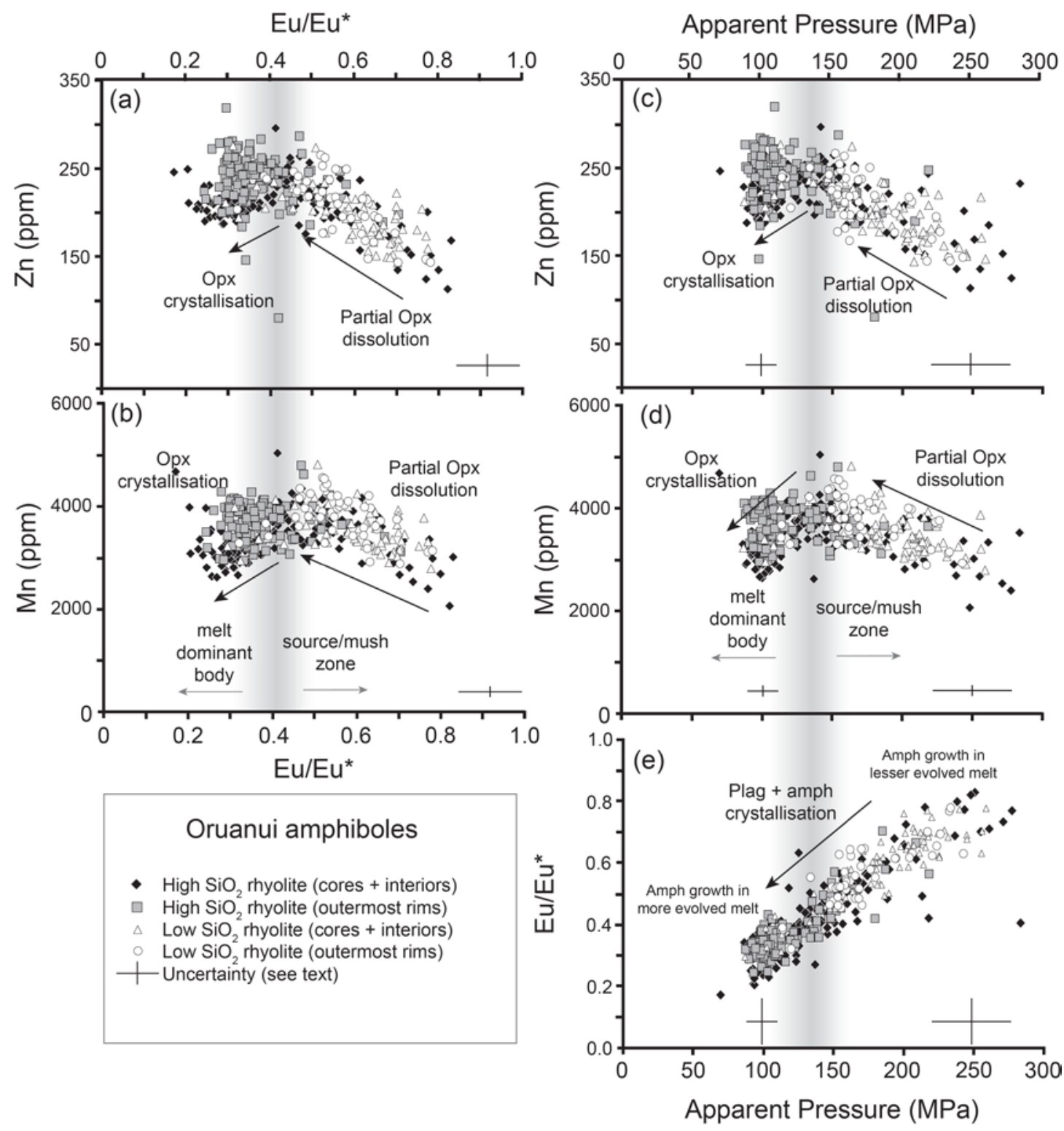

Figure 3.3.In-situ trace element compositions of amphiboles from Oruanui rhyolite clasts. The amphibole $\mathrm{Eu} / \mathrm{Eu}^{*}$ is an index of the evolution of the host melt (high values = less evolved; low values $=$ more evolved) at the time of crystallisation. Apparent pressures were calculated using the Al-based barometer of Ridolfi et al. (2010) and correspond to the exact locations of the trace element analyses. Trace element uncertainties are \pm 2 relative standard deviations, based on repeat analyses of the BCR$2 \mathrm{G}$ glass standard and accounting for elemental abundance in the amphiboles (see Appendix A1 for standard data). Uncertainties on pressure estimates are \pm the 'max uncertainty' as indicated by the Ridolfi et al. (2010) formulations at the given pressure.

resorption rather than a short-lived increase in pressure as would be indicated by the Ridolfi et al. (2010) barometer. We would emphasise, however, that regardless of the absolute values returned by the Ridolfi et al. (2010) model pressure estimates, the large range of $\mathrm{Al}$ contents (5.23 to $10.98 \mathrm{wt} \% \mathrm{Al}_{2} \mathrm{O}_{3}$ ) in Oruanui amphiboles is consistent with their crystallisation over a considerable range of pressures (e.g. Johnson and Rutherford 
1989; Schmidt 1992; Ernst and Liu 1998) and consistent with a generalised decompression trend associated with progressive melt evolution and formation of the melt-dominant magma body.

Second, it is important to consider whether this positive relationship could be the result of an artefact of combining two spatially related datasets collected using contrasting analytical methods. It is possible that artificial linear correlations between estimates of apparent pressure (and other intensive parameters) from the Ridolfi et al. (2010) model and trace element concentrations could be generated if the element adopted as an internal standard for LA-ICP-MS analyses of the amphiboles exerts a significant influence on the Ridolfi et al. (2010) thermobarometric formulations, potentially introducing uncertainties which are elongated parallel to the trends in the data. For example, the $\mathrm{SiO}_{2}$ content of the Oruanui amphiboles is strongly linearly and negatively correlated with the pressure and temperature estimates $\left(R^{2}\right.$ of 0.86 and 0.84 , respectively) and there is a moderate, but significant, linear relationship with $\mathrm{SiO}_{2}$ content and estimates of oxygen fugacity and melt $\mathrm{H}_{2} \mathrm{O}\left(\mathrm{R}^{2}\right.$ of 0.59 and 0.56, respectively) as estimated using the equations of Ridolfi et al. (2010). The use of minor isotopes of silicon (e.g. ${ }^{29} \mathrm{Si}$ or ${ }^{30} \mathrm{Si}$ ) as an internal standard could therefore result in artificial correlations between the model outputs and trace element concentrations because the Si content of the amphiboles imparts a significant leverage on the model temperature and pressure calculations. In contrast, the $\mathrm{CaO}$ content of the Oruanui amphiboles, which typically varies by $<0.5 \mathrm{wt} \%$ (or $\sim 5 \%$ relative), shows negligible correlations with pressure, temperature, fugacity or melt $\mathrm{H}_{2} \mathrm{O}$ estimates ( $\mathrm{R}^{2}$ of $0.05,0.08,0.10,0.03$, respectively). For this reason, ${ }^{43} \mathrm{Ca}$ was employed as the internal standard isotope when determining the trace element concentration of the amphiboles and this choice allows some confidence that correlations between amphibole trace elements and in-situ estimates of apparent pressure and/or temperature are real.

The abundances of $\mathrm{Zn}$ and $\mathrm{Mn}$ in the amphiboles show a prominent inflection when plotted against apparent pressure, with element concentrations increasing with decreasing pressure from $\sim 275 \mathrm{MPa}$ to peak abundances at pressures of $\sim 140 \mathrm{MPa}$, in similar fashion to trends with respect to $\mathrm{Eu} / \mathrm{Eu}^{*}$ values (Figure 3.3). At apparent pressures $<\sim 140 \mathrm{MPa}$ there is a general decrease in the $\mathrm{Zn}$ and $\mathrm{Mn}$ concentrations. These inflections in amphibole trace element signatures indicate that a prominent chemical change occurred in the Oruanui magma and the apparent pressure estimates suggest this change occurred at 
about $140 \mathrm{MPa}$ or a crustal depth of 5.5 to $6 \mathrm{~km}$. We interpret this change in the context of our textural and chemical observations of orthopyroxene in subsequent sections.

\subsection{ORTHOPYROXENE AND AMPHIBOLE CHARACTERISTICS}

\subsubsection{Compositional groupings of Oruanui orthopyroxene and amphibole}

It is evident from our major and trace element data (Figures 3.2 and 3.3), that the core and interior compositions of amphibole and orthopyroxene in high-SiO $\mathrm{S}_{2}$ rhyolite clasts overlap considerably with the compositions from crystals in the low- $\mathrm{SiO}_{2}$ rhyolite samples. In contrast, the degree of compositional overlap between crystals in the low-SiO 2 rhyolite and the outermost rims of the high- $\mathrm{SiO}_{2}$ rhyolite crystals is much less. Major element analyses (EPMA) of matrix glass fragments from individual low- $\mathrm{SiO}_{2}$ rhyolite pumices (ASR Allan, unpublished data) identified a bimodal matrix glass population. The dominant population has a mean $\mathrm{SiO}_{2}$ content of $74.3 \mathrm{wt} \%$ and is an appropriate melt composition for the low$\mathrm{SiO}_{2}$ rhyolite whole rock compositions with moderate crystal contents $(\sim 3-7 \mathrm{wt} \%)$. The other population, however, is more evolved and corresponds to the matrix glass composition of the volumetrically dominant high- $\mathrm{SiO}_{2}$ rhyolite pumices (mean $\mathrm{SiO}_{2}$ of $77.8 \mathrm{wt} \%$ : Allan et al. 2012) which is also equivalent to that measured in tephrostratigraphic studies of the widespread Oruanui fall deposit (e.g. Lowe et al. 2008). That the two glass populations persisted without any mixing trend between them is taken to indicate that the low- $\mathrm{SiO}_{2}$ rhyolite mixed with the volumetrically dominant high- $\mathrm{SiO}_{2}$ rhyolite only syneruptively en-route to the surface. In this light the small degree of compositional overlap between crystals from low- $\mathrm{SiO}_{2}$ rhyolite and the outer rims of crystals in the high- $\mathrm{SiO}_{2}$ rhyolite are considered to reflect the exchange of a small component of high-SiO 2 rhyolite crystals (i.e. amphiboles with $\mathrm{Al}^{\mathrm{IV}}<1.2$ and orthopyroxene with $\mathrm{En}<48$ ) into the low- $\mathrm{SiO}_{2}$ clasts that accompanied the latest-stage exchange of melt.

On the basis of the evidence outlined above we infer that the majority of crystal cores and interiors in the high- $\mathrm{SiO}_{2}$ rhyolite are consistent with having originated from magma(s) with broadly similar compositions to that represented by the low- $\mathrm{SiO}_{2}$ rhyolite clasts. Two implications are important to note from these inferences. Firstly, the low- $\mathrm{SiO}_{2}$ rhyolite pumices can be considered to approximate the composition of magma that was extracted from the Oruanui crystal mush/source zone as feedstock for the melt dominant magma 
body. The matrix glass relationships discussed above suggest that the low- $\mathrm{SiO}_{2}$ rhyolite pumices erupted during phases 3 and 6 (Wilson 2001) and sampled by us here represent isolated pockets of crystal-poor magma that persisted in the mush/source zone up until the point of eruption. Secondly, there was significant evolution in the melt-dominant magma body prior to eruption reflecting cooling and crystallisation that drove the magma to the observed high- $\mathrm{SiO}_{2}$ rhyolite compositions. This latter point is consistent with the findings of Wilson et al. (2006) who noted that the Oruanui high- $\mathrm{SiO}_{2}$ rhyolite compositions can be generated from the low- $\mathrm{SiO}_{2}$ rhyolite after $\sim 28 \%$ crystallisation of the observed phenocryst phases.

\subsubsection{Origin of textural features in Oruanui orthopyroxene}

The marked contrast between orthopyroxene core plus interior compositions when compared to the outermost rims in the high- $\mathrm{SiO}_{2}$ rhyolite samples (Figure 3.2a) indicates that at some stage prior to eruption there was a significant shift in the growth composition of Oruanui orthopyroxene. Inspection of BSE images of individual orthopyroxene crystals also suggests that most orthopyroxenes in the high- $\mathrm{SiO}_{2}$ rhyolite clasts underwent a departure from, followed by a return to, equilibrium conditions (Figure 3.1). Some orthopyroxene crystals from low- $\mathrm{SiO}_{2}$ rhyolite clasts record what we infer to be an earlier snapshot of this disequilibrium process (Figure 3.1a) where the crystal cores have evidently undergone partial dissolution ( \pm resorption) and appear riddled with melt inclusions, with minimal annealing of the cores having occurred before quenching on eruption.

Although the zonation of orthopyroxene from high- $\mathrm{SiO}_{2}$ rhyolite clasts is complex when approached at the level of individual crystals, there are some key overarching features that imply that the majority ( $\sim 90 \%$ ) of Oruanui orthopyroxenes in the high- $\mathrm{SiO}_{2}$ rhyolite share a common history. The shared part of this history is most clearly evidenced by the prevalence of prominent $40-500 \mu \mathrm{m}$ thick rim zones. These rim zones record a compositional gradient from more $\mathrm{Mg}$-rich compositions $\left(\mathrm{En}_{48-58}\right)$ to a narrow range of more Fe-rich compositions $\left(\mathrm{En}_{46 \pm 2}\right)$ in the outermost rims. We infer that these rim zones are the orthopyroxene equivalent to the clear euhedral overgrowth rims previously described for Oruanui plagioclase (Charlier et al. 2008) which recorded an oscillating but consistent decrease in An content outward to a narrow range of values averaging $\sim \mathrm{An}_{36-38}$. In line with the interpretation of euhedral plagioclase rim zones (Charlier et al. 2008), we 
infer that the orthopyroxene rim zones reflect portions of the orthopyroxenes that crystallised in the growing and evolving melt-dominant magma body.

Inboard of the orthopyroxene rim zones the textural features are often complex (Figure $3.1 \mathrm{~b}, \mathrm{c})$. The cores and interior zones contain common inclusions of magnetite, ilmenite, apatite and melt. Streaky, discontinuous zonation, always of more Fe-rich compositions than the surrounding orthopyroxene, commonly extends outwards from these mineral and melt inclusions for several tens of microns along the crystallographic $c$-axis and over much short distances parallel to the $a$-and $b$-axes. Sometimes these streaky discontinuous zones are not visibly associated with inclusions and in these cases the presence of an inclusion immediately above or beneath the plane of the polished surface is generally inferred. These features are interpreted to represent portions of the orthopyroxene interiors that underwent earlier dissolution only to recrystallise at a later stage when orthopyroxene restabilised in the growing melt-dominant magma body. In this light the overall textures in the majority of orthopyroxenes from high- $\mathrm{SiO}_{2}$ rhyolite clasts can be viewed as a progression and 'ripening' of an original texture similar to that shown in Figure 3.1a following time to develop a rim zone and to allow previous dissolved portions to recrystallise. As is evident from the examples in Figure 3.1b and 1c, the original zonation of the orthopyroxene cores has been complexly overprinted by partial dissolution, recrystallisation, and the entrapment of numerous mineral and melt inclusions, all of which appear to have been variably affected by elemental diffusion at magmatic temperatures.

Tomiya and Takahashi (2005) encountered similar textures in orthopyroxenes from historic eruptions from Usu volcano, Japan, classing them as 'type-A' orthopyroxene. In their study the composition modification around the recrystallised portions was inferred to result from $\mathrm{Fe}-\mathrm{Mg}$ interdiffusion, and they noted that diffusion parallel to the $c$-axis appeared to be more rapid than parallel to the $a$ - and $b$-axes. The diffusion of $\mathrm{Fe}$ and $\mathrm{Mg}$ in the Oruanui orthopyroxene is further explored in subsequent sections.

\subsubsection{Origin of the inflections in amphibole trace element chemistry}

Calcic amphiboles are capable of hosting a wide range of petrogenetically significant trace elements in high concentrations, with their partitioning primarily reflecting the structure (degree of polymerisation) and composition of the melt (Tiepolo et al. 2007). As such, trace element signatures can become locked in to the amphiboles as they crystallise from a 
melt. Amphibole therefore has the potential to record transient fluctuations in the magma chemistry that may not be retained in the glass (melt) phase of the quenched eruption products due to vigorous chamber-wide convection prior to eruption, or that are imperceptible in common but less trace element-enriched mineral phases (e.g. plagioclase, pyroxenes and quartz).

The origin of the $\mathrm{Mn}$ and $\mathrm{Zn}$ inflection is unlikely to reflect the influx of a different magma. Influx of a hotter, more mafic magma is ruled out for a number of reasons. Firstly, we would expect prominent shifts in the concentration of many more trace elements (particularly $\mathrm{Mg}$ ), but these are not seen. Secondly, the hinge point of the $\mathrm{Mn}$ and $\mathrm{Zn}$ content is the same no matter whether the amphiboles are sampled from earliest, middle or latest erupted pumices or those erupted from geographically disparate vents within the Oruanui caldera (i.e. phase 3 versus phase 7 - Wilson 2001). This means that whatever process generated the inflections it was a chamber-wide phenomenon. Scaling arguments therefore preclude the injection of a different magma into the chamber as the origin of the inflection, particularly with the absence of other trace element indicators. Finally, the inflection is centred upon a specific pressure $(\sim 140 \mathrm{MPa})$ and temperature $\left(820^{\circ} \mathrm{C}\right)$ along a continued decompression and cooling trend recorded by the amphiboles (Figures 3.3and 3.5a). This observation suggests that the inflections in amphibole $\mathrm{Mn}$ and $\mathrm{Zn}$ concentrations more likely reflect a transient but widespread change in the melt chemistry induced by a change in mineral phase stability that occurred along this decompression path. In light of our textural observations of orthopyroxene in the high-SiO${ }_{2}$ rhyolite, we interpret the inflections in $\mathrm{Mn}$ and $\mathrm{Zn}$ concentration in amphibole to reflect changes in the co-crystallisation behaviour of amphibole and orthopyroxene during decompression.

Oruanui orthopyroxene is typically trace element poor, especially in comparison to the amphiboles (Table S12, Electronic Appendix). The only trace elements that occur in significantly greater abundance in the orthopyroxene are Zn (typically 300-650 ppm) and Mn (typically 8000-15,000 ppm) (see Table S12 of the Electronic Appendix and Figure 3.4). The widespread partial decomposition and resorption of orthopyroxene cores and interiors followed by its subsequent re-stabilisation and development of the rim zones and infilling of raddled cores as indicated by our textural observations provide a mechanism to explain the inflections of $\mathrm{Zn}$ and $\mathrm{Mn}$ in the accompanying amphibole. We interpret the increasing $\mathrm{Zn}$ and $\mathrm{Mn}$ in amphibole with decreasing $\mathrm{Eu} / \mathrm{Eu}^{*}$ (from 0.8 to 0.4: Figure 3.3a, b) to reflect amphibole (and plagioclase) growth that accompanied active dissolution and 


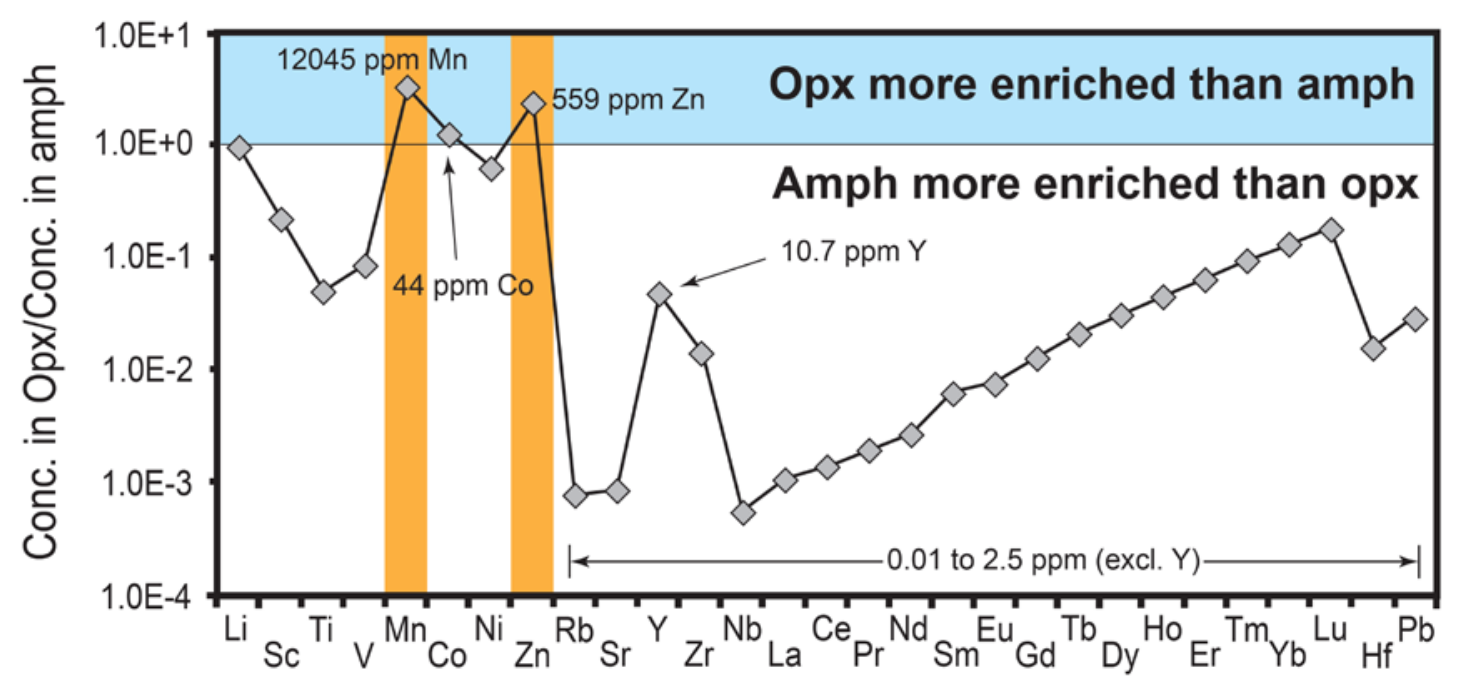

Figure 3.4.Plot showing the mean concentration of trace elements in orthopyroxene rims $(\mathrm{n}=106)$ normalised against the mean abundance in amphibole rims $(\mathrm{n}=96)$ in high-SiO 2 rhyolite clasts (also see Table S12 in the Electronic Appendix). The annotated concentrations refer to the mean concentrations in the orthopyroxenes. Only $\mathrm{Mn}$ and $\mathrm{Zn}$ occur in sufficient abundance in the orthopyroxenes to notably affect the chemistry of crystallising amphibole throughout the changing dissolution/re-growth behaviour of orthopyroxene.

resorption of orthopyroxene cores of the kind indicated by the textural analysis (e.g. Figure 3.1a). $\mathrm{Zn}$ and $\mathrm{Mn}$ liberated into the surrounding melt by the decomposing orthopyroxene was captured by amphibole. The reversal of $\mathrm{Zn}$ and $\mathrm{Mn}$ concentration trends in amphibole at $\mathrm{Eu} / \mathrm{Eu}^{*} \sim 0.4$ we interpret as marking the restabilisation and renewed growth of orthopyroxene. Subsequent overgrowths of more Fe-rich orthopyroxene rim zones extending out to $\mathrm{En}_{46 \pm 2}$ and the infilling of porous, partially-dissolved cores (Figure 3.1b-d) is recorded in the amphibole chemistry as a decreasing abundance of $\mathrm{Zn}$ and $\mathrm{Mn}$ with progressive melt evolution (Figure 3.3a, b) as these elements began again to be preferentially sequestered into orthopyroxene. Although Oruanui ilmenite does have similar concentration levels of $\mathrm{Zn}$ and $\mathrm{Mn}$ to the orthopyroxene (ASR Allan, unpublished data), we can exclude the possibility that any significant contribution to the inflections of those elements originated from ilmenite dissolution because: 1) ilmenite is about two orders of magnitude less abundant than orthopyroxene in any given sample, and 2) no such inflection is seen in the Ti (or V) content of the amphiboles which would be expected if large amounts of Ti had been liberated into the melt from ilmenite dissolution (Oruanui ilmenite has 46 to $50 \mathrm{wt} \% \mathrm{TiO}_{2}$ and $\sim 350 \mathrm{ppm} \mathrm{V}$ ). 
On the basis that the amphibole compositional variations can be linked to apparent pressure estimates (Ridolfi et al. 2010), we infer that partial dissolution of orthopyroxene occurred as Oruanui magma decompressed from $\sim 275 \mathrm{MPa}$ to $\sim 140 \mathrm{MPa}$. The return of orthopyroxene as a stable/equilibrium phase (onset of decreasing $\mathrm{Zn}$ and $\mathrm{Mn}$ in amphibole) occurred only once the ascending magma reached relatively shallow crustal levels ( $140 \mathrm{MPa}$ or $\sim 6 \mathrm{~km}$ depth and shallower).

The textural and chemical evidence that Oruanui orthopyroxene experienced a departure from, and subsequent return to, its stability field is consistent with a history of decompression and associated cooling at moderate-high water contents (Figure 3.5). Experimental phase stability studies for some A-type granites have shown that orthopyroxene will destabilise (to the benefit of amphibole) at moderate pressures ( 200 $\mathrm{MPa}$ ) in association with melt water contents higher than $\sim 5 \mathrm{wt} \%$ (Dall'Agnol et al. 1999; Klimm et al. 2003). The hornblende stability field defined in these studies is also notably horseshoe-shaped/curved in $\mathrm{T}-\mathrm{H}_{2} \mathrm{O}$ space meaning that it is possible to decompress and cool the magma, consistent with the P-T estimates in Figure 3.5a, through the amphibole field (where amph $>>$ opx) and eventually return to an amphibole and orthopyroxene cotectic with only modest changes in the water content (Figure 3.5b-d). These experimental studies also suggest that continued cooling and/or a modest reduction in melt $\mathrm{H}_{2} \mathrm{O}$ content would eventually result in a departure from the amphibole stability field in favour of orthopyroxene (i.e. opx $>>$ amph). This is consistent with our observation that in some of the most evolved pumice samples $\left(\mathrm{SiO}_{2}>76.5 \mathrm{wt} \%\right)$ many amphibole crystals show evidence for significant late-stage resorption and in some cases partial recrystallisation (Figure 3.1f). Analyses of amphibole immediately inboard of these resorbed margins also yield the lowest melt $\mathrm{H}_{2} \mathrm{O}$ estimates (ranging 4.7 to $5.0 \mathrm{wt} \%$ ) from our dataset using the amphibole based hygrometer of Ridolfi et al. (2010). This textural evidence that at least some amphibole underwent some dissolution in the most evolved parcels of magma, is consistent with observations that the high- $\mathrm{SiO}_{2}$ rhyolite pumices were opx-rich and amph-poor (by up to 4:1) and the opposite was true of the low- $\mathrm{SiO}_{2}$ rhyolite clasts (Wilson et al. 2006).

On the basis of our textural and chemical data combined with P-T- $\mathrm{H}_{2} \mathrm{O}$ constraints we infer that the Oruanui melt-dominant magma body accumulated following extraction of vast volumes of melt (plus crystals) from a crystal mush-like source body. The segregation and ascent of magma from the source region we infer is represented by partial breakdown 

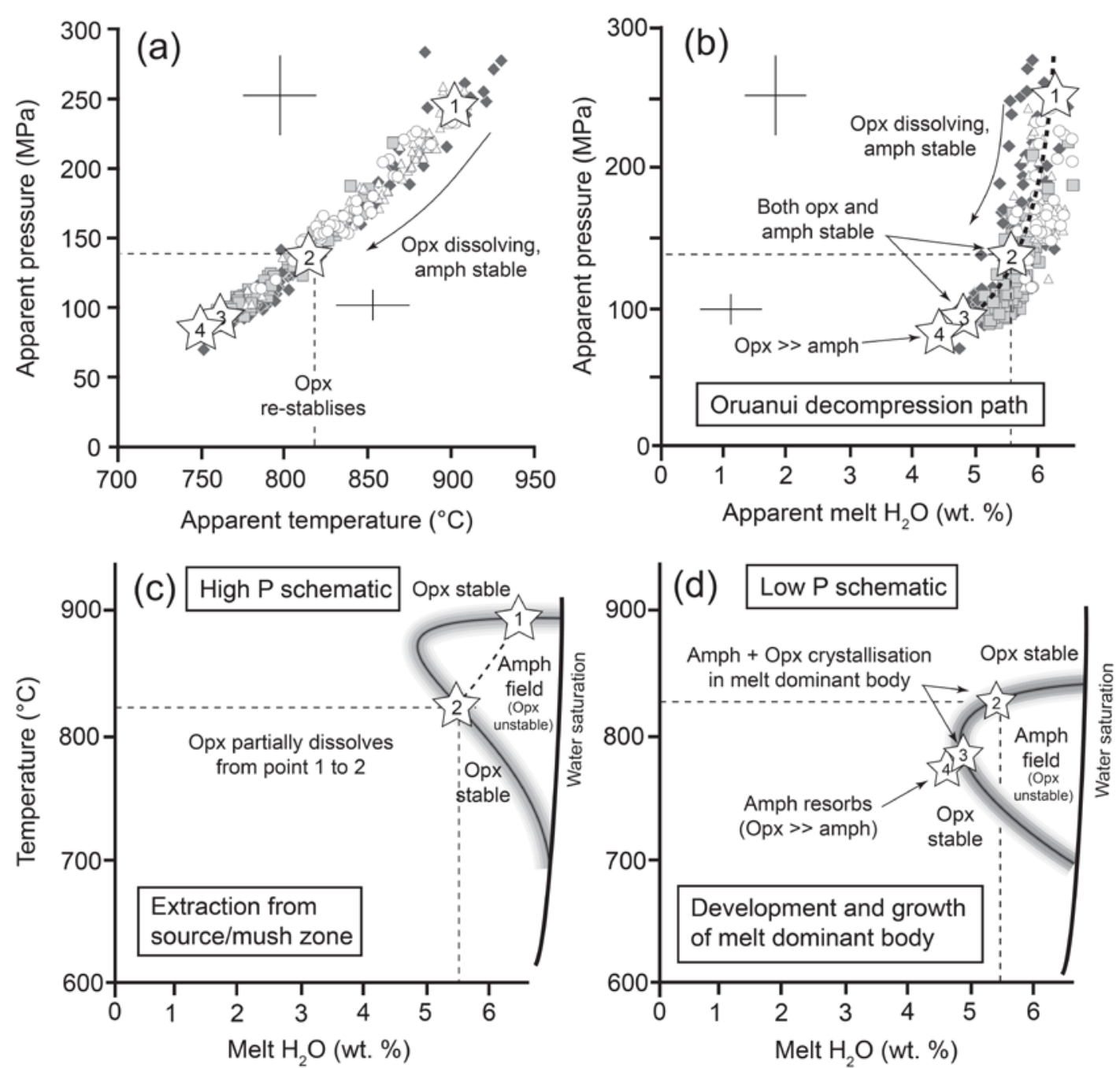

Figure 3.5. Model P-T- $\mathrm{H}_{2} \mathrm{O}$ conditions inferred from Oruanui amphiboles and schematic representation of the phase stability relationships in $\mathrm{P}-\mathrm{T}-\mathrm{H}_{2} \mathrm{O}$ space between orthopyroxene (opx) and amphibole (amph). (a) Model pressures and temperatures from spot analyses of Oruanui amphiboles from the high- and low- $\mathrm{SiO}_{2}$ rhyolites based on the Ridolfi et al. (2010) thermobarometer and representative uncertainty ellipses at the given pressures. Symbols as in Fig 3. (b) Representation of the decompression path in $\mathrm{P}-\mathrm{H}_{2} \mathrm{O}$ space recorded by Oruanui amphibole. Model melt $\mathrm{H}_{2} \mathrm{O}$ content, and the associated uncertainties, estimated using the Ridolfi et al. (2010) equation. (c) Schematic representation of the amphibole-orthopyroxene phase stability boundary at high pressure representing extraction of melt and crystals from a deep source/mush zone. (d) Schematic representation of the phase stability at a lower pressure akin to that in the melt-dominant body. The star symbols labelled 1-4 represent key points in the amphibole-orthopyroxene stability relationship as informed by $\mathrm{P}-\mathrm{T}-\mathrm{H}_{2} \mathrm{O}$ estimates, amphibole chemistry and mineral textures. During the major decompression from $\sim 300$ to $140 \mathrm{MPa}$ (points 1-2) amphibole is much more abundant than orthopyroxene, and orthopyroxene is actively dissolving with liberated orthopyroxene-loving elements (especially $\mathrm{Mn}$ and $\mathrm{Zn}$ ) being sequestered in amphibole. Points 2-3 represent development and growth of the Oruanui melt dominant body at shallow levels $(\sim 3.5-6 \mathrm{~km}$ depth), and the re-stabilisation and renewed crystallisation of opx (accompanying amphibole). In the more evolved parcels of magma orthopyroxene is more abundant than amphibole and in some cases (represented by point 4) P-T- $\mathrm{H}_{2} \mathrm{O}$ conditions leave the cotectic and lead to amphibole resorption. The shape of the amphibole field in panels (c) and (d) is based on the experimental data of Dall'Agnol et al. (1999) and Klimm et al. (2003). Note that the position of the cotectic and the amphibole stability field as shown is schematic only and is projected from a fixed pressure. Decreasing the pressure in either scenario would result in shifting the amphibole stability field to lower values of temperature and melt $\mathrm{H}_{2} \mathrm{O}$. 
and dissolution of the opx cores and interiors, with the restabilisation and recrystallisation of the orthopyroxene (and plagioclase; Charlier et al. 2008) rim zones representing mixing into the growing melt-dominant magma body at shallow levels. The normal zonation of
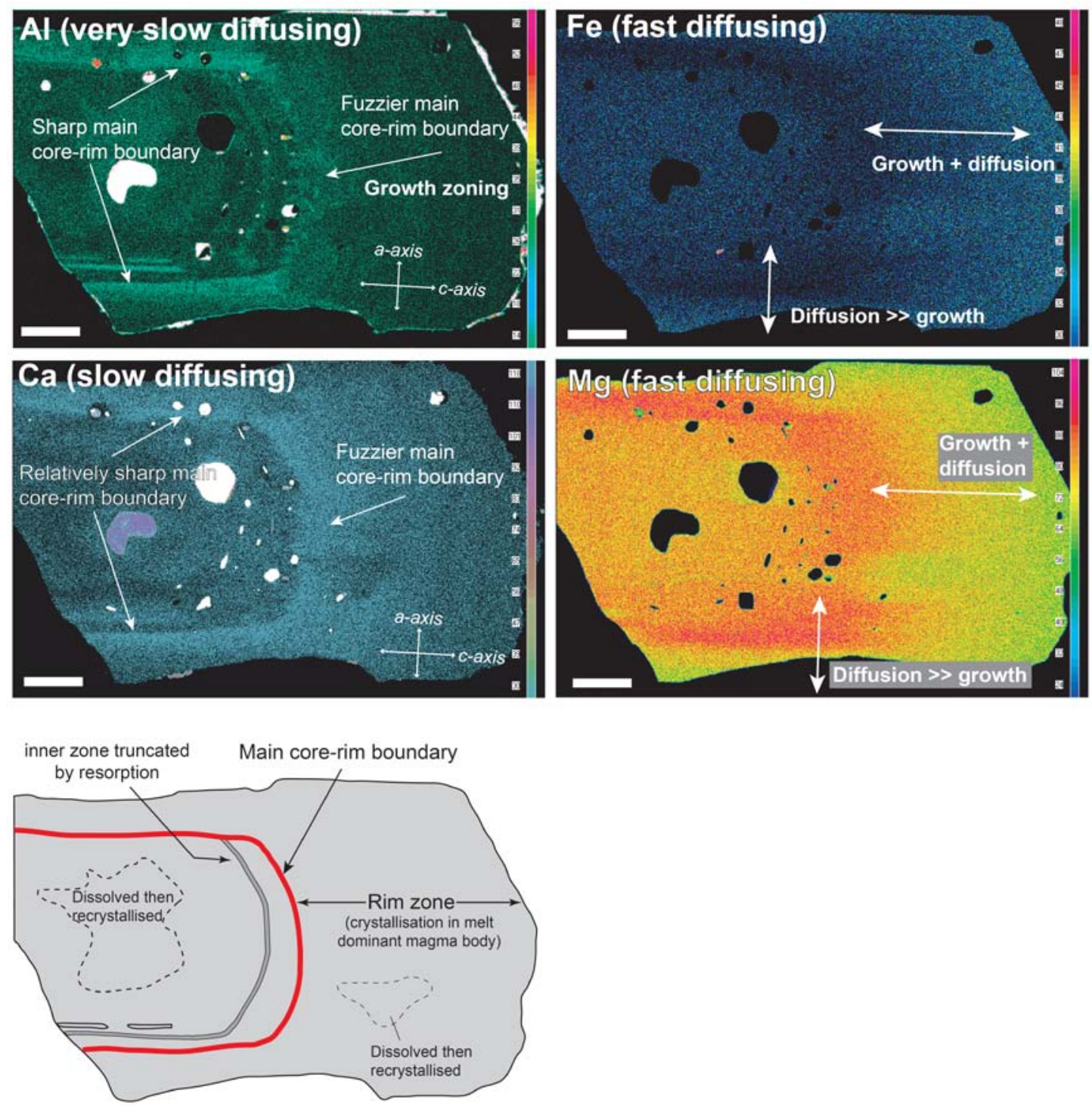

Figure 3.6. Element maps of a representative orthopyroxene crystal from a high-SiO $\mathrm{S}_{2}$ rhyolite clast. Slow$(\mathrm{Ca})$ and very slow- (Al) diffusing elements preserve a sharp main core-rim boundary parallel to the $a$-axis. However, the same boundary parallel to the $c$-axis is fuzzier. In the case of $\mathrm{Al}$ (and probably $\mathrm{Ca}$ ), this fuzziness could not be generated by diffusion in the time available and indicates that much of the zonation parallel to the c-axis is kinematically controlled by rapid crystal growth. Lower left: schematic representation of the underlying crystal zonation with the effects of diffusion stripped away. The main core-rim boundary of orthopyroxene in the high- $\mathrm{SiO}_{2}$ rhyolite is targeted for Fe- $\mathrm{Mg}$ diffusion modelling parallel to the $a$ - and/or $b$ axis. The white scale bars are $100 \mu \mathrm{m}$. 
the rim zones (Figure 3.1b,c, Figures S1 and S2 in the Electronic Appendix; Charlier et al. 2008) reflects crystallisation and fractionation in the growing, cooling and evolving melt dominant high-SiO 2 rhyolite magma body that was eventually erupted. If time constraints can be derived from formation of the main core-rim boundaries in the high- $\mathrm{SiO}_{2}$ rhyolite orthopyroxene crystals, then these can be used to estimate the timescales of assembly of the Oruanui melt-dominant magma body.

\subsection{TIMESCALES OF ORTHOPYROXENE HISTORIES}

The timescales that can be inferred from elemental diffusion in orthopyroxene are of particular relevance here because of the links that can be made with the textural histories of the crystals. Within the overarching features emphasised earlier, the zonation within a given orthopyroxene from the Oruanui high- $\mathrm{SiO}_{2}$ rhyolite in BSE imagery can be complex. This complexity arises as a result of secondary modification of the original crystal zonation by the combined effects of patchy dissolution, late-stage recrystallisation of previously dissolved portions, differential kinetic growth zonation features, and entrapment of mineral and melt inclusions. In addition, zonation evident in the BSE images suggests that all of these features are variously affected by elemental volume diffusion in the crystal prior to quenching on eruption. In some crystals these features appear in close enough proximity that diffusion outwards from one feature will commonly overprint and interact with a diffusion halo around another feature. Examples of some of these effects, and how they can be mitigated against to recover meaningful diffusion profiles are highlighted in Figures 3.6 and 3.7.

In order to assess the extent of original (primary) zonation in the orthopyroxenes we conducted elemental mapping of selected crystals using EPMA (Figures 3.6 and 3.7 for one example). To bracket the influence of cation diffusion on zonation in BSE images we looked at elements with contrasting diffusion rates (Al, very slow to immobile; $\mathrm{Ca}$, slow; Fe and $\mathrm{Mg}$, relatively fast). Al can be considered to be essentially immobile over timescales of $<10,000$ years (Smith and Barron 1991) at the temperatures encountered in the Oruanui system and thus approximates the original growth zonation of the orthopyroxene. Note in Figure 3.6 that the prominent core-to-rim boundary is represented by a sharp, step-wise change in $\mathrm{Al}$ content parallel to the $a$-axis, but that this same boundary parallel to the $c$-axis is noticeably smeared out over several tens of microns. This fuzziness of $\mathrm{Al}$ content 

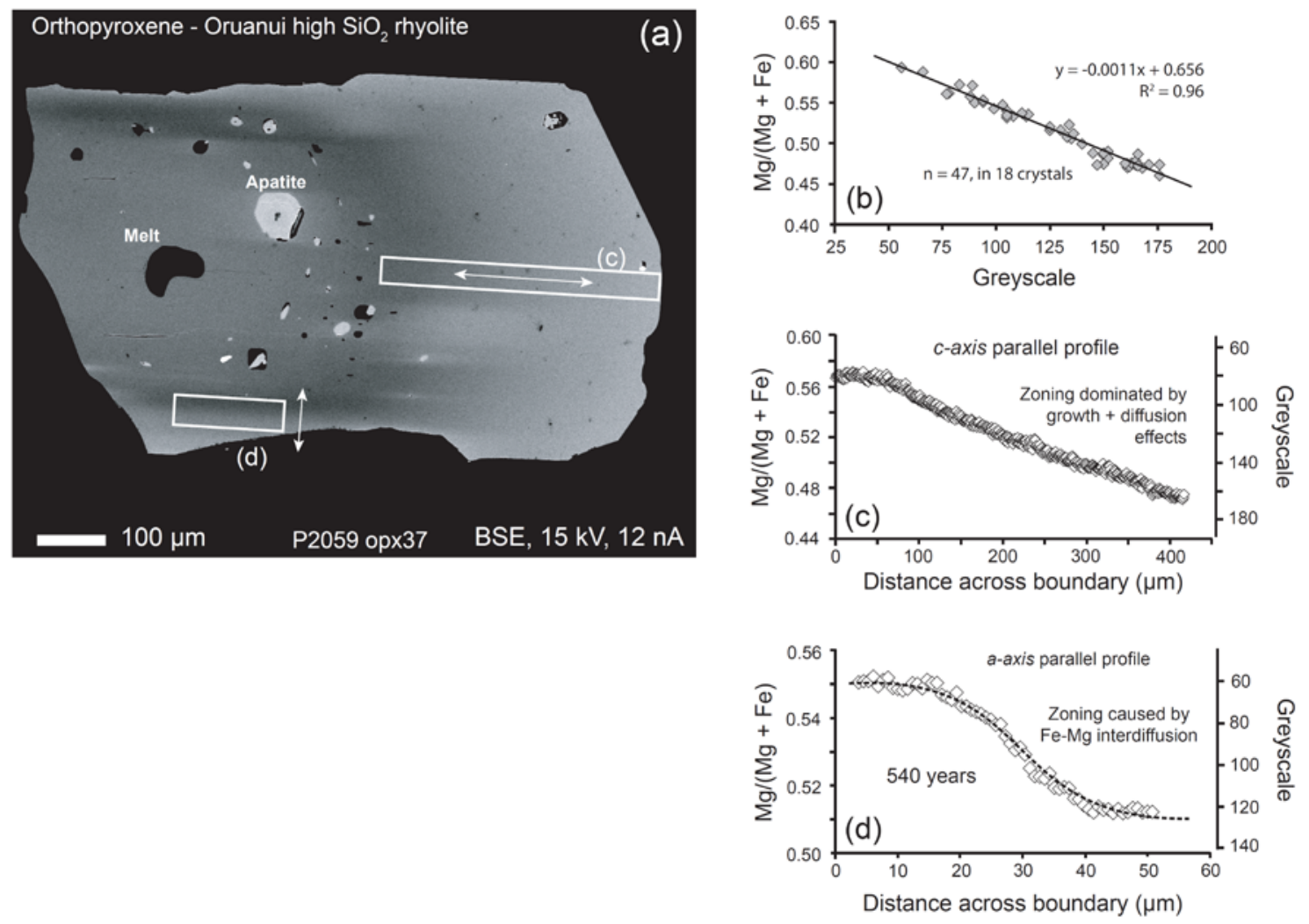

Figure 3.7. (a) BSE image of an orthopyroxene crystal from Oruanui high-SiO 2 rhyolite (see also Figure 3.6). The greyscale intensity correlates strongly with the $\mathrm{Mg}$ and Fe content of the orthopyroxene (panel b). This correlation was determined for a single sample (18 crystals) imaged under identical settings and analysed within a single analytical session. Panel (c) demonstrates the strongly linear gradient of $\mathrm{Mg} /(\mathrm{Mg}+\mathrm{Fe})$ that typifies zonation parallel to the $c$-axis implying that most of the zonation in this crystallographic orientation is controlled by kinetic factors/crystal growth. Zonation of $\mathrm{Mg} /(\mathrm{Mg}+\mathrm{Fe})$ parallel to the $a$-axis (panel d) and $b$-axis (not shown), where unaffected by secondary processes (see text), yields diffusion-modified concentration profiles. Each symbol in the panels (c) and (d) represent the averaged greyscale value (converted into $(\mathrm{Mg} / \mathrm{Mg}+\mathrm{Fe})$ ) for the row of pixels perpendicular to the direction of diffusion within the confines of the white boxes shown in panel (a). The dashed line in (d) shows the modelled profile of an initially sharp compositional boundary after 540 years at $770{ }^{\circ} \mathrm{C}$ and $0.2 \log$ units relative to NNO.

parallel to the $c$-axis at the core-to-rim boundary cannot have been generated by diffusion under any reasonable constraints and must therefore reflect a kinetic, growth-controlled zonation. The sharpness of the boundary parallel to the $a$-axis (and also the $b$-axis, not shown here) suggests that the kinetic zonation in these crystallographic directions is negligible. A similar pattern is evident in the map of $\mathrm{Ca}$ (slow diffusing), reflecting a small amount ( $<5 \mu \mathrm{m}$ transition zone) of diffusion parallel to the $a$-axis with diffusion plus growth affecting $\mathrm{Ca}$ zonation parallel to the $c$-axis. Fe-Mg interdiffusion occurs at a faster rate than that for either $\mathrm{Ca}$ or $\mathrm{Al}$ and as such the original crystal zonation appears much more smeared out along both the $a$ - and $c$-axes. The fine-scale zonation preserved inward 
of the core-rim boundary, evident in the $\mathrm{Al}$ map as discontinuous bright bands, is completely erased by Fe-Mg interdiffusion. Secondary zonation features within this crystal arise from areas that have undergone partial dissolution and subsequent recrystallisation followed by diffusion, commonly resulting in discontinuous diffusion halos in $\mathrm{Fe}-\mathrm{Mg}$ imagery.

A strong negative linear relationship $\left(\mathrm{R}^{2}\right.$ of 0.96$)$ is observed between the BSE greyscale value and the $\mathrm{Mg} /(\mathrm{Mg}+\mathrm{Fe})$ content, both determined at the sites of EPMA analyses, demonstrating that the zonation evident in the BSE images is overwhelmingly a reflection of the Fe-Mg content (Figure 3.7a,b). This observation allows us to investigate the gradients of $\mathrm{Fe}$ and $\mathrm{Mg}$ contents in the orthopyroxenes at a much higher spatial resolution than from spot analyses. In order to quantify spatially resolved $\mathrm{Mg} /(\mathrm{Mg}+\mathrm{Fe})$ profiles we used the freely available Java-based image processing programme, Image (http://rsb.info.nih.gov/ij/). BSE images were rotated so that the boundary of interest was perpendicular to the direction of diffusion (i.e. crystal boundary aligned north-south, with diffusion of atoms occurring east-west). Each symbol in Figures 3.7c and 3.7d represents the averaged greyscale content, converted to $\mathrm{Mg} /(\mathrm{Mg}+\mathrm{Fe})$, from each row of pixels perpendicular to the diffusion direction within the confines of the white boxes.

The Fe-Mg content of the core-rim boundary parallel to the c-axis has a strong linearity to it (Figure 3.7c), inconsistent with diffusive modification of an initially step-wise boundary and suggestive of a dominant growth/kinematic influence, as seen in element maps of $\mathrm{Al}$ and $\mathrm{Ca}$ (Figure 3.6). Similar gradients were also observed in the streaky discontinuous zones emanating from crystal- or melt-inclusions in the partially healed cores and are interpreted also to represent growth zonation. Gradients in Fe-Mg content parallel to the $c$ axis are thus not used for diffusion modelling. The same boundaries, however, measured parallel to the $a$-axis (and $b$-axis) yield a concentration gradient such as would be expected following diffusive modification of an initially step-wise concentration gradient at magmatic temperatures.

\subsection{MODELLING OF FE-MG INTERDIFFUSION IN ORTHOPYROXENE}

We address the scale of diffusion in Oruanui orthopyroxenes in order to constrain the timescales associated with the textural features we observe, in particular, the core-rim boundary in crystals from high- $\mathrm{SiO}_{2}$ rhyolite clasts. Modelling of diffusion in 
orthopyroxene is not straightforward, and there is significant difficulty in assigning a diffusion coefficient. We here give a short review of the state of the art and clarify the methodologies that we have employed in fitting profiles within our crystals.

\subsubsection{Calculation of $\mathrm{D}_{\mathrm{Fe}-\mathrm{Mg}}$}

The state of the art has been summarised by Cherniak and Dimanov (2010), where it is shown that the only experimental determination is that of Schwandt et al. (1998). This was evaluated for compositions of $\mathrm{En}_{88}$ at an oxygen fugacity at the Iron-Wustite (IW) buffer. These conditions are potentially problematic for volcanic applications, because most crystals will be significantly more iron-rich, and because most volcanic systems have oxygen fugacities within two log units of the NNO buffer, which sits some five orders of magnitude above the IW buffer.

An attempt to constrain the composition dependence was made by Ganguly and Tazzoli (1994) which, despite pre-dating the Schwandt et al. (1998) study, was cross-referenced against their early experimental results (see acknowledgments in Ganguly and Tazzoli 1994). Ganguly and Tazzoli (1994) used a theoretical construction of the diffusion coefficient to explain the rate constants of order-disorder transitions in orthopyroxene, processes which are mediated by Fe-Mg interdiffusion across M1 and M2 sites, from an experimental rate study by Besancon (1981). They discovered that between $\mathrm{En}_{100}$ and $\mathrm{En}_{50}$ the diffusion rate increased by roughly 1.3 orders of magnitude.

In addition to compositional dependence, it was speculated by Ganguly and Tazzoli (1994) that an oxygen fugacity dependence of the form

$$
D \propto\left(\frac{f O_{2 \text { (sample) }}}{f O_{2 \text { (reference) }}}\right)^{n}
$$

should operate, where the exponent $n$ has a value of $\sim 1 / 6$ This is consistent with studies in olivine (Dohmen et al. 2007) where vacancies are created by the $\mathrm{Fe}^{3+}$ substitution:

$$
3 \mathrm{Fe}^{2+} \leftarrow \rightarrow 2 \mathrm{Fe}^{3+}+\bullet
$$

where - denotes a vacancy. It should be noted that this is not the only mechanism by which a vacancy can be generated; substitution of trivalent or tetravalent cations onto the M1 and M2 sites without charge-balanced substitutions will lead to lattice defects in the form of vacancies. If the $\mathrm{Fe}^{3+}$ substitution was a dominant mechanism, we would expect 
diffusion to depend upon both crystal composition (amount of Fe) and oxygen fugacity (proportion of $\mathrm{Fe}$ as $\mathrm{Fe}^{3+}$ ) and, indeed, studies by Stimpfl et al. (2005), and early results of ter Heege et al. (2006) are consistent with this view. The study of Stimpfl et al (2005) further indicates that the $\mathrm{fO}_{2}$ dependence ranges down to temperatures as low as $650{ }^{\circ} \mathrm{C}$. One point that seems common across all studies is that the activation energy for diffusion is very similar, irrespective of differing conditions. The data for Schwandt et al. (1998) lie close to the values of Ganguly and Tazzoli (1994), extrapolated for that composition, and later studies have shown that the Ganguly and Tazzoli (1994) results (adjusted for oxygen fugacity) seem to be consistent with diffusion in olivine and clinopyroxene (Klügel, 2001).

In order to reconcile these observations, and to determine the diffusion coefficient in our system $\left(\mathrm{En}_{45-60}, \Delta \mathrm{NNO}-0.2\right)$, we use the parameterisation from Ganguly and Tazzoli (1994) and include a correction for the oxygen fugacity, following equation 1 where:

$$
D_{F e-M g}=\left(-5.54+2.6 X_{F e}-\frac{12530}{T}\right) \times\left(\frac{f_{O_{2}(\text { sample }, T)}}{f_{O_{2}(\text { IW buffer }, T)}}\right)^{\frac{1}{6}}
$$

where $X_{F e}$ is the compositional parameter $\mathrm{Fe} /(\mathrm{Fe}+\mathrm{Mg})$ of the orthopyroxene, $\mathrm{T}$ is the temperature in Kelvin, and $f_{\mathrm{O}_{2}}$ is oxygen fugacity, calculated at magmatic temperature for the sample or the IW buffer, as appropriate.

Our approach of accounting for the compositional and $f \mathrm{O}_{2}$ dependence of $\mathrm{D}_{\mathrm{Fe}-\mathrm{Mg}}$ represents the most significant difference between our approach to model Fe-Mg diffusion in orthopyroxene and a recent application by Saunders et al. (2012) for Mt St Helens orthopyroxene that utilised values for $\mathrm{D}_{\mathrm{Mg}}$ from the Schwandt et al. (1998) experiments determined for compositions of $\mathrm{En}_{88}$ and conducted at the IW buffer.

The $\mathrm{Mg} /(\mathrm{Mg}+\mathrm{Fe})$ compositions across diffusion modified boundaries in the Oruanui orthopyroxene crystals were measured and quantified using the ImageJ software and compositional correction from greyscale values described above (see also Figure 3.7).

\subsubsection{Modelling}

A database of simulated diffusion profiles obeying composition-dependent diffusion under a 1-D (linear) diffusion geometry was generated using finite-difference software (DJ Morgan, unpublished data). As the shape of a composition-dependent diffusion profile itself depends on the ratio of the diffusion coefficients, this allows us to select the appropriate shape of profile from the database, based upon what we know of the crystal 
composition on each side of the profile. Diffusion profiles in 1-D are a reasonable approximation as the profiles are short relative to the grain size, and diffusion is perpendicular to long edges of the grains, yielding an acceptable 1-D geometry. Composition-dependent diffusion in 1-D has the further property that for given boundary conditions, all diffusion profiles are self-similar in time, that is to say, a simple stretch factor applied to the length of the profile can be applied to bring profiles into congruency, such that diffusion after 4 time units will be twice as wide as at 1 time unit, but in all other respects the curves are identical. This allows us to quickly fit profiles repeatably with no subjective estimation. In order to achieve this, the spreadsheet measures the distance between the $20^{\text {th }}$ and $80^{\text {th }}$ percentiles in the diffusion profile extracted from the image and then scales the appropriate model curve by the correct factor before overlaying them (setting the $50^{\text {th }}$ percentile of the profile to $\mathrm{x}=0$ ). The stretch factors are used to adjust the model time to determine the diffusion time. This produced a rapid and repeatable procedure where difficulties can be quickly evaluated.

The largest sources of uncertainty in constraining appropriate values of $\mathrm{D}_{\mathrm{Fe}-\mathrm{Mg}}$, and therefore uncertainties on the calculated timescales, are the values adopted for temperature and oxygen fugacity. Here, for modelling of orthopyroxene in the high- $\mathrm{SiO}_{2}$ rhyolite, we adopt values of $770 \pm 30^{\circ} \mathrm{C}$ and oxygen fugacity of $\Delta \mathrm{NNO}-0.2 \pm 0.3$, for the following reasons. The $770{ }^{\circ} \mathrm{C}$ value is our best estimate of the final pre-eruption temperature in the Oruanui melt-dominant magma body as constrained by five mineral equilibrium based thermometers within reasonable tolerances for each model's uncertainties (i.e. $\pm \sim 30{ }^{\circ} \mathrm{C}$ ). The two most recent Fe-Ti oxide thermometry models (Ghiorso and Evans 2008; Sauerzapf et al. 2008) applied to equilibrium pairs (after Bacon and Hirschmann 1988) from the online supplementary dataset of Wilson et al. (2006) yield mean temperatures of $777^{\circ} \mathrm{C}\left( \pm 29^{\circ} \mathrm{C}, 2 \mathrm{sd}\right)$ and $760{ }^{\circ} \mathrm{C}\left( \pm 19^{\circ} \mathrm{C}, 2 \mathrm{sd}\right)$, respectively. The plagioclase-melt equilibrium thermometer of Putirka (2008, his equation 24a), applied to outermost plagioclase rims from high- $\mathrm{SiO}_{2}$ rhyolite clasts (varying from $\mathrm{An}_{34}$ to $\mathrm{An}_{43}$ ), paired with the relevant matrix glass compositions (Allan et al. 2012) yields a mean temperature of $787^{\circ} \mathrm{C}$. Similarly, the orthopyroxene-melt equilibrium thermometer of Putirka (2008, his equation 28a) yields a mean temperature of $785^{\circ} \mathrm{C}$, based on the observed En values in the outermost rims. For the plagioclase- and orthopyroxene-melt thermometers the value for melt $\mathrm{H}_{2} \mathrm{O}$ used was $5.5 \mathrm{wt} \%$ as derived from the Ridolfi et al. (2010) melt $\mathrm{H}_{2} \mathrm{O}$ formulation applied to the outermost rims of amphiboles in high-SiO 2 rhyolite clasts (cf. Liu et al. 2006). Temperature estimates based on compositions of the outermost rims of amphiboles 
from the high- $\mathrm{SiO}_{2}$ rhyolite clasts return a mean value of $784^{\circ} \mathrm{C}\left( \pm 42^{\circ} \mathrm{C}, 2 \mathrm{sd}\right)$. This value is skewed to slightly higher values owing to a small number of outermost rim analyses that tail off to higher temperatures, up to $\sim 850^{\circ} \mathrm{C}$, corresponding to those amphiboles tailing off to higher values of $\mathrm{Al}^{\mathrm{IV}}$ in Figure 3.2b. Greater than $90 \%$ of these amphibole rims return temperature estimates $<820^{\circ} \mathrm{C}$, and the population as a whole has a prominent modal temperature centred on $\sim 770{ }^{\circ} \mathrm{C}$ (see Figure 3.2a of Wilson et al. 2012).

Note that the final pre-eruptive temperature in the melt dominant body is lower than the temperature at which the main core-rim boundary in the orthopyroxenes initially formed. This temperature, at which orthopyroxene re-stabilised and began to re-grow in the melt dominant body, is constrained to $\sim 820^{\circ} \mathrm{C}$ from the inflection point in the amphibole $\mathrm{Mn}$ and $\mathrm{Zn}$ concentrations (Figures 3.3 and 3.5). Rimward of this core-rim boundary the enstatite values gradually zone out to values of $\mathrm{En}_{46 \pm 2}$ in the outermost rims, consistent with the cooling trend also seen by Oruanui plagioclases (Charlier et al. 2008), to a final magmatic temperature of $\sim 770^{\circ} \mathrm{C}$. The 'true' diffusion ages of the main core-rim boundaries therefore falls somewhere between models run at $770^{\circ} \mathrm{C}$ and those run at $820^{\circ} \mathrm{C}$.

Estimates of the final ambient oxygen fugacity in the melt dominant magma body are decidedly inconsistent. Oxygen fugacity estimates were determined using the Fe-Ti oxide equilibrium models of both Ghiorso and Evans (2008) and Sauerzapf et al. (2008) and the amphibole formulation of Ridolfi et al. (2010, their equation 2). The following mean values ( \pm 2 sd) were determined: $\Delta \mathrm{NNO}-0.20 \pm 0.29$, Ghiorso and Evans (2008) model; $\Delta \mathrm{NNO}+0.47 \pm 0.16$, Sauerzapf et al. (2008) model; $\Delta \mathrm{NNO}+0.88 \pm 0.33$, Ridolfi et al. (2010) model. The oxygen fugacity dependency of $\mathrm{D}_{\mathrm{Fe}-\mathrm{Mg}}{ }^{\mathrm{opx}}$ values means that more negative values of oxygen fugacity (referenced to NNO) will yield a smaller value for the diffusion coefficient and result in a longer calculated timescale. Figure 3.8 illustrates the effect that the adoption of different combinations of temperature and oxygen fugacity would have on the calculated diffusion age for representative (i.e. our oldest, an intermediate and the youngest) core-rim boundaries in orthopyroxenes from the high- $\mathrm{SiO}_{2}$ rhyolite samples. Given these variations, the models were run at the lowest value in order to constrain maximum timescales based on reasonable model inputs and a transparent account of the uncertainties involved. In our discussions of our diffusion age determinations here we conservatively adopt the maximum ages (Figures 3.9 and 3.10). A comprehensive summary of the measured and modelled Fe-Mg diffusion profiles across 
the core-rim boundaries are presented in the Electronic Appendix in Table S13 and Figures S1 and S2.
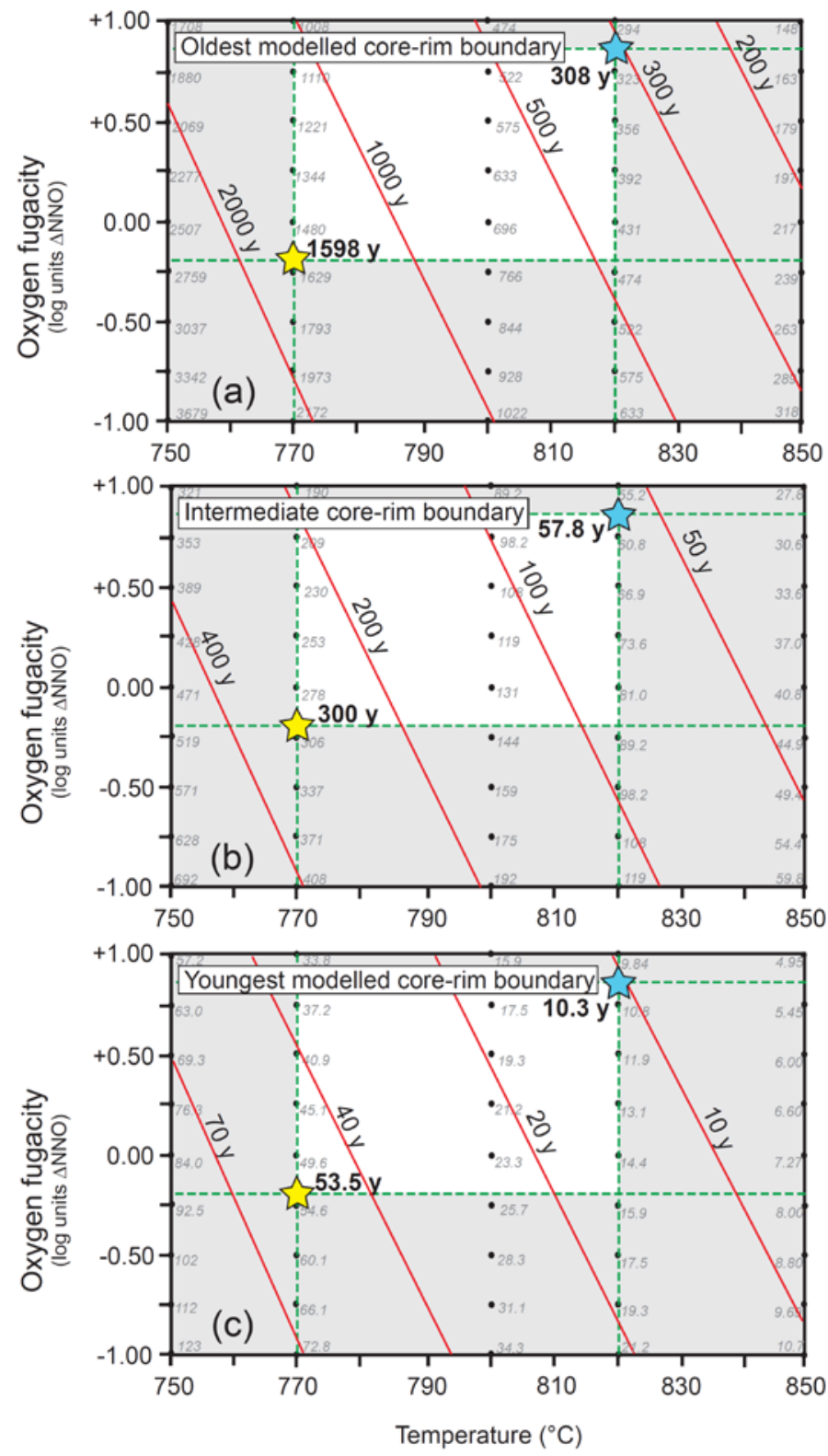

Figure 3.8.Contoured $x-y$ plots showing the effects of varying the imput values of temperature and oxygen fugacity on the modelled $\mathrm{Fe}-\mathrm{Mg}$ interdiffusion age of a given boundary. Three examples are shown to illustrate these influences on (a) the oldest, (b) an intermediate, and (c) the youngest orthopyroxene core-rim boundaries encountered in the high- $\mathrm{SiO}_{2}$ rhyolite. The small black dots and accompanying grey labels show the timescale (in years) for the boundary modelled at the temperature and oxygen fugacity conditions plotted. The white box denotes the upper- and lower-bound temperature $\left(770\right.$ and $\left.820^{\circ} \mathrm{C}\right)$ and oxygen fugacity $(-0.2$ and $+0.88 \mathrm{NNO})$ estimates relevant to the formation of the main core-rim boundaries. The red lines show the approximate position of the rontours as lahelled 

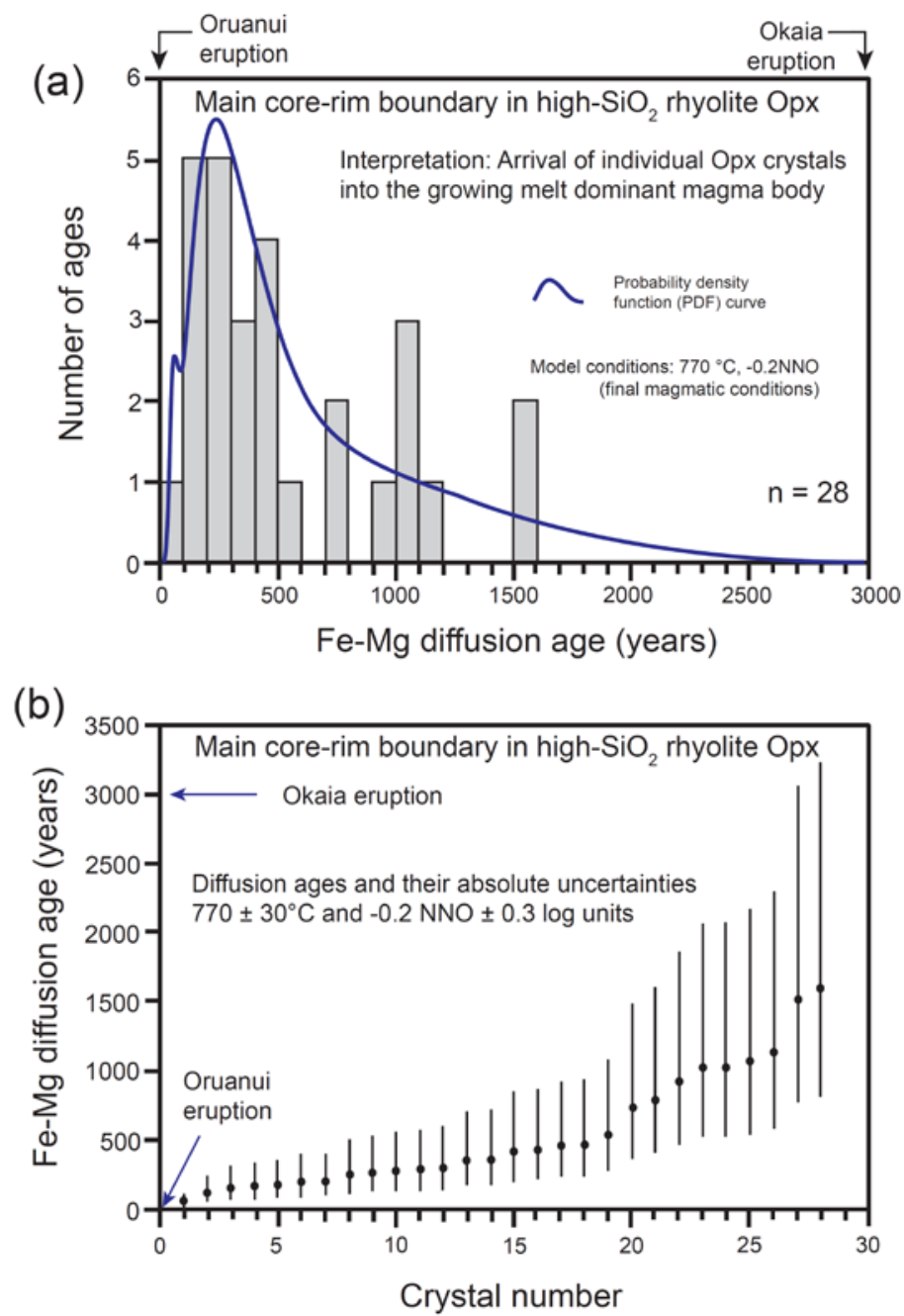

Figure 3.9.(a) Histogram showing the range and frequency of maximum Fe-Mg interdiffusion ages (at $770{ }^{\circ} \mathrm{C}$ and $-0.2 \Delta \mathrm{NNO}$ - see text) determined for the main core-rim boundary in high-SiO 2 rhyolite clasts. The PDF curve represents a population-level probability of all age determinations with the associated uncertainties on each age assuming a temperature uncertainty of $\pm 30^{\circ} \mathrm{C}$ and $\pm 0.3 \log$ units of oxygen fugacity. The relative position of the Oruanui $(25.4 \mathrm{ka})$ and Okaia $(28.6 \mathrm{ka})$ eruptions are marked with arrows for context. (b) Individual ages and their absolute uncertainties based on the propagation of temperature and oxygen fugacity uncertainties $\left( \pm 30^{\circ} \mathrm{C}\right.$ and $\pm 0.3 \log$ units, respectively).

In our modelling of orthopyroxene boundaries from low- $\mathrm{SiO}_{2}$ rhyolite samples we use a temperature of $820^{\circ} \mathrm{C}$ and oxygen fugacity of NNO. These are our best estimates for the final magmatic conditions experienced by these samples as indicated using the models for temperature and oxygen fugacity described above. The mean oxygen fugacity indicated by the various models varies from a lower bound value equal to NNO (Ghiorso and Evans 2008 model) and an upper bound value of +0.5 NNO (Ridolfi et al. 2010). We use the former value to constrain the maximum timescale for boundaries in the low- $\mathrm{SiO}_{2}$ rhyolite samples (Figure 3.11). Orthopyroxenes from these samples lack the prominent core-rim 

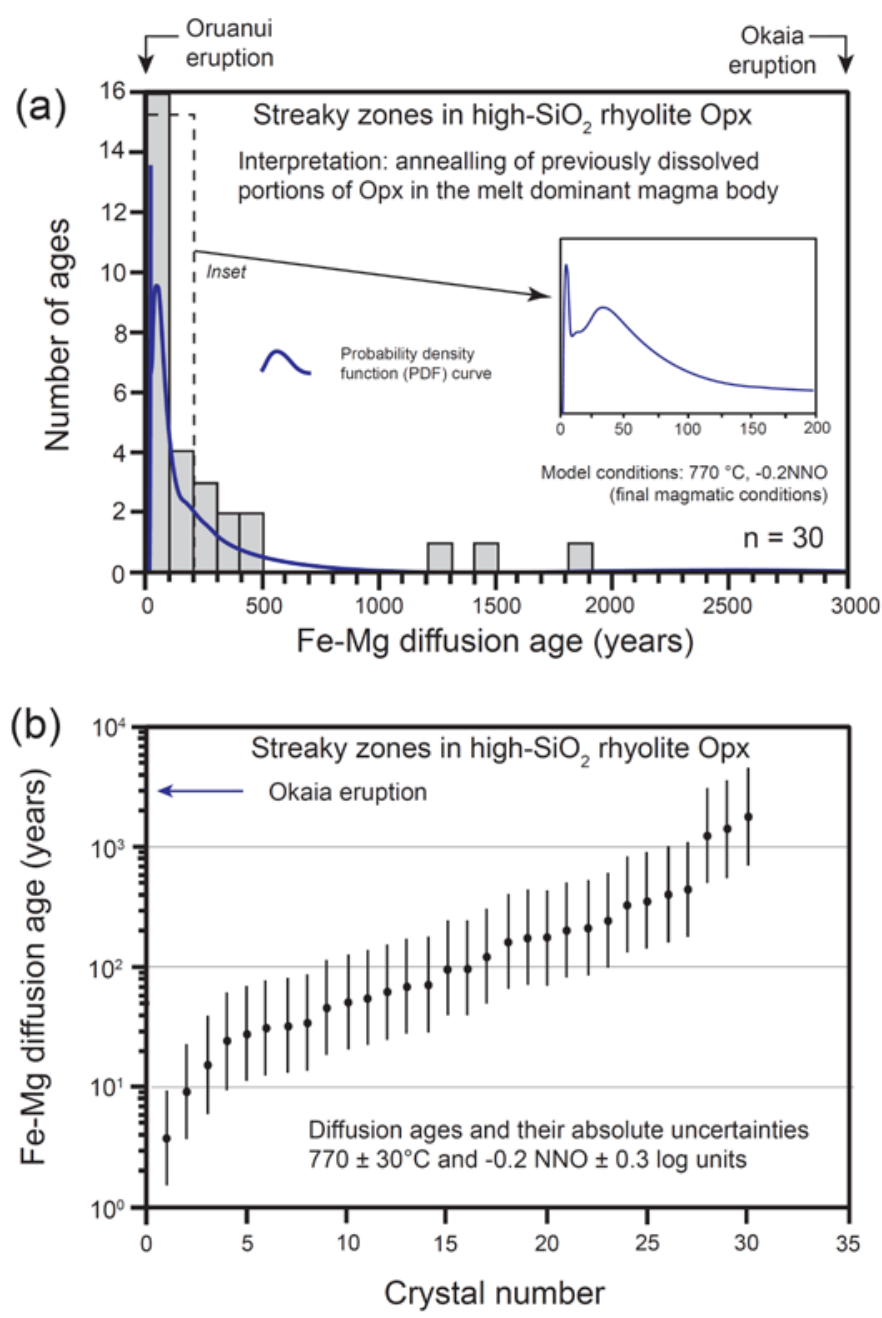

Figure 3.10.(a) Histogram of maximum Fe-Mg diffusion ages for streaky, discontinuous zones (see Figure 3.1 for examples) in orthopyroxene from high- $\mathrm{SiO}_{2}$ rhyolite clasts. Compared to the main core-rim boundaries, the compositional gradients outward from streaky, discontinuous zones are almost always sharper (and thus, younger) than the main core-rim boundaries. (b) Individual ages and their absolute uncertainties based on temperature and oxygen fugacity uncertainties of $\pm 30^{\circ} \mathrm{C}$ and $\pm 0.3 \log$ units, respectively. Note the logarithmic scale.

relationship that typifies orthopyroxenes from high- $\mathrm{SiO}_{2}$ rhyolite samples, with the exception of a few crystals interpreted to have been syneruptively mixed in from the high$\mathrm{SiO}_{2}$ rhyolite (see the section 'Compositional groupings of Oruanui orthopyroxene and amphibole'). As such the diffusion ages we calculate for orthopyroxene in the low- $\mathrm{SiO}_{2}$ rhyolite samples cannot be readily attributed to a specific process. Rather, the ages for these samples should be considered as simply reflecting the age of the various growth zones as the orthopyroxenes grew in isolated melt-rich pockets persisting in the crystal mush/source prior to eruption. 
In considering the uncertainty on single model age determinations we account for temperature uncertainties of $\pm 30{ }^{\circ} \mathrm{C}$ and $\pm 0.3 \log$ units for the oxygen fugacity. We also consider uncertainties on the profile shapes (i.e. the uncertainty on the compositional reliability of the BSE images) and the profile length (based upon the absolute reliability of the magnification provided by the microprobe imaging, which is taken as a conservatively large $\pm 3 \%$ ).
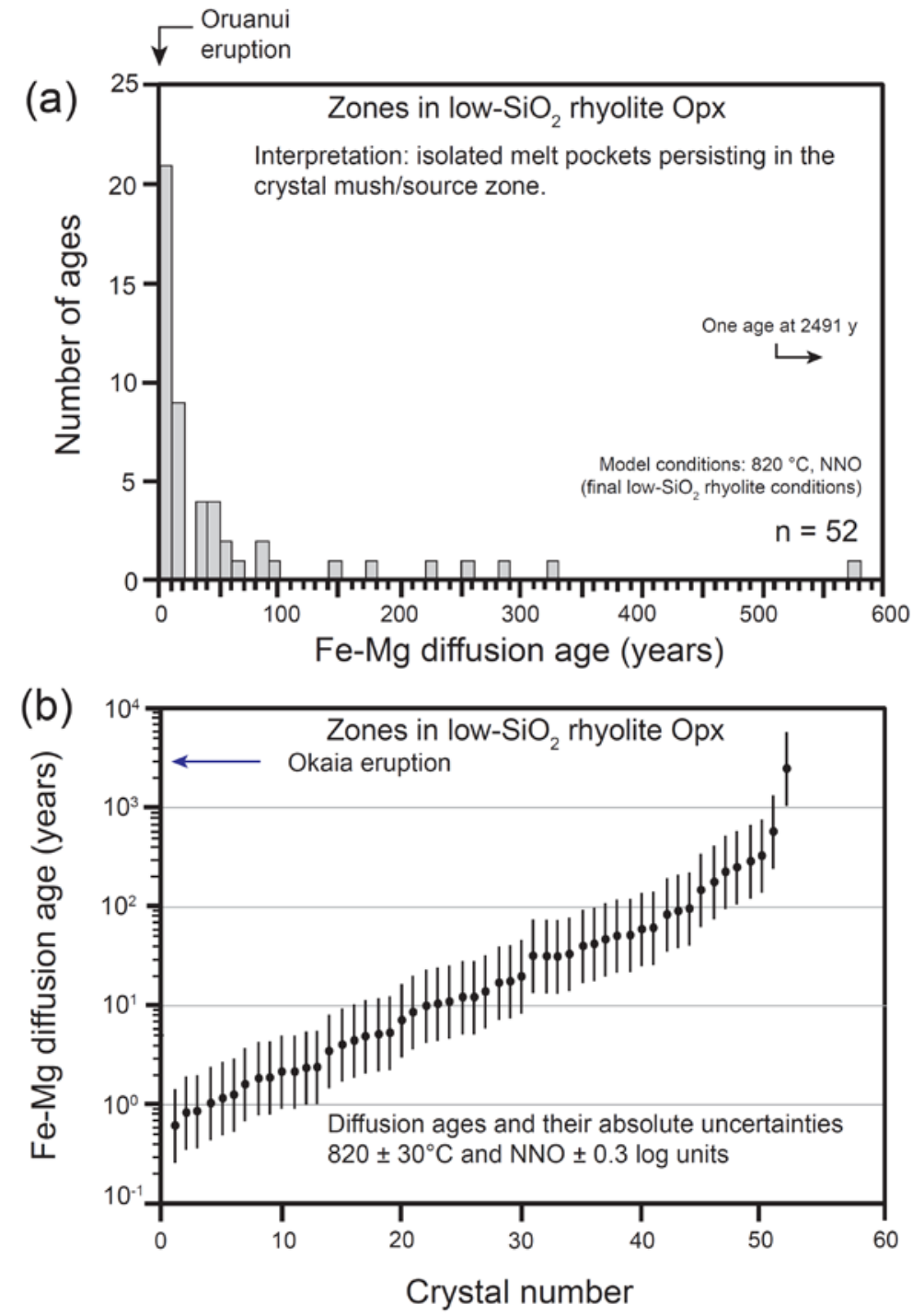

Figure 3.11.(a) Histogram of maximum diffusion ages for boundaries occurring in orthopyroxenes from low- $\mathrm{SiO}_{2}$ rhyolite clasts. (b) Individual ages and their absolute uncertainties based on temperature and oxygen fugacity uncertainties of $\pm 30^{\circ} \mathrm{C}$ and $\pm 0.3 \log$ units, respectively. 


\subsection{IMPLICATIONS OF FE-MG DIFFUSION TIMESCALES IN ORUANUI ORTHOPYROXENE}

A previous maximum timescale for the physical assembly of the Oruanui melt dominant magma body was proposed from U-Th zircon age spectra (Charlier et al. 2005; Wilson and Charlier 2009). The coincident vent locations yet strongly contrasting zircon model-age spectra for Oruanui and Okaia zircons led Wilson and Charlier (2009) to conclude that the $530 \mathrm{~km}^{3}$ Oruanui melt-dominant magma body became established only after the Okaia eruption. On the basis of the most recent age calibrations for both eruptions $(25.4 \pm 0.2 \mathrm{ka}$ Oruanui, Vandergoes et al. 2013; $28.6 \pm 1.5$ ka Okaia, Lowe et al. 2013), the U-Th zircon age datasets thus suggested a maximum duration of $\sim 3000$ years for assembly of the melt dominant magma body.

Our diffusion-based approach to constrain the timing of the physical extraction and establishment of the melt dominant magma body is consistent with (and even shorter than) these zircon age constraints. Even allowing for our use of lower bound temperature and oxygen fugacity estimates (see discussion above and Figures 3.8 and 3.9) which yield maximum ages, and allowing for the uncertainties on single ages, none of the diffusion age estimates for the main core-rim orthopyroxene boundaries here date back to pre-Okaia times. Our maximum age constraints suggest that extraction of large volumes of melt plus crystals from the Oruanui mush/source zone began only about 1600 years prior to eruption, and even then most of the volume appears to have been extracted in $\sim 500$ years, with the population-level probability density function (PDF) curve indicating a peak probability age of $\sim 230$ years (Figure 3.9). The rate of the extraction process appears to have followed a run-away increase up until this peak before it all but ceased, with only one core-rim boundary returning an age estimate within 100 years of the eruption (Figure 3.9; $53.5 \mathrm{y})$. In contrast, the modelled ages from the streaky, discontinuous zones in high- $\mathrm{SiO}_{2}$ clasts show a similar exponential increase right up to within only a few years before the eruption (Figure 3.10b) as the riddled orthopyroxene cores continued to recrystallise in the melt dominant magma body. The apparent lack of 'young' ages determined for the corerim boundaries (Figure 3.9a) may however, be partly or wholly an artefact of our approach, for two reasons. First, adoption of parameters to generate the maximum diffusion times may have created an artificial time gap between the diffusion-based estimates and eruption age. Second, our choice of crystals may be biased. It is possible that the $\sim 10 \%$ of orthopyroxenes in the studied clasts which lack a prominent core-rim boundary reflect 
crystals that were introduced into the melt-dominant magma body much closer to the eruption, such that they did not have sufficient time for the development of a prominent rim-zone and were not measured. The abundances of such non-rimmed grains are not adequate though to completely explain the scarcity of near-eruption-age rim growth estimates.

Gualda et al. (2012a) investigated the timescales of quartz crystallisation in the $760 \mathrm{ka}$ Bishop Tuff magma on the basis of Ti diffusion in quartz, kinetics of melt inclusion faceting, crystal size distributions and modelling of thermodynamics and heat flow. They reported that Bishop quartz crystallisation histories were comparatively young, mostly 500 to 3000 years. On the basis of an invariant temperature of crystallisation $\left(\sim 756^{\circ} \mathrm{C}\right)$ for the Bishop system (cf. Hildreth and Wilson 2007; Bindeman and Valley 2002), inferred via the application of the rhyolite-MELTS model (Gualda et al. 2012b), the century-to-millenniascale quartz crystallisation histories were extrapolated to the crystallisation of all phases in the Bishop magma body (Gualda et al. 2012a; cf. Simon and Reid 2005).

In contrast, our observations here, particularly regarding the decompression and associated cooling trend in the amphiboles (Figure 3.3) and down-temperature signals in the rim zones of orthopyroxene (Figure 3.1b,c) and plagioclase (Charlier et al. 2008), imply that the crystal record for the Oruanui cannot be reconciled with a simple, invariant temperature of crystallisation (Figure 3.5). This means that the timescales inferred from one particular phase (in this case, orthopyroxene) cannot necessarily be extended to the other crystal phases. This is particularly true of Oruanui quartz which is absent from the low- $\mathrm{SiO}_{2}$ rhyolite samples, argued by us to approximate the initial composition of magma(s) extracted from the source/mush zone that gave rise to the melt-dominant magma body. If this interpretation is correct then by implication the oldest Ti diffusion timescales recovered from Oruanui quartz may not necessarily reflect any particular process in the Oruanui magma, but rather the point at which the melt dominant magma body had evolved to compositions where crystallisation of new (or preservation of xenocrystic) quartz was possible.

The short timescales and consequently extreme accumulation rates $\left(>0.33 \mathrm{~km}^{3} / \mathrm{y}\right.$ based on the oldest boundary age of $1597 \mathrm{y}$, possibly reaching $>1 \mathrm{~km}^{3} / \mathrm{y}$ ) we infer for the $\sim 530 \mathrm{~km}^{3}$ Oruanui melt-dominant magma body imply the involvement of a more dynamic and efficient driver of crystal-liquid separation than the commonly invoked quasi-static drivers such as hindered crystal settling, micro-settling and compaction (Bachmann and Bergantz 
2004). Numerical modelling of liquid-solid segregation rates driven by these processes predict the accumulation of an Oruanui sized melt-dominant magma body would take one to two orders of magnitude longer than the timescale we infer here $\left(10^{4}-10^{5}\right.$ years for a $>500 \mathrm{~km}^{3}$ body, Bachmann and Bergantz 2004). The mush zone that fed the Oruanui magma was established and contributing much smaller volumes of high- $\mathrm{SiO}_{2}$ rhyolite magmas into the upper crust for at least $20 \mathrm{kyr}$ before the Oruanui eruption (i.e., the Tihoi, New plinian and Okaia events: Sutton et al. 1995; Charlier et al. 2005; Wilson and Charlier 2009). If ambient crystal settling and compaction drove the melt accumulation/extraction process at Taupo, why then was a $\sim 1.5 \mathrm{~km}^{3}$ body of crystal-poor rhyolite magma extracted at $\sim 28.6 \mathrm{ka}$ (Okaia), only for a magma body two orders of magnitude more voluminous to follow only $\sim 3$ kyr later?

Another commonly-invoked, and more dynamic, driver of crystal-melt segregation within the framework of the crystal mush model is related to the rejuvenating influence of mafic magma underplating the silicic mush pile. In this scenario upward heat advection is induced by the exsolution of volatiles from underplated, gas-saturated mafic magmas, i.e., 'gas sparging' or mafic 'wind' (Bachmann and Bergantz, 2006). Gas sparging, however, accompanies an upwards shift in the magma temperature, a feature that would generate widespread up-temperature signals in the phenocryst phases, such as reverse zoning of plagioclase and pyroxenes and/or high Al rims in amphiboles (e.g. Bachmann and Dungan, 2002).

Despite the co-eruption of $\sim 5 \mathrm{~km}^{3}$ of mafic magmas (of two distinct lineages, tholeiitic and calc-alkaine; Wilson et al. 2006), crystals in the high-SiO${ }_{2}$ Oruanui rhyolite display consistent cooling trends towards the outermost crystal rims, precluding chamber-wide heating of the melt dominant magma body by heat and volatile transfer from the Oruanui mafic magmas. A strong apparent internal fractionation trend in the tholeiitic mafic clasts, their coarser, mushy groundmasses and mixing trends with sparse high-MgO rhyolite led Wilson et al. (2006) to suggest that this magma may have ponded at the base of the established melt-dominant magma body for a period of time before eruption, inducing vigorous chamber-wide mixing and stirring of the crystal cargo (Liu et al. 2006). The lack of any significant chemical variability in the calc-alkaline mafic magma and the fresher glassier appearance of the groundmass suggested that this magma only encountered the rhyolite syn-eruptively. 
The presence of the Oruanui mafic magmas, as sampled during the eruption, may be considered to be symptomatic of a more general underlying process. It is exceedingly rare for any non-trivial volumes of mafic magma to reach the surface in the central TVZ (Wilson et al. 1995; Hiess et al. 2007). The amount of mafic magma erupted during the Oruanui event is an order of magnitude greater than the largest purely mafic eruption (Tarawera $1886 \sim 0.7 \mathrm{~km}^{3}$, Sable et al. 2009) known in the past $1.6 \mathrm{Ma}$. We hypothesise that both the rapid timescales of the melt extraction and accumulation process, and the presence of unusually large volumes of mafic magmas in the lead up to the eruption can be reconciled by an enhanced and localised episode of magma-assisted rifting in the Taupo region in the lead up to the Oruanui eruption at $25.4 \mathrm{ka}$.

There is a complex interplay between, and positive feedbacks associated with, tectonism, magmatism and volcanism in the central Taupo Volcanic Zone (Rowland et al. 2010). For mafic magma to ascend from depth requires the assistance of rifting processes. The supply of mafic magma to mid-crustal levels then has a positive feedback in that it lubricates fault planes and alters the thermal state of the crust to promote further rifting processes.

Similarly, rifting and extension of crystal-mush-bearing crust could provide a mechanism to promote extraction of crystal-poor magma from the mush-like body in the extraordinarily rapid manner that we infer for the Oruanui. Rifting-related processes would promote the development of melt channels allowing melt (plus some crystals) to escape, ascend and pond at shallow crustal levels. In time this process would become self-propagating in that when a volume of the mush body became sufficiently drained of melt its increased density would induce disruption of the surrounding melt-bearing crystal network (c.f. the smaller scale crystal-settling; Bachmann and Bergantz 2004), redistributing and forcing large volumes of melt into other open channels. In turn, the Oruanui mush source was effectively drained of melt during and immediately after the eruption. This is shown by the different and distinctive chemical and isotopic characteristics of dacites and rhyolites erupted through the Oruanui caldera area from $\sim 21$ ka onwards (Sutton et al. 2000). The earliest post-Oruanui rhyolites at $12 \mathrm{ka}$ have zircons with post- and pre-Oruanui model ages, but the magma compositions do not follow any mixing or evolutionary trends with Oruanui melt compositions (Sutton et al. 2000; Wilson and Charlier 2009). 


\subsection{CONCLUSIONS}

The textural and chemical features in orthopyroxene and amphibole crystals from the Oruanui eruption deposits, combined with thermobarometric constraints, record the physical assembly of the erupted $\sim 530 \mathrm{~km}^{3}$ melt dominant magma body. Decompression from $\sim 300$ to $140 \mathrm{MPa}$ (12 to $6 \mathrm{~km}$ depth) is recorded in the amphibole crystals, marking the extraction of vast volumes of crystal-poor rhyolite from the Oruanui crystal mush/source zone, followed by the growth and evolution of the melt dominant magma body at 90 to $140 \mathrm{MPa}$ (3.5 to $6 \mathrm{~km}$ depth). Textural analysis indicates that during the decompression and ascent of magma from depth, the entrained orthopyroxenes actively dissolved and resorbed, returning to growth only after reaching the melt-dominant magma body, and resulting in the development of prominent (40 to $500 \mu \mathrm{m}$ thick) rim zones. Models of Fe-Mg interdiffusion across the core-rim boundaries of orthopyroxenes from the high- $\mathrm{SiO}_{2}$ rhyolite samples place constraints on the timing of this extraction event. The resulting maximum timescales suggest this process began only $\sim 1600$ years earlier but underwent a run-away increase in rate reaching a peak extraction rate $\sim 230$ years prior to eruption. The timescales are consistent with, and younger than, previous maximum constraints on the timing of the physical assembly of the melt dominant body at shallow levels afforded by the strongly contrasting model zircon age spectra of the geographically coincident Okaia eruption only $\sim 3$ kyr earlier (Charlier et al. 2005; Wilson and Charlier 2009).

The rapidity of the melt extraction process at Taupo volcano in the lead-in to the Oruanui supereruption, and the extreme magma accumulation rates that are implied, suggest the involvement of a much more dynamic driver than the traditionally invoked small-scale internal processes of crystal settling and compaction (e.g. Bachmann and Bergantz 2004). In light of the evidence that the underlying extensional tectonic regime is able to impart a significant influence on the timing and tempo of silicic volcanism in magma-bearing crust at Taupo and elsewhere (e.g. Gravley et al. 2007; Cooper et al. 2012; Allan et al. 2012), we suggest the rapidity of the melt extraction process that enabled the generation of the supersized Oruanui magma body was related to a particularly enhanced episode of magmaassisted rifting. Given the presence of a mature crystal mush-like body at shallow- to midcrustal levels and an actively extending tectonic regime, the transition from an uneruptible mush to a highly-eruptible, super-sized, crystal-poor magma body can be achieved in centuries. 


\title{
4. From diversity to uniformity: origins of the unzoned crystal-poor Oruanui magma from a stratified crystal-rich reservoir
}

\begin{abstract}
The processes and timescales associated with the generation and syn-eruptive withdrawal of the $530 \mathrm{~km}^{3}$ Oruanui magma body are investigated through detailed textural and chemical records preserved in the main mineral phases. The crystals have been extracted from samples representing early (phases 1 to 3), middle (phase 7) and late (phase 10) parts of the eruption. This dataset allows the origins of the crystals and the dynamics of processes in the pre-eruptive magma chamber to be established on timescales from hours to 1-2,000 years. The resulting timescales for pre- and syn-eruptive processes are the most comprehensive yet documented for a pre-historic silicic eruption.

Detailed crystal chemical and textural records from plagioclase, orthopyroxene, amphibole, quartz and Fe-Ti oxides establish a unifying scenario for the development of the Oruanui melt-dominant magma body. Prior to onset of growth of this body, there was developed a thermally and compositionally zoned crystal mush body. The top was quartz-bearing and as shallow as $\sim 3.5 \mathrm{~km}$, and the roots quartz-free and extending to at least $10 \mathrm{~km}$ depth. The Oruanui crystals record in their textures and compositions the extraction of vast volumes of low-silica rhyolite melt at $\sim 820^{\circ} \mathrm{C}$, plus some fraction of crystals, from this mush source into a sill-like melt dominant magma body that eventually extended between 3.5 and $6 \mathrm{~km}$ depth. During the melt extraction process, crystals from all levels of the zoned mush body were entrained upwards into the accumulating melt-dominant magma body, as monitored by model pressure estimates in amphiboles. The associated decompression caused plagioclase and orthopyroxene to temporarily destabilise, restabilising once they reached the melt-dominant magma body. Amphiboles continued to grow throughout the decompression process, but their chemical compositions change in response to release of certain trace elements from the de-stabilised phases, in particular $\mathrm{Zn}$ and $\mathrm{Mn}$ from the dissolving orthopyroxene. The plagioclase and orthopyroxene crystals then developed rim-zones reflecting equilibrium crystallisation in an evolving and cooling melt, while the amphiboles also continued equilibrium crystallisation. The outermost
\end{abstract}


plagioclase, amphibole and orthopyroxene crystal rims yield model temperatures of $770{ }^{\circ} \mathrm{C}$ that agree within analytical uncertainties and are the same as estimates from Fe-Ti oxides. The uniformity of the model temperatures indicates that immediately prior to eruption the melt-dominant magma body was uniform in composition, vigorously convecting and lacked any significant thermal gradient.

Diffusion modelling of core-rim zones in orthopyroxene using $\mathrm{Mg}$-Fe compositional profiles have been used to date the transition from mush to melt-dominant body. From these data, the physical assembly of the melt-dominant body by drainage of the mush zone was geologically rapid, beginning only $\sim 1600$ years before eruption (using a conservatively low temperature estimate of $770{ }^{\circ} \mathrm{C}$ ) and with most of the volume accumulating in less than 500 years. This rapid transition from mush to melt-dominant magma body is reflected in the crystals as the transition from textural and compositional diversity in the cores to uniformity in the outermost rim compositions.

The eruption also vented 3-5 $\mathrm{km}^{3}$ of mafic material of two contrasting lineages: tholeiitic and calc-alkaline. Despite the co-eruption of these mafic compositions in amongst the volumetrically dominant rhyolite, the ubiquitous down-temperature signals in crystal rims from the rhyolite preclude mafic recharge from having played any driving role in disassembling the mush zone or controlling temperatures in the growing melt-dominant magma body. Rather the presence of the mafic magmas appears to be a consequence of magma-assisted rifting processes intersecting the crystal mush-bearing crust beneath Taupo during the lead in to the Oruanui eruption.

Remarkable and distinctive features of the Oruanui eruption and its magma body include: the exceedingly rapid generation of the melt-dominant magma body (rates of up to $\sim 1$ $\mathrm{km}^{3} / \mathrm{yr}$ ), evidence for vigorous convection and mixing in the rhyolite magma, and clear evidence for interaction of mafic magmas with the antecedent mush body prior to and during the eruption. The evidence from the crystal phases coupled with field observations indicates a central controlling role for tectonic processes in regulating pre- and syn-eruptive processes and timings. Such a direct role for an external factor in the behaviour of a supersized rhyolite magma chamber arises from recognition and correlation of textural features in the crystal cargo, and suggests that petrological evidence may yield valuable insights into dynamic processes before and during large silicic eruptions. 


\subsection{INTRODUCTION}

\subsubsection{The nature and generation of large silicic magma bodies}

The study of large silicic eruptions and their parental magmatic systems offers many challenges. One central issue is determining whether the processes and timescales involved in the generation of relatively small volumes of evolved magma are the same as for those that result in the accumulation of 'super-sized' magma bodies (i.e., those exceeding $10^{15} \mathrm{~kg}$ or $\sim 450 \mathrm{~km}^{3}$ magma). Do very large eruptible bodies of magma take correspondingly longer to be generated (e.g., Smith 1979; Shaw 1985; Reid 2008), or are the times involved similar, but the rates of processes much faster (e.g., Wilson and Charlier 2009; Gualda et al. 2012a)? By extension, the questions arise as to how are vast volumes of melt-rich magma able to accumulate in the shallow crust without erupting and, once the magma is in its final position, what is it that determines the precise moment of eruption?

In general terms, answers to these questions are sought by two contrasting approaches: numerical modelling of magma chambers (e.g., Jellinek and DePaolo 2003, Bachmann and Bergantz 2004; Huber et al. 2011 2012), and chemical and petrological insights from minerals and glasses in quenched eruption deposits themselves (e.g., Girard and Stix 2010; Gualda et al. 2012a). While both approaches inevitably have their advantages and pitfalls, both approaches benefit enormously from ground-truthing from field-based observations (e.g. Bain et al. 2013; Wilson et al. 2006; Wilson and Charlier 2009; Allan et al. 2012 2013). Questions that remain controversial in many cases (particularly the Bishop Tuff) relate to the nature of the crystals found in single parcels of magma (i.e., single pumice clasts). One end-member view is that they are grown in situ together, possibly over a narrow range of intensive variables (Hildreth 1979; Gualda et al. 2012a b). However, in the same way as many intermediate volcanic products have been shown to include crystal cargoes from a wide range of sources (e.g., Eichelberger 1978; Gamble et al. 1999; Dungan and Davidson 2004; Davidson et al. 2005) rhyolitic crystal cargoes may similarly represent derivation from a variety of materials.

Chemical and petrological approaches often emphasise a particular story told by one particular mineral phase (e.g., Bishop Tuff quartz - Wark et al. 2007; Thomas et al. 2010; Peppard et al. 2001; Bishop Tuff Fe-Ti oxides - Ghiorso and Gualda 2013). While such individually focused studies are necessary and yield important constraints on the behavioural dynamics of large silicic magma systems, it is less common that data from all 
the major crystal phases are considered as a whole (e.g., Hildreth 1979; Girard and Stix 2010).

\subsubsection{The crystal archive as a record of processes in crystal-poor ignimbrites}

The crystal mush model (Hildreth 2004; Bachmann and Bergantz 20042008 for reviews) provides a very useful framework with which to explore the nature and development of large (particularly super-sized) bodies of evolved silicic magma at upper-crustal levels. The mush itself has generally been envisaged as a viscous, largely uneruptible body of material (Smith 1979), and much of the emphasis in numerical modelling studies has been focused on determining the timescales required to defrost and/or remobilise a mush body (Burgisser and Bergantz 2011; Huber et al. 2010 2011) and/or consideration of preservation or destruction of compositional gradients (Huber et al. 2012). Mafic magma is often inferred to play a key role by supplying the heat and volatiles required to reactive and/or remobilise the mush in order to facilitate the eruption of large volumes of crystalrich magma (e.g., Bachmann and Dungan 2002; Fish Canyon Tuff). However, less emphasis has been given to origins of crystal-poor rhyolites which are generally thought have been extracted from a mush zone and accumulated at shallow crustal levels prior to eruption.

Within the current framework of the crystal mush model, two consequences are of considerable importance to the study of crystal-poor rhyolites, particularly those of 'supereruption' size such as the Oruanui considered here. (1) First, that large volumes of evolved melt may be present and available for extraction from a mush zone at any given point in time. (2) If a voluminous crystal-poor rhyolite magma body is thought to originate first from a crystal-rich reservoir then, by implication, crystal-melt segregation on a massive scale is required to occur at some stage prior to eruption. Recognition of these two consequences leads to two further important questions about the nature of the crystal archive in crystal-poor magma bodies. First, is the physical process of separating huge volumes of melt from a crystalline mush source recorded, in any tangible way, in the crystals themselves? Second, if large-scale crystal-liquid separation processes can be shown to have occurred, what temporal and physical constraints can be placed on these events? Also pertinent to the study of crystal-poor rhyolites in particular is consideration of what proportion of a single crystal's history can be attributed to growth within the melt-rich 'holding chamber' from which it ultimately erupted. Consideration of this point raises 
questions of what crystals may be considered phenocrystic versus antecrystic versus xenocrystic, and the possibility arises that a given crystal may contain domains that could be attributed to all three origins.

In this paper we combine information from individual crystal phases to document the timing of pre- and syn-eruptive processes that culminated in the world's youngest supereruption, the $\sim 25.4 \mathrm{ka}$ Oruanui eruption from Taupo, New Zealand. To achieve this we present and discuss a dataset that integrates both new and published geochemical and petrological data at whole-rock and single crystal scales (see Table 4.1 for details). The new results include a comprehensive dataset of in situ major and trace element compositions for plagioclase and melt inclusions in the Oruanui rhyolites and for the main mineral phases in juvenile mafic clasts. These data are given context from new and extended datasets of whole rock chemistry. Finally the specific relationships between crystal phases, and the crystal cargo as a whole, and information that they yield about the assembly of the immediately pre-eruptive Oruanui magma body, and the pre- and syn-eruptive processes that operated, are explored.

\subsection{THE ORUANUI ERUPTION}

\subsubsection{Eruption summary}

The Oruanui eruption at $25.4 \pm 0.2$ calibrated ka (Vandergoes et al. 2013) from Taupo volcano in the central North Island of New Zealand (Figure 4.1) is the youngest supereruption on Earth (Wilson 2001; Wilson et al. 2006). About $530 \mathrm{~km}^{3}$ of moderate- to high-silica rhyolite magma containing 3 to $13 \mathrm{wt} \%$ crystals were to generate estimated bulk volumes of $430 \mathrm{~km}^{3}$ of fall and $320 \mathrm{~km}^{3}$ of pyroclastic density current deposits (mostly ignimbrite), together with $\sim 420 \mathrm{~km}^{3}$ of intracaldera fill (Wilson 2001). Ten eruptive phases were identified, based on bedding characteristics in the fall deposits used to define ten fall units. The eruption was episodic with several time breaks varying in duration from probably only hours (i.e., long enough for the eruption plume to have dispersed and ash wholly settled out before the next phase began) to several weeks to months between phases 1 and 2 (Wilson 2001). Extensive degrees of magma-water interaction in the eruption caused rapid chilling and extensive fragmentation (Self and Sparks 1978; Self 1983). As a consequence, the deposits are fresh, glassy and entirely non-welded throughout. However, pumice clasts large enough for detailed study are almost entirely 
Table 4.1. Summary of the new and existing datasets integrated in this work.

\begin{tabular}{|c|c|c|c|}
\hline Material/crystal phase & $\begin{array}{l}\text { Juvenile compositions } \\
\text { covered }\end{array}$ & Data available & Data sources/key references \\
\hline \multicolumn{4}{|l|}{ Whole-rock analysis } \\
\hline Single \& multiple clasts & $\begin{array}{l}\text { HSR, LSR, CA, TH, \& } \\
\text { streaky pumices }\end{array}$ & $\begin{array}{l}\text { Major and trace elements by XRF, some } \mathrm{Sr} \text { and Nd isotopic data, limited INAA } \\
\text { trace element data }\end{array}$ & Wilson et al. (2006) \\
\hline Single clasts & HSR, BtB & Major and trace elements by XRF and ICP-MS, respectively & Allan et al. (2012) \\
\hline Single clasts & HSR and LSR & Major and trace elements by XRF & Allan et al. (2013) \\
\hline Single clasts & $\begin{array}{l}\text { TH and CA, plus } \\
\text { additional HSR samples }\end{array}$ & Major and trace elements by XRF and ICP-MS, respectively & This study \\
\hline \multicolumn{4}{|l|}{ Glass analysis } \\
\hline Bulk glass & HSR and LSR & Bulk glass separates analysed for major and trace elements by XRF & Wilson et al. (2006) \\
\hline Fall deposits & $\begin{array}{l}\text { Equivalent to HSR } \\
\text { groundmass }\end{array}$ & Major and trace element EPMA and LA-ICP-MS, respectively & $\begin{array}{l}\text { Allan et al. (2008); Vandergoes et } \\
\text { al. (2013) }\end{array}$ \\
\hline Matrix glass & HSR & Major elements by EPMA & Allan et al. (2012) \\
\hline Matrix glass & LSR & Major elements by EPMA & This study \\
\hline Quartz-hosted melt inclusions & HSR & Volatiles by FTIR, trace elements by ion probe, limited EPMA & Liu et al. (2006) \\
\hline Quartz-hosted melt inclusions & HSR & Major and trace elements by EPMA and LA-ICP-MS, respectively & This study \\
\hline Plag-host melt inclusions & LSR & Major and trace elements by EPMA and LA-ICP-MS, respectively & This study \\
\hline \multicolumn{4}{|l|}{ Mineral analysis - rhyolites } \\
\hline Quartz & HSR & Trace elements by ion probe, $\mathrm{CL}$ imaging & Liu et al. (2006) \\
\hline Amphibole & HSR, BtB, LSR & Major and trace elements by EPMA and LA-ICP-MS, respectively & Allan et al. $(2012 ; 2013)$ \\
\hline Orthopyoxene & HSR, LSR & Major and trace elements by EPMA and LA-ICP-MS, respectively & Allan et al. (2013) \\
\hline Fe-Ti oxides & HSR, LSR & Major elements measured by EPMA & Wilson et al. (2006) \\
\hline Plagioclase & HSR, LSR & Major and trace elements by EPMA and LA-ICP-MS, respectively & This study \\
\hline Zircon & HSR & $\mathrm{U} / \mathrm{Th}$ age apectra & $\begin{array}{l}\text { Charlier et al. (2005); Wilson and } \\
\text { Charlier (2009) }\end{array}$ \\
\hline \multicolumn{4}{|l|}{ Mineral analysis - mafic magmas } \\
\hline Plagioclase & $\mathrm{CA}, \mathrm{TH}$ & Major and trace elements by EPMA and LA-ICP-MS, respectively & This study \\
\hline Amphibole & $\mathrm{CA}, \mathrm{TH}$ & Major and trace elements by EPMA and LA-ICP-MS, respectively & This study \\
\hline Orthopyroxene & $\mathrm{CA}, \mathrm{TH}$ & Major and trace elements by EPMA and LA-ICP-MS, respectively & This study \\
\hline Clinopyroxene & $\mathrm{CA}, \mathrm{TH}$ & Major and trace elements by EPMA and LA-ICP-MS, respectively & This study \\
\hline Olivine & $\mathrm{CA}, \mathrm{TH}$ & Major and trace elements by EPMA and LA-ICP-MS, respectively & This study \\
\hline Fe-Ti oxides & $\mathrm{CA}, \mathrm{TH}$ & Major and trace elements by EPMA and LA-ICP-MS, respectively & This study \\
\hline
\end{tabular}

$\mathrm{HSR}$ - High $\mathrm{SiO}_{2}$ rhyolite (>74 wt\% $\mathrm{SiO}_{2}$ ); LSR - Low-SiO 2 rhyolite (<74 wt\%); CA - calc-alkaline mafic magma; TH - tholeiitic mafic magma; $\mathrm{BtB}$ - biotite-bearing rhyolite (See Table 2) 


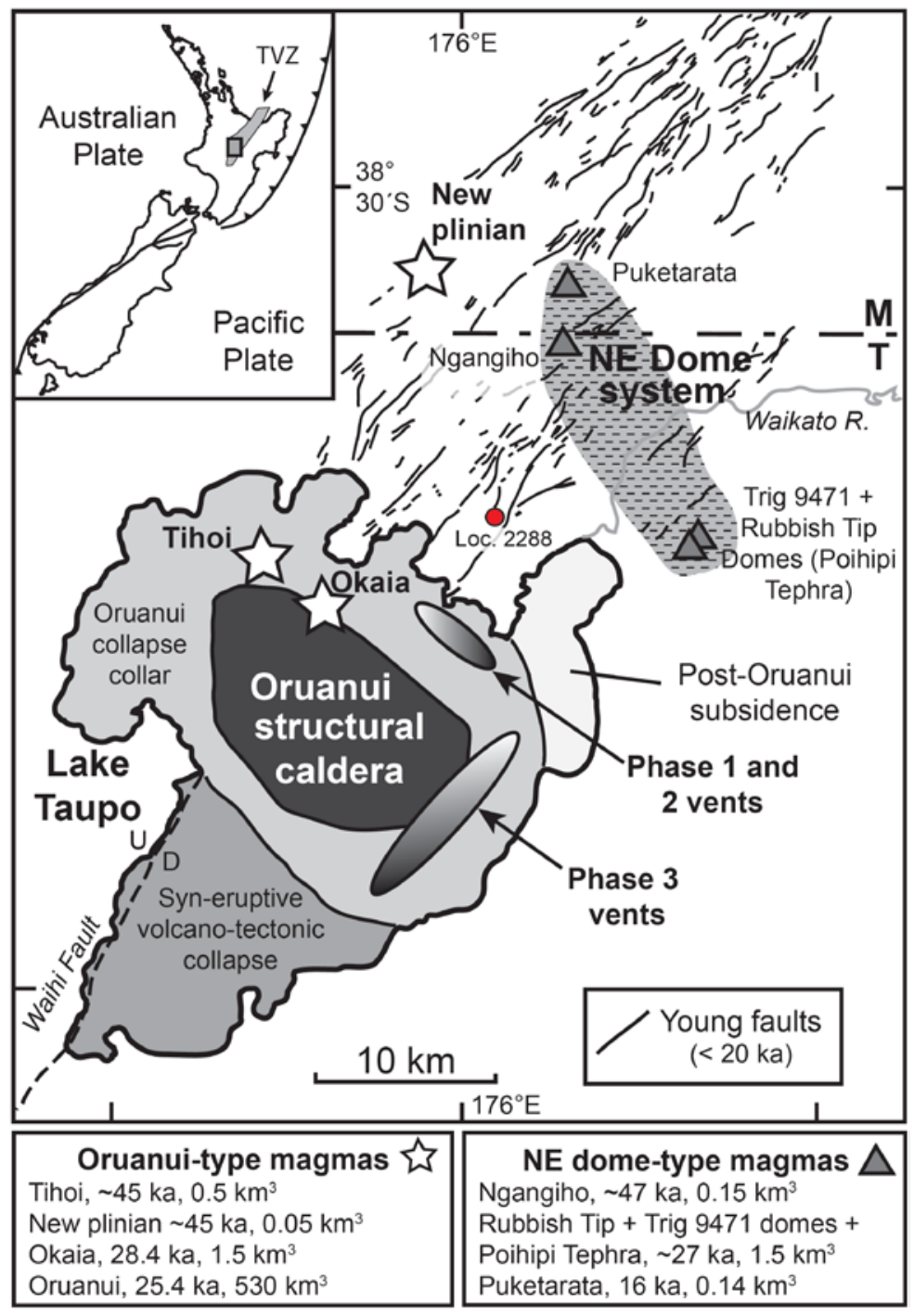

Figure 4.1. Key volcano-tectonic features of the Taupo-Maroa area, located in the central North Island of New Zealand (inset: TVZ - Taupo Volcanic Zone). Caldera structure and vent envelope for phases 1, 2 and 3 of the Oruanui eruption are from Wilson (2001). The NE-SW alignment of 'young' faults (ruptures < 20 kyr old: GNS Science 2013) form the axis of regional extension in the modern TVZ. Dashed line marks the boundary between Taupo (T) and Maroa (M) volcanoes (Sutton et al. 1995). The stippled grey region encompasses the NE Dome magmatic system and associated biotiterhyolite domes erupted in the last $\sim 50 \mathrm{kyr}$ (triangles - after Sutton et al. 1995). Modified from Wilson and Charlier (2009).

restricted to the ignimbrite, although proximal fall units 1 and 2 also have yielded clasts suitable for detailed study. The interbedded nature of the fall deposits and ignimbrite, and spikes in the abundance of juvenile mafic material, allow the eruption phase boundaries to be linked between the fall and flow deposits (Wilson 2001), such that large pumices sampled from the ignimbrite can be placed within a time-stratigraphic context. 


\subsubsection{Juvenile products}

Juvenile products of the Oruanui eruption fall into six categories, all of which can be recognised in hand specimen from the colour, crystal content and the relative abundances of the ferromagnesian minerals. The main characteristics, approximate volumes, and key references for each of these magma types are summarised in Table 4.2. The most voluminous magma type, comprising $\geq 99 \%$ of the total erupted volume, is represented by moderate-to-highly vesicular white pumices of high- $\mathrm{SiO}_{2}$ rhyolite (HSR hereafter), compositionally defined as clasts with whole-rock $\mathrm{SiO}_{2}$ contents of $>74 \mathrm{wt} \%$. In hand sample the HSR is readily identified by the presence of quartz and a ferromagnesian assemblage that is dominated by orthopyroxene over amphibole. In contrast to the volumetrically dominant HSR, the low-SiO${ }_{2}$ rhyolite pumices (LSR, whole-rock compositions of $<74 \mathrm{wt} \% \mathrm{SiO}_{2}$ ) can be distinguished by the lack of quartz and dominance

Table 4.2. Juvenile products of the Oruanui eruption.

\begin{tabular}{|c|c|c|c|c|}
\hline Magma type & Features & $\begin{array}{l}\text { Approximate } \\
\text { magma } \\
\text { volume }\end{array}$ & $\begin{array}{l}\text { Abbreviations } \\
\text { used in this } \\
\text { paper }\end{array}$ & Key references \\
\hline High-SiO ${ }_{2}$ rhyolite & $\begin{array}{l}\text { Whole-rock } \mathrm{SiO}_{2}>74 \\
\text { wt\%; } 3-13 \% \text { crystals; qtz- } \\
\text { bearing, opx>amph }\end{array}$ & $\begin{array}{c}525 \mathrm{~km}^{3} \\
(>99 \% \text { of } \\
\text { total volume })\end{array}$ & HSR & $\begin{array}{l}\text { Wilson et al. (2006); Liu et al. } \\
\text { (2006); Allan et al. (2012, } \\
\text { 2013) }\end{array}$ \\
\hline Low-SiO ${ }_{2}$ rhyolite & $\begin{array}{l}\text { Whole-rock } \mathrm{SiO}_{2}<74 \\
\text { wt } \% \text {, qtz-free, amph>opx. } \\
\text { Greatest abundance in } \\
\text { phase } 3 \text { and } 6 \text { deposits. }\end{array}$ & $0.5 \mathrm{~km}^{3}$ & LSR & $\begin{array}{l}\text { Wilson et al. (2006); Allan et } \\
\text { al. }(2012,2013)\end{array}$ \\
\hline $\begin{array}{l}\text { Biotite-bearing } \\
\text { rhyolite }\end{array}$ & $\begin{array}{l}\text { Biotite-bearing, } 12-24 \% \\
\text { crystals. Rhyolite derived } \\
\text { from an adjacent } \\
\text { magmatic system during } \\
\text { phases } 1 \text { and } 2\end{array}$ & $0.03 \mathrm{~km}^{3}$ & BtB & Allan et al. (2012) \\
\hline Juvenile mafic 1 & $\begin{array}{l}\text { Calc-alkaline trend, olivine } \\
\text { common, finer } \\
\text { groundmass texture }\end{array}$ & $1-2 \mathrm{~km}^{3}$ & $\mathrm{CA}$ & $\begin{array}{l}\text { Sutton (1995); Wilson et al. } \\
(2006)\end{array}$ \\
\hline Juvenile mafic 2 & $\begin{array}{l}\text { Tholeiitic trend, sugary } \\
\text { recrystallised } \\
\text { groundmass, olivine rare }\end{array}$ & $1-2 \mathrm{~km}^{3}$ & $\mathrm{TH}$ & $\begin{array}{l}\text { Sutton (1995); Wilson et al. } \\
(2006)\end{array}$ \\
\hline $\begin{array}{l}\text { Streaky/mixed } \\
\text { pumices }\end{array}$ & $\begin{array}{l}\text { Streaky mixtures that fall } \\
\text { along a trend of least } \\
\text { evolved tholeiite mafic } \\
\text { magma and HSR. } \\
\text { Exceedingly rare as hand } \\
\text { specimens }\end{array}$ & - & - & $\begin{array}{l}\text { Sutton (1995); Wilson et al. } \\
(2006)\end{array}$ \\
\hline
\end{tabular}


of amphibole over orthopyroxene. Allan et al. (2013) argued that, rather than representing a compositional continuum within a uniform magma body, the HSR and LSR magmas were separate magma bodies (see also Results section below) that only encountered each other syn-eruptively. Two other minor but significant rhyolitic components to the Oruanui eruption products have previously been identified. Sutton (1995) and Wilson et al. (2006) noted that a small sub-group of rhyolite pumices had higher $\mathrm{MgO}$ contents at a given value of $\mathrm{SiO}_{2}$ and attributed this to mixing of what we term here HSR with more mafic compositions. A further rhyolite type, sampled as denser, more crystalline, biotite-bearing rhyolite pumices in fall units 1 and 2 was identified by Allan et al. (2012) and identified by them as a foreign magma sourced from the independent and geographically distinct NE dome system (Sutton et al. 1995; Figure 4.1). The biotite-bearing magma was interpreted to have been fed laterally into the Oruanui conduit at the onset of eruption and throughout phases 1 and 2 (Allan et al. 2012). Due to their minor volumes and late-stage origins, neither the high-Mg nor biotite-bearing rhyolites are discussed further here.

Clasts of juvenile mafic magma from two physically and chemically distinct lineages have been identified within the Oruanui deposits: an olivine-bearing calc-alkaline group and a tholeiitic group in which olivine is very rare. Based on detailed componentry of ash-grade material from the fall deposits (Wilson 2001), together the two mafic magmas contributed an estimated 3-5 $\mathrm{km}^{3}$ of the total erupted magma volume. The occurrence of the mafic magmas as macroscopic clasts suitable for detailed study, however, is uncommon and, as such, the relative proportions of the calc-alkaline to tholeiitic end-members are not well constrained. Although there is considerable variability, the tholeiitic clasts in general have a more mature, mushy looking groundmass in hand specimen whereas calc-alkaline examples appear fresher and glassier. The mafic clasts are inferred to be juvenile on the basis of cauliform or crenulated margins indicating the clasts themselves were hot and plastically deforming up until quenching on eruption. Most hand specimens (typically 5-7 $\mathrm{cm}$ across) also have thin adhering rinds of rhyolite and sparse micro-inclusions of vesicular rhyolitic glass (Wilson 2001; Wilson et al. 2006). The two mafic groups are compositionally distinguished on plots of whole-rock $\mathrm{SiO}_{2}$ versus $\mathrm{FeO}_{\mathrm{t}} / \mathrm{MgO}$ with both calc-alkaline and tholeiitic groups being almost entirely contained within the appropriate fields as defined by Miyashiro (1974). Wilson et al. (2006) also reported the occurrence of exceedingly rare streaky, grey pumices. Whole-rock compositional data for these streaky mixtures plotted along a trend between the least evolved tholeiitic mafic magma compositions and the HSR. Because they represent a latest-stage variant composition, we 
do not consider the streaky pumices in our work here. Rather our focus in the current work lies with the Oruanui tholeiitic and calc-alkaline mafic clasts.

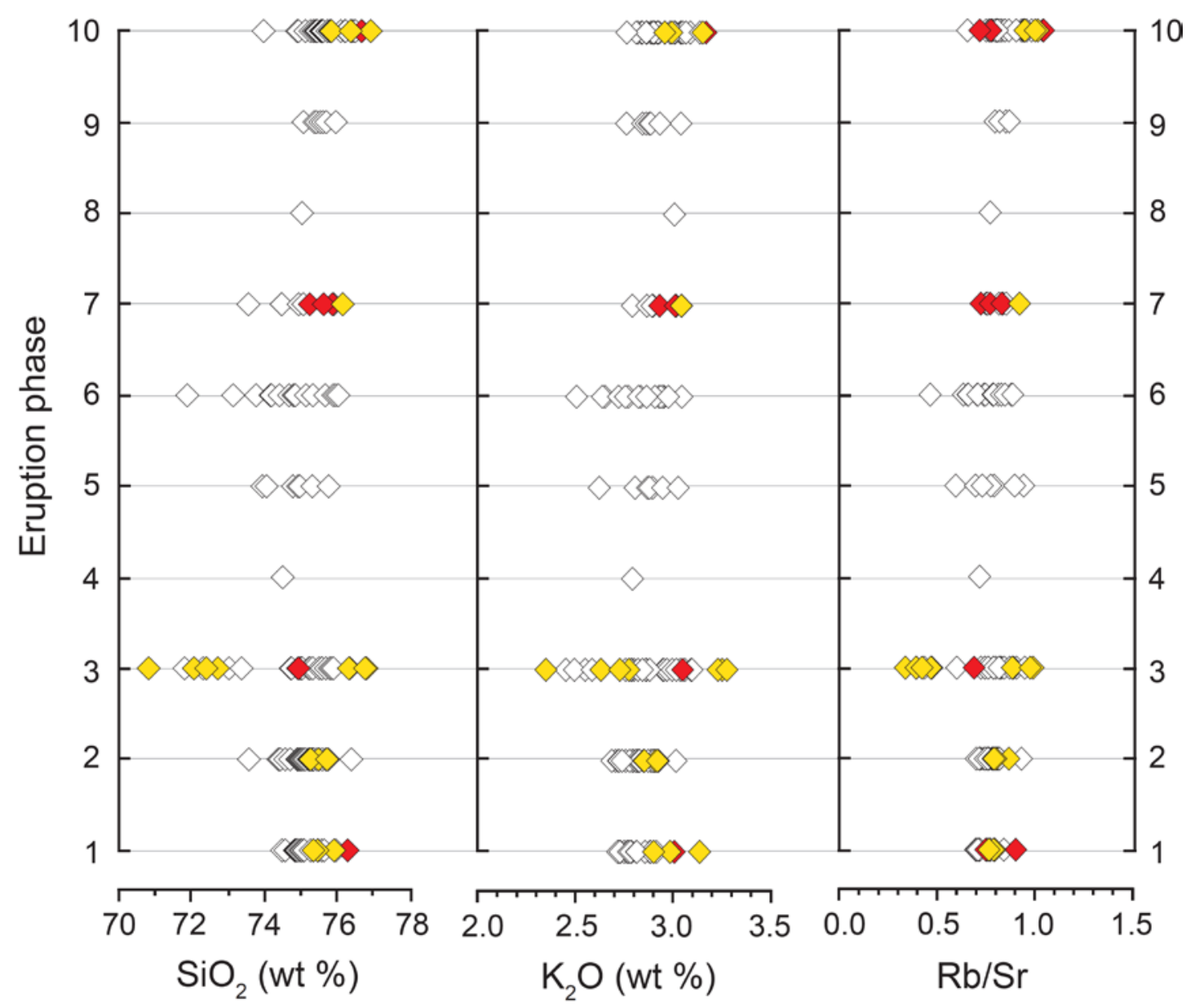

Figure 4.2. Selected whole-rock analytical data from Oruanui rhyolite pumices versus eruption phase (i.e. stratigraphic height). Open symbols are the XRF data of Wilson et al. (2006); coloured diamonds are the XRF and ICP-MS data for single pumices clasts reported here. The yellow diamonds denote pumice clasts that have been used for crystal-specific investigations in this study, and by Allan et al. (2013) and the phase 1 and 2 HSR clasts used by Allan et al. (2012), and the red diamond denote pumices for which crystal specific data has not been acquired.

\subsubsection{Samples studied}

We sampled HSR pumices from early- (phases 1 to 3), mid- (phase 7) and late- (phase 10) erupted deposits within the stratigraphic framework established by Wilson (2001). Wilson et al. (2006) showed that, although there was notable compositional variability within the Oruanui rhyolites, the deposits themselves were not systematically zoned with respect to stratigraphic height. Our new data confirm this interpretation (Figure 4.2). The melt- 
dominant magma body, accordingly, was inferred to have undergone thorough mixing at some stage prior to eruption (Wilson et al. 2006). In contrast, our sampling of the LSR was strategically restricted to within the phase 3 ignimbrite deposits at the Hinemaiaia Dam section in Lake Taupo Forest (locality 1086 of Wilson 2001), where LSR material was previously observed to be more abundant, to ensure sufficient recovery of LSR clasts.

Twelve newly recovered macroscopic clasts of juvenile mafic magma were sampled from the proximal phase 7 ignimbrite at the Punatekahi scoria quarry (loc. 2288 of Wilson 2001). Of the new samples, 10 fall into the tholeiitic group and 2 within the calc-alkaline group. In addition, we also used remaining material for 14 of the mafic clasts studied by Wilson et al. (2006). These samples comprised 7 clasts of each of the compositional groups.

\subsection{Analytical TechniQues}

\subsubsection{Whole rock analytical methods}

Single clasts of rhyolitic (Allan et al. 2012, 2013, this study) and mafic compositions (this study) were analysed for their bulk chemistries by X-ray fluorescence (XRF) and ICP-MS techniques. Following field collection, clasts were cleaned to remove any adhering matrix, soaked overnight in de-ionised water, and placed in a fan-forced oven at $110{ }^{\circ} \mathrm{C}$ until dry. The mafic clasts, which commonly contained thin adhering rinds of white rhyolite, were coarsely crushed using an agate mortar and pestle, so that fragments of rhyolite could be picked out prior to powdering to ensure characterisation of the mafic end-member. The clasts were then reduced to powder using an agate mill. The major element oxide compositions were determined by XRF by Spectrachem Analytical (CRL Energy LTD, Wellington, New Zealand). The international rock standards BHVO-2 (USGS, Hawaiian basalt), BCR-2 (USGS, Columbia River basalt), and JR1 (JGS, rhyolite) were analysed during the same sessions. Data for these standards are summarised in the supplementary material of Allan et al. (2013).

Trace element compositions of rhyolitic and mafic clasts were determined using an Agilent 7500CS ICP-MS at Victoria University of Wellington. Sample and standard powders were digested using conventional $\mathrm{HF}+\mathrm{HNO}_{3}$ methods for which 50 drops of concentrated $\mathrm{HF}$ and 15 drops of concentrated $\mathrm{HNO}_{3}$ were added to $50 \mathrm{mg}$ of powder, capped in $23 \mathrm{~mL}$ Savillex Teflon beakers and placed on a hotplate at $120^{\circ} \mathrm{C}$. After 48 hours the caps to the beakers were removed and the sample-acid solution allowed to reduce to incipient dryness before two further stages of digestion took place in $6 \mathrm{M} \mathrm{HCl}$, followed by concentrated 
$\mathrm{HNO}_{3}$ before the final dissolution in $9 \mathrm{~mL}$ of $1 \mathrm{M} \mathrm{HNO}_{3}$. All acids were ultra-high purity Optima acids. Calculation of trace element concentrations were determined from raw count rates, after correction for off-peak zeros, by reference to the known elemental concentrations of the BHVO-2 whole-rock standard, and utilising ${ }^{43} \mathrm{Ca}$ is used as an internal standard with the $\mathrm{CaO}$ content of samples previously determined to $\sim 1 \%$ by XRF. The international rock-powder standards, BCR-2, BHVO-2 and JR-1, were analysed under identical conditions and during the same analytical sessions as the Oruanui rhyolitic (Allan et al. 2012) and mafic samples (this study). Data for these standards are available in the online supplementary information of Allan et al. (2012).

One aspect of the whole-rock trace element technique that is worth highlighting here is that the conventional $\mathrm{HF}-\mathrm{HNO}_{3}$ digestion methods that we employed do not necessarily result in complete digestion of zircon. As a result the ICP-MS data for single clasts of zircon-bearing rhyolite reported by Allan et al. (2012), and expanded on here, underestimate the true concentrations of $\mathrm{Zr}$ and $\mathrm{Hf}$. This conclusion is indicated by the fact the mean Zr concentration of our HSR samples measured by ICP-MS (mean $=118$ ppm, range $=107-134 \mathrm{ppm}$ ) are noticeably lower in comparison to the values of Wilson et al. (2006) determined by XRF (mean $=155 \mathrm{ppm}$, range 132-176 ppm) for rhyolites covering the same $\mathrm{SiO}_{2}$ range. Other elements, however, are entirely consistent between the two datasets; e.g., mean $\mathrm{Sr}_{\text {ICP-MS }}=123$ ppm (ranging 107-141 ppm), versus mean $\mathrm{Sr}_{\mathrm{XRF}}$ $=123$ ppm (ranging 102-138 ppm).

\subsubsection{In-situ analytical methods}

The in situ analysis of glass and mineral phases of the Oruanui eruption products considered here (Allan et al. 2012 2013, and new data) were determined using a JEOL JXA-8230 EPMA and a New Wave 193 nm laser ablation system coupled to an Agilent 7500CS ICP-MS at Victoria University of Wellington. Glass analyses by EPMA were conducted at an accelerating voltage of $15 \mathrm{kV}$ and current of $8 \mathrm{nA}$ with the beam defocussed to $10 \mu \mathrm{m}$ and count times for $\mathrm{Na}$ reduced to minimise the effects of alkali-loss. Mineral analyses by EPMA were conducted at $12 \mathrm{nA}$ under a focussed electron beam $(\sim 2$ $\mu \mathrm{m})$. Standardisation was determined using a series of natural and synthetic standards, chosen to match as closely as possible the matrix composition of the material being analysed. Secondary mineral standards (Engels' amphibole, Johnstown hypersthene, NMNH 115900 plagioclase, Kakanui augite, Springwater olivine) and glass standards 
(ATHO-G, VG-A99, VG-568) were analysed throughout the analytical sessions to monitor signal stability and inform estimates of precision and accuracy.

Trace element analysis by LA-ICP-MS utilised the technique developed by Pearce et al. (1996) where a minor isotope of a major element (typically ${ }^{29} \mathrm{Si}$ or ${ }^{43} \mathrm{Ca}$ ), previously determined by EPMA, is included in the ICP-MS analysis and used as an internal standard. For analysis of the ferromagnesian mineral phases, the USGS basaltic glass standard, BHVO-2G, was used as the calibration standard, whereas the artificial glass, NIST612, was used for analysis of plagioclase and melt inclusions. The ICP-MS was tuned by adjusting the positions of the torch, lenses, and the inflow of ultra-pure He while rastering at 2 $\mu \mathrm{m} / \mathrm{sec}$ across the calibration standard. Data for samples and standards were collected under identical conditions during $60 \mathrm{~s}$ acquisitions (plus $60 \mathrm{~s}$ for backgrounds), under a static laser beam of 25 to $35 \mu \mathrm{m}$ diameter, and pulsed at $5 \mathrm{~Hz}$. Analytical data were reduced using the Iolite software package using the trace element (Internal Standard) data reduction scheme (Hellstrom et al. 2008). The raw time-resolved signal from each analysis was scrutinised to identify and remove any data compromised by the accidental ablation of contaminant (non-targeted) phases, before final trace element contents were calculated. Estimates of precision and accuracy of LA-ICP-MS data are informed by repeat analyses of the glass standards BCR-2G (USGS, Columbia River basalt), and ATHO-G (MPI-DING, Icelanic rhyolite). Data for these standards appear in Appendix 1.

\subsection{RESULTS}

\subsubsection{Oruanui rhyolite compositions}

\subsubsection{Whole rock and glass chemistry}

The whole-rock analytical dataset of Wilson et al. (2006) established the compositional end-members within the juvenile eruption products, and the chemical trends within them. We use our whole-rock data here primarily to confirm our sampling and categorisation of the relevant magma-types (i.e., HSR, LSR, and calc-alkaline and tholeiitic mafic magmas), and to provide context for our crystal-specific data. Figure 4.2 illustrates how our rhyolite samples fit with respect to the data of Wilson et al. (2006). In particular, our new data significantly extend the dataset for high-precision determinations of relatively low abundance trace elements, particularly REEs and $\mathrm{Pb}, \mathrm{Th}, \mathrm{U}$. Representative analyses of HSR and LSR are presented in Table 4.3, with the full datasets presented in the Electonic Appendices. 
Table 4.3. Representative major (XRF) and trace element (ICP-MS) analyses of Oruanui rhyolitic clasts.

\begin{tabular}{|c|c|c|c|c|c|c|c|c|c|c|}
\hline $\begin{array}{l}\text { Sample no } \\
\text { Eruption phase }\end{array}$ & $\begin{array}{c}\text { P1957-3 } \\
1 \\
\end{array}$ & $\begin{array}{c}\text { P1959 } \\
1 \\
\end{array}$ & $\begin{array}{c}\mathrm{P} 2110 \mathrm{~F} \\
3 \\
\end{array}$ & $\begin{array}{c}\text { P1676 } \\
3 \\
\end{array}$ & $\begin{array}{c}\text { P2075 } \\
7 \\
\end{array}$ & $\begin{array}{c}\text { P2059 } \\
10 \\
\end{array}$ & $\begin{array}{c}\mathrm{P} 1670 \\
3 \\
\end{array}$ & $\begin{array}{c}\text { P2110C } \\
3 \\
\end{array}$ & $\begin{array}{c}\mathrm{P} 2110 \mathrm{~A} \\
3 \\
\end{array}$ & $\begin{array}{c}\text { P2110B } \\
3 \\
\end{array}$ \\
\hline $\mathrm{SiO}_{2}$ & 75.90 & 75.33 & 76.31 & 76.76 & 76.14 & 75.83 & 70.80 & 72.05 & 72.71 & 72.39 \\
\hline $\mathrm{TiO}_{2}$ & 0.19 & 0.22 & 0.18 & 0.16 & 0.20 & 0.17 & 0.47 & 0.40 & 0.37 & 0.38 \\
\hline $\mathrm{Al}_{2} \mathrm{O}_{3}$ & 13.19 & 13.30 & 12.97 & 12.81 & 12.84 & 13.78 & 14.96 & 14.56 & 14.39 & 14.52 \\
\hline $\mathrm{Fe}_{2} \mathrm{O}_{3}$ & 1.72 & 1.92 & 1.69 & 1.60 & 1.81 & 1.68 & 3.25 & 2.93 & 2.82 & 2.87 \\
\hline $\mathrm{MnO}$ & 0.06 & 0.06 & 0.06 & 0.05 & 0.06 & 0.05 & 0.10 & 0.10 & 0.09 & 0.09 \\
\hline $\mathrm{MgO}$ & 0.27 & 0.37 & 0.26 & 0.22 & 0.26 & 0.20 & 0.76 & 0.63 & 0.59 & 0.55 \\
\hline $\mathrm{CaO}$ & 1.65 & 1.81 & 1.55 & 1.42 & 1.50 & 1.41 & 2.81 & 2.38 & 2.25 & 2.33 \\
\hline $\mathrm{Na}_{2} \mathrm{O}$ & 4.04 & 4.07 & 3.70 & 3.68 & 4.11 & 3.87 & 4.35 & 4.21 & 3.91 & 4.05 \\
\hline $\mathrm{K}_{2} \mathrm{O}$ & 2.98 & 2.90 & 3.23 & 3.27 & 3.04 & 2.99 & 2.35 & 2.63 & 2.77 & 2.73 \\
\hline $\mathrm{P}_{2} \mathrm{O}_{5}$ & 0.02 & 0.03 & 0.04 & 0.03 & 0.04 & 0.02 & 0.13 & 0.10 & 0.09 & 0.10 \\
\hline LOI & 2.82 & 3.41 & 3.44 & 3.36 & 2.76 & 3.39 & 3.91 & 4.14 & 4.63 & 4.47 \\
\hline SUM & 96.80 & 96.15 & 95.80 & 96.62 & 96.63 & 95.96 & 95.68 & 95.14 & 94.58 & 94.63 \\
\hline $\mathrm{FeO}^{*} / \mathrm{MgO}$ & 5.82 & 4.64 & 5.81 & 6.54 & 6.23 & 7.51 & 3.84 & 4.16 & 4.27 & 4.73 \\
\hline $\mathrm{Li}$ & 31.0 & 28.4 & 13.7 & 13.5 & 35.8 & 29.0 & 16.6 & 15.5 & 25.7 & 25.5 \\
\hline $\mathrm{Sc}$ & 5.73 & 6.81 & 5.89 & 5.33 & 6.68 & 5.99 & 11.9 & 10.21 & 10.6 & 10.1 \\
\hline $\mathrm{Ti}$ & 1084 & 1355 & 1101 & 970 & 1266 & 1031 & 2824 & 2419 & 2305 & 2234 \\
\hline V & 5.96 & 10.8 & 5.87 & 4.67 & 6.24 & 4.51 & 16.1 & 8.46 & 9.50 & 9.58 \\
\hline $\mathrm{Cr}$ & 1.18 & 4.30 & 1.30 & 0.82 & 0.54 & 2.23 & 1.17 & 2.43 & 4.49 & 3.40 \\
\hline Co & 1.28 & 1.95 & 1.78 & 1.15 & 1.20 & 0.98 & & & & \\
\hline $\mathrm{Ni}$ & $\mathrm{N} / \mathrm{A}$ & $\mathrm{N} / \mathrm{A}$ & N/A & N/A & 1.51 & 1.26 & & & & \\
\hline $\mathrm{Cu}$ & 4.54 & 4.63 & 3.13 & 3.15 & 3.07 & 4.07 & 2.86 & 4.15 & 5.75 & 4.64 \\
\hline $\mathrm{Zn}$ & 55.6 & 61.5 & 62.6 & 57.6 & 45.9 & 45.2 & 76.3 & 79.1 & 65.6 & 64.6 \\
\hline $\mathrm{Ga}$ & 15.2 & 15.6 & 15.3 & 14.8 & 14.8 & 15.2 & 17.8 & 17.5 & 17.3 & 17.1 \\
\hline $\mathrm{Rb}$ & 102 & 102 & 108 & 110 & 105 & 103 & 72.3 & 75.9 & 83.3 & 78.6 \\
\hline $\mathrm{Sr}$ & 129 & 133 & 122 & 113 & 114 & 108 & 213 & 193 & 178 & 186 \\
\hline$Y$ & 22.8 & 23.6 & 23.7 & 22.9 & 23.9 & 21.9 & 28.1 & 28.4 & 27.8 & 27.4 \\
\hline $\mathrm{Zr}$ & 114 & 123 & 112 & 108 & 120 & 114 & 280 & 270 & 264 & 272 \\
\hline $\mathrm{Nb}$ & 6.47 & 6.74 & 6.61 & 6.36 & 7.26 & 7.00 & & & & \\
\hline Cs & 5.48 & 5.42 & 6.06 & 6.03 & 4.68 & 4.40 & 3.76 & 4.03 & 4.37 & 3.43 \\
\hline $\mathrm{Ba}$ & 628 & 604 & 646 & 614 & 658 & 672 & 510 & 539 & 565 & 545 \\
\hline La & 21.5 & 21.8 & 22.7 & 22.2 & 22.5 & 21.0 & 20.5 & 21.6 & 21.4 & 21.3 \\
\hline $\mathrm{Ce}$ & 44.0 & 44.3 & 46.6 & 44.8 & 46.5 & 44.6 & 43.9 & 45.9 & 44.8 & 45.1 \\
\hline $\mathrm{Pr}$ & 4.90 & 4.97 & 5.20 & 5.07 & 5.14 & 4.79 & 5.27 & 5.47 & 5.34 & 5.33 \\
\hline $\mathrm{Nd}$ & 17.8 & 18.5 & 19.1 & 18.5 & 18.8 & 17.4 & 20.9 & 21.7 & 21.1 & 20.8 \\
\hline $\mathrm{Sm}$ & 3.60 & 3.80 & 3.89 & 3.81 & 3.85 & 3.49 & 4.60 & 4.74 & 4.61 & 4.51 \\
\hline $\mathrm{Eu}$ & 0.82 & 0.84 & 0.80 & 0.78 & 0.82 & 0.77 & 1.32 & 1.33 & 1.23 & 1.25 \\
\hline $\mathrm{Gd}$ & 3.72 & 3.90 & 3.93 & 3.79 & 3.90 & 3.59 & 4.91 & 4.87 & 4.71 & 4.63 \\
\hline $\mathrm{Tb}$ & 0.57 & 0.60 & 0.60 & 0.57 & 0.60 & 0.55 & 0.76 & 0.76 & 0.74 & 0.72 \\
\hline Dy & 3.67 & 3.81 & 3.87 & 3.69 & 3.85 & 3.54 & 4.75 & 4.76 & 4.70 & 4.56 \\
\hline $\mathrm{Ho}$ & 0.78 & 0.80 & 0.80 & 0.78 & 0.81 & 0.74 & 1.02 & 1.01 & 1.00 & 0.95 \\
\hline $\mathrm{Er}$ & 2.38 & 2.46 & 2.43 & 2.37 & 2.45 & 2.24 & 2.95 & 3.00 & 2.95 & 2.86 \\
\hline $\mathrm{Tm}$ & 0.36 & 0.38 & 0.37 & 0.36 & 0.38 & 0.34 & 0.45 & 0.45 & 0.45 & 0.44 \\
\hline $\mathrm{Yb}$ & 2.54 & 2.64 & 2.62 & 2.58 & 2.60 & 2.39 & 3.01 & 3.03 & 3.05 & 2.97 \\
\hline Lu & 0.39 & 0.40 & 0.40 & 0.39 & 0.39 & 0.36 & 0.47 & 0.47 & 0.47 & 0.46 \\
\hline $\mathrm{Hf}$ & 3.49 & 3.64 & 3.43 & 3.38 & 3.58 & 3.57 & 6.36 & 6.48 & 6.43 & 6.26 \\
\hline $\mathrm{Pb}$ & 12.7 & 12.6 & 13.2 & 13.1 & 13.1 & 13.7 & 9.91 & 10.8 & 11.4 & 11.0 \\
\hline Th & 10.7 & 10.7 & 11.1 & 11.0 & 10.6 & 11.3 & 7.44 & 7.96 & 8.60 & 8.01 \\
\hline$U$ & 2.43 & 2.40 & 2.47 & 2.55 & 2.44 & 2.37 & 1.78 & 1.89 & 1.99 & 1.93 \\
\hline $\mathrm{Rb} / \mathrm{Sr}$ & 0.79 & 0.76 & 0.88 & 0.97 & 0.92 & 0.95 & 0.34 & 0.39 & 0.47 & 0.42 \\
\hline $\mathrm{Eu} / \mathrm{Eu}^{\star}$ & 0.68 & 0.67 & 0.62 & 0.62 & 0.65 & 0.66 & 0.85 & 0.84 & 0.80 & 0.84 \\
\hline
\end{tabular}

In contrast to the glass chemistry reported by Wilson et al. (2006), from XRF analyses of bulk glass separates, the glass chemistry reported here was determined entirely by in-situ analytical techniques (EPMA and LA-ICP-MS). Compositional data from of single 
fragments of matrix glass from individual HSR and LSR pumices are summarised in Figure 4.3 and Table 4.4, with the full datasets available in the Electronic Appendices. Whereas the HSR pumices are characterised by a relatively uniform glass shard population, all LSR clasts so far analysed by EPMA have yielded bimodal glass population. The more evolved of these glass populations, which is compositionally identical to the HSR matrix glass population and glass from the widespread Oruanui fall deposits (Table 4.4), has been interpreted to reflect latest-stage entrainment HSR melt during the physical eruption of LSR magma through the voluminous HSR magma body (Allan et al. 2013). There is no mixing relationship between the two glass populations, supporting the notion that only late stage interactions between the HSR and LSR magmas occurred and justifying their treatment, here and elsewhere (Allan et al. 2013), as separate magmas.
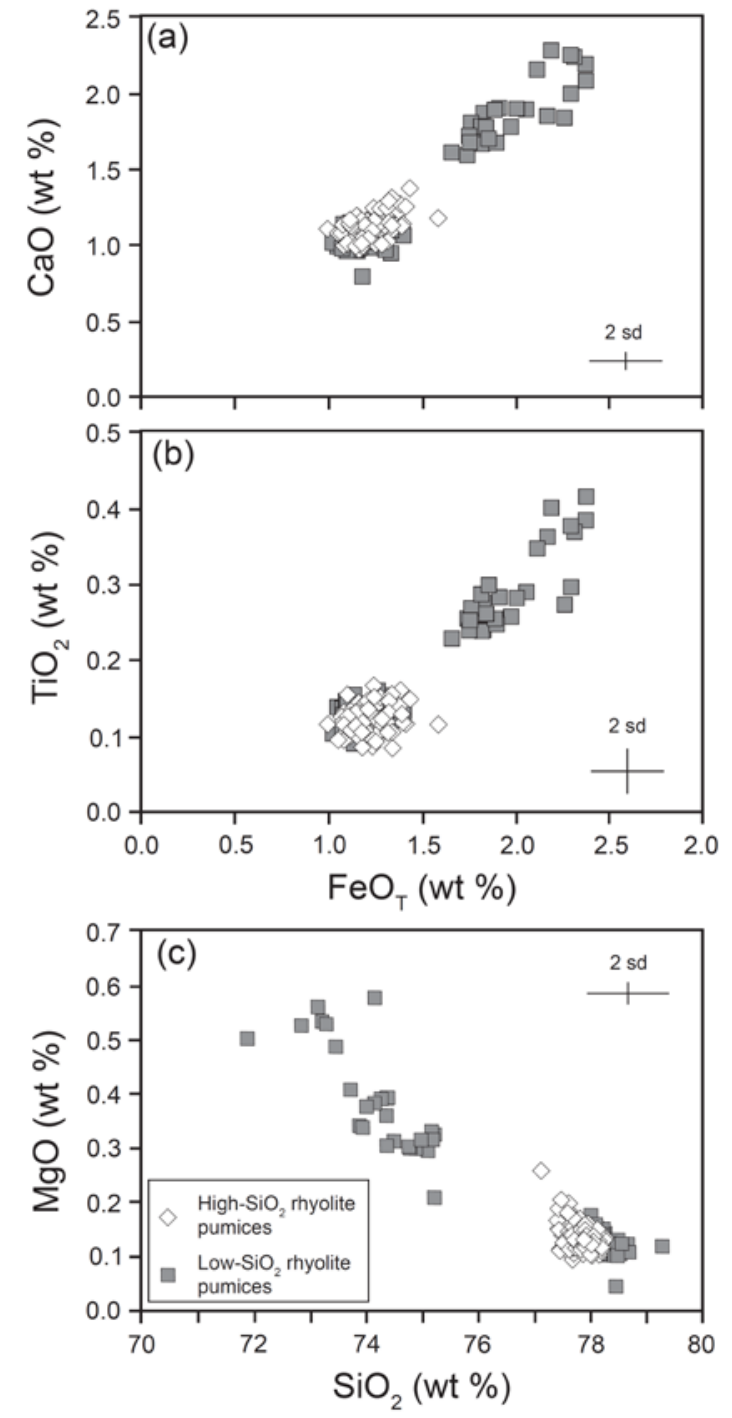

Figure 4.3. Selected major element data from fragments of pumice matrix glass in Oruanui high-silica rhyolite (HSR) and lowsilica rhyolite (LSR) clasts (see text for definitions). All LSR clasts contain bimodal glass compositions, the most evolved of which corresponds to that of the HSR clasts. The lack of a mixing/ mingling relationship between the two groups of compositions suggests that the two rhyolite magmas only encountered each other syneruptively. 
Table 4.4. Mean major element composition of glass fragments from Oruanui pumices and glass shards from distal Oruanui fall deposits.

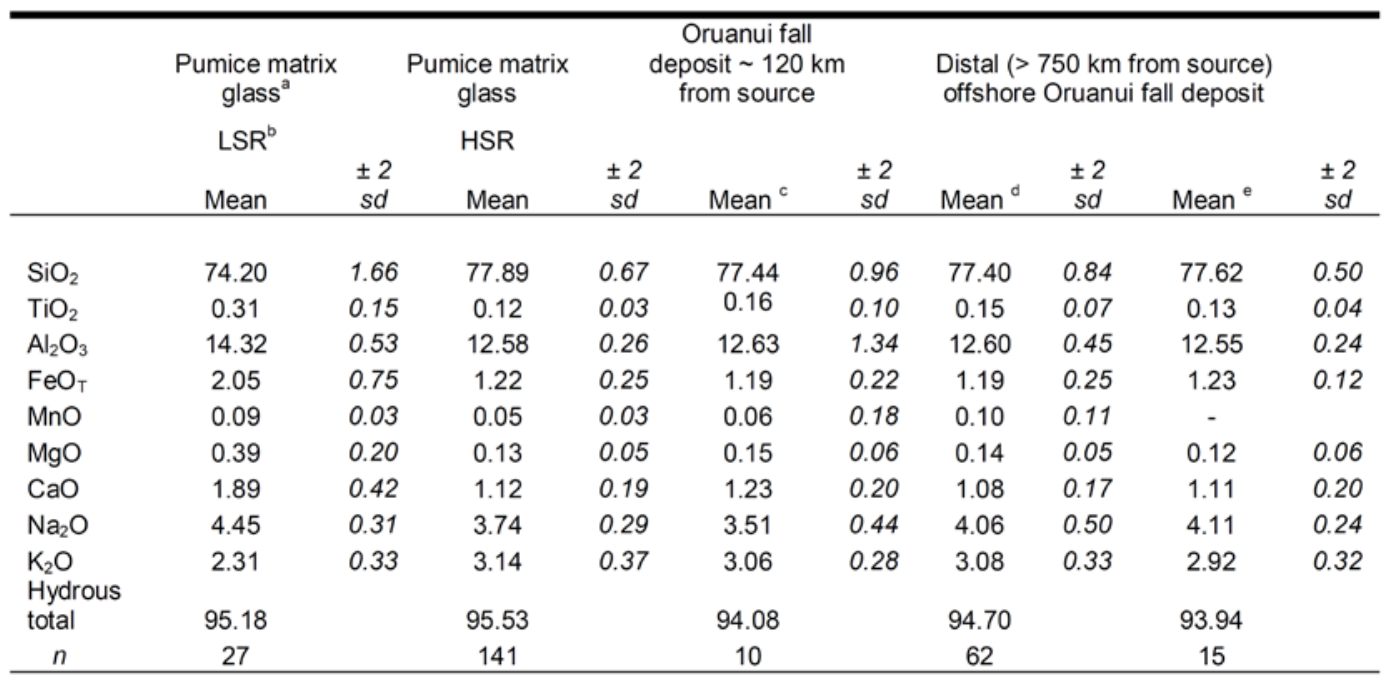

${ }^{a}$ Data for pumice matrix glass are the mean and 2 standard deviations $(2 \mathrm{sd})$ of single fragments of pumice matrix glass. ${ }^{b}$ LSR data here excludes the more evolved glass shard population inferred to represent syn-eruptively mixed in HSR melt (see Fig X. and text). ${ }^{c}$ Shulmeister et al (2001), Lake Poukawa, Hawke's Bay - sample 97/18.25. ${ }^{d}$ Allan et al. (2008), ODP Site 1123 - sample AT-331. eAlloway et al. (2005), ODP 1124 - sample AT-505. Oruanui fall deposit referred to as Kawakawa Tephra in these other studies.

Owing to their very thin bubble walls (typically $<15 \mu \mathrm{m}$ ), single fragments of pumice matrix glass were not able to measured for their trace element content by laser ablation methods which requires a beam diameter $\geq 25 \mu \mathrm{m}$ to generate high quality data. The major element compositional data, however, confirm that the HSR groundmass is compositionally identical to data from glass shards sampled from the widespread Oruanui fall deposits (Table 4.4) (e.g. Lowe et al. 2008; Allan et al. 2008; Vandergoes et al. 2013). Individual glass shards in these fall deposits are typically coarser grained ( $>40 \mu \mathrm{m}$ thick) than those typically recovered from pumice groundmass, and published in-situ trace element data is available. The trace element data for the Oruanui fall deposits reported in Allan et al. (2008) and Vandergoes et al. (2013) were determined by ASRA using identical techniques and equipment to the new glass data collected and reported here, so the datasets can be reliably compared.

New major and trace element data for trapped melt inclusions hosted in Oruanui quartz are presented in Figure 4.4. These data confirm previous inferences by Liu et al. (2006) that the glass in enclosed quartz-hosted melt inclusions in HSR samples is almost exclusively more evolved than the groundmass glass (Figure 4.4). Although there is some overlap 
between the least-evolved quartz melt inclusions and most-evolved matrix glass, these data indicate that, for at least part of their history, most Oruanui quartz crystals grew from melts that were more evolved than that which made up most of the volume of the meltdominant magma body from which they were erupted. Direct comparison of the Liu et al. (2006) quartz melt inclusion dataset with the new dataset presented here is problematic. The reasons for this are two-fold: 1) contrasting analytical methodologies and protocols were employed, and 2) issues surrounding the analysis of certain trace elements in Liu et al. (2006) (including $\mathrm{Rb}, \mathrm{Nb}, \mathrm{Zr}$, and $\mathrm{La}$ ) result in their data being offset relative to the new data reported here.

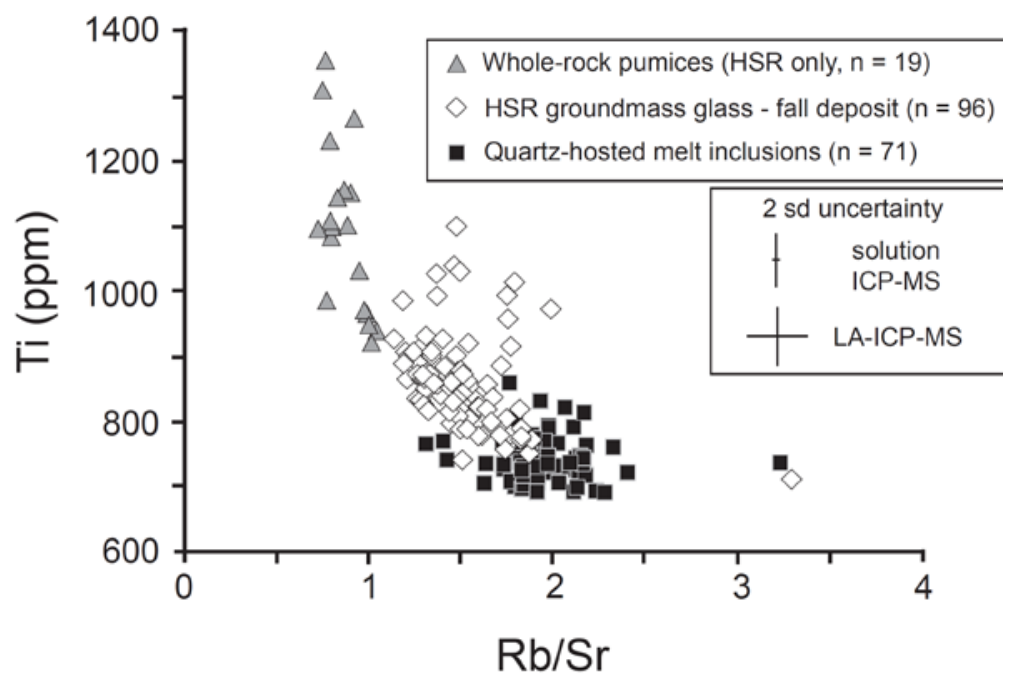

Figure 4.4. Ti versus Rb/Sr of (whole-rock) HSR pumices, HSR groundmass glass, and quartz-hosted melt inclusions. The majority of quartz-hosted melt inclusions record more evolved compositions (higher $\mathrm{Rb} / \mathrm{Sr}$ ratio and lower concentrations of compatible elements) than the groundmass glass. Data sources: HSR pumice (Allan et al. 2012 and this study); quartz-hosted melt inclusions (this study); HSR groundmass glass from Allan et al. (2008) and Vandergoes et al. (2013).

As with the HSR, LSR pumice matrix glass fragments were too fine grained for LA-ICPMS analyses. However, we were able to measure trace elements for glass in LSR samples on plagioclase selvedges where the glass was $>40 \mu \mathrm{m}$ wide and in plagioclase-hosted melt inclusions. On a plot of $\mathrm{Rb} / \mathrm{Sr}$ versus Ti there appears to be two trends within the glass data (Figure 4.5); a steeper, higher Ti array, and a shallower, lower Ti array. Analyses from both melt inclusions and selvedges appear along both trends. 


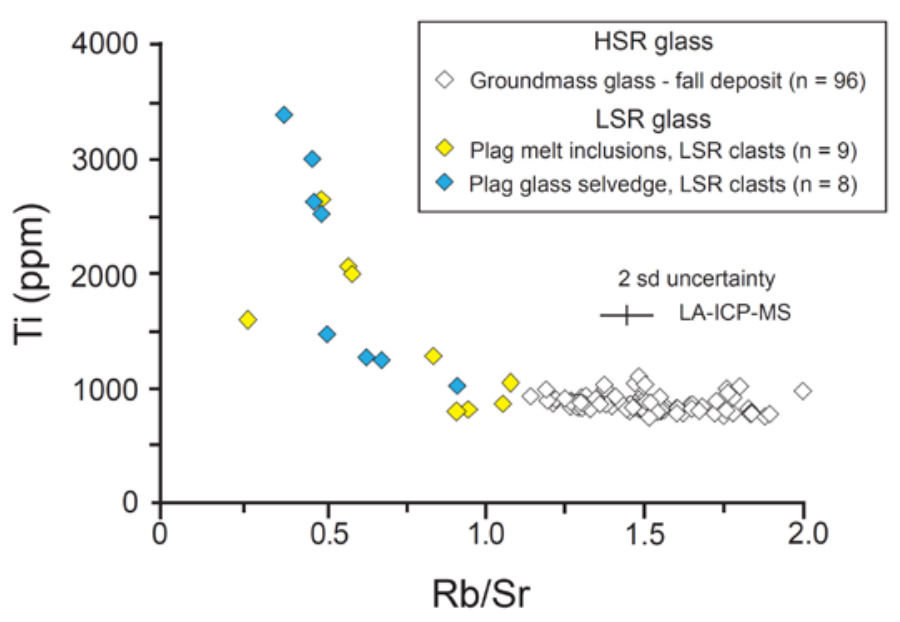

Figure 4.5. Ti versus $\mathrm{Rb} / \mathrm{Sr}$ of Oruanui rhyolite glasses. The HSR groundmass glass here is from the distal fall deposits where single glass shards are large enough for analysis by LA-ICP-MS ( $>40 \mu \mathrm{m}$ thick). The LSR glass values are from selvedges on, and melt inclusions in, plagioclase crystals in LSR clasts. The LSR glass shows two distinct trends, a steeper trend to higher Ti and a shallower, lower Ti trend.

\subsubsection{Textural linkages between crystal phases in the HSR}

Prior to in-situ chemical characterisation of the HSR and LSR mineral phases, high resolution back-scattered electron (BSE) images of each crystal were examined. These images were used to note crystal textures and zonation features and infer, where possible, a crystal stratigraphy to ensure that at least the inferred oldest and youngest, and most- and least-evolved, domains of each crystal were targeted for analysis.

Inspection of the BSE images (and cathodoluminescence [CL] images of quartz) also revealed key overarching textural and zonation features common between some of the main crystal phases, particularly in the volumetrically dominant HSR. Some of the key zonation features of orthopyroxene, plagioclase and quartz from the HSR are summarised in Figures 4.6, 4.7 and 4.8. Allan et al. (2013) noted that $~ 90 \%$ of HSR orthopyroxene (from a census of 170 grains) showed distinctive core-rim relationships, in which a more $\mathrm{Mg}$ - and inclusion-rich core was surrounded by 40-400 $\mu \mathrm{m}$ thick inclusion-poor rims that were normally zoned out to a final and consistent composition of $\mathrm{En}_{46 \pm 2}$ in the outermost parts (Figure 4.6). Complexities within this overall zonation pattern in individual orthopyroxene can be shown to result primarily from the combined effects of dissolution and recrystallisation, unequal kinetic/growth zonation and overprinting from Fe-Mg interdiffusion (Allan et al. 2013). The remaining $~ 10 \%$ of HSR orthopyroxene tended to be inclusion-poor and lacked any significant core-rim zonation. Detailed study of BSE 


\section{Orthopyroxene in Oruanui high-SiO $(>74 \mathrm{wt} \%)$ rhyolite clasts}

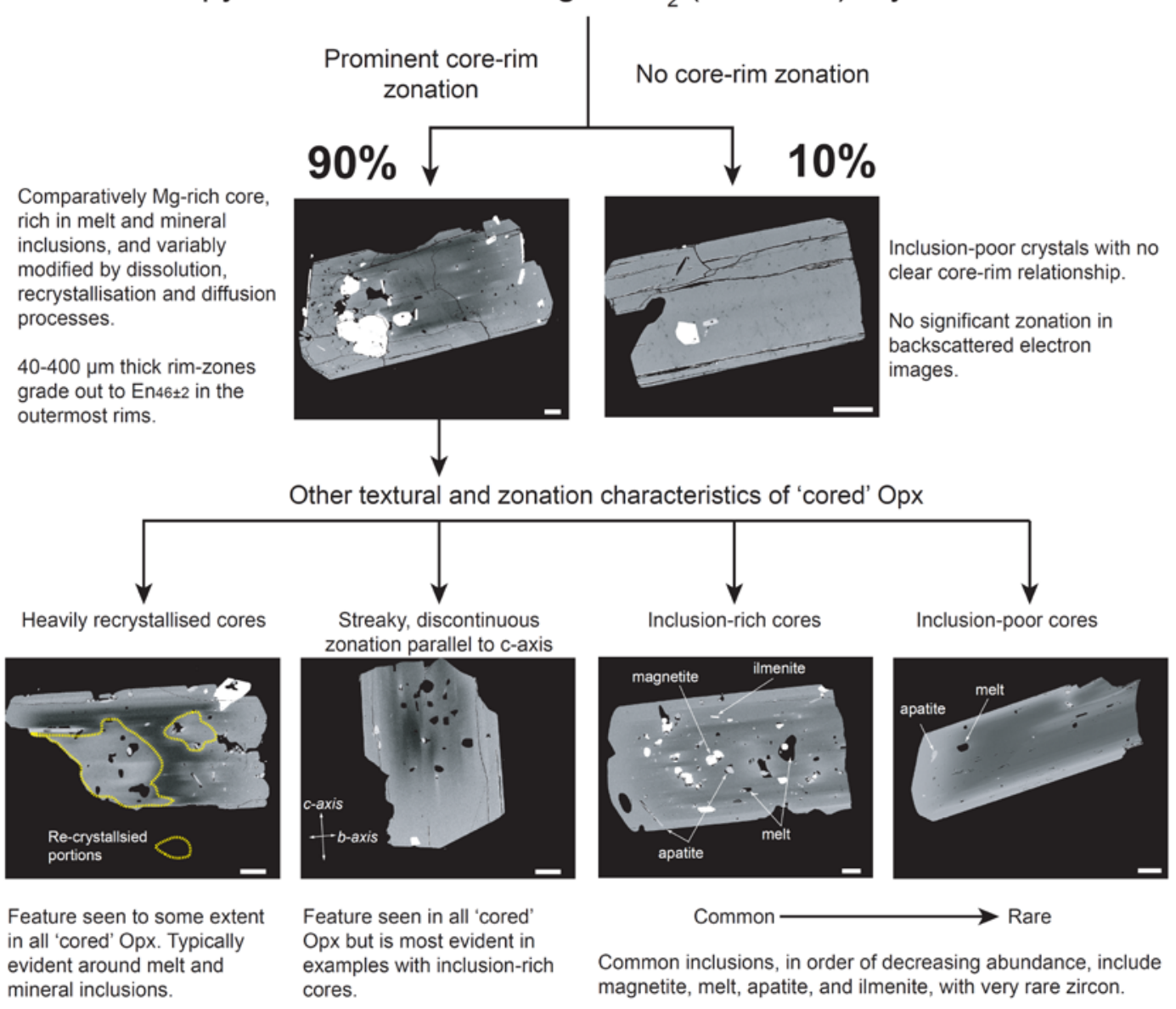

Figure 4.6. Pictorial summary of the textural and zonation characteristics of orthopyroxene from Oruanui HSR clasts. $90 \%$ of HSR orthopyroxenes have a prominent core-rim zonation in which a comparatively Mg-rich core is overgrown by a 40-400 $\mu \mathrm{m}$ thick rim-zone that grades out normally to a value of $\mathrm{En}_{46 \pm 2}$ in the outermost rim. The cores and interiors are commonly rich in melt and mineral inclusions, and are variously effected by dissolution, recrystallisation, and diffusion effects (see Allan et al. 2013). White scale bars are $100 \mu \mathrm{m}$.

images of individual HSR plagioclase crystals has revealed that the plagioclase record a similar and complementary suite of textures to the orthopyroxenes. $89 \%$ of the HSR plagioclase crystals (from a census of 168 crystals) also have a prominent core-rim zonation (Figure 4.7). This is most clearly identified by the rim-zones that in general exhibit euhedral overgrowths surrounding a resorbed core, and that are normally zoned outwards towards a final composition of $\mathrm{An}_{38 \pm 2}$ in the outermost rims. Within the $89 \%$ of plagioclase crystals that have these rim-zones, the cores can be sub-divided into two further groups: $48 \%$ which are patchy/sieve textured, and $41 \%$ that show significant resorption but no evidence of sieve texturing. The remaining $11 \%$ of HSR plagioclase that did not have a prominent 


\section{Plagioclase in Oruanui high- $\mathrm{SiO}_{2}(>74 \mathrm{wt} \%)$ rhyolite clasts}

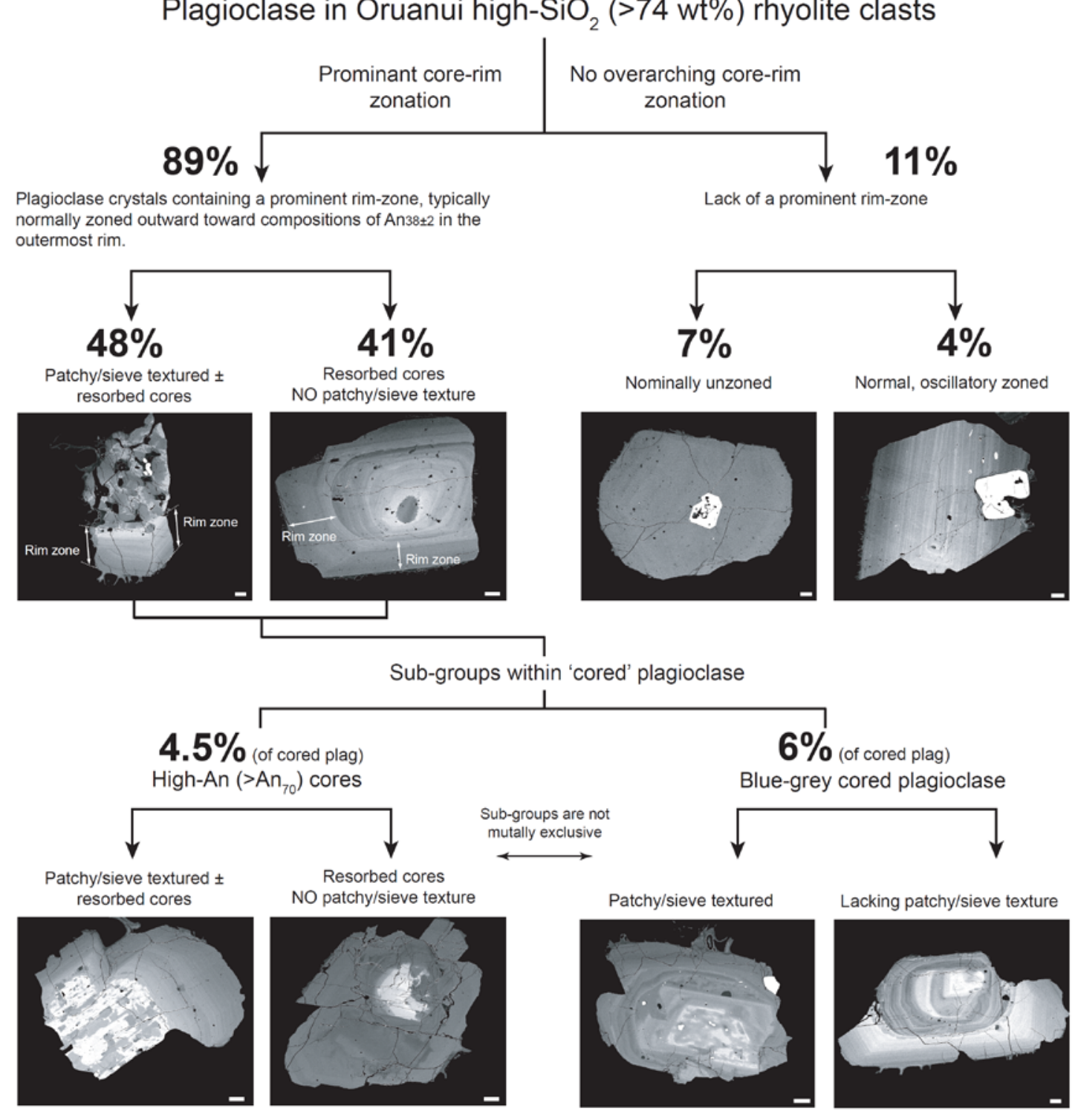

Figure 4.7. Pictorial summary of the textural and zonation characteristics of plagioclase crystals from HSR clasts. Approximately $89 \%$ of plagioclase have a prominent core-rim relationship in the backscattered electron (BSE) images. In these examples the cores are typically truncated by at least one episode of resorption and are surrounded by subhedral to euhedral overgrowths, rim-zones, normally zoned towards values of $\mathrm{An}_{38 \pm 3}$ in the outermost rims. The 'cored' plagioclase group can be further divided on the basis of the presence or absence of patchy/sieve textures in the crystal cores. Further subgroups of cored plagioclase are identifiable such as those with high $\mathrm{An}\left(>\mathrm{An}_{70}\right)$ cores and those with prominent blue-grey coloured cores when viewed in hand sample. The blue-grey colouration is imparted by exsolved needles of Fe-Ti oxides ( \pm rutile) and correspond to the plagioclase group explored in detail by Charlier et al. (2008). The remaining $\sim 11 \%$ of plagioclase that lack a prominent core-rim relationship can be separated into those that are nominally unzoned $(\sim 7 \%$; within crystal variations of $<5 \mathrm{~mol} \%)$ and those with fine wavelength $(10-20 \mu \mathrm{m})$ normal oscillatory zonation. White scale bars are $100 \mu \mathrm{m}$.

core-rim zonation were either nominally unzoned (An contents varying by $<3 \mathrm{~mol} \%$, and accounting for $\sim 7 \%$ of all HSR plagioclase), or showed normal, oscillatory zonation with no distinction between core- or rim-zones. Within the majority group of 'cored' 
plagioclase, further distinctive sub-groups were recognised, in particular, plagioclase with high-An (>70 mol\%) cores and the blue-grey cored feldspars that were studied by Charlier et al. (2008). These two sub-groups comprise around 5\% of the 'cored' feldspar population although they are not mutually exclusive.

(a)
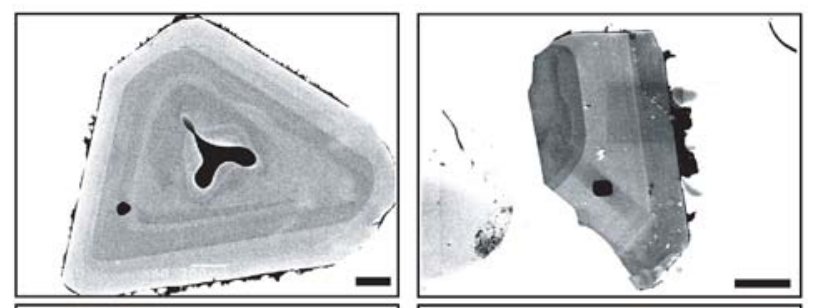

(b)
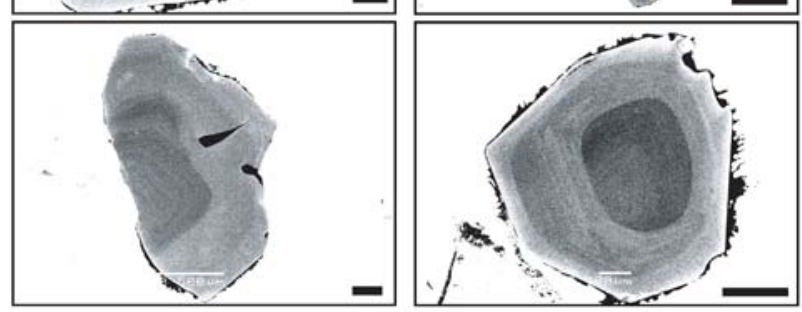

(c)
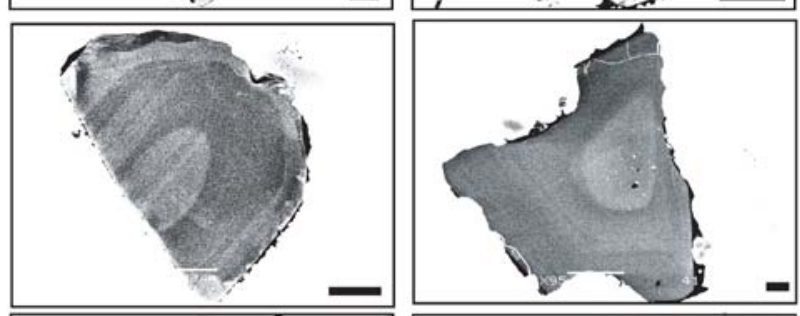

(d)
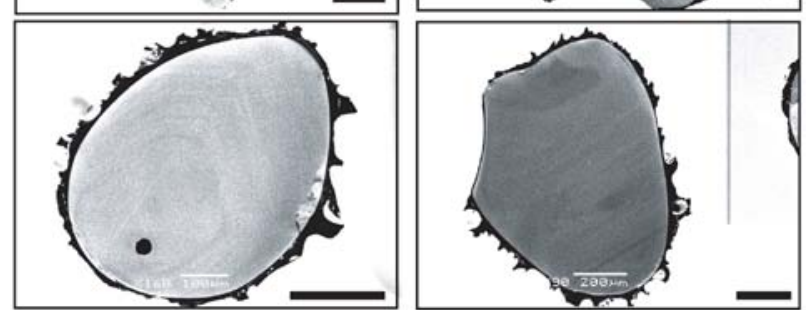

Figure 4.8. Examples of quartz zonation under cathodoluminescence (CL) imagery. (a) Multiply zoned crystals, (b) dark CL cores, bright CL rims, (c) bright CL cores, dark CL rims, (d) nominally unzoned. The black scale bars are $200 \mu \mathrm{m}$.

The HSR quartz textures in CL imagery indicate a history for the quartz that is not directly comparable to the plagioclase and orthopyroxene (Figure 4.8). Dark portions of quartz under CL are generally considered to reflect lower Ti concentrations, as opposed to brighter, higher Ti quartz (Wark et al. 2007; Matthews et al. 2012a,b). The Ti content of magmatic quartz as shown by CL imagery is generally considered to reflect thermal fluctuations in the magma from which the quartz grew, and from a qualitative sense brighter CL is generally taken to indicate hotter conditions (e.g., Wark and Watson 2006; 
Wark et al. 2007). Recent contributions, however, have suggested that changing $\mathrm{Ti}$ contents may reflect changing pressures of quartz crystallisation (Thomas et al. 2010), and/or the combined influence of changing temperature, pressure and melt compositions (Wilson et al. 2012). Regardless of the ultimate control on CL ( $\approx$ Ti) zonation in quartz, the Oruanui HSR quartz does not appear to follow an overarching zonation pattern. Some quartz have darker cores and brighter rims, and some have the opposite. Many crystals are multiply zoned with many bright and dark bands, yet some crystals are devoid of any CL zonation at all. In direct contrast to the plagioclase and orthopyroxene, the outermost quartz rims do not appear to collapse towards a consistent final zonation pattern. This is consistent, however, with the Ti-in-quartz concentration data from Liu et al. (2006) in which quartz rims show roughly the same mean $(\sim 85 \mathrm{ppm})$ and range of Ti concentrations ( $\sim 50$ to $120 \mathrm{ppm})$ as the dataset as a whole.

\subsubsection{Compositional characteristics of HSR and LSR crystals}

Plagioclase. In-situ major and trace element data for HSR and LSR plagioclase crystals are presented in Figures 4.9 and 4.10. The HSR crystals cover a considerable range of anorthite contents from $\mathrm{An}_{26}$ to $\mathrm{An}_{88}$. However, the majority of analyses have $\mathrm{An}<60$ and the majority of the outermost rims fall within the range of $\mathrm{An}_{38 \pm 2}$. A small component of the cores and interiors yields compositions more evolved than are encountered in the outermost rims $\left(\mathrm{An}_{26-35}\right)$ indicative of growth in a melt more evolved than the melt in which they were suspended on eruption. The LSR plagioclase crystals, in contrast, exhibit a more restricted range of compositions with the majority of analyses ranging between $\mathrm{An}_{38}$ and $\mathrm{An}_{60}$. The outermost rims of LSR plagioclase are relatively restricted in composition and cluster around $\mathrm{An}_{44 \pm 6}$. The LSR plagioclases show a steep positive trend between $\mathrm{An}$ and $\mathrm{FeO}_{\mathrm{t}}$ (Figure 4.9d). A plot of the same parameters for the HSR crystals hints at the possibility of two limiting trends in the cores and interiors data; a steeper and a shallower trend, that converge around the compositions of the outermost rims (Figure 4.9b).

Two end-member limiting trends are also apparent in the trace element data for cores and interiors of HSR plagioclase, when plotted against An content (Figure 4.10). Plots of Sr and $\mathrm{Mg}$ versus An content show broad positive correlations, although a component of the HSR cores and interiors form a much shallower trend with lower concentrations of Sr and $\mathrm{Mg}$ at higher values of $\mathrm{An}$. Some trace elements, such as $\mathrm{Ba}$ and $\mathrm{Pb}$, show negative trends with An, (Figure $4.10 \mathrm{c}, \mathrm{d}$ ). A subordinate population of the HSR cores and interiors, 

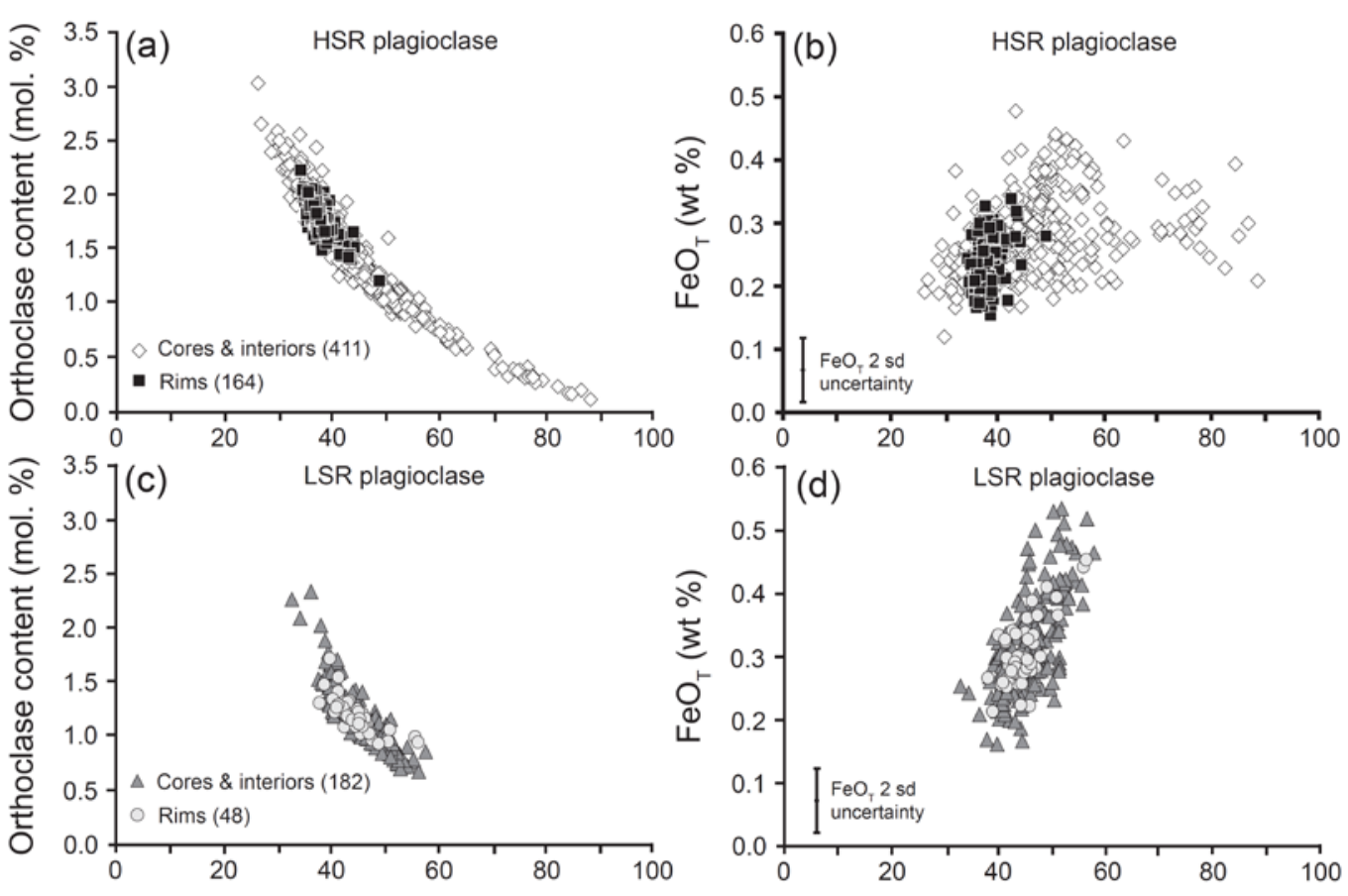

Anorthite content (mol. \%)

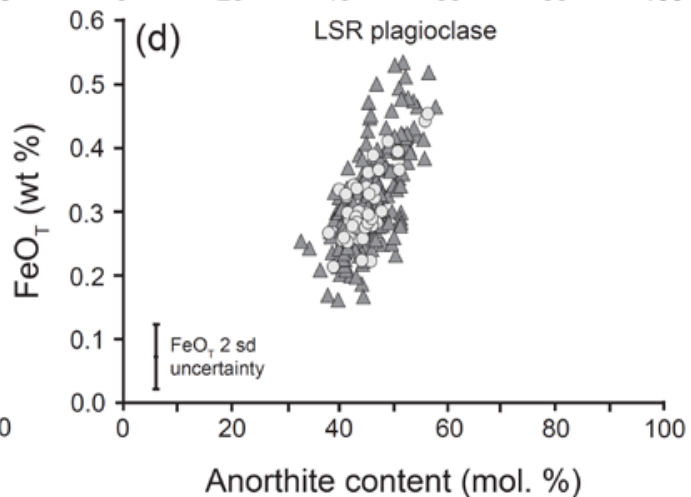

Figure 4.9. Selected major element compositional data for plagioclase from $\operatorname{HSR}(\mathrm{a}, \mathrm{b})$ and LSR (c, d) clasts.
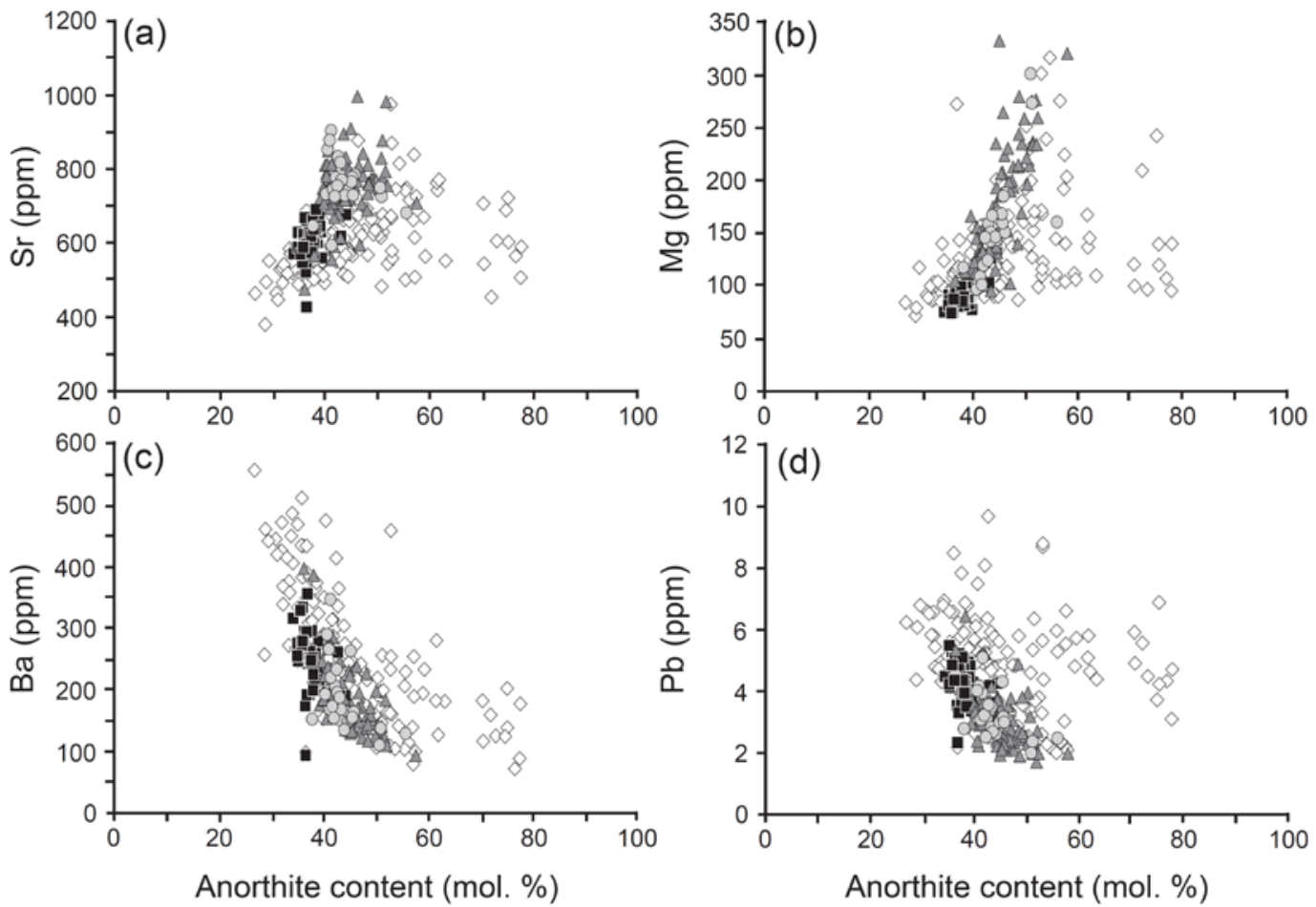

$$
\begin{array}{ll}
\diamond \text { Cores \& interiors (160) } & \Delta \text { Cores \& interiors (71) } \\
\text { - Rims (51) } & \circ \operatorname{Rims~(25)}
\end{array}
$$

Figure 4.10. Selected trace element data versus An content of plagioclase from HSR and LSR pumices. 

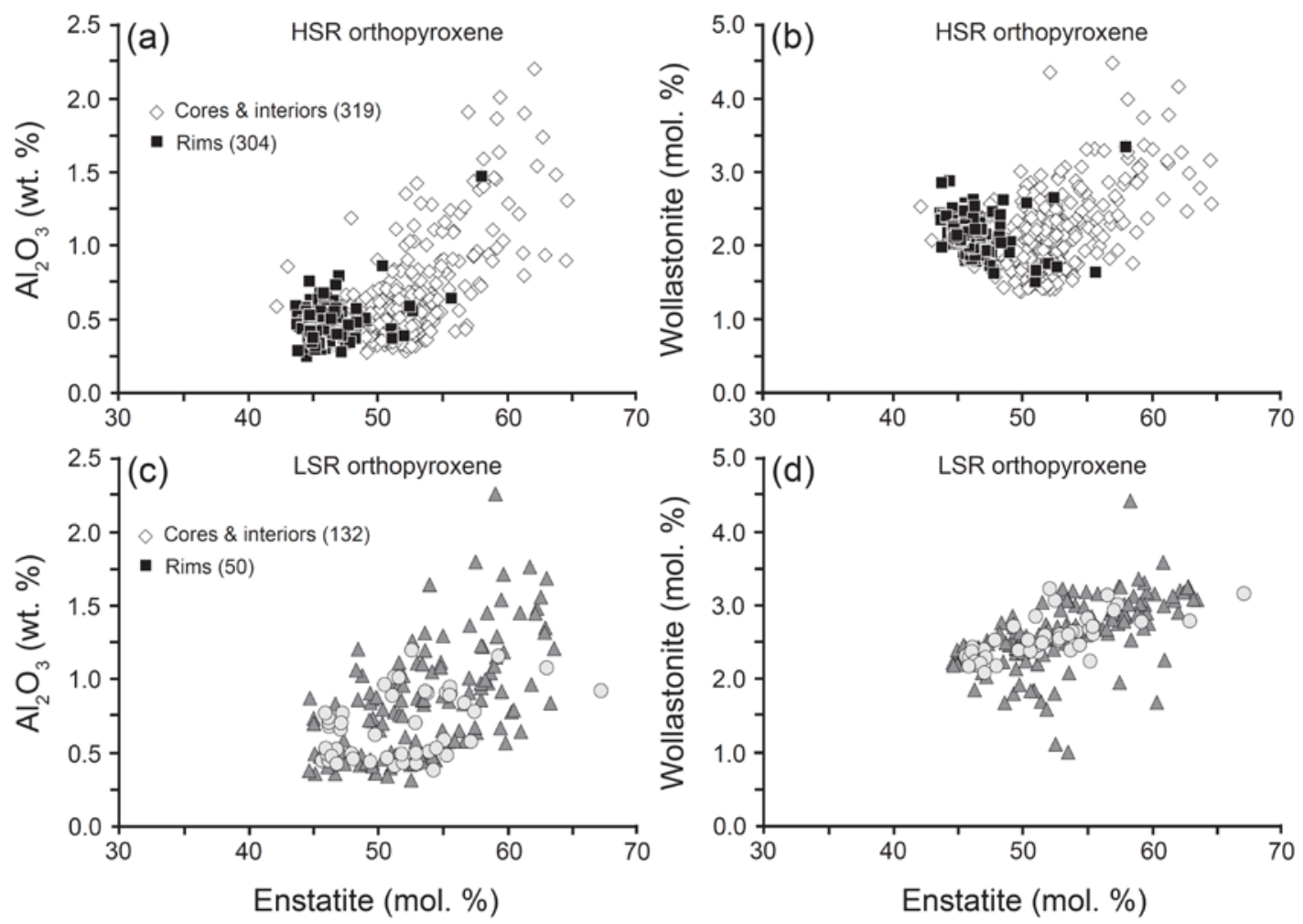

Figure 4.11. Selected major element compositional data for orthopyroxene from HSR (a, b) and LSR (c, d) clasts.
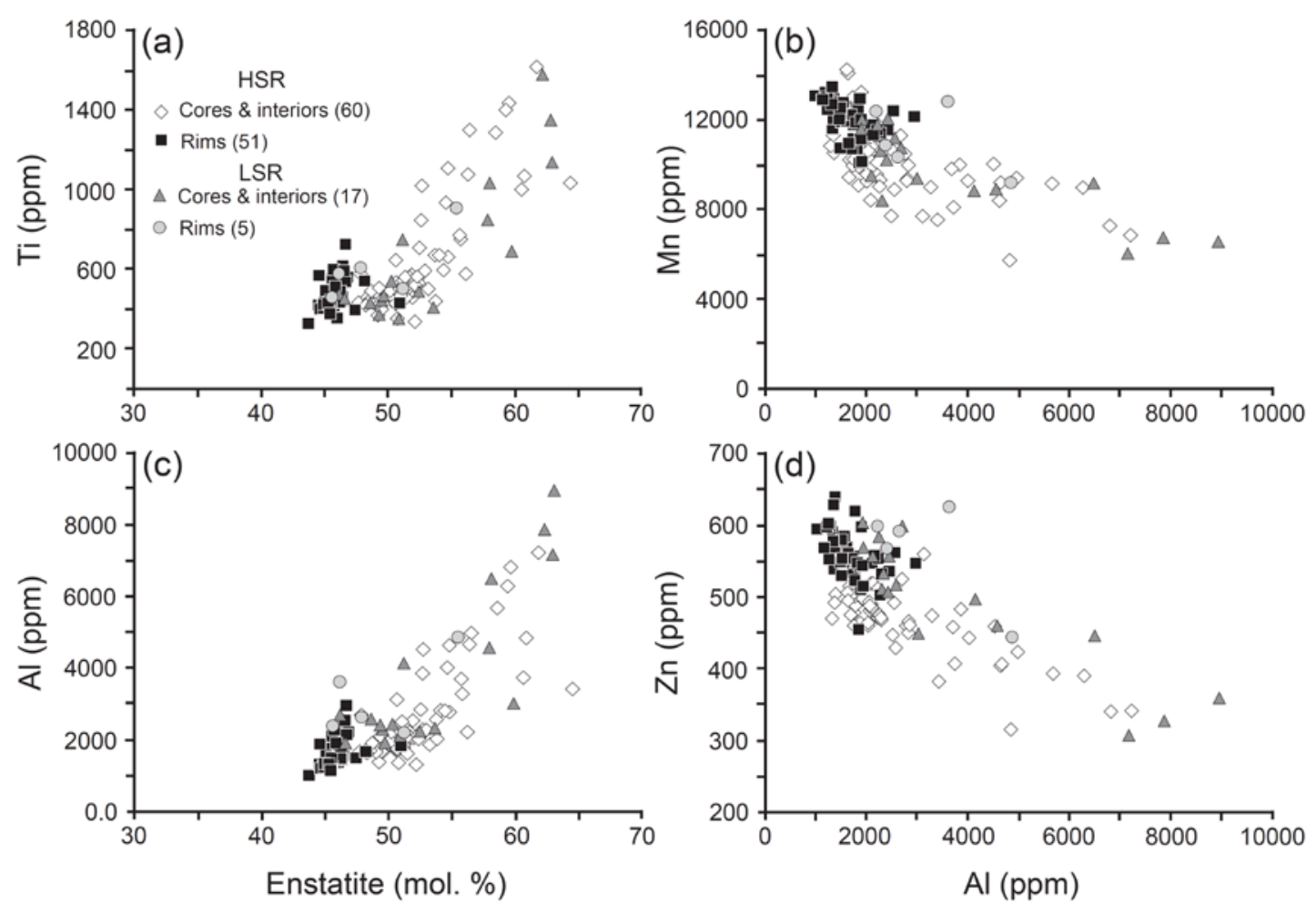

Figure 4.12. Selected trace element data for orthopyroxenes from HSR (a, b) and LSR (c, d) clasts. 
equivalent to the low Sr-Mg plagioclase mentioned above, plot outside of the main trends, with higher concentrations of $\mathrm{Ba}$ and $\mathrm{Pb}$ at higher An contents.

Orthopyroxene. Major and trace element data for HSR and LSR orthopyroxenes (after Allan et al. 2013) are presented in Figures 4.11 and 4.12. Orthopyroxenes from both rhyolites show very similar compositional ranges. The most notable difference is that the outermost rims of the HSR grains collapse down to a very restricted compositional range, with $95 \%$ of HSR orthopyroxene rims plotting in the range $\mathrm{En}_{46 \pm 2}$, whereas the outermost rims of the LSR orthopyroxenes are more diverse (Figure 4.11). A higher Al content in orthopyroxene is qualitatively taken to indicate crystallisation from higher pressure conditions (e.g., Putirka 2008). With the exception of a single analysis, the rims of HSR orthopyroxenes have very uniform $\mathrm{Al}_{2} \mathrm{O}_{3}$ contents. Although there is considerable overlap with the rims, the HSR cores and interiors have a significant tail-off to higher $\mathrm{Al}$ values. The LSR orthopyroxenes show an almost identical compositional range to the HSR crystals, but in general a greater proportion of their analyses are in the higher $\mathrm{Al}_{2} \mathrm{O}_{3}$ range.

The orthopyroxenes are generally fairly trace element poor. Of the trace and minor elements measured by LA-ICP-MS, Mn, Al, Ti and $\mathrm{Zn}$ tended to be the most abundant. Ti and $\mathrm{Al}$ trend positively with En content, whereas $\mathrm{Mn}$ and $\mathrm{Zn}$ are anti-correlated (Figure 4.12). As with the major element data, the trace element data show that there are no significant compositional differences between the HSR and LSR orthopyroxenes. Amphibole. The major element and trace element data for HSR and LSR amphiboles (after Allan et al. 2013) are presented in Figures 4.13 and 4.14. $\mathrm{SiO}_{2}$ and $\mathrm{TiO}_{2}$ are negatively correlated in both HSR and LSR samples. The majority of HSR outermost rim compositions are tightly clustered $\left(47 \pm 1 \mathrm{wt} \% \mathrm{SiO}_{2}, 1.4 \pm 0.2 \mathrm{wt} \% \mathrm{TiO}_{2}, 7 \pm 1 \mathrm{wt} \%\right.$ $\left.\mathrm{Al}_{2} \mathrm{O}_{3}, 12 \pm 1 \mathrm{wt} \% \mathrm{MgO}\right)$. The data from cores plus interiors significantly overlap this grouping; however, it also extends to notably higher concentrations of these elemental oxides. The LSR amphibole data show near identical compositional ranges (Figure 4.13c, d) but with comparatively few analyses $(<10 \%)$ overlapping with the outermost rim compositions of the HSR crystals.

The Eu/Eu* in amphibole was used by Allan et al. (2013) as a proxy for the melt composition from which the amphiboles grew, with higher $\mathrm{Eu} / \mathrm{Eu}^{*}$ values indicating growth from lesser evolved melts and vice versa. Allan et al. (2013) reported a clear inflection in the concentration of $\mathrm{Mn}$ and $\mathrm{Zn}$ with decreasing $\mathrm{Eu} / \mathrm{Eu}^{*}$ of the amphiboles (e.g., Figure 4.14a). Concentrations of these elements show an initial increase with 

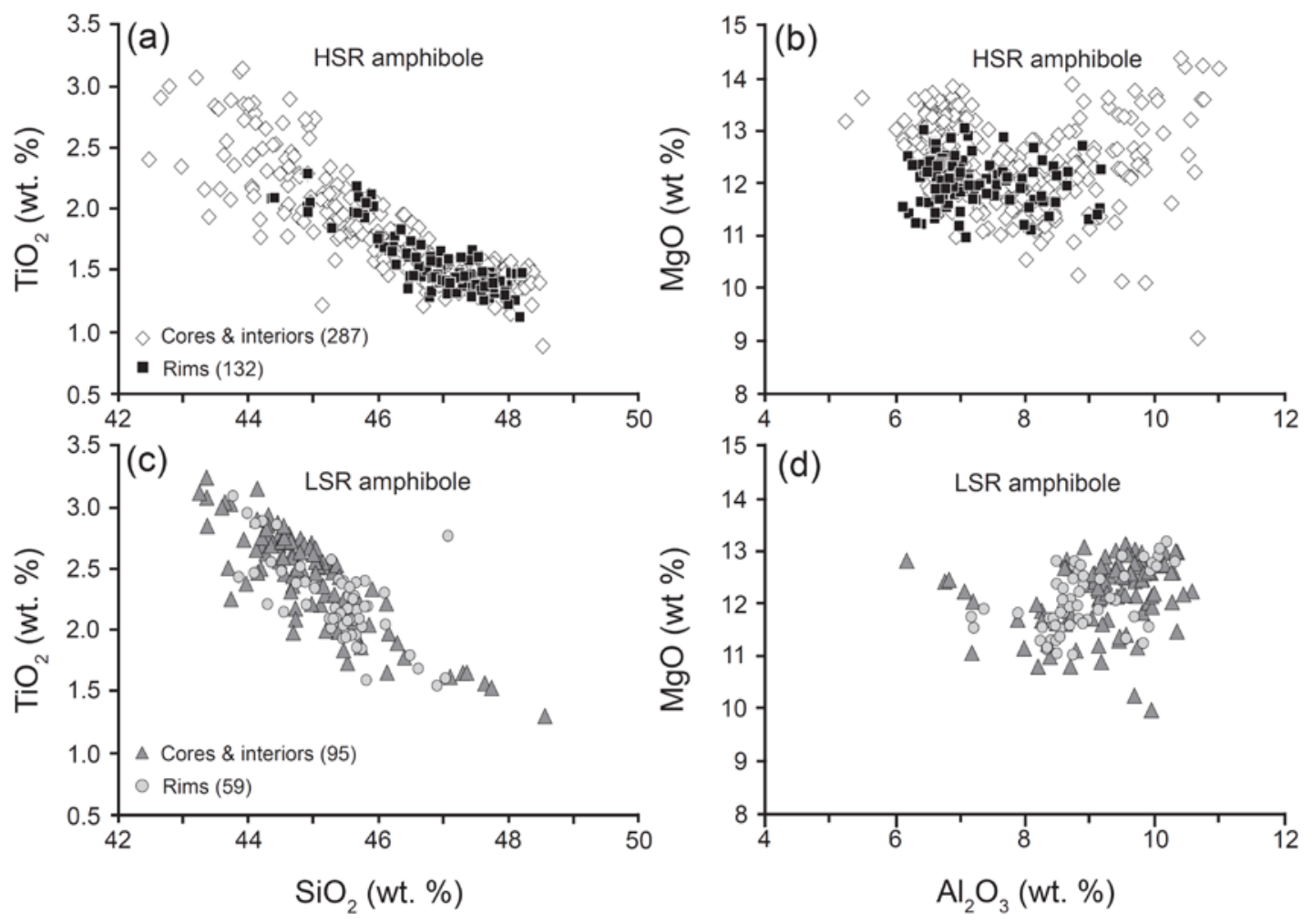

Figure 4.13. Selected major element compositional data for amphibole crystals from HSR (a, b) and LSR (c, d) clasts.

decreasing $\mathrm{Eu} / \mathrm{Eu}^{*}$ but then their abundance decreases below $\mathrm{Eu} / \mathrm{Eu}^{*}$ of $\sim 0.45$. Similar noteworthy inflections in the abundances of Eu (going from static to decreasing abundances; Trend A), and $\mathrm{Ni}$ and $\mathrm{Co}$ (going from static to increasing abundances; Trends B and C, respectively) are also evident around this same hinge point (Figure 4.14). The significance of these signatures recorded in the amphiboles are explored in subsequent sections. Allan et al. (2013) showed that the $\mathrm{Eu} / \mathrm{Eu}^{*}$ of the amphiboles was strongly linearly and positively correlated $\left(\mathrm{R}^{2}\right.$ of 0.83$)$ with the apparent pressures of amphibole crystallisation as determined by the Ridolfi et al. (2010) barometric formulation. The abundances of $\mathrm{Mn}, \mathrm{Eu}, \mathrm{Ni}$ and Co plotted against the apparent amphibole pressures (Figure 4.14e-h) suggest these chemical changes in the amphiboles occurred once the amphiboles crystallised at pressures less than $\sim 140-160 \mathrm{MPa}$ (or depths of ca. $6 \mathrm{~km}$ ). 

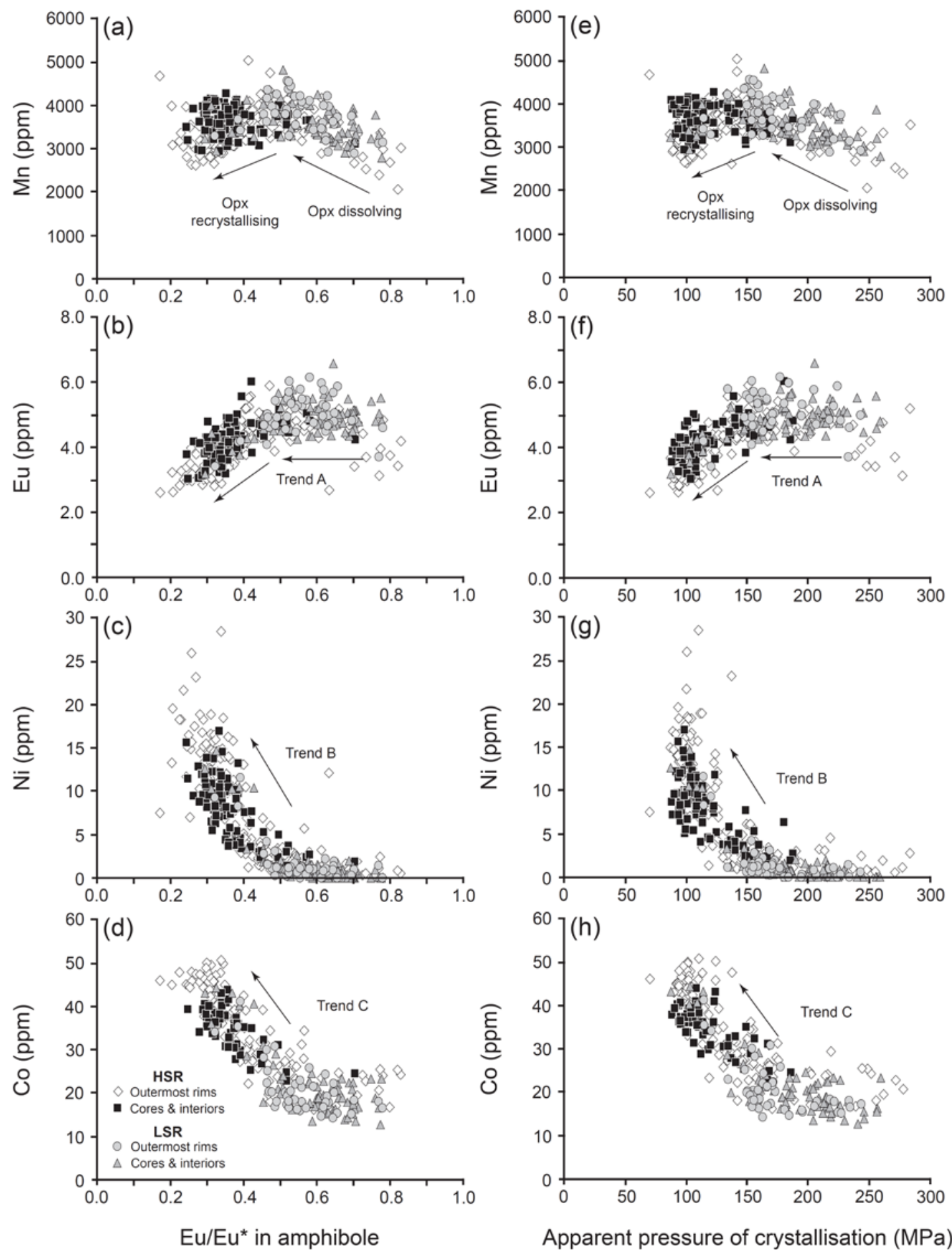

Figure 4.14. Selected trace element concentration data for amphiboles from HSR and LSR clasts. Data shown in panels $(\mathrm{a}-\mathrm{d})$ are plotted against the $\mathrm{Eu} / \mathrm{Eu}^{*}$ of the amphibole, a qualitative measure of evolution of the melt from which the amphibole grew. The origins of Trends A, B and C are discussed in sections 4.5.2 and 4.5.3. Data in panels (e-h) are plotted against the apparent crystallisation pressure as modelled by the Ridolfi et al. (2010) total-Al barometer. 


\subsubsection{Intensive variables}

Presentation of intensive invariables data for the Oruanui magma requires cognisance of ongoing issues raised in recent contributions to the literature that have questioned the validity of some models (e.g., Wilson et al. 2012 versus Thomas et al. 2010; Ghiorso and Gualda 2013 versus Evans and Bachmann 2013). The data presented below are considered by us to represent the most reliable and well-founded estimates for intensive variables in the Oruanui rhyolites. An extended discussion of some of the controversies in applying these methods follows in Chapter 5 of this thesis.

Estimates of magma intensive variables and water contents for the Oruanui magmas are summarised in Tables 4.5-4.7 along with additional information regarding model inputs and parameters. The results of preferred thermometric models, i.e., those that gave sensible, consistent and reproducible temperature estimates, are also summarised in Figure 4.15 and Table 4.5. Fe-Ti oxide thermometry for HSR and LSR magmas utilised the compositional data for magnetite and ilmenite crystals published in the online supplementary information of Wilson et al. (2006). Pairs of magnetite and ilmenite crystals extracted from the same clasts were tested for equilibrium following the criteria established by Bacon and Hirschmann (1988). Application of the Ghiorso and Evans (2008) model to equilibrium pairs yielded mean temperatures of $777{ }^{\circ} \mathrm{C}$ and $824{ }^{\circ} \mathrm{C}$ for the HSR and LSR magmas, respectively. Blundy and Cashman (2008) tested the performance of the several Fe-Ti oxide formulations against experimental datasets that were not used during the initial calibrations of those models. They determined the Ghiorso and Evans (2008) formulations yielded at absolute average deviation of $\pm 44^{\circ} \mathrm{C}$. Alternatively, the same Fe-Ti oxide pairings can be applied to the Sauerzapf et al. (2008) model, which was not tested by Blundy and Cashman (2008), which returned mean temperatures of $760{ }^{\circ} \mathrm{C}$ for the HSR and $799^{\circ} \mathrm{C}$ for the LSR. Despite an offset between the mean model values from the two Fe-Ti oxide models of $\sim 15$ to $25{ }^{\circ} \mathrm{C}$, both models indicate a $\sim 40$ to $50{ }^{\circ} \mathrm{C}$ difference between the final pre-eruptive temperatures of the HSR and LSR magmas.

The compositions of outermost amphibole rims for the HSR and LSR magmas, using the $\mathrm{Si}^{*}$ parameter of Ridolfi et al. (2010; their equation 1), yielded mean temperatures of 784 ${ }^{\circ} \mathrm{C}$ for the HSR and $843{ }^{\circ} \mathrm{C}$ for the LSR. However, both rhyolite groups have a subordinate component of crystal rims that tail off to higher temperatures, shifting the mean towards higher values. A prominent mode of temperature estimates centre on $\sim 770$ ${ }^{\circ} \mathrm{C}$ for the HSR rims and $\sim 830{ }^{\circ} \mathrm{C}$ for the LSR rims (Figure 4.15). Additional constraints 
Table 4.5. Summary of estimates for the pre-eruptive temperature of the Oruanui melt-dominant magma body according to various mineral equilibrium based techniques

\begin{tabular}{|c|c|c|c|c|c|}
\hline $\begin{array}{l}\text { Estimates of outermost rim } \\
\text { crystallisation temperatures }\left(\mathrm{T}^{\circ} \mathrm{C}\right)\end{array}$ & $\begin{array}{l}\text { Number of } \\
\text { estimates }\end{array}$ & Mean temp $\left({ }^{\circ} \mathrm{C}\right)$ & $\begin{array}{c}\text { Temp range } \\
\left({ }^{\circ} \mathrm{C}\right)\end{array}$ & $\begin{array}{l}\text { Modal } \\
\text { values }\end{array}$ & Model details and/or parameters \\
\hline \multicolumn{6}{|l|}{ HSR magma } \\
\hline Plag-melt (rims) & 158 & 787 & $783-797$ & & Putirka (2008), eqn $24 \mathrm{a}$, matrix glass and $5.5 \mathrm{wt} \%$ melt $\mathrm{H}_{2} \mathrm{O}$ \\
\hline Opx-melt (rims) & 222 & 785 & $779-793$ & & Putirka (2008), eqn 28a, matrix glass and $5.5 \mathrm{wt} \%$ melt $\mathrm{H}_{2} \mathrm{O}$ \\
\hline Amphibole compositions (rims) & 121 & 784 & $751-851$ & $770-780$ & Ridolfi et al. (2010) model \\
\hline Fe-Ti oxides & 379 & 777 & $742-821$ & $770-790$ & Ghiroso and Evans (2008) model \\
\hline \multicolumn{6}{|l|}{ LSR magma } \\
\hline Plag-melt (rims) & 47 & 831 & & $820-840$ & Putirka (2008), eqn $24 a$, matrix glass and $6 \mathrm{wt} \%$ melt $\mathrm{H}_{2} \mathrm{O}$ \\
\hline Opx-melt (rims) & 49 & 830 & & $820-840$ & Putirka (2008), eqn 28a, matrix glass and 6 wt $\%$ melt $\mathrm{H}_{2} \mathrm{O}$ \\
\hline Amphibole compositions (rims) & 59 & 837 & $783-903$ & $820-850$ & Ridolfi et al. (2010) model \\
\hline Fe-Ti oxides & 61 & 824 & $769-910$ & $820-840$ & Ghiroso and Evans (2008) model \\
\hline
\end{tabular}

Table 4.6. Summary of pressure estimates for the Oruanui HSR and LSR magmas.

\begin{tabular}{lccccl}
\hline $\begin{array}{l}\text { Estimates of outermost rim crystallisation } \\
\text { pressures }\end{array}$ & $\begin{array}{c}\text { Number } \\
\text { of } \\
\text { estimates }\end{array}$ & $\begin{array}{c}\text { Mean } \\
\text { pressure } \\
(\mathrm{MPa})\end{array}$ & $\begin{array}{c}\text { Pressure } \\
\text { range (MPa) }\end{array}$ & $\begin{array}{c}\text { Modal } \\
\text { values } \\
\text { (MPa) }\end{array}$ & Model details and/or parameters \\
\hline $\begin{array}{l}\text { HSR magma } \\
\text { Amphibole compositions (rims) }\end{array}$ & 121 & 113 & $88-185$ & $90-120$ & Ridolfi et al. (2010) \\
Volatile contents in qtz melt inclusions & 65 & 138 & $94-188$ & $120-150$ & Liu et al. (2006), trapped (closed) inclusions only \\
& & & & & Ridolfi et al. (2010) \\
LSR magma & 59 & 174 & $114-173$ & & \\
Amphibole compositions (rims) & & & &
\end{tabular}


Table 4.7. Summary of oxygen fugacity and melt $\mathrm{H}_{2} \mathrm{O}$ estimates for the final pre-eruptive conditions in the HSR and LSR magmas.

\begin{tabular}{|c|c|c|c|c|}
\hline $\begin{array}{l}\text { Estimates of oxygen fugacity } \\
(\Delta N N O)\end{array}$ & & Mean $(\triangle \mathrm{NNO})$ & Range $(\triangle N N O)$ & Model details and/or parameters \\
\hline \multicolumn{5}{|l|}{ HSR magma } \\
\hline Fe-Ti oxides & 379 & -0.20 & -0.52 to 0.03 & Ghiroso and Evans (2008) model \\
\hline $\begin{array}{l}\text { Amphibole rims } \\
\text { LSR magma }\end{array}$ & 121 & 0.90 & 0.40 to 1.20 & Ridolfi et al. (2010) model \\
\hline Fe-Ti oxides & 59 & 0.5 & $0.2-0.8$ & Ghiroso and Evans (2008) model \\
\hline Amphibole rims & 59 & 0.5 & $0.2-0.8$ & Ridolfi et al. (2010) model \\
\hline Estimates of $\mathrm{H}_{2} \mathrm{O}$ melt (wt \%) & & Mean (wt \%) & Range & Model details and/or parameters \\
\hline $\begin{array}{l}\text { HSR magma } \\
\text { Amphibole rims }\end{array}$ & 121 & 5.5 & $5.0-6.2$ & Ridolfi et al. (2010) model \\
\hline Quartz-host melt inclusions & 66 & 4.5 & $3.8-5.1$ & Liu et al. (2006), $\mathrm{H}_{2} \mathrm{O}$ in trapped quartz-hosted melt inclusions measured by FTIR \\
\hline Empirical $\mathrm{H}_{2} \mathrm{O}$ solubility model & & 5.3 & $4.0-6.8$ & Moore et al. (1998), model run at $770^{\circ} \mathrm{C}$ and $90-240 \mathrm{MPa}$, mean value at $150 \mathrm{MPa}$ \\
\hline Glass $\mathrm{H}_{2} \mathrm{O}$ by difference & 141 & 4.5 & $0.6-7.4$ & Difference from $100 \mathrm{wt} \%$ of raw EPMA totals for pumice matrix glass \\
\hline Plag-melt equilibrium & & 4.6 & & Anorthite-method of Housh and Luhr (1991), reported in Wilson et al. (2006) \\
\hline $\begin{array}{l}\text { Plag-melt equilibrium } \\
\text { LSR magma }\end{array}$ & & 6.2 & & Albite-method of Housh and Luhr (1991), reported in Wilson et al. (2006) \\
\hline Amphibole rims & 59 & 6.0 & $5.6-6.5$ & Ridolfi et al. (2010) model \\
\hline
\end{tabular}


on immediately pre-eruptive temperatures were determined using the plagioclase-melt and orthopyroxene-melt thermometers of Putirka (2008; his equations 24a and 28a, respectively), applied to the compositions of outermost crystal rims (Allan et al. 2013) and matrix glass. Plagioclase-melt and orthopyroxene-melt thermometry yielded mean estimates of $787^{\circ} \mathrm{C}$ and $785^{\circ} \mathrm{C}$, respectively, for HSR samples. Plagioclase-melt and orthopyroxene-melt thermometry yielded mean estimates of $831^{\circ} \mathrm{C}$ and $830^{\circ} \mathrm{C}$, respectively, for LSR samples. Attempts to model the temperatures of quartz crystallisation in the Oruanui HSR using models of Ti-in-quartz (Wark and Watson 2006; Thomas et al. 2010) were met with many issues (e.g., Wilson et al. 2012) and are discussed in Chapter 5.
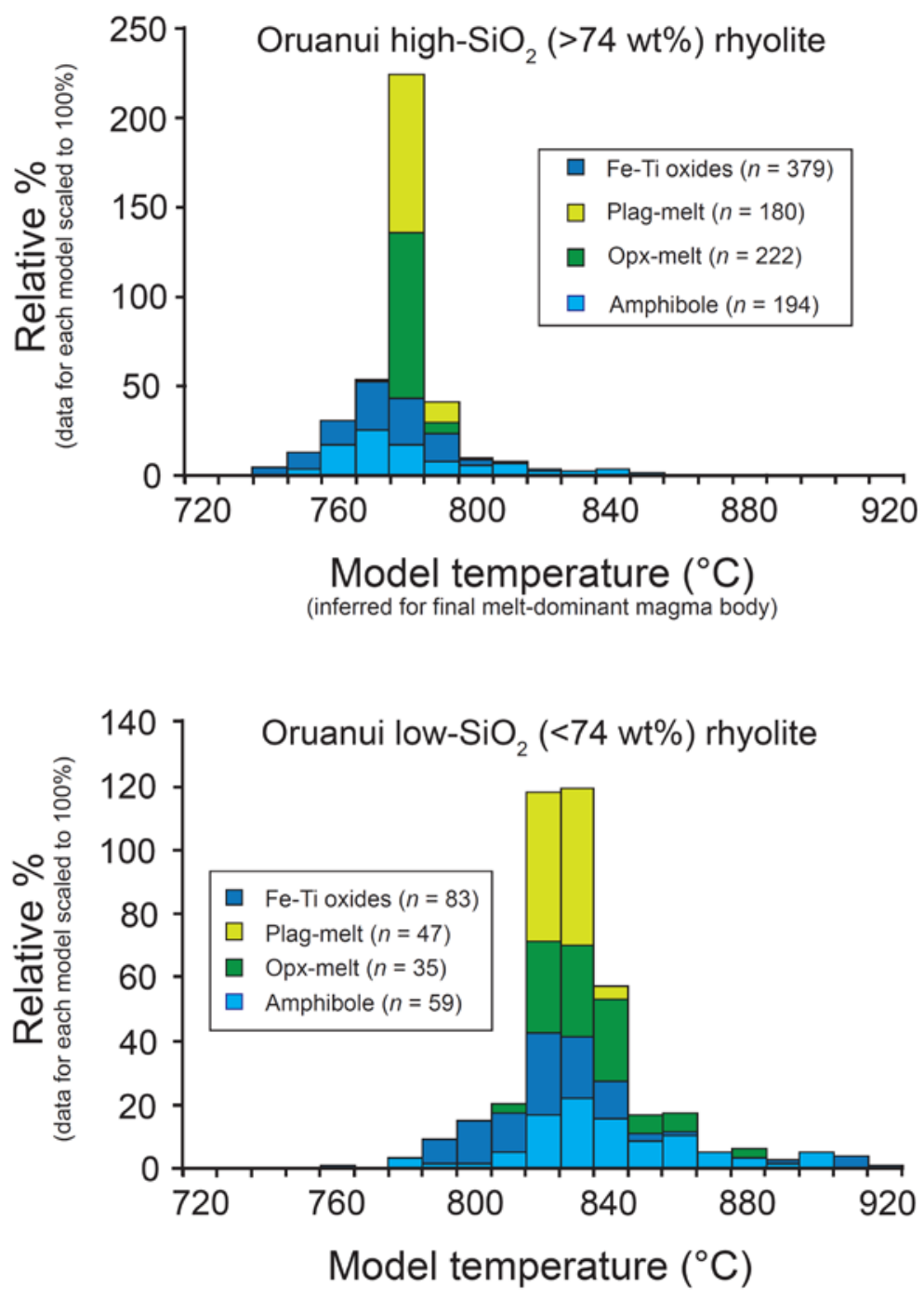

Figure 4.15. Summary of the results of preferred thermometric models applied to (a) HSR crystals and (b) LSR crystals. Models: Fe-Ti oxides - Ghiorso and Evans (2008); Plag-melt and Opx melt Putirka (2008); amphiboles - Ridolfi et al. (2010). Model details and parameters are listed in Table 4.5. See text for discussion. 

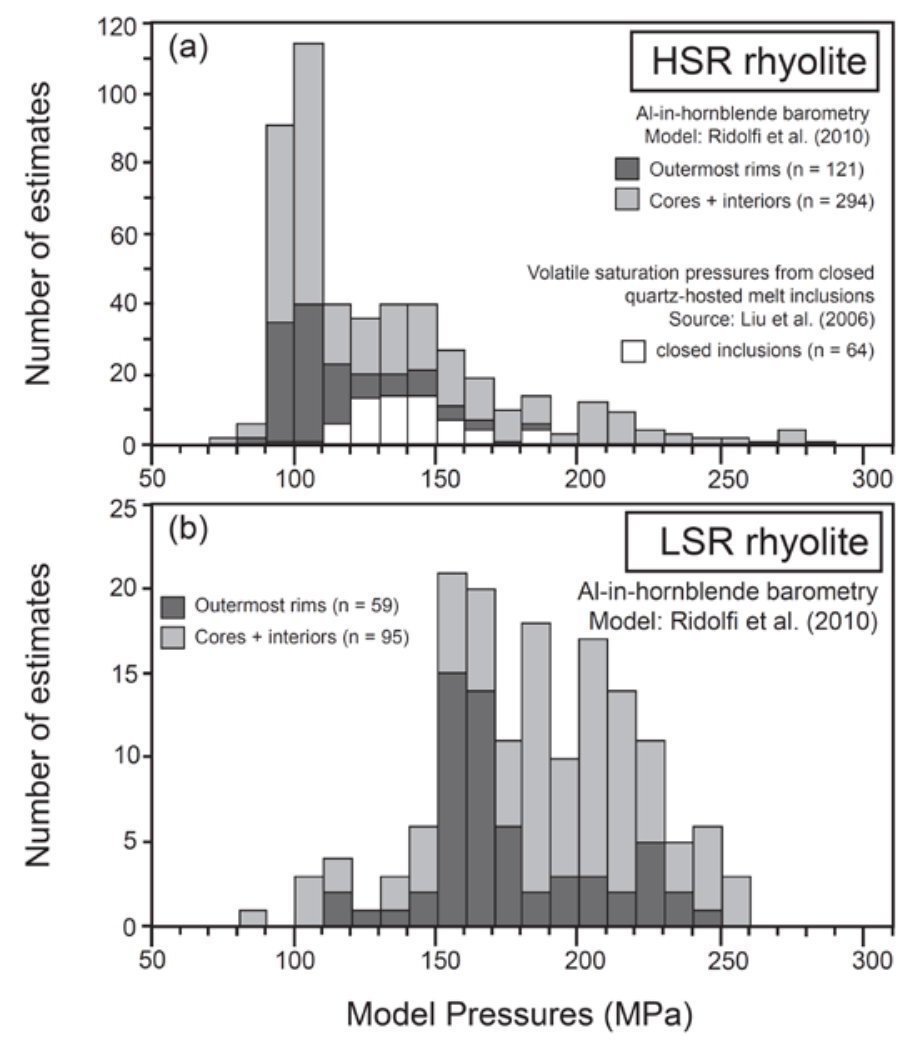

Figure 4.16. Summarised results of preferred barometric models applied to HSR and LSR clasts. (a) There is good agreement between the results of the total-Al based amphibole barometer of Ridolfi et al. (2010) and the volatile saturation pressures form trapped melt inclusions in quartz (Liu et al. 2006). (b) Amphibole barometry estimates for (quartz-free) LSR samples indicate, in general, higher pressures than those obtained from the HSR.

Results of preferred barometric models are summarised in Table 4.6 and Figure 4.16.

Estimates of the final pressures for the Oruanui rhyolites were determined using the totalAl based barometric formulation of Ridolfi et al. (2010; their equation 4) applied to outermost amphibole rim compositions. Based on the outermost rim compositions only, HSR samples yielded a mean apparent crystallisation pressure of $113 \mathrm{MPa}$ (range 88 to 185 $\mathrm{MPa}$ ), with a prominent mode of pressure estimates between 90 and $120 \mathrm{MPa}$. The mean apparent crystallisation pressures for LSR amphibole rims using the Ridolfi et al. (2010) barometer is $174 \mathrm{MPa}$, with values ranging from 114 to $243 \mathrm{MPa}$. As with the HSR amphiboles, the mode of estimates is slightly lower than the mean. These amphibolederived pressure estimates for the HSR are consistent with those estimated from volatile saturation pressures (Liu et al. 2006), inferred from measured concentrations of $\mathrm{H}_{2} \mathrm{O}$ and $\mathrm{CO}_{2}$ in trapped quartz-hosted melt inclusions. These data yielded a mean pressure of 138 $\mathrm{MPa}$ (ranging from 94-188 MPa). Ti-in-quartz derived estimates of quartz crystallisation 
pressures (Thomas et al. 2010) are not considered realistic (Matthews et al. 2012; Wilson et al. 2012) and are discussed in Chapter 5.

Estimates of the final ambient oxygen fugacity for the HSR and LSR were calculated using the compositions of amphibole rims (Ridolfi et al. 2010; their equation 2), and Fe-Ti oxide equilibrium pairs (Ghiorso and Evans 2008; Sauerzapf et al. 2008). Use of the Ghiorso and Evans (2008) model for Fe-Ti oxides in HSR clasts yields a mean estimate of -0.2 NNO, compared to a mean of $+0.47 \mathrm{NNO}$ when the Sauerzapf et al. (2008) model is used. The Ridolfi et al. (2010) formulation applied to amphibole rims yields a mean value of +0.90 NNO. Mean oxygen fugacity calculated for the LSR samples were as follows: -0.07 NNO (Ghiorso and Evans 2008, model); +0.41 NNO (Sauerzapf et al. 2008); +0.50 NNO (Ridolfi et al. 2010).

Measurements and estimates of the mean water content of the Oruanui HSR magma vary from $4.5 \mathrm{wt} \%$ to $6.2 \mathrm{wt} \%$ (Table 4.7). The lowest values come from ion probe measurements of $\mathrm{H}_{2} \mathrm{O}$ in quartz-hosted melt inclusions (Liu et al. 2006). The higher estimates are inferred from amphibole rim compositions (Ridolfi et al. 2010; their eq. 3), empirical modelling of $\mathrm{H}_{2} \mathrm{O}$ solubility for Oruanui HSR compositions (Moore et al. 1998, model) and plagioclase-melt equilibrium models (Housh and Luhr 1991).

\subsubsection{Oruanui mafic compositions}

\subsubsection{Textural characterisation of mafic clasts from thin sections}

Wilson (2001) and Wilson et al. (2006) identified the two compositional groups of mafic clasts and noted some textural generalisations that enabled them to be distinguished in the field on the basis of physical appearance. In particular the tholeiitic clasts were noted as having a more 'mushy' groundmass compared to the much fresher and glassier-looking calc-alkaline samples. Observations of the textures during collection of analytical data for this thesis identified some features not previously recognised that are of importance of understanding the mafic-felsic interactions. Firstly, almost all of the mafic clasts examined under high magnification had micro-crystalline groundmass, even the apparently fresher calc-alkaline samples. Despite the largely microcrystalline nature of the groundmass, the groundmass crystals are coated in thin films (generally $<5 \mu \mathrm{m}$ ) of highly silicic melt (see next section). This would explain how even clasts that are inferred to have interacted for significant periods of time (weeks?) at rhyolite temperatures (i.e. below solidus for the mafic composition concerned), could still maintain evidence for plasticity when ejected. 
Secondly, within the tholeiite group a spectrum of groundmass textures were observed; from originally glassy but devitrified at high temperatures prior to quenching on eruption, to relatively coarse and almost wholly crystalline groundmass with radiating acicular needles of plagioclase and amphibole. Importantly, however, the spectrum of groundmass textures, from those indicating rapid versus more moderate rates of cooling, did not bear any straightforward relationship to whole rock chemistry. This may be suggestive that multiple injections of the tholeiitic mafic magma occurred.

\subsubsection{Whole rock and groundmass chemistry}

Figure 4.17 shows how the new data for mafic clasts reported by us here fit within the compositional framework established by Wilson et al. (2006). As is the case with our whole-rock data for the rhyolites, we use our bulk chemical data for the mafic clasts here primarily to confirm our sampling. In addition, however, our new ICP-MS data comprise higher quality data for rare earth elements (REEs) and lower-abundance trace elements than the XRF-data in Wilson et al. (2006). Data for representative examples of both compositional groups are shown in Table 4.8 with the full dataset available in the electronic appendix. A notable feature of the REE data is that almost all samples (both new and reanalysed) have $\mathrm{Eu} / \mathrm{Eu}^{*}>1$ (Figure 4.17), a feature indicative of plagioclase accumulation.
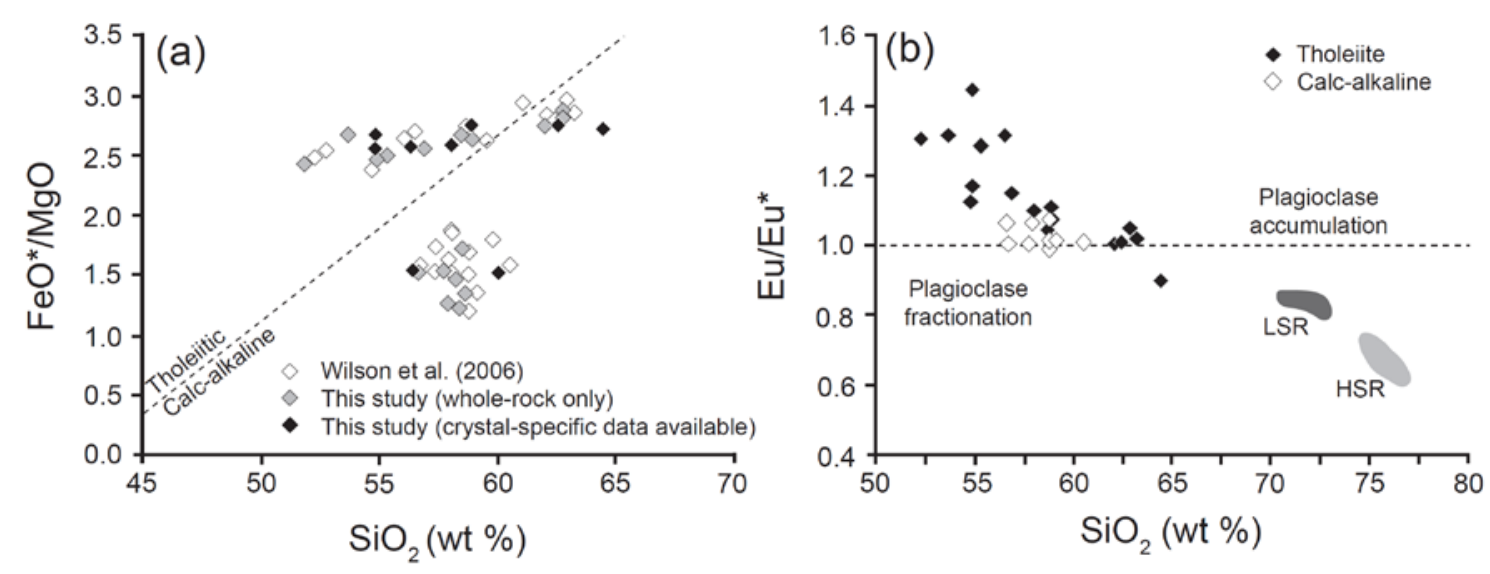

Figure 4.17. Selected whole-rock analytical data for single Oruanui mafic clasts. (a) Plot of FeO*/MgO versus $\mathrm{SiO}_{2}$ to show the two compositional groupings (calc-alkaline and tholeiitic) reported by Wilson et al. (2006). Our new data are plotted with that of Wilson et al. (2006) for comparison. (b) The new ICPMS derived trace element data (Table 4.8 and supplementary data) represent the first high precision determinations of rare earth elements (REEs) for these samples. A notable feature, of the tholeiitic group in particular, is the positive $\mathrm{Eu}$ anomalies (i.e., $\mathrm{Eu} / \mathrm{Eu}^{*}>1$ ) of most clasts, indicative of plagioclase accumulation. 
Table 4.8. Representative major (XRF) and trace element (ICP-MS) analyses of Oruanui juvenile mafic clasts.

\begin{tabular}{|c|c|c|c|c|c|c|c|c|c|c|}
\hline $\begin{array}{l}\text { Sample no } \\
\text { Group }\end{array}$ & $\begin{array}{l}\text { P554 } \\
\text { TH }\end{array}$ & $\begin{array}{c}\text { P1975 } \\
\text { TH }\end{array}$ & $\begin{array}{l}\text { P581 } \\
\text { TH }\end{array}$ & $\begin{array}{c}\text { P1974 } \\
\text { TH }\end{array}$ & $\begin{array}{l}\text { P574 } \\
\text { TH }\end{array}$ & $\begin{array}{c}\text { P1976 } \\
\text { TH }\end{array}$ & $\begin{array}{c}\mathrm{P} 1643 \\
\mathrm{CA}\end{array}$ & $\begin{array}{l}\text { P919 } \\
\text { CA }\end{array}$ & $\begin{array}{c}\mathrm{P} 1664 \\
\mathrm{CA}\end{array}$ & $\begin{array}{c}\text { P987 } \\
\text { CA }\end{array}$ \\
\hline $\mathrm{SiO}_{2}$ & 52.27 & 54.83 & 56.52 & 58.05 & 62.43 & 64.47 & 56.66 & 56.74 & 57.90 & 60.53 \\
\hline $\mathrm{TiO}_{2}$ & 1.44 & 1.31 & 1.68 & 1.24 & 1.02 & 0.79 & 0.79 & 0.80 & 0.67 & 0.78 \\
\hline $\mathrm{Al}_{2} \mathrm{O}_{3}$ & 16.92 & 16.54 & 17.67 & 16.71 & 16.59 & 14.89 & 17.84 & 17.25 & 17.74 & 16.61 \\
\hline $\mathrm{Fe}_{2} \mathrm{O}_{3}$ & 12.60 & 11.04 & 9.60 & 8.81 & 6.30 & 6.86 & 7.56 & 7.83 & 6.91 & 6.53 \\
\hline $\mathrm{MnO}$ & 0.19 & 0.17 & 0.18 & 0.16 & 0.15 & 0.12 & 0.14 & 0.15 & 0.12 & 0.14 \\
\hline $\mathrm{MgO}$ & 4.57 & 3.89 & 3.20 & 3.07 & 2.03 & 2.27 & 4.47 & 4.45 & 4.92 & 3.70 \\
\hline $\mathrm{CaO}$ & 8.13 & 7.62 & 5.98 & 6.53 & 5.23 & 4.94 & 8.31 & 8.69 & 7.44 & 6.59 \\
\hline $\mathrm{Na}_{2} \mathrm{O}$ & 3.28 & 3.51 & 4.30 & 4.06 & 4.46 & 3.70 & 3.15 & 3.06 & 3.16 & 3.67 \\
\hline $\mathrm{K}_{2} \mathrm{O}$ & 0.48 & 0.77 & 0.74 & 0.96 & 1.40 & 1.78 & 0.85 & 0.83 & 0.97 & 1.22 \\
\hline $\mathrm{P}_{2} \mathrm{O}_{5}$ & 0.11 & 0.33 & 0.14 & 0.41 & 0.40 & 0.19 & 0.23 & 0.20 & 0.17 & 0.22 \\
\hline LOI & 1.80 & 0.80 & 2.22 & 1.01 & 1.22 & 1.47 & 0.91 & 0.76 & 1.23 & 1.46 \\
\hline SUM & 100.30 & 99.31 & 100.32 & 99.07 & 99.36 & 98.55 & 99.06 & 98.57 & 98.78 & 99.18 \\
\hline $\mathrm{FeO}^{*} / \mathrm{MgO}$ & 2.48 & 2.55 & 2.70 & 2.58 & 2.79 & 2.72 & 1.52 & 1.58 & 1.26 & 1.58 \\
\hline $\mathrm{Li}$ & 10.7 & 14.7 & 13.4 & 16.0 & 11.7 & 23.05 & 14.50 & 13.5 & 12.83 & 15.0 \\
\hline Sc & 39.9 & 32.4 & 28.3 & 28.1 & 21.1 & 20.5 & 28.1 & 29.6 & 25.0 & 23.1 \\
\hline $\mathrm{Ti}$ & 8549 & 7819 & 9609 & 7740 & 6442 & 4892 & 4709 & 4710 & 4203 & 4348 \\
\hline V & 364 & 272 & 123 & 163 & 78.2 & 159 & 154 & 162 & 122 & 102 \\
\hline $\mathrm{Cr}$ & 4.70 & 3.83 & 0.76 & 3.09 & 1.81 & 8.56 & 102 & 111 & 99.9 & 85.0 \\
\hline Co & 27.7 & 22.1 & 9.63 & 13.7 & 7.54 & 14.1 & 20.7 & 20.6 & 22.2 & 15.0 \\
\hline $\mathrm{Ni}$ & 3.60 & 2.34 & 2.04 & 1.68 & 1.88 & 2.04 & 20.5 & 18.4 & 40.6 & 20.4 \\
\hline $\mathrm{Cu}$ & 12.9 & 14.3 & 6.04 & 6.84 & 4.83 & 13.5 & 14.6 & 14.5 & 13.8 & 8.58 \\
\hline $\mathrm{Zn}$ & 106 & 94.3 & 107 & 92.9 & 82.7 & 68.6 & 74.4 & 74.5 & 80.5 & 73.5 \\
\hline $\mathrm{Ga}$ & 21.3 & 19.8 & 21.9 & 20.2 & 19.9 & 17.9 & 18.2 & 17.9 & 17.6 & 18.0 \\
\hline $\mathrm{Rb}$ & 10.6 & 19.7 & 19.8 & 26.6 & 43.7 & 60.1 & 26.3 & 24.2 & 34.5 & 37.9 \\
\hline $\mathrm{Sr}$ & 338 & 332 & 367 & 333 & 312 & 237 & 295 & 271 & 267 & 271 \\
\hline$Y$ & 17.3 & 19.9 & 20.3 & 23.5 & 26.6 & 22.1 & 20.2 & 20.0 & 19.3 & 22.4 \\
\hline $\mathrm{Zr}$ & 90.3 & 114 & 204 & 180 & 231 & 110 & 149 & 138 & 154 & 187 \\
\hline $\mathrm{Nb}$ & 2.75 & 3.49 & 6.23 & 5.12 & 6.76 & 5.47 & 3.98 & 3.79 & 4.24 & 5.14 \\
\hline Cs & 0.41 & 0.98 & 0.83 & 1.31 & 1.79 & 3.14 & 0.96 & 0.96 & 1.65 & 1.51 \\
\hline $\mathrm{Ba}$ & 152 & 200 & 279 & 253 & 365 & 405 & 313 & 212 & 285 & 302 \\
\hline La & 5.05 & 9.26 & 8.31 & 11.9 & 16.3 & 15.7 & 10.0 & 9.61 & 9.70 & 12.7 \\
\hline $\mathrm{Ce}$ & 14.5 & 20.5 & 19.6 & 26.7 & 36.2 & 33.4 & 22.7 & 21.5 & 22.1 & 28.3 \\
\hline $\mathrm{Pr}$ & 1.82 & 2.90 & 2.47 & 3.60 & 4.51 & 3.94 & 2.96 & 2.84 & 2.75 & 3.54 \\
\hline $\mathrm{Nd}$ & 8.60 & 12.8 & 11.0 & 16.0 & 19.3 & 15.9 & 12.9 & 12.4 & 11.9 & 15.1 \\
\hline $\mathrm{Sm}$ & 2.48 & 3.24 & 2.97 & 4.03 & 4.57 & 3.53 & 3.22 & 3.13 & 2.84 & 3.66 \\
\hline $\mathrm{Eu}$ & 1.13 & 1.25 & 1.37 & 1.50 & 1.57 & 1.07 & 1.17 & 1.08 & 1.06 & 1.25 \\
\hline $\mathrm{Gd}$ & 2.85 & 3.53 & 3.39 & 4.35 & 4.95 & 3.74 & 3.55 & 3.46 & 3.23 & 3.90 \\
\hline $\mathrm{Tb}$ & 0.48 & 0.55 & 0.56 & 0.68 & 0.74 & 0.58 & 0.56 & 0.54 & 0.51 & 0.61 \\
\hline Dy & 3.14 & 3.53 & 3.67 & 4.27 & 4.68 & 3.68 & 3.60 & 3.50 & 3.31 & 3.92 \\
\hline Ho & 0.67 & 0.73 & 0.76 & 0.87 & 0.97 & 0.77 & 0.75 & 0.73 & 0.69 & 0.81 \\
\hline $\mathrm{Er}$ & 1.89 & 2.07 & 2.19 & 2.53 & 2.80 & 2.28 & 2.18 & 2.13 & 2.04 & 2.39 \\
\hline $\mathrm{Tm}$ & 0.27 & 0.31 & 0.32 & 0.36 & 0.40 & 0.34 & 0.32 & 0.31 & 0.30 & 0.34 \\
\hline $\mathrm{Yb}$ & 1.84 & 2.02 & 2.16 & 2.39 & 2.66 & 2.31 & 2.13 & 2.07 & 2.01 & 2.31 \\
\hline Lu & 0.27 & 0.29 & 0.32 & 0.36 & 0.41 & 0.35 & 0.32 & 0.32 & 0.31 & 0.35 \\
\hline $\mathrm{Hf}$ & 2.30 & 2.73 & 4.64 & 4.04 & 5.24 & 3.00 & 3.44 & 3.21 & 3.51 & 4.21 \\
\hline $\mathrm{Pb}$ & 3.35 & 6.42 & 8.16 & 4.89 & 6.95 & 14.39 & 3.96 & 4.07 & 5.20 & 5.87 \\
\hline Th & 1.49 & 2.08 & 3.09 & 3.04 & 4.80 & 6.15 & 2.79 & 2.66 & 3.42 & 3.98 \\
\hline$U$ & 0.38 & 0.53 & 0.73 & 0.73 & 1.15 & 1.40 & 0.67 & 0.65 & 0.84 & 0.97 \\
\hline $\mathrm{Rb} / \mathrm{Sr}$ & 0.03 & 0.06 & 0.05 & 0.08 & 0.14 & 0.25 & 0.09 & 0.09 & 0.13 & 0.14 \\
\hline $\mathrm{Eu} / \mathrm{Eu}^{*}$ & 1.30 & 1.13 & 1.31 & 1.10 & 1.01 & 0.90 & 1.06 & 1.00 & 1.07 & 1.01 \\
\hline
\end{tabular}


Attempts to analyse groundmass glass in the mafic clasts were difficult because all clasts, even the fresher, glassier-looking calc-alkaline samples, had an almost entirely microcrystalline groundmass. Visible under ultra-high magnification, needle-like nano-inclusions of plagioclase and ferromagnesian minerals made it impossible to find an area where a 10 $\mu \mathrm{m}$ electron beam could fit on groundmass glass. As a result, the electron beam was focussed to $\sim 3 \mu \mathrm{m}$ diameter enabling the recovery of 28 glass analyses from the groundmass of two tholeiitic mafic clasts. These analyses, in clasts with whole rock compositions ranging 54.8 to $64.5 \mathrm{wt} \% \mathrm{SiO}_{2}$, returned high-SiO $\mathrm{S}_{2}$ rhyolite glass compositions ( $>77 \mathrm{wt}^{0} \% \mathrm{SiO}_{2}$ ) (see Electronic Appendices). Although the values for alkali elements $(\mathrm{Na}$ in particular) were likely compromised by the analytical technique used, the $\mathrm{Ti}, \mathrm{Mg}$ and $\mathrm{Ca}$ contents of the interstitial glass were notably higher than adhering rinds of rhyolite that more closely matched the HSR groundmass compositions. The highly evolved interstitial glass in the mafic clasts represents flash crystallisation of the groundmass resulting from severe undercooling when the mafic magmas encountered cooler rhyolite, either in the melt-dominant magma body or in the mush zone.

\subsubsection{Compositional characteristics of mafic crystals}

In-situ analysis of crystal phases from the mafic clasts was approached in two ways. In the first, crystals were handpicked from the 0.5 to $1.0 \mathrm{~mm}$ size fraction of gently crushed material and then mounted in epoxy resin blocks. In the second approach, clasts were thin sectioned so that mineral phases could be imaged and analysed in their host groundmass. In these sectioned clasts many crystals $<0.5 \mathrm{~mm}$ were able to be analysed. Only the crystal separates were analysed for their trace element contents by LA-ICP-MS.

There are some major element compositional differences between the datasets collected for crystal separates and sectioned samples (Figure 4.18). In general the sectioned samples comprise greater proportions of more primitive crystals (higher En orthopyroxene, lower $\mathrm{SiO}_{2}$ amphibole, higher An plagioclase), and these typically are the smaller crystals, not represented in the hand-picked samples. The distribution of the two datasets (sectioned clasts versus handpicked separates) shown in Figure 4.18 highlights that the trace element dataset for crystals from the mafic clasts may under-represent the abundance of lesser evolved crystals as an artefact of the crystal size fraction used for LA-ICP-MS analysis. It is also apparent that most of the major element compositional ranges in the larger crystals fall entirely within the compositional fields defined by the corresponding crystal species in the HSR and LSR rhyolites. 

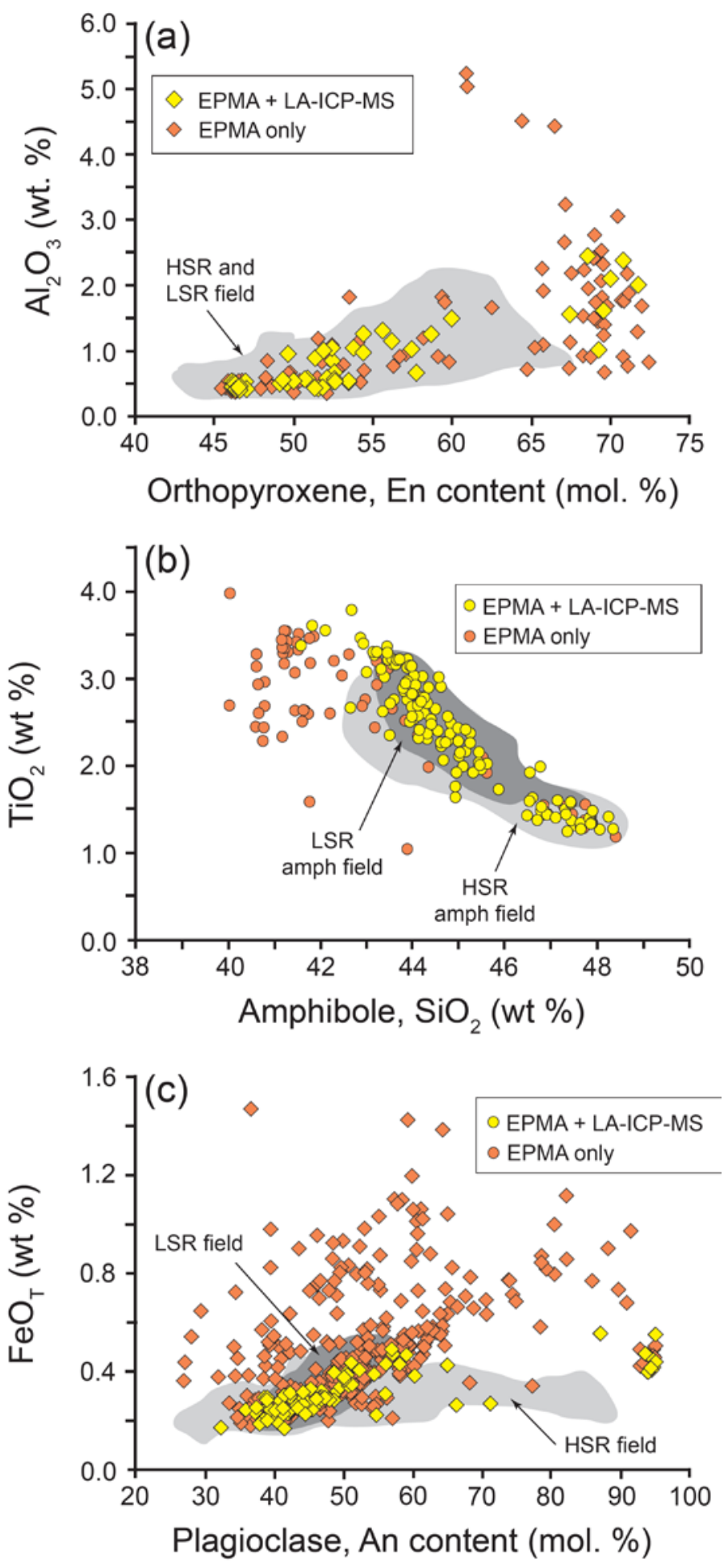

Figure 4.18. A comparison of selected major element compositions of crystals from the mafic versus rhyolitic clasts. The yellow symbols identify analyses for which in situ trace element data was also able to be acquired, whereas the orange symbols show analyses for which there is no corresponding trace element data. The higher spatial resolution of EPMA versus LA-ICP-MS was the main limiting factor in determining which crystals could be analysed for their trace element contents. 
The plagioclase data in Figure 4.18 appears most significantly affected by this apparent sampling bias, with no mafic plagioclase with FeOt contents between 0.5 and $1.5 \mathrm{wt} \%$ having been analysed by LA-ICP-MS. Linkages between plagioclase texture and major element chemistry where explored and are summarised in Figure 4.19. Although complex in detail, some broad characterisations can be made. Firstly, the majority of analyses that returned high Fe contents at a given An content were almost exclusively analyses on groundmass plagioclase (microlites) or from very thin $(<5 \mu \mathrm{m})$ quench crystallisation rims on larger crystals. Of the plagioclase crystals that are consistent with derivation from the rhyolites (i.e., overlapping the compositional fields defined for HSR and LSR crystals), most show at least very thin rims that increase markedly in BSE brightness (i.e., higher An content), a reflection of their late-stage immersion in hotter, more mafic compositions. Others appear have significant ( $>100 \mu \mathrm{m}$ thick) rim zones of mottled high An surrounding relatively featureless sodic cores (e.g., upper middle examples in Figure 4.19), indicating a more prolonged exposure to mafic compositions.

In addition, major element data were also collected for olivine, clinopyroxene, magnetite and ilmenite (see Electronic Appendices). Olivines from calc-alkaline clasts were almost entirely unzoned with respect to BSE imagery and major element composition, and returned uniform compositions of $\mathrm{FO}_{85 \pm 1}$. However, the outermost rims of these olivines had very thin $(<5 \mu \mathrm{m})$ BSE-brighter, more Fe-rich rims that reached compositions of $\mathrm{FO}_{74}$. Olivine is extremely rare in the tholeiitic clasts but three examples were analysed by EPMA in the sectioned clasts, returning compositions between $\mathrm{FO}_{75}$ and $\mathrm{FO}_{65}$. Trace element data for representative olivine from the calc-alkaline samples $\left(\mathrm{Fo}_{85}\right)$ and tholeiitic olivine $\left(\mathrm{FO}_{72}\right)$ appear in the supplementary information. Clinopyroxene was only encountered in the sectioned clasts so only major element data are available. These crystals ranged from $\mathrm{En}_{34}$ to $\mathrm{En}_{49}$ and $\mathrm{WO}_{32}$ to $\mathrm{Wo}_{44}$.

The trace element compositions of analysed crystals of plagioclase (Figure 4.20), orthopyroxene (Figure 4.21) and amphibole (Figure 4.22) from the mafic clasts also fall almost entirely within the HSR and LSR crystal fields. Notable exceptions to this in the calc-alkaline clasts are the very high-An plagioclase $\left(\mathrm{An}_{85-95}\right)$, and in the tholeiitic clasts the high-En orthopyroxenes and some of the least evolved amphiboles $\left(\mathrm{Eu} / \mathrm{Eu}^{*}>\sim 0.8\right)$.

Due to the considerable compositional overlap between crystals from the mafic clasts and those from HSR and LSR samples, there is considerable difficulty in identifying which crystals can be considered phenocrystic in the mafic magmas. Only the clinopyroxenes, 

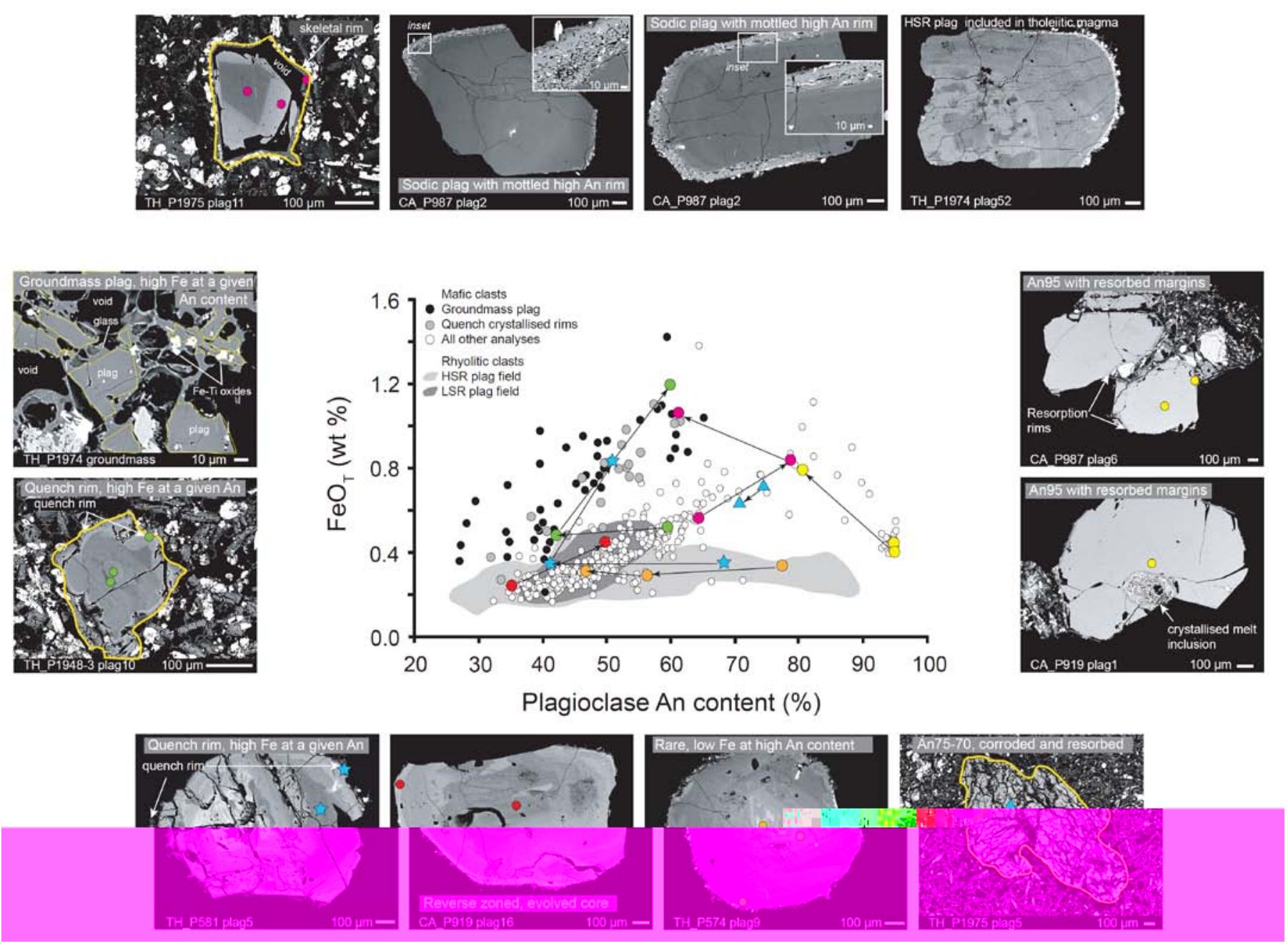

Figure 4.19. Figure to illustrate the textural and compositional linkages between plagioclase in the mafic clasts. BSE images of selected crystals are shown here to highlight some of the linkages that can be made between textures and composition, represented by a plot of $\mathrm{FeO}_{\mathrm{t}}$ versus An content. Analysis spot points in the crystal images are marked with circles that correspond to the symbols in the central plot. For example, the portion of the dataset that plots at higher FeOt contents at a given value of An (black and grey filled circles) is entirely comprised of analyses of rapidly grown plagioclase, i.e., flash crystallised microlites in the groundmass and thin, quench-crystallised rims. The samples are labelled at the bottom of the images with CA and TH denoting crystals from calc-alkaline and tholeiitic clasts, respectively. The coloured symbols on the plot correspond to the analysis positions marked by the same colours on the BSE images. 
which are exceedingly rare in the rhyolites (and inferred from their compositions to be xenocrystic), and other crystals with more primitive compositions than are observed in the rhyolites can reasonably be inferred to belong in the fractionation history of the mafic magmas.
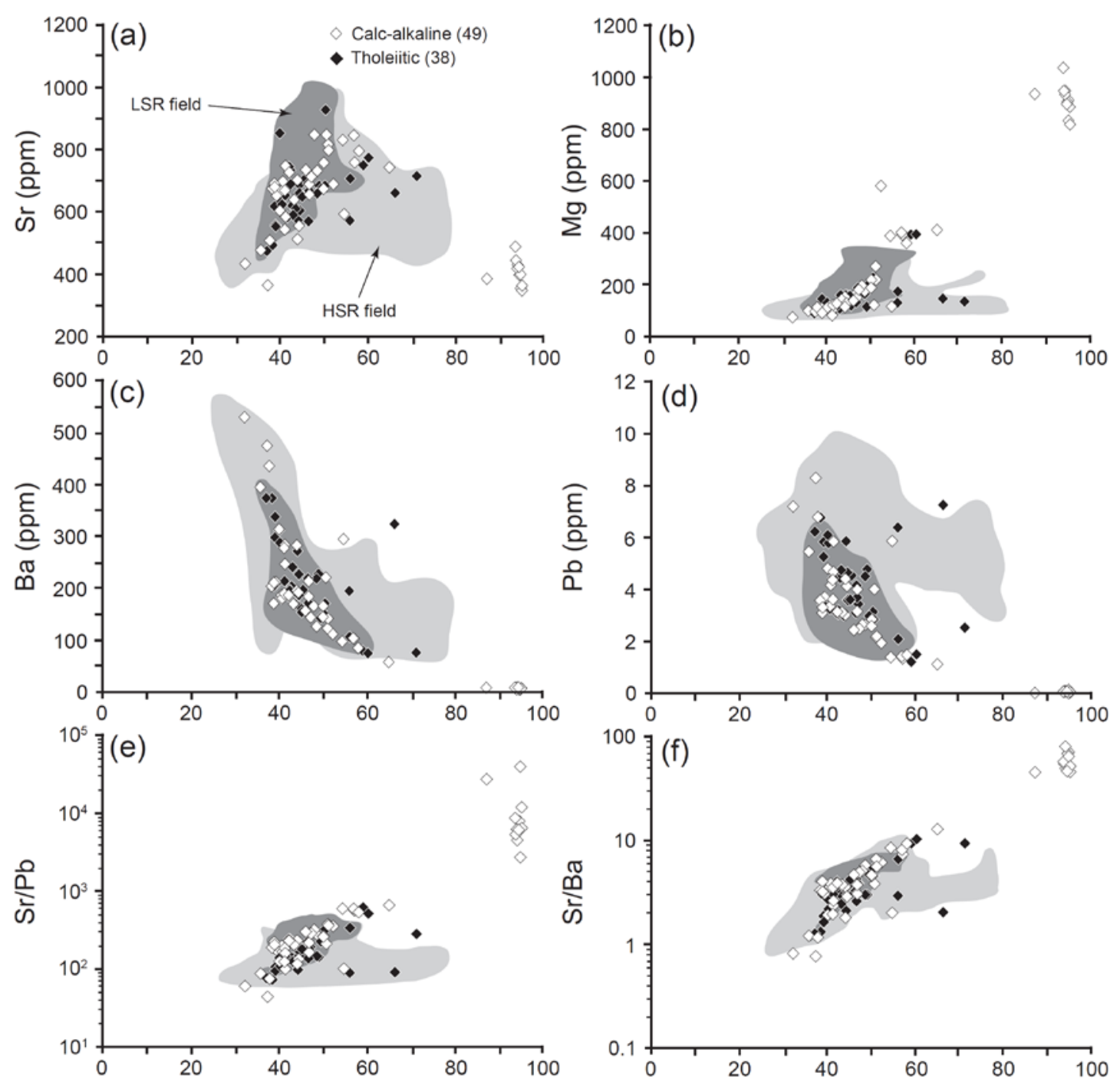

Anorthite content (mol. \%)

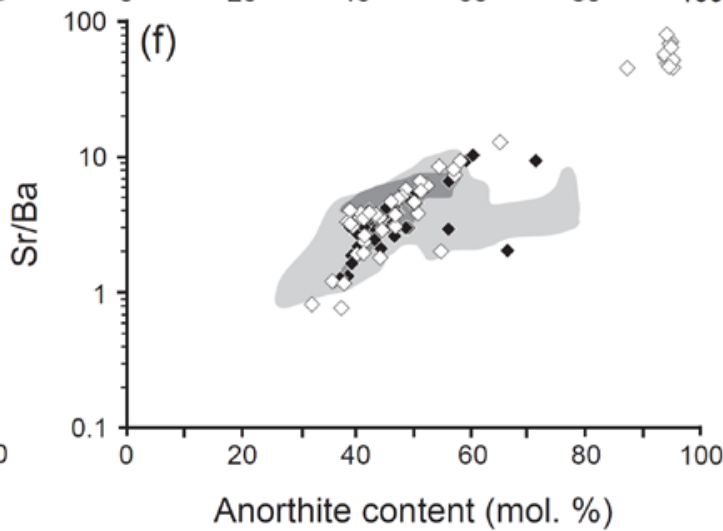

Figure 4.20. Selected trace element compositional data of plagioclase crystals from Oruanui juvenile mafic clasts. Note the logarithmic scales on panels (e) and (f). The grey shaded regions show the compositional ranges from the HSR (light grey) and LSR (dark grey) plagioclase crystals. 

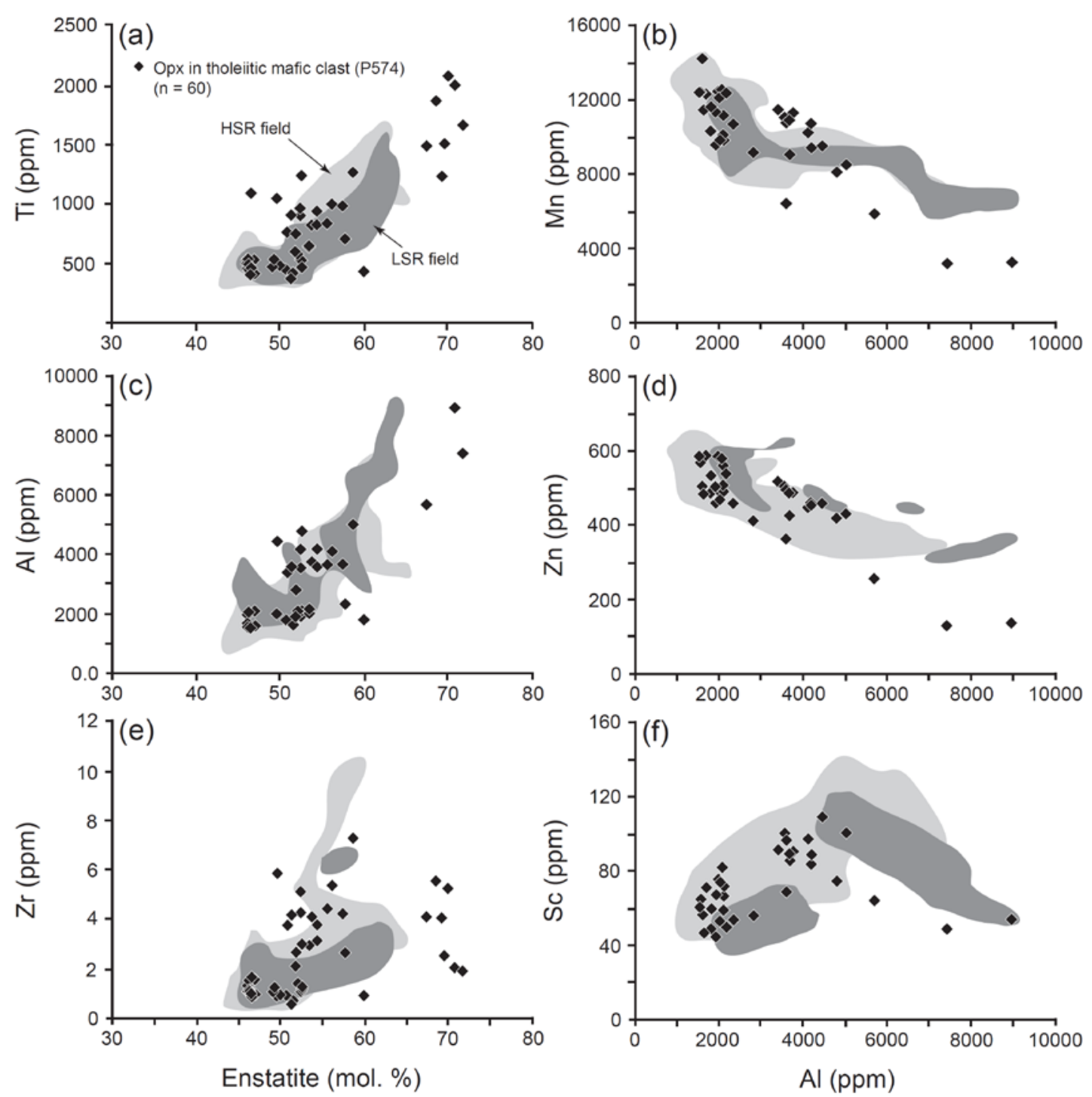

Figure 4.21. Selected trace element compositional data for orthopyroxene from a representative evolved tholeiitic mafic clast (P574; $\left.\mathrm{SiO}_{2}=62.4 \mathrm{wt} \%\right)$. Note: only 35 of the 60 analyses by LA-ICPMS on this sample included $\mathrm{Al}$ in the analytical scan.

\subsubsection{Intensive variables}

Constraining magma intensive variables in the Oruanui mafic magmas is challenging because the compositional and textural data indicates that many of the crystals in the mafic clasts are not equilibrium phases. Of the models and phases available to constrain preeruptive temperatures, Fe-Ti oxides may be considered best because they are known to reequilibrate very rapidly at magmatic temperatures (typically days to weeks; e.g. Freer and Hauptman 1978; Hammond and Taylor 1982; Venezky and Rutherford 1999).

Temperatures calculated from equilibrium pairs (after Bacon and Hirschmann 1988) of FeTi oxides from the mafic samples return bimodal temperature estimates centred around 

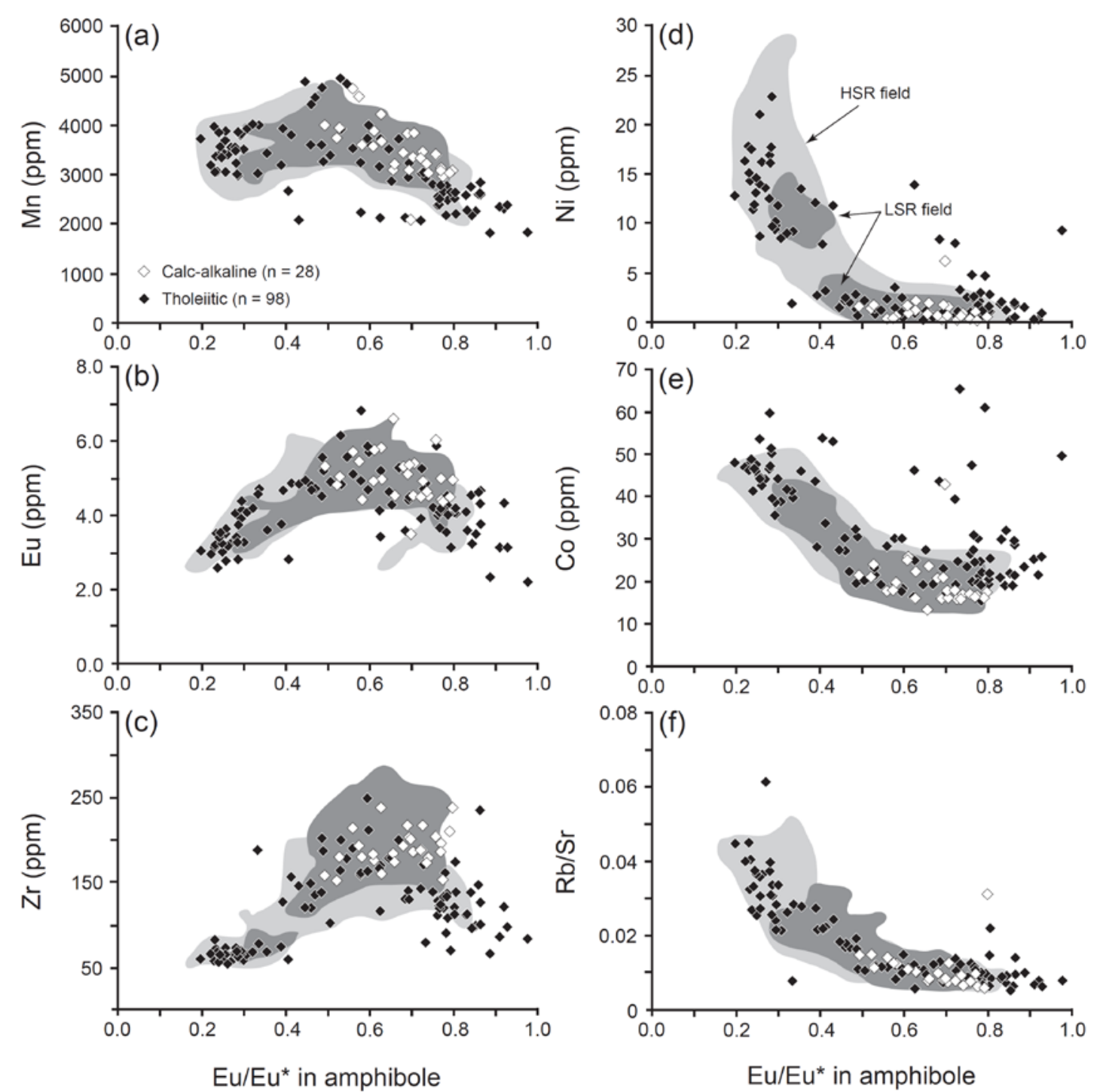

Figure 4.22. Selected trace element compositional data for amphibole crystals from the Oruanui mafic clasts.

$1000{ }^{\circ} \mathrm{C}$ and $820^{\circ} \mathrm{C}$ (Figure 4.23). This bimodality suggests that there are Fe-Ti oxides from both the mafic and rhyolitic end-members in the mafic clasts. We do not use the Ridolfi et al. (2010) thermobarometric formulations for these amphiboles because the larger crystals are clearly inherited from the rhyolite and the groundmass amphiboles are not likely to have maintained equilibrium during the rapid crystallisation of the groundmass.

Two-pyroxene thermometry can be applied by pairing together clinopyroxene (inferred to be entirely phenocrystic to the mafic magmas) and the most primitive orthopyroxenes (i.e., those with compositions that are only found in the mafic clasts). When only pairings that 
pass the Fe-Mg exchange equilibrium test of Putirka (2008) (i.e., $K_{D}=1.09 \pm 0.14$ ) are used 19 equilibrium pairings remain. Estimates based on these pairs return average temperatures of $\sim 1010{ }^{\circ} \mathrm{C}$ or $1038{ }^{\circ} \mathrm{C}$ using the Brey and Kohler (1990) and Putirka (2008) models, respectively (Figure 4.23).
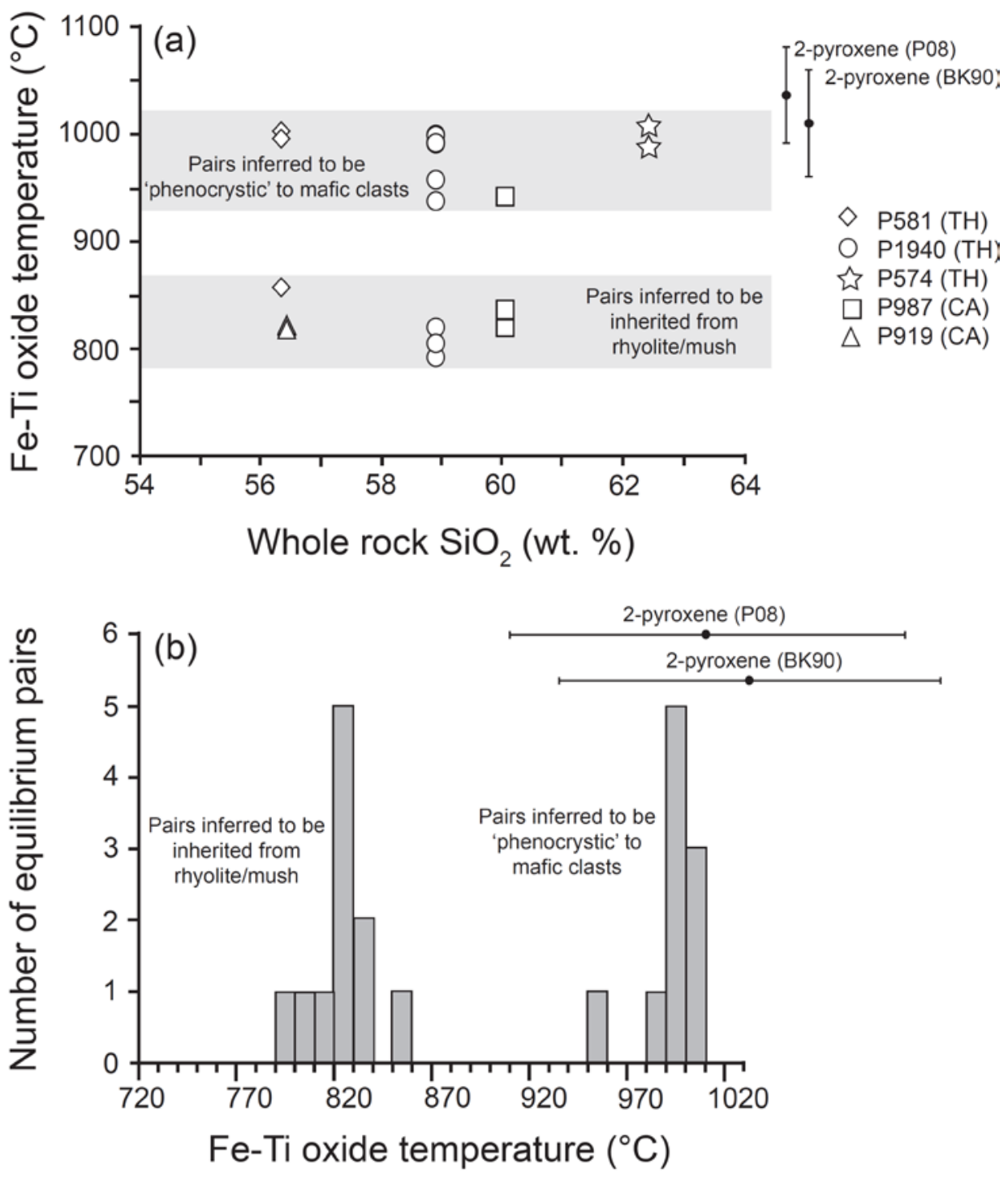

Figure 4.23. Fe-Ti oxide temperatures for equilibrium pairs (after Bacon and Hirschmann 1988) extracted from Oruanui juvenile mafic clasts. Temperatures are calculated using the model of Ghiorso and Evans (2008). Note the bimodality of the temperature estimates. The lower temperature group are assumed to represent pairs of oxides that were entrained from the crystal mush pile and/or during interactions with the rhyolite body. Also shown are the mean $( \pm 2 \mathrm{sd})$ temperature determinations from two-pyroxene thermometry for 19 equilibrium opx-cpx pairs (i.e., $\mathrm{K}_{\mathrm{D}}(\mathrm{Fe}-\mathrm{Mg})=$ $1.09 \pm 0.14)$. BK90 - Brey and Kohler (1990); P08 - Putirka (2008, his eqn. 37). 


\subsection{DISCUSSION}

\subsubsection{Absence of zonation in the Oruanui HSR magma body}

Wilson et al. (2006) showed that although there was significant whole-rock compositional diversity in the Oruanui rhyolitic clasts, there was no systematic zonation with respect to eruption phase (i.e., stratigraphic height: Figure 4.2). This observation rules out the systematic tapping of a stratified magma chamber. Our new and extended crystal-specific analytical data confirm this view and enable some new insights to be made. For example, comparison of compositional data of plagioclase crystals extracted from early- versus lateerupted HSR clasts (corresponding to the approximate top and bottom, respectively, of the erupted melt-dominant magma body) show no significant differences in composition

(Figure 4.24), ruling out vertical stratification of crystal compositions in the magma body.
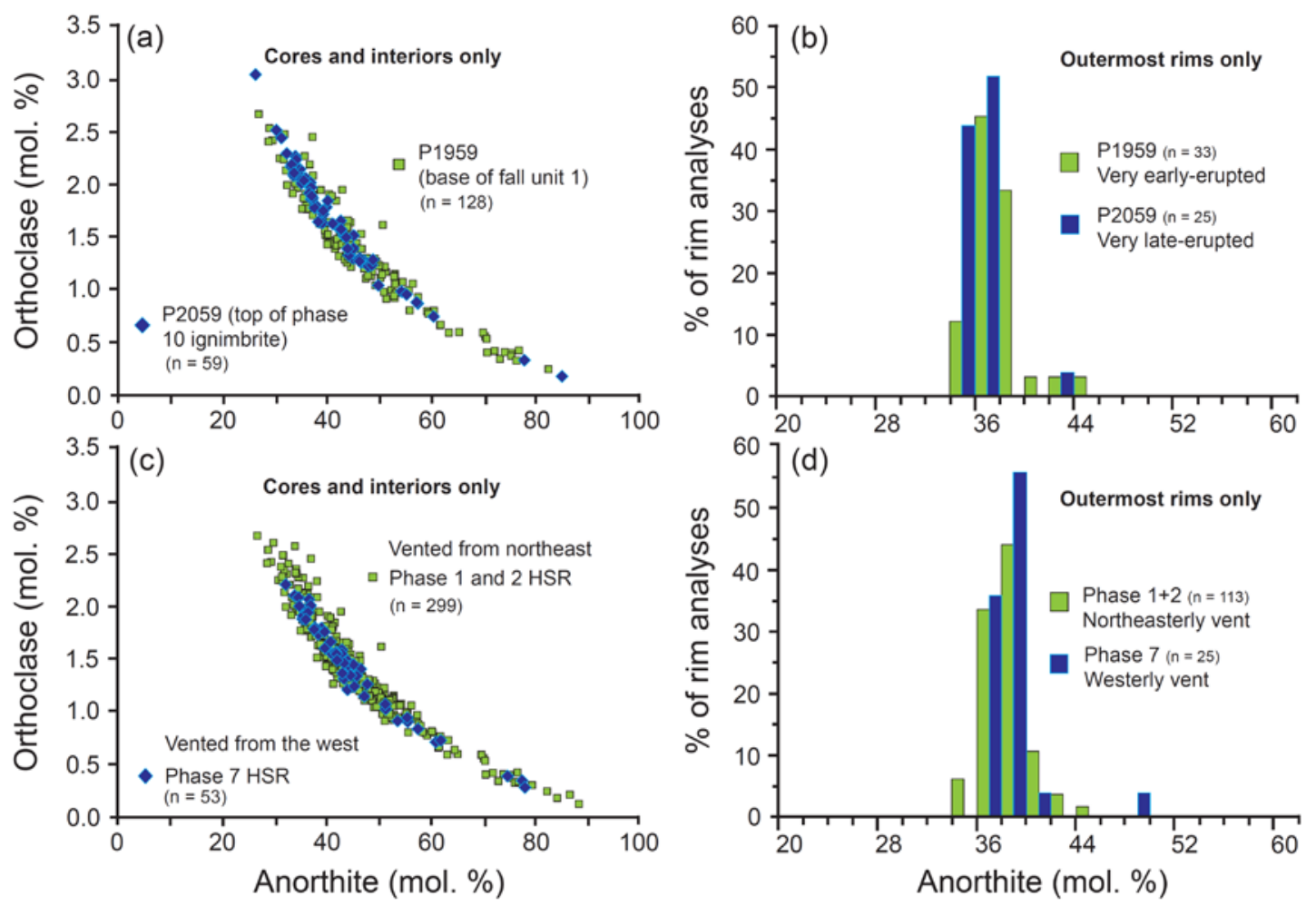

Figure 4.24. Comparisons of HSR plagioclase compositions between early- versus late-erupted clasts in (a) and (b), and those erupted from geographically distinct areas of the Oruanui caldera in (c) and (d). Panels (a) and (c) comprise all compositional data for cores and interiors of plagioclase in the clasts shown. Panels (b) and (d) show only data for the outermost rims of the plagioclase crystals. There is no significant differences between the compositional ranges of plagioclase early- versus late-erupted clasts or those erupted from laterally distinct margins of the caldera, and the outermost rims show a near identical range. 
Comparisons of samples inferred to have been vented from laterally distinct regions within the Oruanui caldera are also possible. Wilson (2001) delineated the approximate position of the phase 1 and 2 vents along the north-eastern margin of the modern Lake Taupo (Figure 4.1) on the basis of isopach reconstructions from the proximal fall deposits. The vent positions of most later eruption phases are not able to be discerned due to the partialto-complete removal of proximal fall deposits during the emplacement of later-stage ignimbrites. However, in some instances field relationships enable some qualitative constraints to be applied. For example, at the Punatekahi scoria quarry site (loc. 2288 of Wilson 2001; Figure 4.1), it is apparent from erosion patterns at the base of the ignimbrite flow units that ignimbrite of phases 2 and 3 was emplaced by flows originating from a source east of the NNE-SSW alignment of the local topographic ridge crest, whereas the later powerful phase 7 flows traversed that site from a source west of the ridge alignment. We thus infer that the phase 7 flows were sourced from vents now concealed beneath the northwestern part of Lake Taupo. The compositions of crystals extracted from clasts erupted from easterly- versus westerly-located vents show no significant differences (Figure $4.24 \mathrm{c}, \mathrm{d}$ ), however, ruling out any significant lateral stratification of the HSR magma body.

Two further features of the plagioclase data presented in Figure 4.24 require emphasis. First, the cores plus interior domains of the plagioclase crystals in a given HSR pumice clast exhibit significant compositional diversity. (Although not plotted here, the same is also true for orthopyroxenes [Wilson et al. 2006] and amphiboles in any given HSR clast: see Electronic Appendix for data). To a first order this diversity of compositions (An in plagioclase, En in orthopyroxene, $\mathrm{Al}$ in amphibole) is consistent with the cores and interior domains of the HSR crystals having crystallised from magma(s) of a range of compositions and temperatures. Application of the Ridolfi et al. (2010) thermobarometric formulations to the cores and interiors of HSR amphibole crystals (Allan et al. 2013, their Figure 5) supports this notion, returning a significant range of P-T values (broadly $70-270 \mathrm{MPa}$, and 750 to $920^{\circ} \mathrm{C}$ ). Variations in these intensive parameters are correlated with the $\mathrm{Eu} / \mathrm{Eu}^{*}$ of the amphiboles (Allan et al. 2013, their Figure 3), a compositional parameter that is interpreted to reflect the degree of evolution of the melt from which the amphiboles grew. Second, the compositions of the outermost plagioclase rims are nearly uniform, regardless of the inferred depth tapped within the pre-eruptive magma chamber (i.e., early- versus late-erupted samples) or relative lateral separation of the vent sites (Figure 4.24b, d). This uniformity of crystal rim compositions is also apparent in the HSR orthopyroxenes and 
amphiboles (Allan et al. 2013; Figures 4.11-14; see Electronic Appendices for data from individual clasts). The relative homogeneity of the crystal rims indicate that their final episode of growth occurred in an environment, interpreted to be the melt-dominant magma body, that was near uniform in (melt) composition (Figure 4.3) and held within a limited range of pressures and temperatures (Tables 4.5 and 4.6).

\subsubsection{Generation of the Oruanui melt-dominant magma body}

Allan et al. (2013) proposed, on the basis of amphibole and orthopyroxene textural and chemical data, combined with $\mathrm{P}-\mathrm{T}-\mathrm{H}_{2} \mathrm{O}$ constraints, that the voluminous Oruanui HSR magma body had accumulated following rapid extraction of large volumes of melt (plus entrained crystals) from a crystal-dominated mush-like source body. The significant decompression event reflected in the in-situ chemistry of amphibole cores and interiors also captured a chemical signature of the orthopyroxene dissolution-recrystallisation history that is apparent in textural analysis (Figure 4.6). Orthopyroxene destabilisation occurred during decompression from as much as $270 \mathrm{MPa}$ to $140 \mathrm{MPa}$, recorded in the amphiboles as increasing levels of $\mathrm{Mn}$ and $\mathrm{Zn}$, two elements notably enriched in the orthopyroxenes and inferred to have been taken up as the orthopyroxenes dissolved. Decompression to less than $\sim 140 \mathrm{MPa}$ saw the re-stabilisation and re-growth of orthopyroxene rims and a decrease in the abundance of $\mathrm{Mn}$ (Figure 4.14) and $\mathrm{Zn}$ in the cocrystallising amphiboles.

The model put forward by Allan et al. (2013) on the basis of amphibole and orthopyroxene is also consistent with the new data presented here for plagioclase. The significant resorption \pm sieve texturing of $\sim 90 \%$ of the plagioclase cores, followed by overgrowths of rim-zones (Figure 4.7) are inferred to be equivalent to the same disequilibrium-thenregrowth history experienced by most of the orthopyroxenes (Figure 4.6). Experimental studies on andesitic compositions have shown that sieve-textures similar to that observed in the HSR plagioclase cores can form in response to rapid decompression (Nelson and Montana 1992). The notable decrease in the abundance of Eu in the amphiboles at $\sim 140$ $\mathrm{MPa}$ is commensurate with the inflection of Mn concentrations (Figure 4.14; Trend A) that Allan et al. (2013) interpreted to reflect the re-stabilisation and re-growth of orthopyroxene upon reaching the accumulating melt-dominant magma body. This decrease in Eu content of the amphiboles may similarly reflect the restablisation and crystallisation of plagioclase in the melt-dominant magma body following decompression. 
A common history can thus be inferred for the majority of plagioclase, orthopyroxene and amphibole crystals in the HSR clasts: derivation from a deeper, hotter and lesser evolved source mush region, followed by entrainment and crystallisation of rim-zones in the cooler, shallower and more evolved melt-dominant magma body. The earlier history of HSR quartz crystals, however, contrasts with that inferred for these other main phases, with the trapped melt inclusions recording more evolved compositions than the final (HSR) meltdominant magma body. Crystallisation of the quartz rim-zones took place in the meltdominant magma body, along with plagioclase, orthopyroxene and amphibole, as shown by the close correspondence between compositions of the host melt and those of reentrant inclusions (Liu et al. 2006).

Allan et al. (2013) highlighted the significant compositional overlap between the earlier history of the HSR crystals (i.e., cores plus interiors) and crystals from the LSR, in addition to overlapping P-T conditions indicated by the amphiboles. They argued that the LSR magma approximated the composition of crystal-poor magma extracted from the Oruanui crystal-mush/source zone that, following crystallisation of the rim-zones and some associated cooling, culminated in the final HSR composition. This notion is consistent with the finding of Wilson et al. (2006) that the HSR compositions can be generated from LSR compositions following $\sim 28 \%$ fractionation of the crystal phases recorded in the pumices. In this light the LSR pumices that were sampled by the Oruanui eruption may be considered to represent isolated pockets of crystal-poor rhyolite magma that existed in the crystal-mush source reservoir, and that were syn-eruptively tapped during evacuation of the HSR magma body. Allan et al. (2013) pointed out that all LSR clasts were quartz-free and that quartz may have only begun to grow in the melt-dominant magma body after the melt had sufficiently evolved to Si-saturated conditions.

In light of the expanded crystal-specific dataset considered here, we update and modify this model in order to more fully explain some of the features of quartz and other crystal phases discussed above.

\subsubsection{A revised (tweaked) model for the generation of the melt-dominant magma body}

The diversity of measured crystal compositions and inferred P-T conditions for the crystal cores and interiors are envisaged to reflect the derivation of the crystals from a thermally and compositionally zoned crystal-mush source. During the processes of crystal-liquid separation, large volumes of melt plus entrained crystals were carried upwards into the melt-dominant magma body that was forming at shallow crustal levels $(\sim 90-140 \mathrm{MPa}$, or 
3.5-6 km depth). Convection and stirring of the accumulating melt-rich body resulted in the destruction and near homogenisation of the melt, reflected in the subsequent growth and compositional characteristics of the crystal rim-zones.

In recognition of intricacies of the melt inclusion dataset from quartz (indicating crystal growth from more evolved melts during the crystallisation of the interiors, to slightly less evolved conditions in the melt-dominant magma body: Figure 4.4; Liu et al. 2006), we envisage that quartz was stable in the uppermost layers of the mush body. The interstitial melt in this part of the mush was very evolved (on the basis of $\mathrm{Rb} / \mathrm{Sr}$ ratios) and the modal values from volatile saturation pressures (Liu et al. 2006) indicate this zone probably was at $\sim 120$ to $150 \mathrm{MPa}(\sim 4.5-5.5 \mathrm{~km}$ depth) but not greater than $\sim 190 \mathrm{MPa}$ (>7 km depth). It thus seems likely that some of the plagioclase, amphibole and orthopyroxene cocrystallised with quartz in this upper part of the mush layer. A small percentage of plagioclase crystals have cores and interiors with compositions notably more evolved than the outermost rims (i.e., $\mathrm{An}_{26}$ to $\mathrm{An}_{35}$; Figure 4.9a) and can thus be inferred to have cocrystallised alongside quartz. Similarly a small component of the amphibole cores and interiors have low-Al compositions that may reflect their earlier growth and crystallisation from evolved interstitial melt in the quartz-bearing portion of the mush.

Below this upper quartz-bearing mush layer, downward thermal and compositional stratification of the mush is reflected in the compositions of plagioclase (increasing An content) and orthopyroxene (increasing Mg content). The amphibole compositions reflect increasing model temperatures with depth in the mush pile, reaching $\sim 920{ }^{\circ} \mathrm{C}$ at pressures of $\sim 270 \mathrm{MPa}$ or $\sim 10 \mathrm{~km}$ depth, with corresponding compositional gradients reflected in co-related $\mathrm{Eu} / \mathrm{Eu}^{*}$ values (Allan et al. 2013).

In addition, the plagioclase compositional data from HSR clasts show evidence for two contrasting sources for the higher-An $($ An $>50)$ plagioclase (Figure 4.10). A subordinate population has notably depleted concentrations of compatible elements (e.g., Sr and $\mathrm{Mg}$ ) and elevated levels of incompatible elements $(\mathrm{Ba}$ and $\mathrm{Pb})$ at given values of $\mathrm{An}>50$ (Figure 4.10). Although these particular domains are consistent with growth from (qualitatively) hot and/or dry melts, their trace element characteristics indicate that those melts were comparatively more evolved. The dominant population of plagioclase crystals show higher $\mathrm{Sr}, \mathrm{Mg}$ and lower $\mathrm{Ba}, \mathrm{Pb}$ contents and are clearly derived from contrasting melts. On the basis of these characteristics it is suggested that the high An, low Sr and $\mathrm{Mg}$ plagioclase domains grew from melts with a high crustal component. In contrast the low 
$\mathrm{Ba}, \mathrm{Pb}$ crystals are inferred to have grown from more broadly intermediate melts, with lower crustal contributions. This inference is in line with evidence from An and Srisotopic profiles in the blue-grey cored plagioclase crystals presented by Charlier et al. (2008), in which high An, high ${ }^{87} \mathrm{Sr} /{ }^{86} \mathrm{Sr}$ overgrowths around the cores were inferred were interpreted as growing from almost 'pure' crustal melts.

\subsubsection{The role of mafic magma}

In applications of the crystal mush model to the development and eruption of large crystalrich ignimbrites, importance is placed on the role of mafic magmas to provide heat and volatiles to defrost and remobilise the mush (e.g., Bachmann and Bergantz 2006). The involvement of at two distinct mafic magmas in the Oruanui eruption raises questions as to what role mafic magma had in mush reactivation or initiating the eruption. The estimated total volume of mafic magma erupted $\left(\sim 3-5 \mathrm{~km}^{3}\right)$ is significantly larger than any other known eruption of purely mafic material in the TVZ (Wilson 2001). The ubiquitous downtemperature signatures in the rim-zones of the main crystal phases (e.g., decreasing An content in plag, decreasing En contents in Opx) precludes the notion that injection of mafic triggered the eruption through mafic recharge processes. Wilson et al. (2006) suggested that the tholeiitic mafic magma may have ponded at the base of the primed Oruanui melt-dominant magma body in the weeks to months prior to eruption. The resulting convection and stirring brought about the hot mafic floor was suggested by them to explain the homogenisation of any significant pre-existing zonation within the meltdominant magma body.

Chemical analysis of the macroscopic crystals from individual mafic clasts (Figures 4.20-22) showed that many of these crystals were inherited crystals equivalent to those found in HSR and LSR clasts. The positive Eu/Eu* in almost all of the tholeiitic clasts (Figure 4.17) is also indicative that this magma accumulated significant amounts of plagioclase. One of the two trends observed in the trace element glass compositions of LSR plagioclase melt inclusions and selvedges (Figure 4.5) can be explained by binary mixing between LSR compositions and the least evolved tholeiitic magma (Figure 4.25).

Trends within the whole-rock data can be re-visited in the inference that the mafic magmas accumulated a significant component of 'rhyolitic' crystals. Three similar, but subtly different trends are highlighted within the tholeiitic clasts (Figure 4.26) suggesting that the overall tholeiitic group itself may comprise at least three discrete batches of magma. The 
overall patterns within the whole rock data tend to trend towards LSR compositions rather than the volumetrically dominant HSR magma. The exception to this is three samples (trend 3 on Figure 4.26) that plot on compositional trajectories towards HSR compositions.

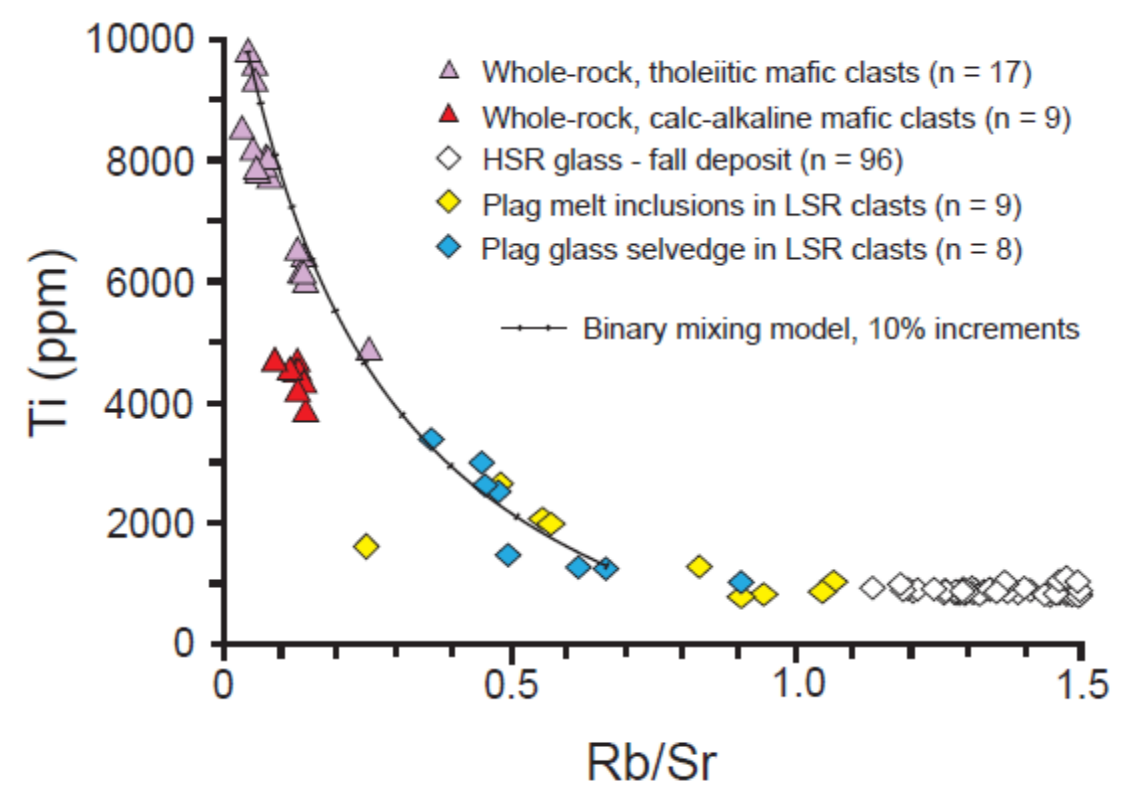

Figure 4.25. Ti versus Rb/Sr data for rhyolitic glasses (as annotated) and juvenile mafic clasts (wholerock). The steeper trend observed in the LSR plagioclase selvedge and melt inclusion data are taken as indicative of an involvement of the tholeiitic mafic magma.

The whole-rock compositional trends within the suites of mafic magmas, particularly the tholeiitic group, and the apparent mixing trend seen in the glass data of LSR samples indicate that mafic magma may have interacted with rhyolitic compositions for some time before the eruption commenced. In particular, a feature of the amphibole trace element data is the unusual increase in $\mathrm{Ni}$ and $\mathrm{Co}$ abundance with decreasing $\mathrm{Eu} / \mathrm{Eu}^{*}$ and model crystallisation pressure (Figure 4.14; Trends B and C). These two elements occur at very low levels in the HSR rhyolite (Table 4.3), and Taupo Volcanic Zone rhyolites in general (e.g., Allan et al. 2008). It seems counter-intuitive that the concentration of these elements, which behave compatibly in mafic systems, should be so enriched in the amphiboles that are inferred from their $\mathrm{Eu} / \mathrm{Eu}^{*}$ values to have crystallised from the most evolved melts. Mafic recharge can be eliminated as a potential cause for the increased $\mathrm{Ni}$ and Co levels in the amphiboles because the HSR amphiboles (plus orthopyroxene and plagioclase) zone outward to compositions reflecting cooler and more evolved melt compositions. It seems 

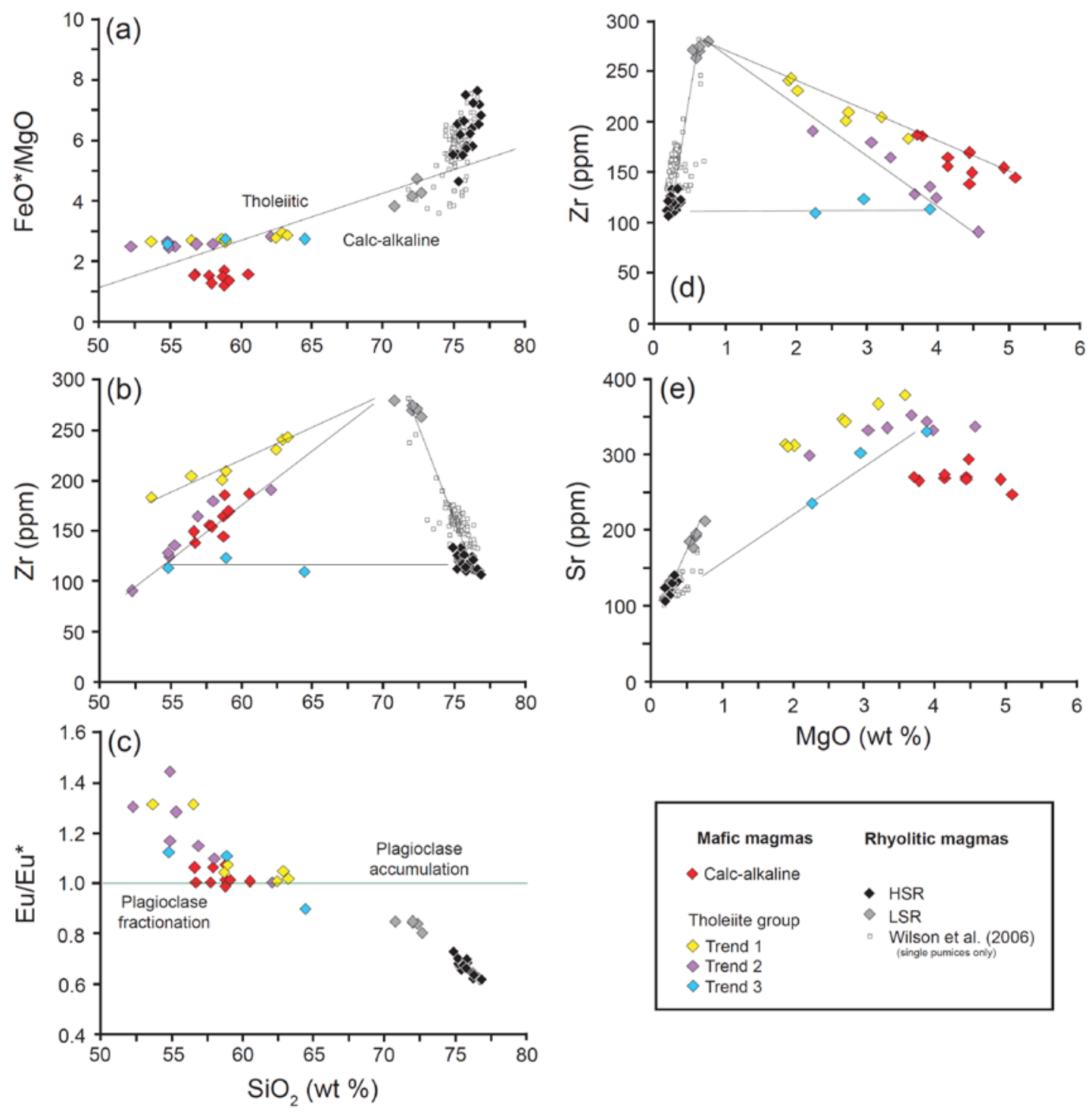

Figure 4.26. Selected whole-rock analytical data for Oruanui felsic and mafic clasts. The tholeiitic group is split into three sub-groups on the basis of possible mixing trends. Chemical trends in the mafic groups overwhelmingly trend towards the LSR compositions and only 3 clasts ('trend 3') are linked towards the volumetrically dominant HSR compositions.

more likely that elevated $\mathrm{Ni}$ and Co levels reflect the dissolution of a high Ni-Co phase into the HSR magma, with these elements subsequently being incorporated into the amphiboles. None of the other crystal phases in the Oruanui rhyolites contain sufficient concentrations of $\mathrm{Ni}$ or $\mathrm{Co}$ to generate the observed increase through their dissolution. The high forsterite olivines $\left(\mathrm{Fo}_{85}\right)$ found in the calc-alkaline mafic magmas, however, are strongly enriched in these elements (Ni 750 ppm; Co 180 ppm: Electronic Appendices). We infer that at some pre-eruptive stage, relatively primitive olivine crystals made their way into either the melt-dominant body or, more likely, the upper, evolved levels of the crystal 
mush, and dissolved. Due to the relatively trace-element poor nature of these olivines (see Electronic Appendices), their dissolution into a large rhyolitic magma body could be expected to be fairly cryptic, with Fe-Mg contents being readily sequestered into the ferromagnesian minerals in the rhyolitic assemblage. If this scenario is correct, then the elevated $\mathrm{Ni}$ and Co contents in the HSR amphibole rims may be evidence for a greater role of mafic calc-alkaline magma, in the earlier assembly of the Oruanui melt-dominant magma body than can be inferred from any other means.

\subsubsection{Timescales of processes in the Oruanui system}

Several approaches have been made or are presented here to infer the chronology of assembly and eruption of the Oruanui melt-dominant magma body. Elemental diffusion in volcanic crystals can be used to provide information about the timescales of sub-surface processes (Costa et al. 2008, for review), and here we highlight three mineral species in particular.

\subsubsection{Fe-Mg diffusion timescales in orthopyroxene}

Within the Oruanui magmas pre-eruptive timescales on the order of decades to millennia have been obtained from modelling of Fe-Mg diffusion in orthopyroxenes and interpreted to represent the physical accumulation of the melt-dominant magma body (Allan et al. 2013). They modelled the prominent main core-rim boundaries in HSR orthopyroxenes (Figure 4.6), a feature that they interpreted to represent the physical arrival of individual orthopyroxene crystals along with packages of LSR melt into the growing melt-dominant magma body. With allowance for maximum uncertainties in model parameters (especially temperature and oxygen fugacity), it is interpreted that the crystal-liquid segregation process that led to the generation of the melt-dominant magma body did not begin until only $\sim 1600$ years prior to the eruption. Probability density function analysis indicated that the peak 'extraction age' was $\sim 230$ years earlier and that there was an apparent period of stasis $\sim 60$ years. This extremely short generation time for the melt-dominant body is, however, consistent with the constraints from model-age data from Oruanui zircons (Wilson and Charlier 2009).

\subsubsection{Fe-Ti diffusion timescales from magnetite}

Inspection in BSE imagery of Fe-Ti oxide crystals extracted from the mafic clasts identified that many magnetite crystals in these samples were zoned (Figure 4.27). Fe-Ti oxides, 

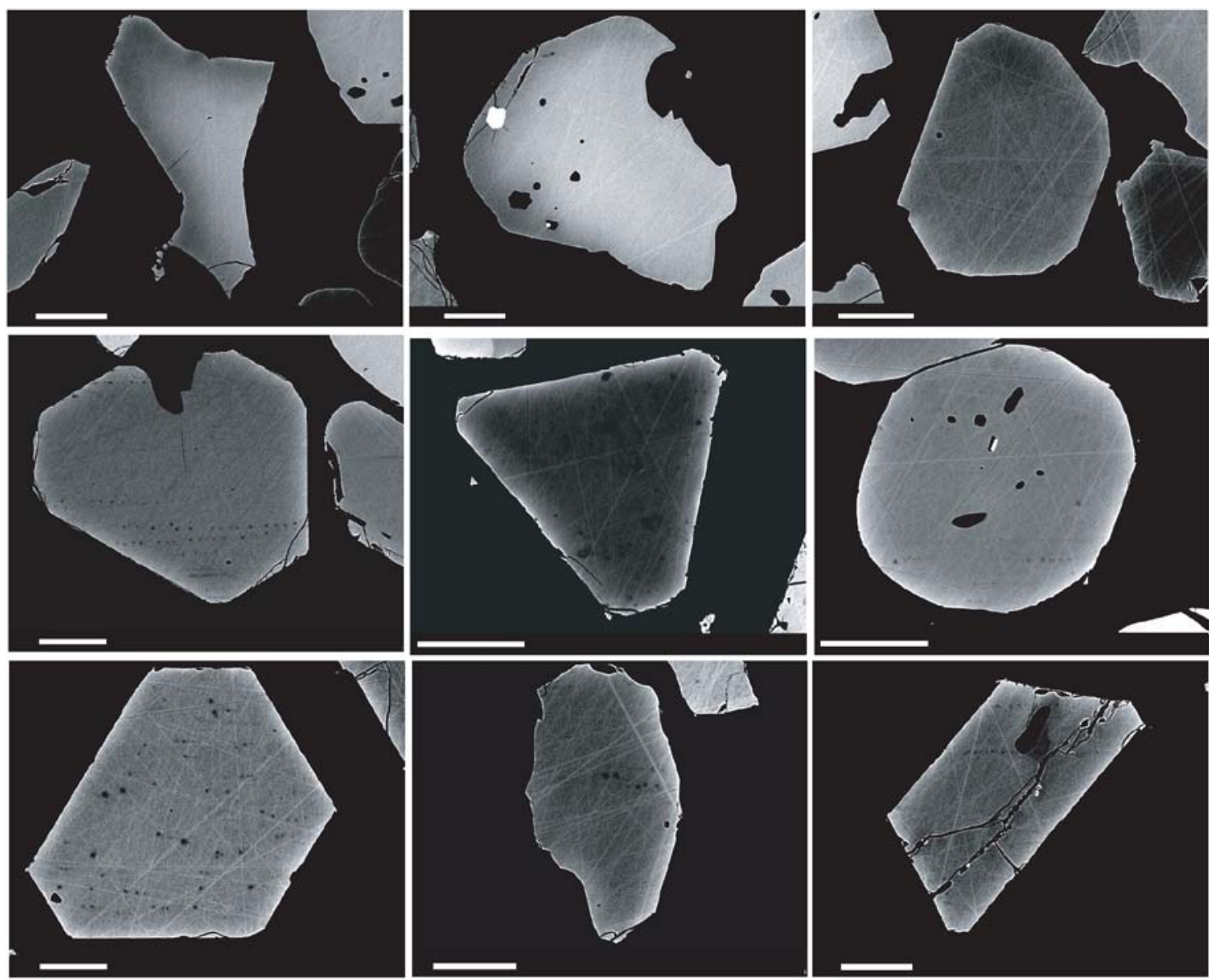

Figure 4.27. Examples of zoned magnetite crystals in Oruanui juvenile mafic clasts. All scale bars are 50 $\mu \mathrm{m}$ across.

magnetite in particular, are known to rapidly re-equilibrate in response to fluctuations in magmatic conditions (Freer and Hauptman 1978; Nakamura 1995; Venezky and Rutherford 1999; Devine et al. 2003). The preservation of Fe-Ti zonation in magnetite crystals in the Oruanui mafic clasts, therefore, is a record of a process (or processes) operating shortly before quenching on eruption. Using the freely available Java-based image processing software, ImageJ (http://rsb.info.nih.gov.ij/), we retrieved spatiallyresolved transects across the BSE images and compared them to the chemical composition along the same transects as measured by EPMA (Figure 4.28). The greyscale values from the BSE images strongly reflected changes in the Fe-Ti content of the magnetite. Although zonation in some minor element oxides was also evident (e.g. $\mathrm{Al}_{2} \mathrm{O}_{3}$ and $\mathrm{MgO}$, Figure $4.28 \mathrm{e}, \mathrm{f}$ ), variations in the concentration of these elements appeared to have little or no influence over the greyscale zonation.

Using the changing greyscale intensity of the zoned magnetite crystals to infer the changing Fe-Ti content of the crystals, we were able to use the BSE images to recover information 

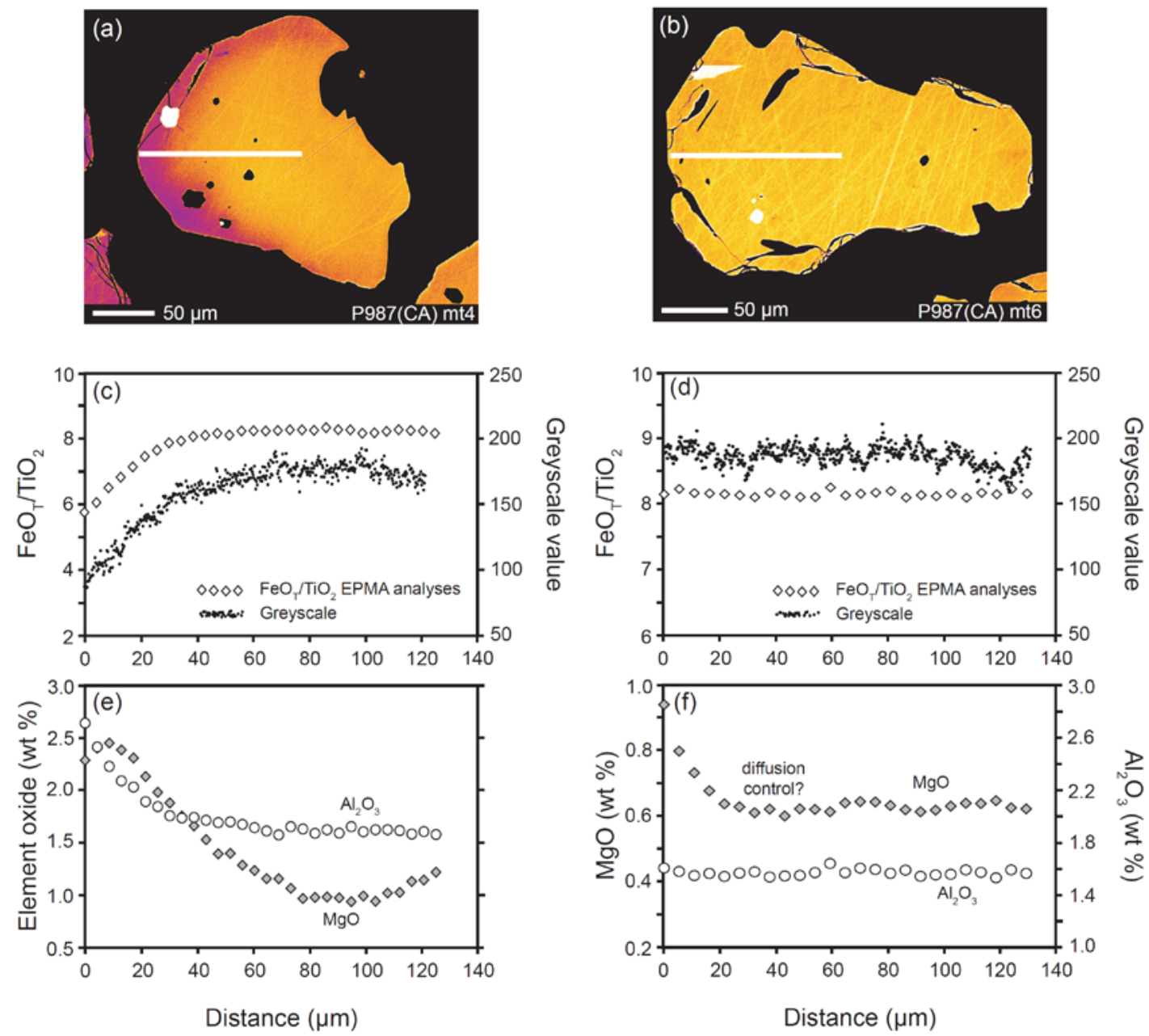

Figure 4.28. False-coloured BSE images and compositional profiles of two magnetite crystals from a single calc-alkaline mafic clast (P987). The magnetite in panel (a) is zoned in greyscale and Fe-Ti content, whereas the crystal in panel (b) is not. The greyscale zonation correlates strongly with the Fe-Ti content of the magnetite (panels c,d), even when there is compositional variation of other minor elements within the crystal (panels e,f). Note: the profile in panel (a) was taken at an acute angle to the zonation boundary in order to allow more EPMA analyses within the gradient region, which has the effect of stretching the 'true' profile.

about Fe-Ti zonation at a higher spatial resolution than given by EPMA spot analyses. We modelled Fe-Ti interdiffusion in magnetite crystals to calculate the timescale(s) over which mafic-felsic mingling occurred prior to quenching upon eruption (Figure 4.29). In order to determine the magnetite Fe-Ti diffusion coefficient $\left(\mathrm{D}_{\mathrm{Fe}-\mathrm{Ti}}\right)$ in the Oruanui system, we used the experimentally derived parameterisation of Freer and Hauptman (1978). We conducted our modelling at conditions of $820^{\circ} \mathrm{C}$ and an oxygen fugacity of NNO. These conditions correspond to the lower modal temperature and oxygen fugacity conditions inferred measured from the cores of equilibrium Fe-Ti oxide pairings within the mafic clasts (Figure 4.23) and should yield a maximum estimate. On this basis, the timescales obtained are 
between 6.7 and 36.6 hours $(n=18)$, but mostly $<18$ hours, and are interpreted to reflect syn-eruptive mixing processes prior to quenching at the surface. There is field evidence for a prolonged (months) time break between phases 1 and 2 of the eruption and a scarcity of juvenile mafic material in the deposits of phases 1 and 2 (Wilson 2001). These factors suggest that the Fe-Ti oxide zonation is recording syn-eruptive timescales related to inputs of fresh mafic magma prior to the outbreak of phase 7 , the ignimbrite of which yielded the samples used in this case.
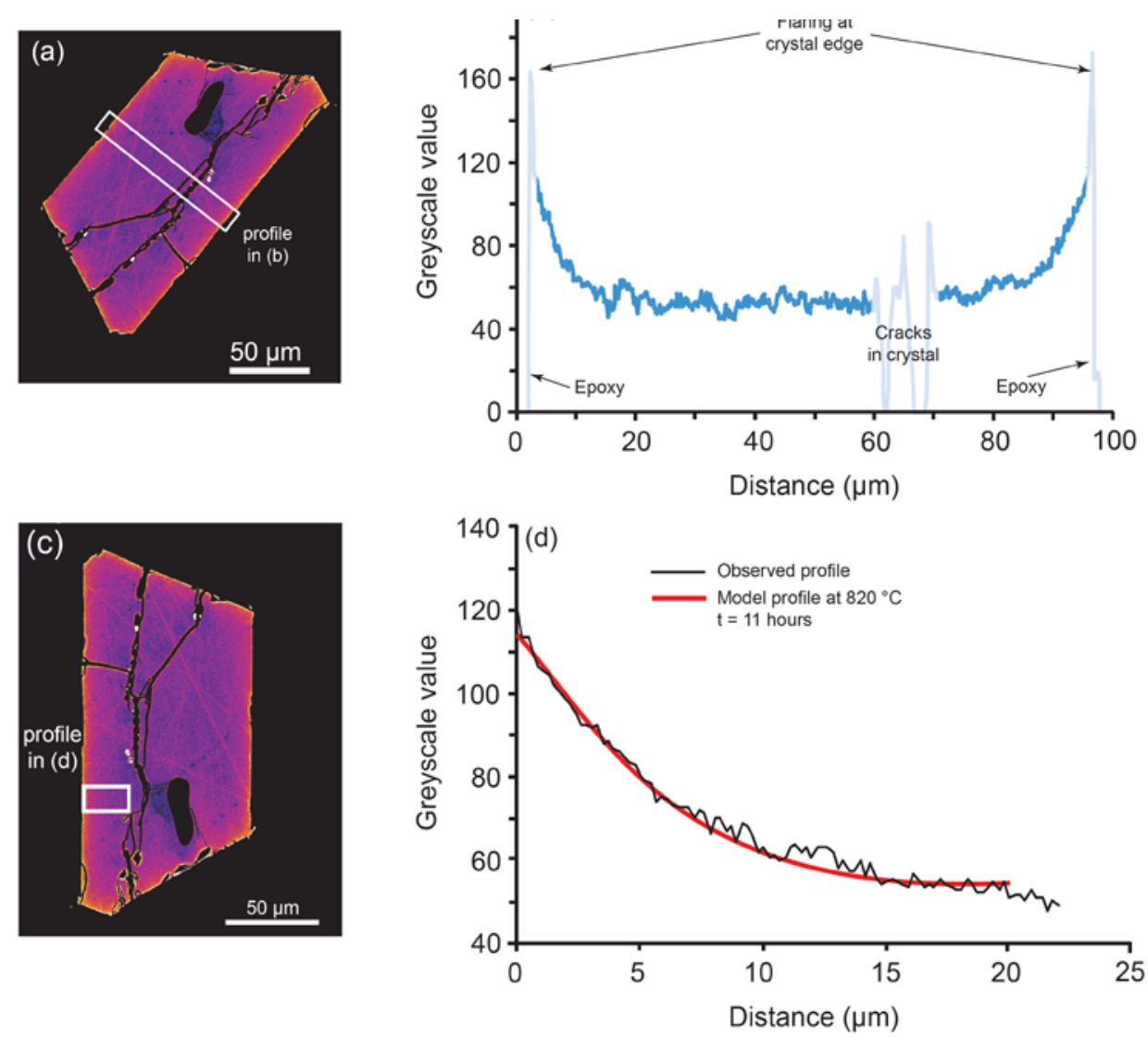

Figure 4.29. An example of a Fe-Ti diffusion modelling of a zoned magnetite crystal from clast P987 (CA). In panels (a) and (b) the greyscale zonation across the crystal is examined to check for symmetry of the profile. Note the 'flaring' effect at the very edges of the crystal. In panel (c) a higher resolution portion of the crystal is selected for modelling, and in panel (d) a modelled curve is fitted to the observed profile. In this case the crystal is interpreted to record a thermal perturbation in the final $\sim 11$ hours prior to quenching on eruption.

The $\mathrm{MgO}$ profile in Figure 4.28f is intriguing. It is the only element to show zonation in this crystal and the shape of the curve is suggestive of a diffusion control. Exploration of the potential timescales that this and similar Mg profiles may record were hindered due to the lack of experimental constraints on $\mathrm{Mg}$ diffusion rates in magnetite. However, a recent 
application of $\mathrm{Mg}$ diffusion modelling in magnetite crystals by Suzuki et al. (in press) estimate an average $\mathrm{Mg}$ diffusivity based on the experimental constraints of similar 2+ cations $\mathrm{Mn}$ and $\mathrm{Co}$. When Fe-Ti interdiffusion coefficients are calculated at the same conditions that Suzuki et al. (in press) calculate their $\mathrm{Mg}$ diffusion coefficients (i.e., $900{ }^{\circ} \mathrm{C}$, $\mathrm{XTi}=0.1, \mathrm{NNO})$, the $\mathrm{Mg}$ appears to diffuse about one order of magnitude faster than FeTi (i.e., $\sim 10^{-15} \mathrm{~m} / \mathrm{s}$ versus $\sim 10^{-16} \mathrm{~m} / \mathrm{s}$ ). If $\mathrm{Mg}$ diffusion rates in magnetite are in line with those suggested by Suzuki et al. (in press), then at the appropriate conditions inferred for the Oruanui crystals here, the $\mathrm{Mg}$ profile in Figure 4.28f would represent a heating event only ca. 1.5 hours prior to quenching.

\subsubsection{Fe-Mg diffusion timescales from olivine}

Despite the abundance of olivine in the calc-alkaline mafic clasts, very few crystals were suitable for Fe-Mg diffusion modelling. All of the large $(1-2 \mathrm{~mm})$ olivine crystals in the calc-alkaline samples have very thin $(<5 \mu \mathrm{m})$ bright rims in the BSE images reflecting a higher Fe-content in the outermost rims. However, closer inspection of the greyscale zonation patterns of the rims (for which the changes in greyscale correlate directly to the changes in the Fe-Mg content of the olivine, e.g., Martin et al. 2008) suggests that these zonation features are not solely diffusion controlled. Rather these fine-scale rim zonation features appear to reflect a quench crystallisation/growth feature of the olivines, probably resulting from the mafic-felsic interaction. Although the rim zonation was not suitable for more rigorous $\mathrm{Fe}-\mathrm{Mg}$ diffusion modelling, based on their small length-scales $(<5 \mu \mathrm{m})$ we can estimate a maximum timescale over which they could possibly be preserved before diffusion at magmatic conditions would result in their homogenisation. Based on a lowerbound temperature estimate of $\sim 820^{\circ} \mathrm{C}$ and an oxygen fugacity at $\mathrm{NNO}$, the olivine rim zonations are recording an event that occurred no longer than a few weeks before quenching on eruption. Although more rigorous constraints are not available we suggest it is likely that the quench rims on the olivines formed during the same event recorded by the zoned magnetite crystals (discussed above).

\subsubsection{A cascade of timescales inferred from the Oruanui crystal archive}

By combining our new results and previously published studies an overview of the timescales of pre- and syn-eruptive processes culminating in the Oruanui eruption can presented (Figure 4.29). At the longer-scale end, the timescale for the growth of the Oruanui mush zone, with its distinctive chemical and isotopic compositional characteristics and zircon model-age spectra goes back at least 20-40,000 years (Sutton et al. 1995; Wilson 


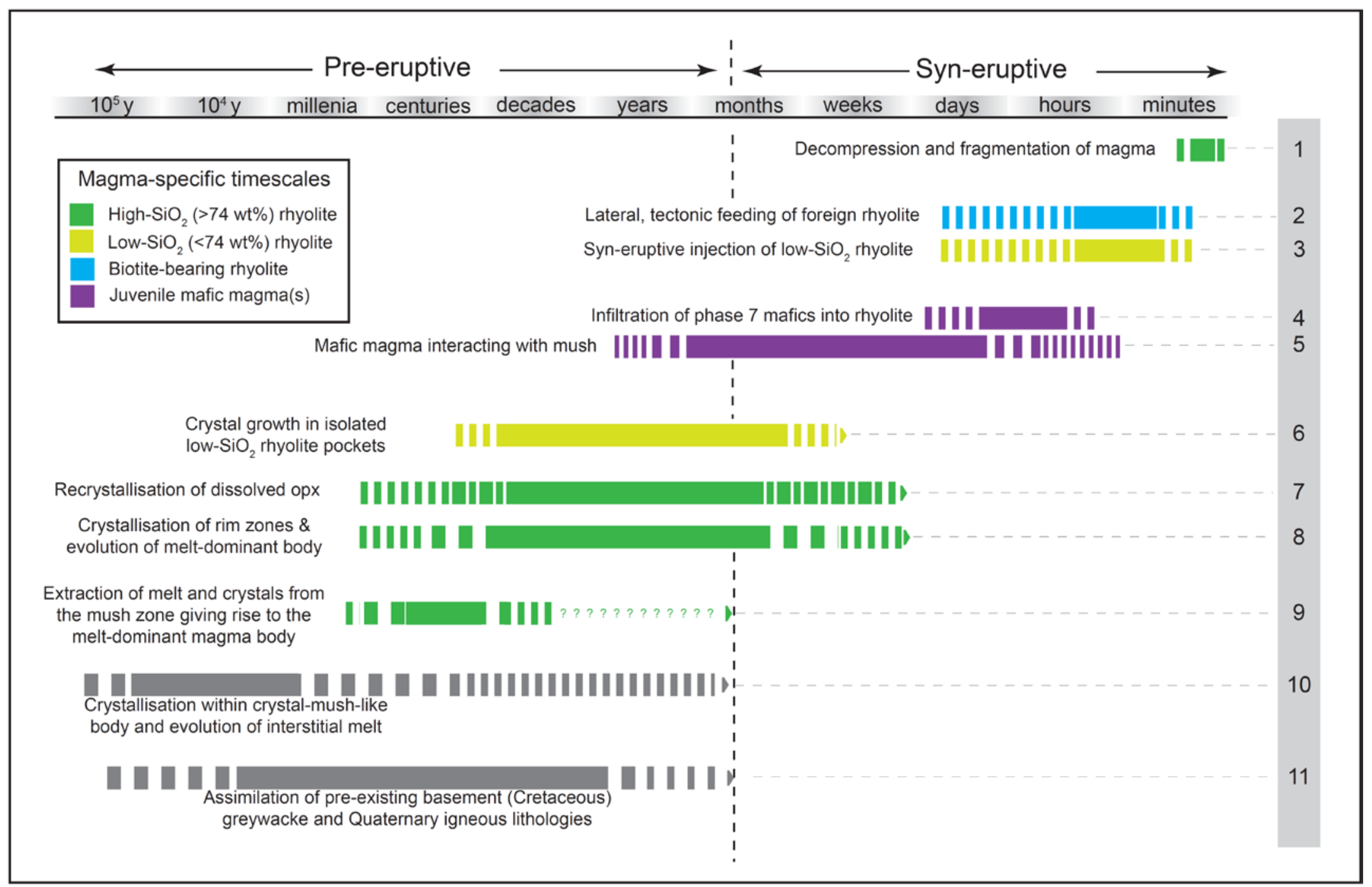

Figure 4.30. Figure caption on next page. 
Figure 4.30. Summary figure to show the time-scales of processes involved in the generation, accumulation and destruction of the Oruanui magma body as inferred from combined crystal-specific and field studies. 1. $\mathrm{Li}$ diffusion timescales in plagioclase and quartz (Charlier et al. 2012) and $\mathrm{H}_{2} \mathrm{O}$ and $\mathrm{CO}_{2}$ diffusion timescales from melt pockets (Liu et al. 2007); 2. Compositional source fingerprinting and field constraints (Allan et al. 2012); 3 Compositional relationships in matrix glass and crystals (this study); 4. Fe-Ti diffusion timescales in magnetite crystals (this study); 5. Crystal inheritance pathways, textural observation and disequilibrium textures (this study); 6. Fe-Mg diffusion timescales from growth zones in Opx (Allan et al. 2013); 7. Fe-Mg diffusion timescales from re-crystallised streaky, discontinuous zones in Opx (Allan et al. 2013); 8. Fe-Mg diffusion timescales across the main core-rim boundaries in Opx (Allan et al. 2013). The equivalent boundary is texturally observed in plagioclase (this study and Charlier et al. 2008); 9. Processes identified by reconciliation of textural, thermobarometric and compositional data from Opx and amphibole (Allan et al. 2013). Timescales constrained as outlined in point 8; 10. U-Th age spectra of zircons and crystal inheritance patterns with Oruanui pre-cursor eruptions (Charlier et al. 2005; Wilson and Charlier 2009); 11. Compositional characteristic of melt inclusions in xenocrystic quartz cores (Liu et al. 2006), radiogenic fingerprinting of xenocystic blue-grey-cored plagioclase (Charlier et al. 2008), U-Pb zircon age fingerprinting of 'old' zircons (Charlier et al. 2010).

et al. 2006; Wilson and Charlier 2009). Extraction of melt plus entrained crystals to form the melt-dominant body that erupted occurred in the gap between the Oruanui and its precursor Okaia event, only $\sim 3000$ years previously. This is bracketed by zircon model-age spectra (Charlier et al. 2005; Wilson and Charlier 2009), but quantified in detail by the textural information and diffusion-profile model age information from Oruani pyroxenes to be mostly accomplished in centruies (Allan et al. 2013).

Over intermediate timescales, such as years to days, interactions between the mafic and rhyolitic magmas may become important. In many examples, modern and ancient, it has been inferred that injection of mafic magma into a body of evolved magma may serve to trigger an eruption on a scale of days to months (e.g., Sparks et al. 1977; Pallister et al. 1992; Snyder 2002; Leonard et al. 2002). In the case of the Oruanui, however, evidence from the deposits of phases 1 and 2 implies strongly that external tectonic forces also played a critical role in starting and modulating the eruption over comparable time periods (Allan et al. 2012). The evidence also for a 'foreign' rhyolitic magma migrating at shallow levels into the Oruanui conduit implies strongly that the onset and initial stages of the eruption were not controlled by properties (overpressure, volatile saturation, etc.) of the magma chamber itself (cf. Blake 1984; Foroozan et al. 2011; Gregg et al. 2012). What is uncertain is whether the large volumes of mafic magmas involved in the Oruanui eruption were opportunistic in exploiting the stress field to rise into the mush zone and base of the melt-dominant body, or acted in concert to control the crustal stress field (cf. Rowland et al. 2010). The higher abundances of mafic material found in the phase 7 deposits (Wilson 2001, Figure 4.3), sampled by us for mafic clasts used for Fe-Ti oxide diffusion modeling 
(above) suggest that the sharply defined onset of phase 7 reflected the injection of a batch of mafic magma.

The shortest timescales that can be quantified are limited by the ability of the eruption products to respond to changing conditions in a form that is preserved into the geological record. The limits set for the Oruanui are those timescales that are captured by fastdiffusing elements or species that can react to changes in physical conditions associated with magma rise during activity. Water and $\mathrm{CO}_{2}$ gradients in melt pockets in quartz (Liu et al. 2007) record rise rates of $5-35 \mathrm{~cm} / \mathrm{s}$ as the magma starts to actively vesiculate, and $\mathrm{Li}$ gradients in quartz and feldspar record transient processes as the magma ascends at metres to tens of metres per second (Charlier et al. 2012).

\subsubsection{Comparisons and contrasts}

Hildreth and Wilson (2007) put forward a model for the Bishop Tuff in which gradients in melt chemistry, crystal content and temperature were established and maintained through incremental accumulation of the erupted magma body from a source mush reservoir. This model is very similar to that proposed by Allan et al. (2013) and re-emphasised here for the Oruanui. However, several features of the deposits from the two eruptions are in stark contrast to one another. For example, the Bishop Tuff magma was compositionally zoned at the time of eruption such that first erupted compositions were the most evolved, while less evolved and more crystal-rich compositions become more prominent as the eruption progressed (Hildreth and Wilson 2007). In direct contrast to the Oruanui, the early-erupted crystals in the Bishop magma lack prominent zonation and lack evidence for any significant and widespread dissolution/disequilibrium features. (Later-erupted Bishop crystals do, however, show evidence for influx of a contrasting magma and growth of compositionally contrasting rims on quartz, feldspar and zircons: Peppard et al. 2001; Wark et al. 2007; Reid et al. 2011.) Such characteristics have led previous researchers to conclude that the Bishop Tuff magma underwent largely in situ crystallisation (e.g., Hildreth 1979). In contrast, the Oruanui crystals seem to have two readily identifiable and distinct periods of growth; one occurring within the thermally and compositionally zoned mush body, and the other in which the rim-zones crystallised within the unzoned melt-dominant magma body. In the case of the Oruanui HSR orthopyroxenes and plagioclase, the earlier and later histories are readily distinguished on the basis of resorption horizons \pm sieved texturing or 
patchy zonation in the cores (Figure 4.6, 7), features which are absent in the crystals of the Bishop Tuff.

These observations lead to the logical question: if both magma bodies supposedly accumulated following a broadly similar method/model, what factors led to the strongly contrasting characteristics of the melt-dominant magma bodies and their crystal cargoes? We suggest that the answer may lie in the process(es) that ultimately drive the crystal-liquid segregation and the rate at which large-scale melt extraction process take place. The orthopyroxene-based diffusion estimates of timescales involved in accumulating the $\sim 530$ $\mathrm{km}^{3}$ Oruanui melt-dominant magma body (mostly $<500$ years) suggest the physical extraction and assembly was extremely rapid, possibly exceeding $1 \mathrm{~km}^{3} / \mathrm{y}$ (Allan et al. 2013). They suggest that magma-assisted rifting processes may have acted to enhance the melt extraction process by creating gashes through the mush body that acted as highly concentrated channels for melt (and crystals) to migrate upwards and accumulate. The vigor with which melt and crystals from contrasting compositions, depths and temperatures were brought together in the shallow crustal holding chamber, and the inferred heat loss associated with the $\sim 50{ }^{\circ} \mathrm{C}$ cooling and crystallisation of the crystal rimzones in the melt-dominant magma body (Allan et al. 2013), likely resulted in significant convection and stirring that acted to homogenise out compositional and thermal gradients in the process of forming the melt-dominant magma body. Additionally, any early increments of mafic magma that reached the floor of the melt-dominant body may have served to intensify the mixing processes. Although timescales involved in the physical assembly of the Bishop Tuff melt-dominant magma body are not yet established (or are controversial: Gualda et al. 2012a), it seems necessary that in order to maintain the apparent equilibrium relationships between crystals and melt and vertical compositional and thermal stratification, the processes involved must have been much more sluggish. As yet, no clearly identified mineral textures have been identified in the Bishop eruption products (particularly the early-erupted material) that could represent the contrasts between growth in the crystal-dominant mush versus in the melt-dominant body above. Identifying minerals or portions thereof as phenocrystic, antecrystic or xenocrystic in the Oruanui pumices is sometimes challenging. The clearest xenocrystic components are older zircons found as whole grains or cores, and identifiable as such from their age spectra (Charlier et al. 2005 2010), quartz cores with contrasting entrapped melt inclusion compositions (Liu et al. 2006) and cloudy feldspar cores with contrasting Sr-isotopic systematics (Charlier et al. 2008). The sieve-textured or resorbed cores in the Oruanui HSR 
plagioclase and orthopyroxenes (Figures 4.6 and 4.7) could be characterised as antecrystic, with the interiors having grown in a parental mush-like reservoir that was, however, physically, compositionally and temporally distinct from the melt-dominant magma body that ultimately erupted. The zircons in the Oruanui and its precursor eruptions that show an older $\sim 95 \mathrm{ka}$ model-age peak also are best thought of as antecrystic. The phenocryst population, sensu stricto, of the Oruanui pumices is this quite restricted. It includes the rim-zones of those crystals (quartz, feldspar, orthopyroxene) that have resorbed or nonequilibrium cores, together with the sparse grains of the same minerals that have homgeneous textures and compositions appropriate to the melt-dominant body (e.g., T diminishing from 820 to $770{ }^{\circ} \mathrm{C}$ ). The Fe-Ti oxides have to be considered phenocrystic, regardless of their antecedents because any inheritance patterns are erased by rapid diffusion. The Fe-Ti oxides have thus remained in equilibrium with conditions in the meltdominant body (and the rim compositions of other crystal phases) for all except the shortest timescales (days) associated with syn-eruptive magma mixing. The amphiboles include antecrystic cores and phenocrystic rims (plus subordinate phenocrystic grains), but these are only identifiable by chemical analysis and not distinguishable on a textural basis.

Wilson et al. (2006) presented a scaled, schematic cross section of the Oruanui magmatic system immediately prior to eruption based. This cross section is revised and updated in Figure 4.31 in light of important details that have become apparent from subsequent studies, including Allan et al. (2012, 2013) and the current work. Integration of the new and existing datasets presented here highlight the following important details.

1) The realisation that rifting-related processes played an integral part in triggering the initial rupturing and onset of the Oruanui eruption. A body of biotite-bearing rhyolite magma was present in the shallow crust beneath the NE dome system (Figures 4.1 and 4.31). Syn-eruptive rifting processes resulted in the propagation of the NE dome magma laterally to intercept Oruanui HSR in the conduit during the phases 1 and 2 of the eruption (Allan et al. 2012).

2) Although the approximate depth to the top of the melt-dominant magma body is very similar, the newer data suggest a slighter thinner melt-dominant magma body, i.e., approximately between $3.5-6.0 \mathrm{~km}$ depth ( 90 to $140 \mathrm{MPa})$. These dimensions, inferred from thermobarometry applied to the outermost rims of amphibole crystals in the HSR, are consistent with the lack of thermal and compositional gradient within the melt- 


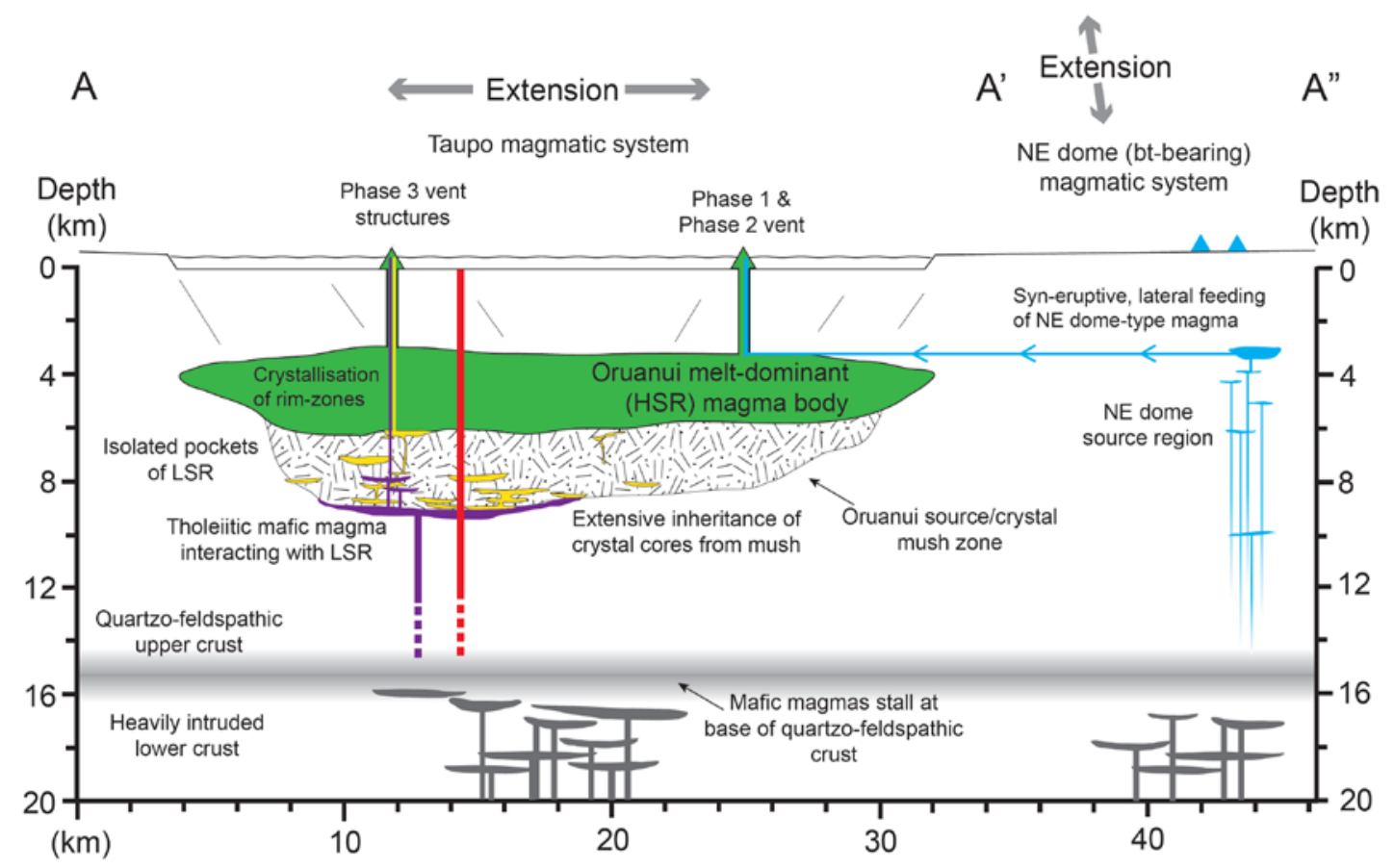

Specific Oruanui magma types

High-SiO ${ }_{2}$ rhyolite (HSR, whole-rock $>74$ wt $\% \mathrm{SiO}_{2}$ )

- forms bulk of magma that is erupted

- thermally and compositionally unzoned at eruption

- evolved from LSR-type compositions following extraction from mush

Low- $\mathrm{SiO}_{2}$ rhyolite (LSR, whole-rock $<74 \mathrm{wt} \% \mathrm{SiO}_{2}$ )

- isolated pockets of crystal-poor rhyolite in mush

- compositional forerunner to HSR

- syn-eruptive exchange of melt and crystals with HSR

- some mixing with tholeiitic mafic magma

Biotite-bearing rhyolite

- foreign magma, sourced from NE dome system

- syn-eruptive lateral feeding into Oruanui conduit

-syn-eruptive mixing in of some HSR melt and crystals

Tholeiitic group

- extended interaction(s) with LSR-type material in the mush zone

- most macroscopic crystals inherited from HSR and/or LSR

Calc-alkaline group

- less extensive interaction with rhyolites

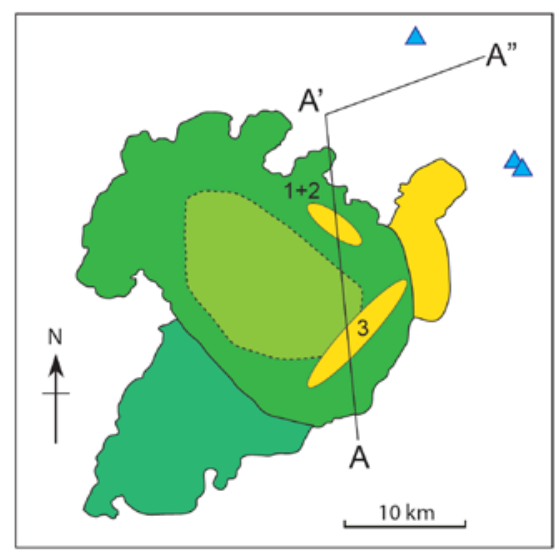

Figure 4.31. Scaled cross section through the Taupo area showing the sources, depths and pathways for the various crystal and melt components in the Oruanui magmas. 
dominant magma body, and consistent with the pre-eruptive body being contained entirely within Wilson's (2001) 'Areas A' and 'B' of the Oruanui caldera.

2) Recognition of the diverse sources of the crystals. Approximately $90 \%$ of the crystal cargo in the HSR is inferred to have cores and interior domains that were inherited from a stratified crystal mush body prior to their confluence in the melt-dominant magma body. Quartz are inferred to have originated from an upper Si-saturated and most-evolved layer, whereas the majority of amphibole, orthopyroxene and plagioclase largely originated from deeper, lesser-evolved levels.

3) The pumices sampled on eruption as LSR magma were originally inferred by Wilson et al. (2006) to represent deeper and hotter parts of the melt dominant body. These samples are now recognised to represent isolated pockets of crystal-poor rhyolite that within the crystal mush and that ruptured syneruptively. This is based on the distinct differences between their characteristics and minor degrees of hybridisation in the pumices (i.e., minor melt and crystal exchanges between HSR and LSR as inferred by Allan et al. 2013).

4) Wilson et al. (2006) suggested that the Oruanui mafic magmas, in particular the tholeiitic magma, had ponded at the base of the melt-dominant magma body and initiated chamber wide stirring and homogenisation. Subsequent data (Allan et al. 2013 + this study) show that the mafic magmas were dominantly interacting with mush as indicated by their ingested felsic crystal populations and whole-rock trajectories towards LSR (rather than HSR) compositions. Commensurate with that, our data suggests very strongly that vigorous stirring was an inherent feature of the melt-dominant body from the moment of its inception.

\subsection{CONCLUSIONS}

The assembly and eruption of the Oruanui magma body was a complex but geologically short-lived sequence of events. The work presented here and in other papers cited shows that there is a rich petrological record of these events in the compositions of melts and minerals, and in the textures of the mineral phases. The associated processes can be resolved into a chain of events with a resolution of tens of thousands of years for the development of the deeper source mush zone to tens of seconds for the last stages of magma rise before fragmentation and quenching. Key conclusions from the integration of previous and current datasets are as follows. 
1. Detailed compositional and textural records within Oruanui HSR quartz, plagioclase, orthopyroxene and amphibole crystals highlight the transition from compositional diversity in their early history, to uniformity immediately prior to eruption. These records are consistent with earlier growth in a compositionally stratified crystal mush body followed by extraction, ascent, and accumulation of the crystals along with large quantities of melt into a shallow (3.5-6 km km depth) holding chamber of crystal-poor rhyolite. The earlier history of quartz, indicative of growth from more evolved compositions than the host glass is in contrast to the compositions of most plagioclase, orthopyroxene and amphibole crystals which show evidence for growth in less-evolved melts than the one in which they sat on eruption., This contrast is interpreted to reflect the presence of a silica-saturated quartz-bearing cap overlying a deeper zone of quartz-free mush material. Melt extraction from the mush zone entrained crystals from all levels of the stratified crystal mush body, resulting in the juxtaposition of a diverse range of crystals within the melt-dominant magma body. Rapid heat loss drove vigorous convection in the melt-dominant magma body, resulting in a lack of any significant compositional or thermal gradients and a general outwards-cooling trend reflected in most mineral compositions.

2. The Oruanui mafic magmas record significant interactions/inheritance of 'rhyolite' crystals (i.e., crystals with compositions appropriate for growth from rhyolite melts) from traversing through the mush residue and melt-dominant magma body during their eruption. Inherited crystals within the mafic clasts themselves suggest varying timescales of interaction, with reaction rims on 'rhyolitic' plagioclase crystals varying from only a few microns to $>100 \mu \mathrm{m}$. However, the ubiquitous down-temperature signals recorded in plagioclase, orthopyroxene and amphibole crystals from HSR samples precludes the possibility that mafic magmas played any significant role in wholesale re-heating/remobilisation of the mush to cause eruption (cf. Bachmann and Dungan 2002). Syneruptive interactions between the mafic magmas and the melt-dominant magma body are recorded in zoned magnetite and olivine crystals. Fe-Ti diffusion timescales from the magnetites suggest infiltration of the phase 7 mafic magmas into the voluminous (but partially evacuated) rhyolite body mostly occurred in the final 6-18 hours prior to quenching on eruption.

3. The disparate textural and compositional domains within single crystals, particularly HSR plagioclase and orthopyroxene, obscure definitions of phenocrysts versus antecrysts. Despite the near uniformity of rim compositions in the HSR crystals, the majority of compositions and magma intensive parameters recorded by the crystal cores and interiors 
bear no direct relation to the melt-dominant body in which they were immersed at the time of eruption.

4) The magmatic systems giving rise to voluminous crystal-poor rhyolites can be considered to operate on two contrasting timescales: longer-term processes governing the broad compositional characteristics of the magma (i.e. fractional crystallisation, protolith assimilation etc) versus more short-lived processes governing physical assembly of the melt dominant magma body that actually erupts. In the context of the new and extended datasets for the main crystal phases (Allan et al. 2013; this study), the Oruanui zircon agespectra (Charlier et al. 2005; Wilson and Charlier 2009) can be viewed as recording the timing of the major differentiation event within the crystal mush body prior to the physical accumulation of the melt-dominant magma body. The major crystallisation associated with the Oruanui magmatic system is represented by a dominant peak of zircon ages centred on $\sim 40 \mathrm{ka}$ (Charlier et al. 2005; Wilson and Charlier 2009). This is in line with the U/Th age of bulk separates of the main crystal phases of $33 \mathrm{ka} \mathrm{(+18} \mathrm{ka/-16} \mathrm{ka)} \mathrm{(Charlier} \mathrm{et} \mathrm{al.}$ 2005). Physical assembly of the melt-dominant magma body, as determined by Fe-Mg diffusion modelling in orthopyroxene (Allan et al. 2013), occurred in less than 1600 years, and mainly within the last $\sim 500$ years prior to eruption (i.e. 1-2 orders of magnitude faster than the chemical generation of the progenitor melts).

5. The model inferred for the Oruanui (extraction of melt plus some fraction of crystals from a crystal mush into a melt-dominant holding chamber) is similar to a model invoked for the Bishop Tuff (Hildreth and Wilson 2007). Despite these broad similarities, the zonation characteristics of the deposits from these two eruptions are greatly contrasting at whole-rock and single-crystal scales. The ubiquitous evidence for short-lived disequilibrium textures in plagioclase and orthopyroxene (Allan et al. 2013; this study), the timescales inferred from Fe-Mg diffusion modelling of orthopyroxene (Allan et al. 2013), and inferences from U/Th age spectra in zircons (Charlier et al. 2005; Wilson and Charlier 2009) all indicate that the extraction and accumulation processes in the Oruanui system were geologically rapid (on the order of centuries, and an absolute maximum of $\sim 3000$ years). In contrast, the lack of widespread disequilibrium textures in Bishop Tuff crystals suggests a more sluggish accumulation process. The rapidity with which the Oruanui meltdominant magma body accumulated and the inferred rapid rates of heat loss led to vigorous convection that destroyed any significant compositional and thermal zonation within the melt-dominant magma body prior to eruption. 
6. The timescales inferred for the accumulation of the $\sim 530 \mathrm{~km}^{3}$ Oruanui melt-dominant magma body are much shorter than estimates based on numerical modelling for similar sized magma bodies (e.g., Bachmann and Bergantz 2004). The notion that mafic magmas may play an immediate and driving role in the generation of crystal-poor rhyolites is at odds with the ubiquitous down-temperature zonation of crystal rims in the $\sim 530 \mathrm{~km}^{3}$ Oruanui melt-dominant magma body. The involvement of the Oruanui mafic magmas, and the rapid accumulation of the melt-dominant magma body is inferred to be the consequence of an enhanced episode of magma-assisted rifting in the crystal mush-bearing crust beneath Taupo during the lead-in to the Oruanui eruption. 


\section{Intensive parameters of silicic magmas: an extended discussion}

\subsection{INTRODUCTION}

One of the key aspects of modern petrology is the availability of numerous models with which to reconstruct magmatic histories preserved in the compositions of crystals. An accurate assessment of parameters such as temperature, pressure and oxygen fugacity, is essential for many aspects of igneous petrology. For example, the adoption of one particular modelled temperature input over another into any variety diffusion-based chronometric, thermomechanical or petrological models can generate widely disparate results. As many of the broad-scale interpretations surrounding magmatic systems, the timescales on which they operate, and the nature and immediacy of the associated volcanic hazards, are informed by many of these key intensive magmatic variables, their estimation must be reliable and reproducible.

Recent contributions to the literature have questioned the veracity of some of the more routinely applied models for constraining magmatic variables, in particular, Fe-Ti oxides (e.g. Ghiorso and Gualda 2013 vs. Evans and Bachmann 2013) and Ti-in-quartz (Wilson et al. 2012 vs. Thomas and Watson 2012). In contrast, some newer models (e.g., the Ridolfi et al. 2010 amphibole formulations) have escaped rigorous scrutiny in the literature. In recognition that such controversies persist, this chapter forms an extended discussion around the models of intensive variables that were either investigated or routinely employed during the course of this research (Table 5.1). I also discuss some of the more contentious issues surrounding the veracity of some of these models, including those which I consider to reliably reconstruct magmatic variables in the Oruanui system. Discussions surrounding the application of Ti-in-quartz thermobarometry are built around the comment-reply series of Wilson et al. (2012) and Thomas and Watson (2012) in which I was heavily involved. These two articles appear in full in the Electronic Appendices.

The estimates of intensive parameters discussed here were largely presented in Chapter 4, but the results are summarised again here in Tables 5.2-5.5 for ease of reference. These tables include some additional data for $\mathrm{H}_{2} \mathrm{O}$ and the activity of titania $\left(\mathrm{aTiO}_{2}\right)$ that are also 
Table 5.1. Summary of the models for intensive variables investigated during the course of this research and their perceived reliability.

\begin{tabular}{|c|c|c|c|c|}
\hline & Temperature & Pressure & Oxygen fugacity & Model references \\
\hline Fe-Ti oxides & $\checkmark$ & & $\checkmark$ & Ghiorso and Evans (2008), Sauerzapf et al. (2008) \\
\hline Plagioclase-liquid & $\checkmark$ & $x$ & & Putirka (2008) \\
\hline Amphibole compositions & $\checkmark$ & $\checkmark$ & $\checkmark$ & Ridolfi et al. (2010) \\
\hline Al-in-hornblende & & $?$ & & Anderson and Smith (1995) \\
\hline Plagioclase-amphibole & $?$ & & & Holland and Blundy (1994) \\
\hline Orthopyroxene-liquid & $\checkmark$ & $x$ & & Putirka (2008) \\
\hline Volatile contents in quartz melt inclusions & & $\checkmark$ & & Liu et al. (2005) \\
\hline Ti-in-quartz & $\approx$ & 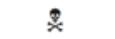 & & Wark and Watson (2006), Thomas et al. (2010) \\
\hline Two-pyroxene & $\hat{\checkmark}$ & & & Brey and Kohler (1990), Putirka (2008) \\
\hline \multicolumn{5}{|l|}{$\checkmark \quad$ Used and relied upon } \\
\hline \multicolumn{5}{|l|}{ ? Modelled values considered questionable } \\
\hline \multicolumn{5}{|c|}{ Unreliable (uncertainties larger than the modelled values themselves) } \\
\hline \multicolumn{5}{|l|}{$\approx$ III advised (see section 5.4 ) } \\
\hline
\end{tabular}

referred to in the following discussions. For the purposes of providing a consistent reference point, much of the data presented here are focussed around estimates for the final conditions of the high-silica rhyolite (HSR) that constitutes $98-99 \%$ of the Oruanui erupted volume.

\subsection{Preferred Models}

Applications of my preferred thermometers and barometers (Table 5.1) to the relevant crystal phases in the HSR and LSR pumices yield consistent estimates for the immediately pre-eruptive temperatures and pressures of these magma bodies (Table 5.2 and 5.3).

Thermometers based on four different crystal phases (magnetite + ilmenite, amphibole, plagioclase, orthopyroxene), all indicate a final temperature of $\sim 770-790{ }^{\circ} \mathrm{C}$, and $820-840$ ${ }^{\circ} \mathrm{C}$ for the HSR and LSR bodies, respectively (Figure 5.1). The volatile saturation pressures inferred from measurements of $\mathrm{CO}_{2}$ and $\mathrm{H}_{2} \mathrm{O}$ in quartz-hosted melt inclusions in the HSR magma (94-188 MPa) are consistent with the range of pressures indicated by the amphibole rim compositions using the Ridolfi et al. (2010) barometric formulation (88-185 $\mathrm{MPa})$ (Figure 5.2).

Despite the consistency and independent calibrations of these various models, they are not without controversy. Subsequent sections highlight some of the more contentious issues surrounding their application and how I have approached their use in this study.

\subsubsection{Fe-Ti oxide thermometry}

Magnetite and ilmenite are known to undergo rapid thermal re-equilibration at magmatic temperatures (typically days to weeks; e.g. Freer and Hauptman 1978; Hammond and 
Table 5.2. Summary of estimates for the pre-eruptive temperature of the Oruanui HSR according to various mineral equilibrium based techniques

\begin{tabular}{|c|c|c|c|c|c|}
\hline Thermometer & $\begin{array}{l}\text { Number of } \\
\text { estimates }\end{array}$ & Mean temp $\left({ }^{\circ} \mathrm{C}\right)$ & $\begin{array}{c}\text { Temp range } \\
\left({ }^{\circ} \mathrm{C}\right)\end{array}$ & $\begin{array}{l}\text { Modal } \\
\text { values }\end{array}$ & Model details and/or parameters \\
\hline Plag-melt & 158 & 787 & $783-797$ & & Putirka (2008), eqn $24 a$, matrix glass and $5.5 \mathrm{w}$ t $\%$ melt $\mathrm{H}_{2} \mathrm{O}$ \\
\hline Opx-melt & 222 & 785 & $779-793$ & & Putirka (2008), eqn 28a, matrix glass and $5.5 \mathrm{w} t \%$ melt $\mathrm{H}_{2} \mathrm{O}$ \\
\hline Amphibole rim compositions & 121 & 784 & $751-851$ & $770-780$ & Ridolfi et al. (2010) model \\
\hline Fe-Ti oxides & 379 & 777 & $742-821$ & $770-790$ & Ghiroso and Evans (2008) model \\
\hline Fe-Ti oxides & 379 & 760 & $737-794$ & $750-770$ & Sauerzapf et al. (2008) model \\
\hline Plag-hbl rims & 121 & 798 & $758-858$ & & Holland \& Blundy (1994), edenite + albite $=$ richterite + anorthite reaction \\
\hline Ti-in-quartz & 48 & 818 & $735-869$ & 820 & Wark and Watson (2006), $\mathrm{aTiO}_{2}=0.52$, see text and associated figure \\
\hline Ti-in-quartz & 48 & 889 & $795-946$ & 890 & Wark and Watson (2006), $\mathrm{aTiO}_{2}=0.32$, see text and associated figure \\
\hline Ti-in-quartz & 48 & 602 & $541-639$ & 600 & Thomas et al. (2010) $\mathrm{aTiO}_{2}=0.52, \mathrm{P}=100 \mathrm{MPa}$ \\
\hline Ti-in-quartz & 48 & 626 & $563-665$ & 620 & Thomas et al. $(2010) \mathrm{aTiO}_{2}=0.52, \mathrm{P}=200 \mathrm{MPa}$ \\
\hline Ti-in-quartz & 48 & 772 & $699-817$ & 770 & Thomas et al. (2010) $\mathrm{aTiO}_{2}=0.52, \mathrm{P}=800 \mathrm{MPa}$ \\
\hline Ti-in-quartz & 48 & 654 & $577-696$ & 650 & Thomas et al. (2010) $\mathrm{aTiO}_{2}=0.32, \mathrm{P}=100 \mathrm{MPa}$ \\
\hline Ti-in-quartz & 48 & 681 & $610-723$ & 680 & Thomas et al. (2010) $\mathrm{aTiO}_{2}=0.32, \mathrm{P}=200 \mathrm{MPa}$ \\
\hline Ti-in-quartz & 48 & 783 & $705-831$ & 780 & Thomas et al. $(2010) \mathrm{aTiO}_{2}=0.32, \mathrm{P}=600 \mathrm{MPa}$ \\
\hline
\end{tabular}

Table 5.3. Summary of pressure estimates for the Oruanui melt-dominant magma body according to various mineral equilibrium based techniques

\begin{tabular}{|c|c|c|c|c|c|}
\hline Barometers & & $\begin{array}{l}\text { Mean pressure } \\
(\mathrm{MPa})\end{array}$ & $\begin{array}{c}\text { Pressure range } \\
(\mathrm{MPa})\end{array}$ & Modal values & Model details and/or parameters \\
\hline \multicolumn{6}{|l|}{ Considered reliable } \\
\hline Volatile contents in qtz melt inclusions & 65 & 138 & $94-188$ & $120-150$ & Liu et al. (2006), trapped (closed) inclusions only \\
\hline Amphibole rims & 121 & 113 & $88-185$ & $90-120$ & Ridolfi et al. (2010) \\
\hline \multicolumn{6}{|l|}{ Questionable (see text) } \\
\hline Amphibole rims & 121 & 118 & $71-140$ & $110-140$ & Anderson \& Smith (1995) model paired with T estimates from Ridolfi et al. (2010) \\
\hline Amphibole rims & 121 & 159 & $83-348$ & & Anderson \& Smith (1995) model paired with constant $\mathrm{T}=770^{\circ} \mathrm{C}$ \\
\hline \multicolumn{6}{|l|}{ Considered unreliable } \\
\hline Ti-in-quartz & 48 & 793 & $615-1114$ & $750-850$ & Thomas et al. (2010) model, Wilson et al (2012) values - $\mathrm{aTiO}_{2}=0.52, \mathrm{~T}=770{ }^{\circ} \mathrm{C}$ \\
\hline Ti-in-quartz & 48 & 501 & $325-818$ & $450-500$ & Thomas et al. (2010) model, Thomas \& Watson (2012) values - $\mathrm{aTIO}_{2}=0.32, \mathrm{~T}=757^{\circ} \mathrm{C}$ \\
\hline
\end{tabular}


Table 5.4. Summary of the final oxygen fugacity conditions inferred for the HSR.

\begin{tabular}{|c|c|c|c|c|}
\hline $\begin{array}{l}\text { Estimates of oxygen fugacity } \\
(\Delta \mathrm{NNO})\end{array}$ & & Mean $(\triangle \mathrm{NNO})$ & Range ( $\triangle \mathrm{NNO})$ & Model details and/or parameters \\
\hline Fe-Ti oxides & 379 & -0.20 & -0.52 to 0.03 & Ghiroso and Evans (2008) model \\
\hline Fe-Ti oxides & 379 & 0.47 & 0.28 to 0.65 & Sauerzapf et al. (2008) model \\
\hline Amphiboles & 121 & 0.90 & 0.40 to 1.20 & Ridolfi et al. (2010) model \\
\hline
\end{tabular}

Table 5.5. Summary of measurements and estimates of melt $\mathrm{H} 2 \mathrm{O}$ content in the HSR.

\begin{tabular}{|c|c|c|c|c|}
\hline Estimates of $\mathrm{H}_{2} \mathrm{O}$ melt (wt \%) & & Mean $(w t \%)$ & Range & Model details and/or parameters \\
\hline Amphibole rims & 121 & 5.5 & $5.0-6.2$ & Ridolfi et al. (2010) model \\
\hline Quartz-host melt inclusions & 66 & 4.5 & $3.8-5.1$ & Liu et al. (2006), $\mathrm{H}_{2} \mathrm{O}$ in trapped quartz-hosted melt inclusions measured by FTIR \\
\hline Empirical $\mathrm{H}_{2} \mathrm{O}$ solubility model & & 5.3 & $4.0-6.8$ & Moore et al. (1998), model run at $770^{\circ} \mathrm{C}$ and $90-240 \mathrm{MPa}$, mean value at $150 \mathrm{MPa}$ \\
\hline Glass $\mathrm{H}_{2} \mathrm{O}$ by difference & 141 & 4.5 & $0.6-7.4$ & Difference from $100 \mathrm{w} t \%$ of raw EPMA totals for pumice matrix glass \\
\hline Plag-melt equilibrium & & 4.6 & & Anorthite-method of Housh and Luhr (1991), reported in Wilson et al. (2006) \\
\hline Plag-melt equilibrium & & 6.2 & & Albite-method of Housh and Luhr (1991), reported in Wilson et al. (2006) \\
\hline
\end{tabular}

Table 5.6. Summary of modelled values for aTiO2 in the Orunaui HSR

\begin{tabular}{lccll} 
Estimates of $\mathrm{aTiO}_{2}$ of the melt & & Mean $(\mathrm{aTiO})$ & Range & Model details and/or parameters \\
\hline Fe-Ti oxides & 379 & 0.55 & $0.50-0.59$ & Ghiroso and Evans (2008), using online calculator \\
MEL TS & & 0.34 & $0.20-0.55$ & Values quoted by Thomas and Watson (2012) for T = 757 ${ }^{\circ} \mathrm{C}$ \\
Glass equilibrium method & 36 & 0.68 & $0.56-0.76$ & Hayden et al. (2007) method applied by Wilson et al. (2012), Ti measured by ion probe \\
Glass equilibrium method & 36 & 0.64 & $0.39-1.08$ & Hayden et al. (2007) method applied by Wilson et al. (2012), Ti measured by EPMA \\
\hline
\end{tabular}



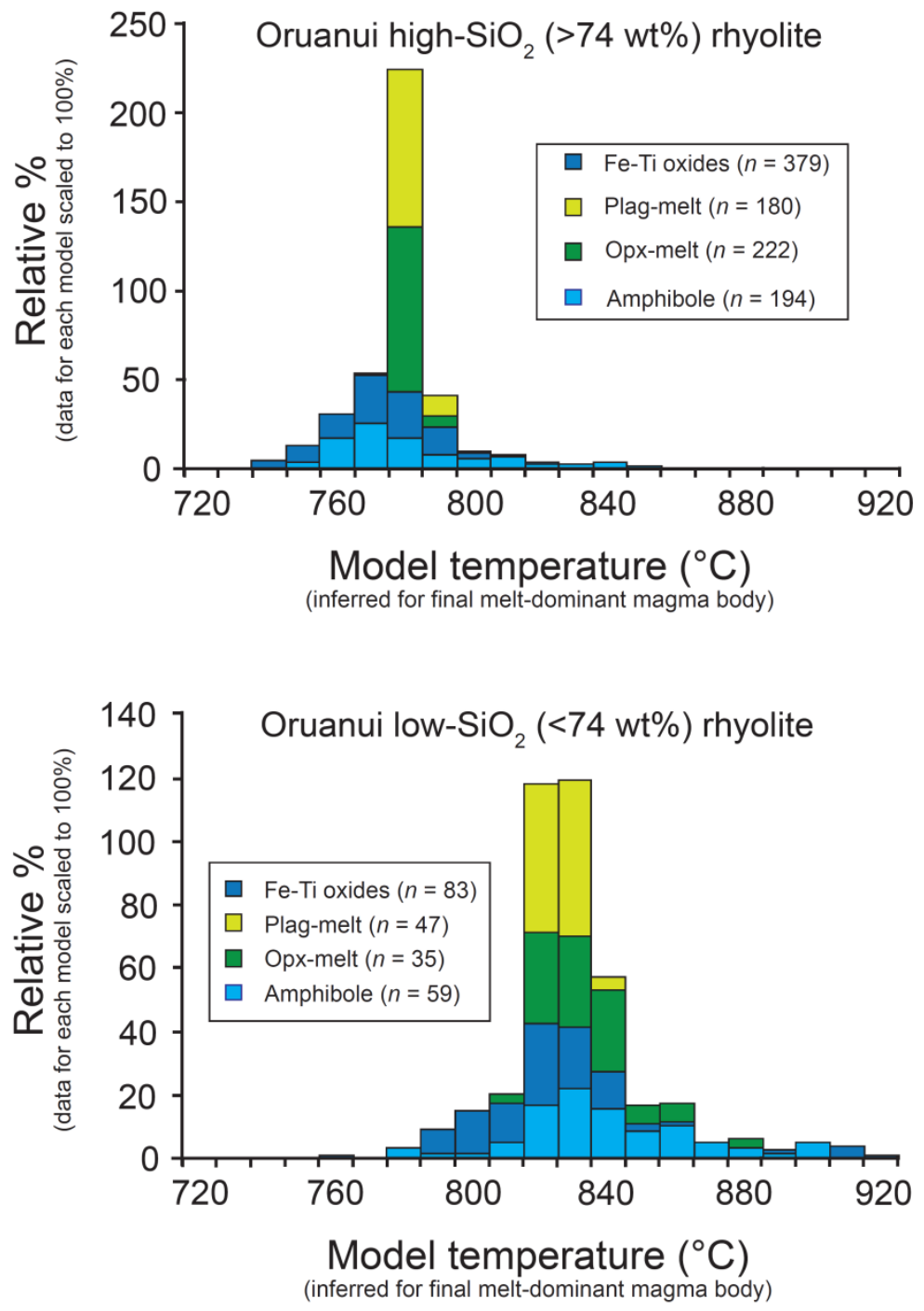

Figure 5.1 Stacked histograms summarising temperature estimates for Oruanui HSR (panel a) and LSR (panel b) clasts, based on my preferred thermometric models. Models: Plag-melt = Putirka (2008) equation 24a applied to outermost rims and matrix glass; Opx-melt = Putirka (2008) equation 28a applied to outermost rims and matrix glass; Fe-Ti oxides = Ghiorso and Evans (2008), Amphiboles $=$ Ridolfi et al. (2010) applied to the outermost rims. The data for each model has been scaled to total $100 \%$ with the number of temperature estimates for each dataset shown in the figure legend.

Taylor 1982; Venezky and Rutherford 1999). As such, temperatures inferred from Fe-Ti oxide thermometry are generally taken to approximate the final magmatic conditions prior to quenching on eruption. Application of two recent formulations (Ghiorso and Evans 2008; Sauerzapf et al. 2008) to the compositional data for magnetite and ilmenite from the Wilson et al. (2006) supplementary information allow for comparisons between the models (Figure 5.3). The most apparent difference is that the Sauerzapf et al. model yields more oxidising values of $\mathrm{fO}_{2}$ (almost entirely above the NNO buffer) when compared to the 

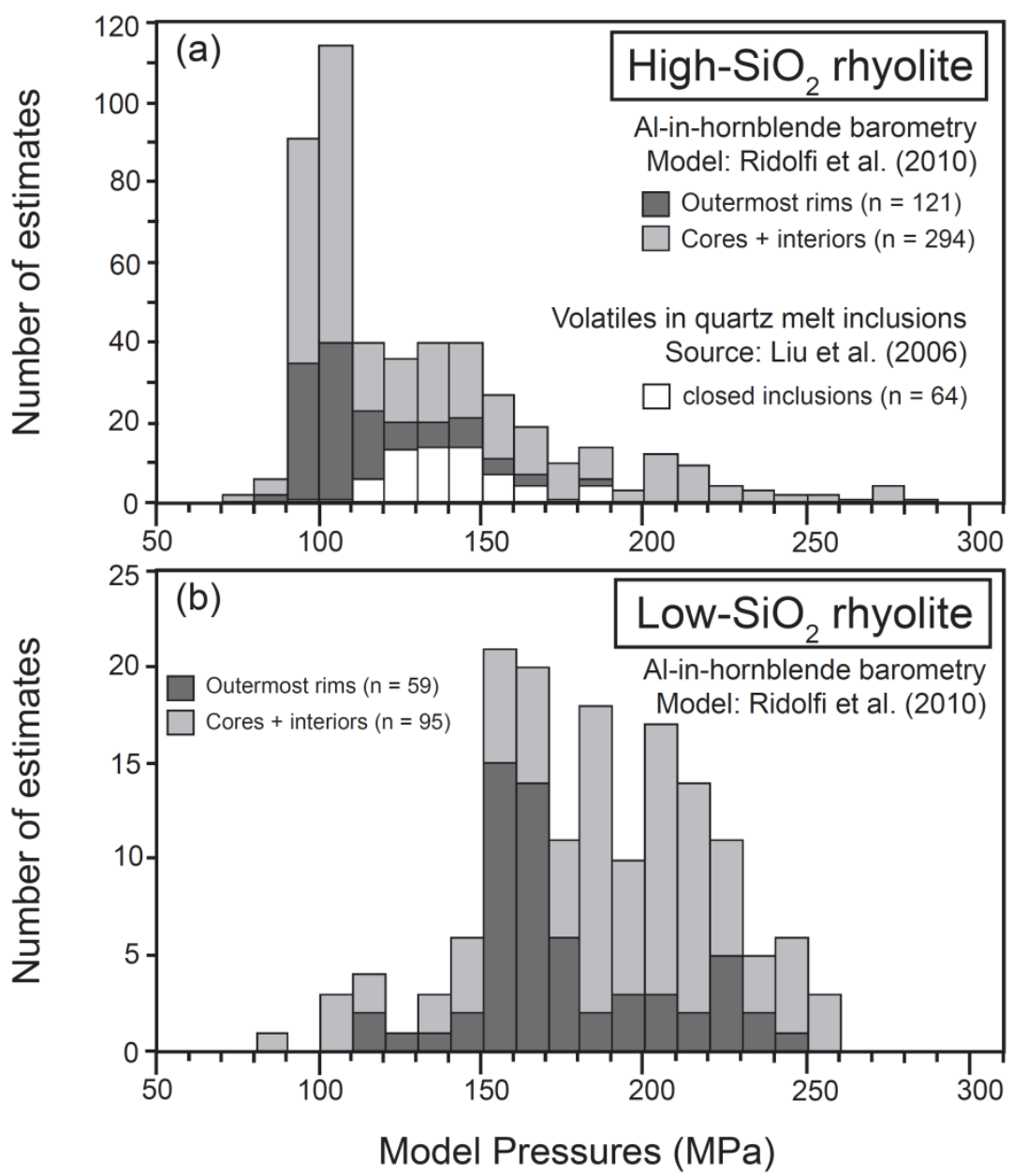

Figure 5.2 Stacked histograms summarising pressure estimates for Oruanui HSR (panel a) and LSR (panel b) clasts, based on my preferred thermometers. Model: Amphiboles = Ridolfi et al. (2010) applied to the outermost rims. Volatile saturation pressures: model of Liu et al. (2005) applied to the data in Liu et al. (2006). The data for each model has been scaled to total $100 \%$ with the number of temperature estimates for each dataset shown in the figure legend.

Ghiorso and Evans model (almost exclusively below NNO). Also apparent in Figure 5.3 is that the temperature estimates from the two models are strongly linearly correlated $\left(\mathrm{R}^{2}=\right.$ 0.98). The slope of the regression line is such that at the higher temperature end of the array the Ghiorso and Evans model yields estimates are $\sim 25$ to $40{ }^{\circ} \mathrm{C}$ hotter, whereas at the lower temperature end of the array this is reduced to $\sim 10-20{ }^{\circ} \mathrm{C}$.

A recent contribution by Ghiorso and Gualda (2013) reported a method of estimating $\mathrm{aTiO}_{2}$ in silicic melts on the basis of the equilibrium compositions of magnetite and ilmenite. One of their main conclusions was that for many eruptions, Fe-Ti oxides pairs (even those previously reported by Ghiorso and Evans 2008, that passed the Bacon and Hirschmann 1988, test for equilibrium) were not in equilibrium with the melt in which they 

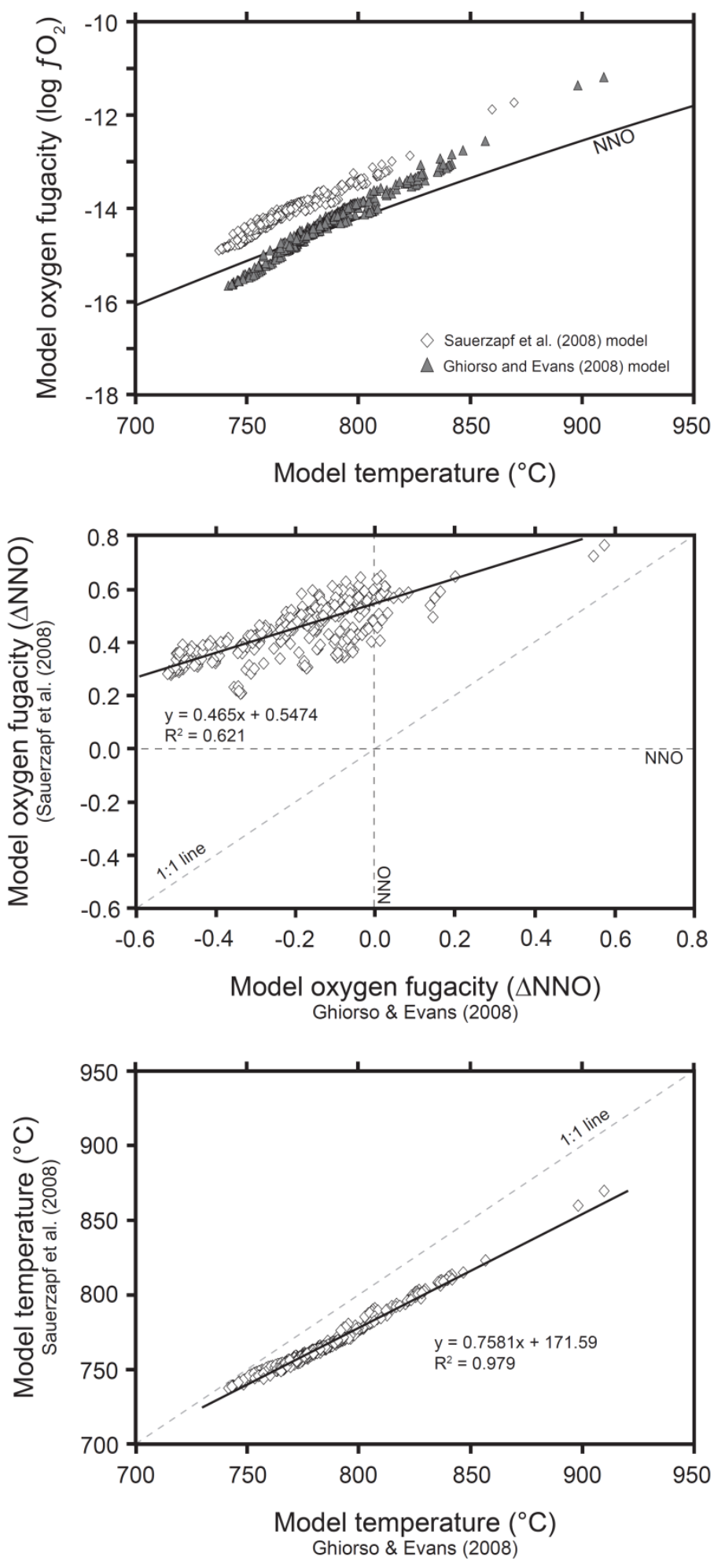

Figure 5.3 A comparison of the results of the Ghiorso and Evans (2008) and Sauerzapf et al. (2008) model estimates of temperature and oxygen fugacity for 379 equilibrium magnetite-ilmenite pairs in Oruanui high- $\mathrm{SiO}_{2}$ rhyolite clasts. Only pairs that pass the equilibrium criteria of Bacon and Hirschmann (1988) are shown. Offsets between temperature and oxygen fugacity conditions indicated by each model can are approximated by the linear relationships as shown. 
were erupted. It was suggested that Fe-Ti oxide pairs that yielded positive correlations between the modelled results for $\mathrm{aTiO}_{2}$ and temperature (and also oxygen fugacity relative to NNO and temperature), were likely not in equilibrium with the melt. Ghiorso and Gualda (2013) singled out the Bishop Tuff and (undisclosed and unreferenced) "New Zealand" examples as instances of such trends, and as cases where the Fe-Ti oxides were not in equilibrium with the melt (see Evans and Bachmann 2013 for a contrasting view). In contrast, Fe-Ti oxides that yielded negative correlations between the modelled temperatures and $\mathrm{aTiO}_{2}$ were inferred by them to be in equilibrium with the melt as these broadly followed their expectations of a crystallising melt approaching rutile saturation. Examples of eruptions that returned such negative correlations include Pinatubo and the Fish Canyon Tuff.

In short, the assertion by Ghiorso and Gualda (2013) that the Bishop Tuff oxides are not in equilibrium with the melt is made on basis that the rhyolite-MELTS algorithms (Gualda et al. 2012) predict values of $\mathrm{aTiO}_{2}$ for melt inclusions in Bishop quartz that are not consistent with the modelled values from Fe-Ti oxides. Ghiorso and Gualda (2013) assert that in order for crystallisation in the Bishop magma to drive $\mathrm{aTiO}_{2}$ down from $\sim 0.7$ to 0.5 over a temperature decrease of $\sim 100{ }^{\circ} \mathrm{C}$ (as indicated by their Fe-Ti oxide model values), then the $\mathrm{TiO}_{2}$ contents of the glass phase should have reduced by $\sim 60 \%$. They then use the melt inclusion data of Anderson et al. (2000) to show that the $\mathrm{TiO}_{2}$ contents of melt inclusions in quartz from early- versus late-erupted Bishop pumices differ by only $\sim 10 \%$ (i.e., $\mathrm{TiO}_{2}=0.09 \mathrm{wt} \%$ in early quartz, compared to $0.08 \mathrm{wt} \%$ in late-erupted quartz).

Several observations about the lines of reasoning and models used by Gualda et al. (2012) and Ghiorso and Gualda (2013) are relevant.

1) Although never explicitly stated, by implication it is apparent that Ghiorso and Gualda (2013) are confident that their modelled values accurately record temperatures, oxygen fugacities and $\mathrm{aTiO}_{2}$ values for equilibrium conditions between the magnetite and ilmenite pairs, but that these parameters do not necessarily translate to the equilibrium conditions of the melt in which the Fe-Ti oxides were enclosed at the time of eruption.

2) Fe-Ti oxides are known to undergo rapid diffusive re-equilibration to surrounding magmatic conditions whilst at magmatic temperatures (Freer and Hauptman 1978; Venezky and Rutherford 1999). Where equilibrium criteria have been satisfied (i.e., after Bacon and Hirschmann 1988), the Fe-Ti oxides are thus widely accepted to reflect the conditions in within the pre-eruptive magma chamber within the days to weeks prior to 
quenching of the eruption products on eruption. In practical terms, if the Fe-Ti oxides are not in equilibrium with the melt in which they resided at the point of eruption, then this requires that some sort of $(\mathrm{P}-\mathrm{T}-\mathrm{X})$ change occurred that altered the equilibrium values of $\mathrm{aTiO}_{2}$ in the melt body, and that this change occurred on such a rapid timescale that the Fe-Ti oxides did not have time to detectably re-equilibrate towards that 'new norm'. In the case of the Bishop or Oruanui magma bodies where the volume of melt involved exceeds $500 \mathrm{~km}^{3}$, this seems extremely unlikely, and is not supported by any other lines of evidence.

3) The melt inclusions analysed by Anderson et al. (2000) were enclosed within quartz crystals and are of unknowable age. There is no way of telling for how long they were isolated from the melt body prior to quenching - they could have been trapped only days before eruption or many centuries or millennia earlier. In light of point (2) above, it seems logical to conclude that the rapidly re-equilibrating $\mathrm{Fe}$-Ti oxides were not in equilibrium with the trapped glass inclusions in Bishop quartz.

4) Ghiorso and Gualda (2013) point out that $f \mathrm{O}_{2}$ and $\mathrm{aTiO}_{2}$ are strongly correlated. Plotting the values of $f \mathrm{O}_{2}$ and $\mathrm{aTiO}_{2}$ for Oruanui equilibrium oxide pairs modelled using their equations yields a positive linear relationship with an $R^{2}$ of $>0.99$ Figure 5.4). However, because both variables are calculated from the same magnetite-ilmenite paired compositins, a close correspondence would be an inescapable outcome. Regardless, it is also clear that if this relationship is real then it would be much easier to calculate $\mathrm{aTiO}_{2}$ simply according to the linear expression in Figure 5.4. Applying this linear expression to the modelled $\Delta \mathrm{NNO}$ values of $f \mathrm{O}_{2}$ derived from the Sauerzapf et al. (2008) formulations, yields a static relationship (i.e., slope of $\sim 0$ ) on a plot of temperature versus $\mathrm{aTiO}_{2}$ with the calculated $\mathrm{aTiO}_{2}$ averaging 0.65 . If this same linear expression is used to convert the modelled $\triangle \mathrm{NNO}$ values derived from amphibole rim compositions using Ridolfi et al. (2010: their equation 2), then plots of temperature versus $\mathrm{aTiO}_{2}$ show a moderate negative correlation $\left(\mathrm{R}^{2}=0.48\right.$; ranging from $\sim 850{ }^{\circ} \mathrm{C}$ and $\mathrm{aTiO}_{2}=0.65$, to $\sim 750{ }^{\circ} \mathrm{C}$ and $\mathrm{aTiO}_{2}=$ $0.75)$.

5) In reaction to Ghiorso and Gualda (2013), Evans and Bachmann (2013) outlined compositional arguments as to why the Fe-Ti oxides in the Bishop Tuff are in equilibrium with the melt and also with the co-crystallising biotite and feldspar. They also reiterate that the $\sim 100{ }^{\circ} \mathrm{C}$ temperature difference between early and late-erupted Bishop samples indicated by the Fe-Ti oxides is also reproduced by oxygen isotope thermometry (Bindeman and Valley 2002), and Ti-in-quartz thermometry (Wark et al. 2007 - although 
this validity of this method is still debated - see section 5.4). Application of two-feldspar thermometry is also indicative of a significant temperature difference between early and late-Bishop materials (Katy Chamberlain, pers. comm.).

Despite the controversy created by the Ghiorso and Gualda (2013) publication, the temperatures returned by Fe-Ti oxide thermometry for the Oruanui samples (either the Ghiorso and Evans 2008 or Sauerzapf et al. 2008 models) are in good agreement with thermometry based on amphiboles, plagioclase and orthopyroxene methods (Figure 5.1). The major inconsistency, arguably, may lie with the formulations in rhyolite-MELTS (Gualda et al. 2012).

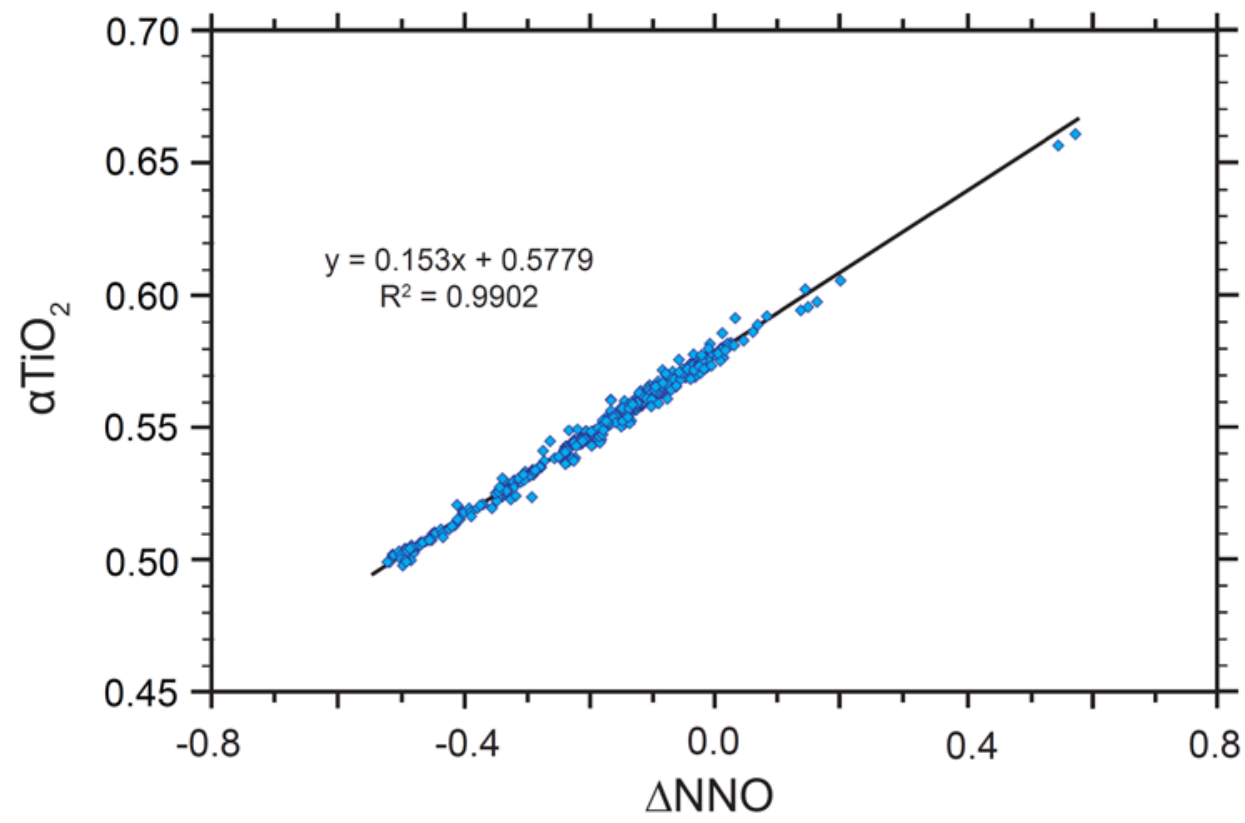

Figure 5.4 Modelled values for oxygen fugacity (relative to the nickel-nickel oxide buffer - NNO) versus the estimated $\mathrm{aTiO}_{2}$ of the melt for all equilibrium pairs of Fe-Ti oxides in the Oruanui HSR and LSR. Values were retrieved using Mark Ghiorso's online Fe-Ti oxide thermometry calculator (accessed at http://ctserver.ofm-research.org/OxideGeothrm/OxideGeothrm.php) that calculates the oxygen fugacity according to the method of Ghiorso and Evans (2008) and melt $\mathrm{aTiO}_{2}$ after Ghiorso and Gualda (2013).

\subsubsection{Amphibole-based thermometry and barometry}

The recent formulations of Ridolfi et al. (2010) allow for the calculation of temperature, pressure, $f \mathrm{O}_{2}$ and melt $\mathrm{H}_{2} \mathrm{O}$, all from a single major element analysis of amphibole. Arguably much of the appeal of this model (e.g., Chapters 2, 3 and 4 of this thesis) lies in this simplicity and ease of use. However, the Ridolfi et al. (2010) models of intensive 
variables have largely escaped rigorous scrutiny in the published literature. Shane and Smith (2013) investigated the records of temperature, pressure and $f \mathrm{O}_{2}$ for a number of Okataina rhyolites as indicated by the Ridolfi et al. (2010) models, and questioned the validity of the associated pressure determinations. They concluded that much of the $\mathrm{Al}$ variations in the Okataina amphiboles could be accounted for by the temperature-sensitive edenite and Ti-Tschermak exchange mechanisms. Despite the Ridiolfi et al. (2010) barometer indicating amphibole crystallisation over a considerable range of pressures (mostly between $70 \mathrm{Mpa}$ and $250 \mathrm{Mpa}$ ), Shane and Smith (2013) discounted the possibility of any considerable pressure variations, following two lines of reasoning. 1) The pressure-sensitive Al-Tschermak exchange (i.e., positive covariation between $\mathrm{Al}^{\mathrm{IV}}$ and $\mathrm{Al}^{\mathrm{VI}}$ ) for their Okataina samples was very weakly developed. 2) Application of the Ridolfi et al. (2010) barometer to EPMA traverses across single crystals indicated large fluctuations in pressure (and hence depth) that were judged physically unlikely. I consider both of these lines of reasoning below with respect to my Oruanui case study.

\subsubsection{The pressure-sensitive Al-Tschermak exchange}

Operation of the pressure-sensitive Al-Tschermak exchange, for which $\mathrm{Al}$ in the octahedral $\mathrm{C}$ site $\left(\mathrm{Al}^{\mathrm{VI}}\right)$ and tetrahedral $\mathrm{T}$ site $\left(\mathrm{Al}^{\mathrm{IV}}\right)$ increase and replace ${ }^{\mathrm{C}}(\mathrm{Mg}, \mathrm{Fe})$ and ${ }^{\mathrm{T}} \mathrm{Si}$, respectively, is recognised as a positive correlation on plots of $\mathrm{Al}^{\mathrm{IV}}$ versus $\mathrm{Al}^{\mathrm{VI}}$. Shane and Smith (2013) reported a very weak correlation $\left(R^{2}=0.111\right)$ between octahedral and tetrahedral Al, leading them to conclude that the Okataina amphiboles did not crystallise within a significant pressure gradient. Part of the difficulty in assessing the Al-Tschermak exchange in the Okataina and Oruanui amphiboles is that the reported absolute values for $\mathrm{Al}^{\mathrm{VI}}$ are small (mostly $<0.1$ atoms per 13 cations) and associated with relatively large uncertainties. Shane and Smith (2013, their Figure 3) show an uncertainty on their plot, but it is not clear what the uncertainty relates to or, how it was determined (i.e., is it a $1 \sigma$, or $2 \sigma$ uncertainty? Is it based on counting statistics or analysis of an amphibole (or some other mineral/glass) standard?). Additional complexities arise because the data were collected over a period of 7-8 years by multiple postgraduate students, and EDS techniques were employed. There is is thus potential that a non-uniform approach to standardisation and analysis of the amphiboles could generate significant contrasts in the reproducibility and overall quality of the $\mathrm{Al}^{\mathrm{VI}}$ allotments. In contrast, the data for the Oruanui amphiboles presented here were collected by WDS techniques, using a consistent approach to standardisation, analytical methodology and analysis of secondary standards throughout. I calculate an uncertainty on my allotments of $\mathrm{Al}^{\mathrm{VI}}$ in the Oruanui amphiboles on the basis 
of repeat analyses of the Engel's amphibole standard that was routinely analysed during sessions when amphibole data was collected.

Site-specific cation concentration data and compositional parameters for the Oruanui HSR amphiboles are summarised in Figure 5.5. There is a notable positive correlation in plots of $\mathrm{Al}^{\mathrm{IV}}$ versus Ti (Figure 5.5a) and $(\mathrm{Na}+\mathrm{K})^{\mathrm{A}}(\mathrm{Fig} 5 \mathrm{~b})$, indicating that the temperaturesensitive Ti-Tshermak and edenite exchange mechanisms, respectively, were operating. Note, however, that most of this covariance occurs at the higher values of $\mathrm{Al}^{\mathrm{IV}}(>1.15$ apfu). The pressure-sensitive Al-Tschermak exchange appears rather weak (Figure 5.5c), although it is somewhat more significant if only the higher $\mathrm{Al}^{\mathrm{IV}}$ portion of the dataset is considered. Figure 5.6 compares the results of the atomic substitution exchanges with the apparent pressures and temperatures of crystallisation as indicated by the Ridolfi et al. (2010) formulations. When only the portion of the dataset with $\mathrm{Al}^{\mathrm{IV}}>1.15$ apfu is considered, the positive correlation between $\mathrm{Al}^{\mathrm{IV}}$ and $\mathrm{Al}^{\mathrm{VI}}$ (i.e., the pressure-sensitive AlTschermak exchange) becomes more significant $\left(\mathrm{R}^{2}=0.48\right.$; Figure 5.6a). In addition, when the uncertainties associated with the allotment of $\mathrm{Al}^{\mathrm{VI}}$ (based on repeat analyses of the Engels' amphibole standard) are superimposed about the regression line, $>90 \%$ of these amphiboles fall within that envelope, indicating that the crystallisation of the Oruanui HSR amphiboles (at least those with $\mathrm{Al}^{\mathrm{IV}}>1.15 \mathrm{apfu}$ ) did occur within a significant pressure gradient. When the apparent crystallisation pressures indicated by the Ridolfi et al. (2010) model for the same data are considered, there is good agreement between the two methods. That is, that almost all of the pressure variation indicated by the Ridolfi et al. (2010) barometer is restricted to portion of the dataset with $\mathrm{Al}^{\mathrm{IV}}>1.15 \mathrm{apfu}$, and for which the Al-Tschermak exchange was significant. Similarly, the temperature sensitive TiTschermak substitution appears to have been most evident in the higher $\mathrm{Al}^{\mathrm{IV}}$ portion of the dataset, which is also consistent with the estimates of crystallisation temperature from the Ridolfi et al. (2010) thermometer. The data for the outermost amphibole rims (yellow symbols in Figure 5.6) overwhelmingly plot within the lower $\mathrm{Al}^{\mathrm{IV}}(<1.15 \mathrm{apfu})$ portion of the dataset, consistent with the very restricted range of temperatures and pressures inferred for the immediately pre-eruptive Oruanui magma body.

\subsubsection{Fluctuations in apparent pressures within single crystals}

The second aspect of their dataset that led Shane and Smith (2013) to question the validity of the Ridolfi et al. (2010) barometer centred on large fluctuations in apparent crystallisation pressures within single crystals. In their Figure 5 they present selected 

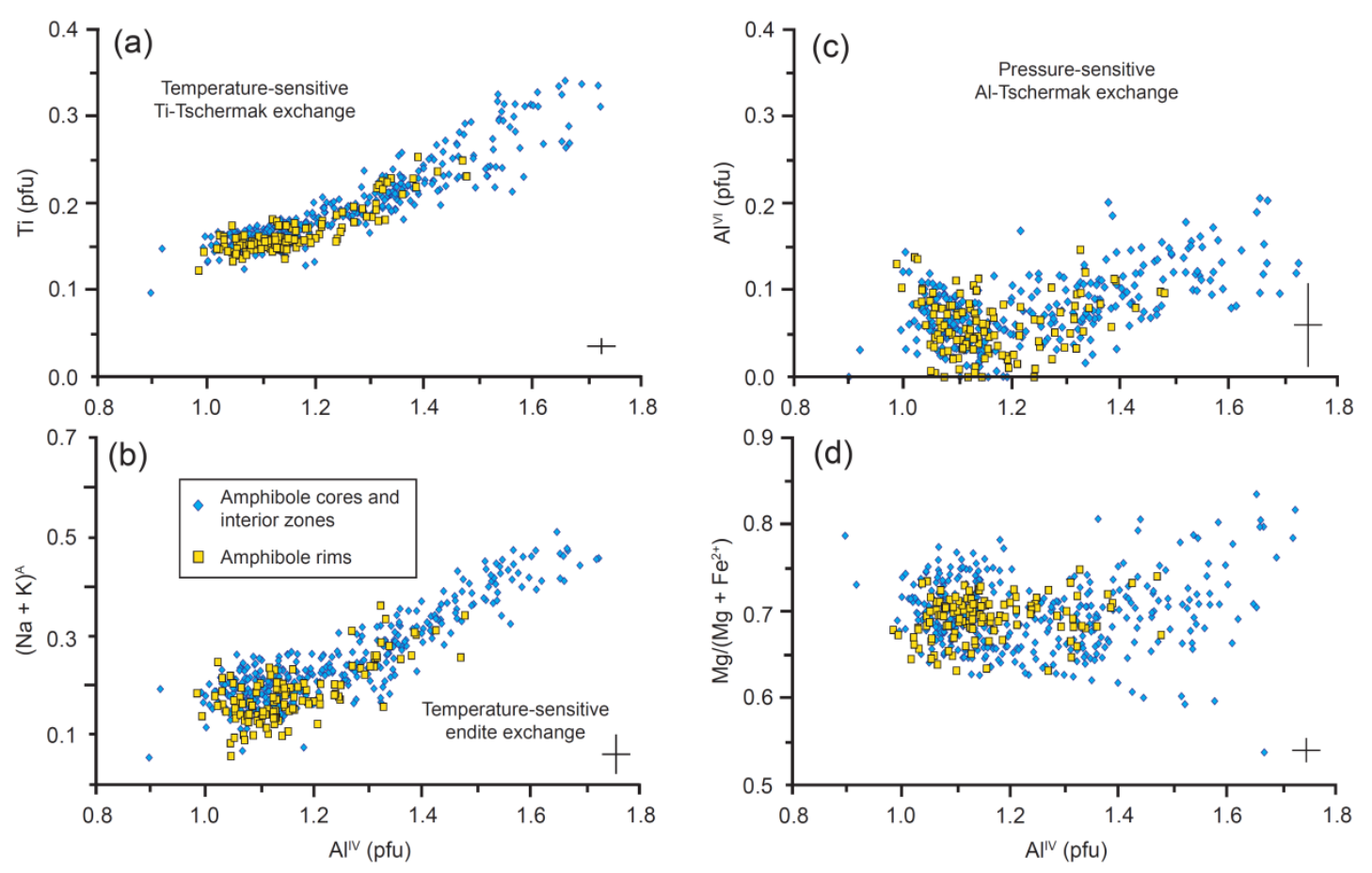

Figure 5.5 Major element cation data (calculated to 13 cations) for amphiboles extracted from Oruanui HSR clasts showing the qualitiative pressure and temperature relationships according to known pressureand temperature-sensitive exchange mechanisms. The temperature-sensitive (a) Ti-Tschermak and (b) edenite exchanges. (c) The pressure-sensitive Al-Tschermak exchange. (d) $\mathrm{Mg} /\left(\mathrm{Mg}+\mathrm{Fe}^{2+}\right)$ shows comparatively small and non-systematic variations with $\mathrm{AllV}$. Uncertainties represent 2 standard deviations from analyses of the Engel's amphibole standard.

compositional data and the pressure, temperature and $f \mathrm{O}_{2}$ estimates from the Ridolfi et al. (2010) models for two amphibole crystals from electron microprobe traverses. Shane and Smith (2013) highlight that, within these single grains, the Ridolfi et al. (2010 barometer indicates several significant fluctuations in pressure ( + temperature and $f \mathrm{O}_{2}$ ), corresponding to absolute changes of $\sim 70$ to $170 \mathrm{Mpa}$, or depth changes of $c a .2 .6$ to 6.4 $\mathrm{km}$. They justifiably argued that it is difficult to conceive that a single crystal can 'yo-yo' up and down in the crust, traversing from upper-crustal $(\sim 3.5 \mathrm{~km})$ to mid-crustal levels $(\sim 9.5$ $\mathrm{km})$ several times over. Their data, however, are lacking some key contextual information that could aid testing of the Ridolfi et al. (2010) models for intensive variables in this situation.

Perhaps the most important piece of context that is missing is images of the amphibole crystals themselves that could be used to assess their textural characteristics and show the crystal stratigraphy and history of the grains, such as evidence for dissolution and recrystallisation (see Chapter 3 for an example in orthopyroxene). If dissolutionrecrystallisation processes had occurred for the crystals reported on by Shane and Smith 
(2013), then it could explain the juxtaposition of portions of apparent high- and lowpressure amphibole without the need to invoke multiple large-scale crustal migrations of single crystals.
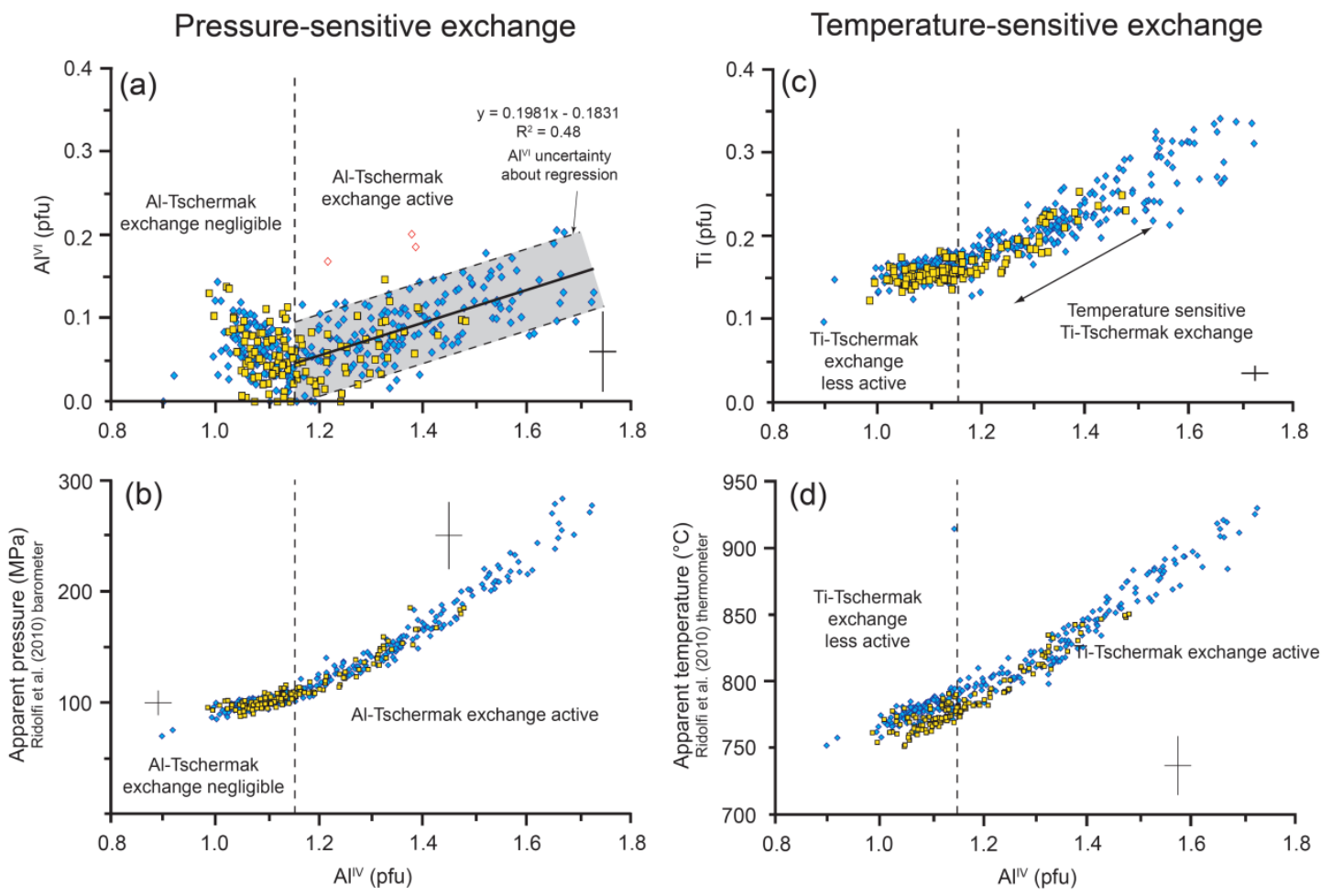

Figure 5.6 Comparision between pressure- and temperature-sensitive atomic exchange reactions with the results from the Ridolfi et al. (2010) barometric and thermometric formulations for amphiboles from the HSR. Blue diamonds are data for cores and interior zones and the yellow squares correspond to the outermost rim analyses. The dashed vertical line at $\mathrm{Al}^{\mathrm{IV}}=1.15$ apfu marks the approximate point at which the atomic exchange mechanisms appear negligible (at values $<1.15 \mathrm{apfu}$ ) or active (at $>1.15 \mathrm{apfu}$ ). These data are consistent with the apparent pressures and temperatures of amphibole crystallisation as determined by the Ridolfi et al. (2010) models. The regression line in panel (a) corresponds only to data with $\mathrm{Al}^{\mathrm{IV}}>1.15$ but excludes three outliers (shown in red). The grey shaded envelope shows the $2 \mathrm{sd}$ uncertainty on the allotment of $\mathrm{Al}^{\mathrm{VI}}$ as determined by repeat analyses of the Engels' amphibole standard.

Element maps from selected amphiboles from Oruanui HSR samples reveal some of the further complexities surrounding textural and compositional zonation in those amphiboles (Figure 5.7). Zonation in back-scattered electron (BSE) images is sometimes controlled by $\mathrm{Si}-\mathrm{Al}$ content (apparent P-T) with little or no change in $\mathrm{Mg}$-Fe content (Figure 5.7a).

However, sometimes the reverse is true with $\mathrm{Mg}-\mathrm{Fe}$ variations seeming to impart a large influence over the BSE intensity, accompanied by little or variation in $\mathrm{Si}-\mathrm{Al}$ (Figure 5.7b), and in other instances both Si-Al and Mg-Fe vary with the BSE intensity (Figure 5.7c, d).

In some cases, short-lived (thin) zones of increased $\mathrm{Al}$ content may potentially reflect localised increases of the availability of this element, for example, as a result of plagioclase 
resorption and/or influx of a different melt with higher $\mathrm{Al}$ concentrations (e.g., highalumina basalts). In both instances, the Ridolfi et al. (2010) formulations, which are based on major element compositional parameters, would indicate an increase in both temperature and pressure. Influx of a hotter, less evolved magma may clearly result in elevated temperatures, but will not be accompanied by any significant increase in pressure. However, due to the enormous volume of the Oruanui magma chamber, any such recharge events would likely have only a very localised effect on melt chemistry and would only effect a very small percentage of crystals. Such recharge events associated with magma bodies of much smaller volume would have more effect on the chamber-wide Al-content and thus may be more problematic for applications of the Ridolfi et al. (2010) barometer. Changes in the behaviour of co-crystallising plagioclase (i.e., sieve texturing, resorption), which acts to buffer the Si-Al content of the amphiboles, may also cause breakdown of the Ridolfi et al. (2010) thermobarometric formulations until such time as plagioclase restabilises. In the case of the Oruanui HSR samples, textural characterisation has shown that there was significant resorption and sieve texturing of plagioclase cores (see Chapter 4 and also Charlier et al. 2008). However, the crystallisation of euhedral plagioclase rim-zones, inferred to represent crystallisation in the Oruanui melt-dominant magma body, suggests that complexities from amphibole-plagioclase crystallisation dynamics should not effect the successful application of the Ridolfi et al. (2010) thermometry and barometry in the outermost rims.

In summary, to expect to be able to accurately deconvolve the entire P-T history of a single grain on the basis of a single compositional profile is unsound without careful analysis of associated textural features. As with many models of magma intensive variables, it is most likely that the final episode of crystal growth (immediately pre-eruptive) will be the most reliably reconstructed. The P-T determinations from cores and interior domains in Oruanui HSR and LSR crystals will likely contain some component of the complexities outlined above. However, the textural characteristics of each Oruanui crystal were carefully investigated from BSE images prior to analysis, and areas that appeared compromised by dissolution-recrystallisation were avoided, and the overarching patterns and ranges are inferred to be real. Trends observed between the apparent crystallisation pressures and temperatures with trace element concentrations and ratios in the amphiboles (especially Eu/Eu*; see Chapter 3), also support the validity of the P-T estimates, if only qualitatively. 
(a)
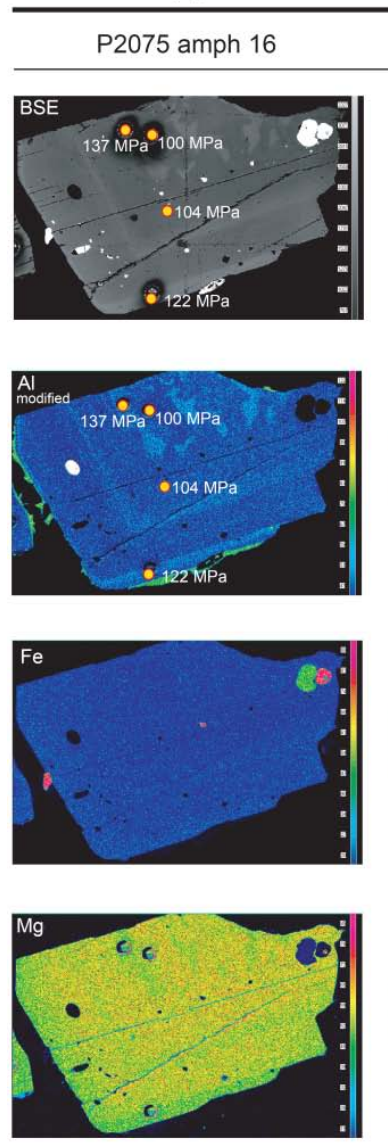

(c)

(d)
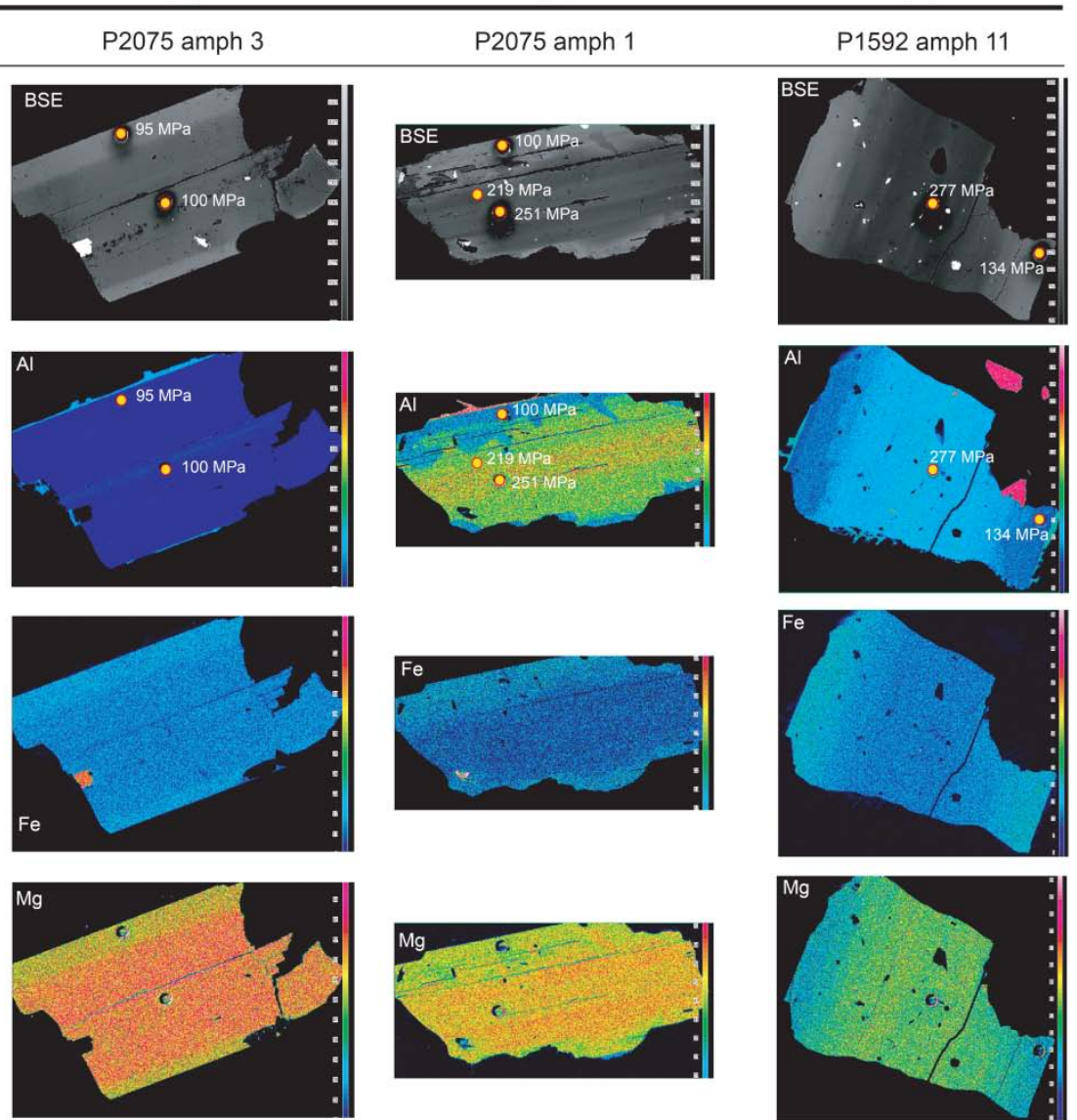

Figure 5.7 WDS-element maps of selected amphibole crystals from Oruanui HSR clasts. Compositional data show that zonation in BSE is sometimes caused by Si-Al variations as in (a), sometimes $\mathrm{Mg}$-Fe as in (b), and sometimes both as in (c) and (d). The yellow spots denoted the location of EPMA spot analyses, and these are here annotated with apparent pressure estimates from the Ridolfi et al.(2010) barometric formulation. The larger pits are from trace element analyses by LA-ICP-MS.

\subsubsection{Plagioclase-melt and orthopyroxene-melt thermometry}

Estimates of the final pre-eruptive temperature of the Oruanui melt-dominant magma body were also made using the plagioclase and orthopyroxene crystal-liquid equilibrium thermometers of Putirka (2008). These thermometers require as inputs the major element oxide compositions of the melt (glass) and plagioclase/orthopyroxene phases. The outermost rims of plagioclase and orthopyroxene, representing the final stages of growth, were paired with compositional data from pumice matrix glass representing the melt in which the crystals resided at the time of eruption. The matrix glass compositions for the HSR and LSR samples used in the application of the crystal-liquid thermometers are shown in Table 5.4. Analyses of matrix glass fragments from individual pumices revealed that all of the LSR samples had bimodal glass compositions (Figure 5.8), the more evolved 
group of which was identical to the matrix glass of the HSR pumices. The lack of a mixing line between the two compositional groups is interpreted to mean that the LSR magma as sampled during the eruption was isolated from the volumetrically dominant HSR and therefore that the two magmas only met syn-eruptively. The outermost rims of orthopyroxene and plagioclase from the LSR clasts were thus paired with matrix glass compositions from the less-evolved grouping (Figure 5.8, Table 5.4).
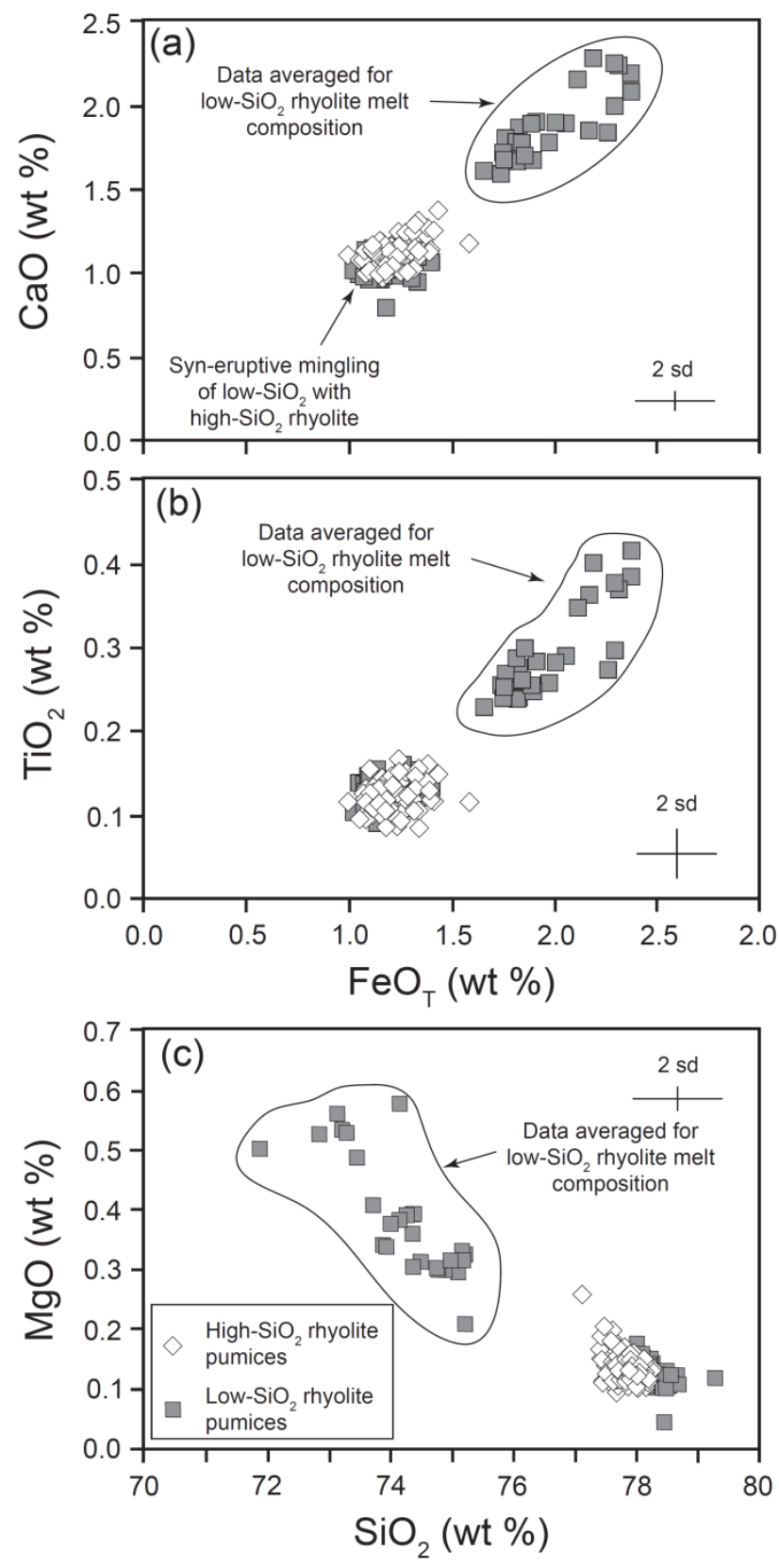

Figure 5.8 Plots of selected major element oxide data for matrix glass fragments from single Oruanui rhyolite pumices. Matrix glass for the high- $\mathrm{SiO}_{2}$ rhyolite clasts (open diamonds) define a single compositional population that is nearly homogenous within analytical uncertainty. Matrix glass data for the low-SiO ${ }_{2}$ rhyolite clasts (filled squares) are bimodal. The evolved compositional group is indistinguishable from the high$\mathrm{SiO}_{2}$ rhyolite group and represents very late-stage (i.e. syn-eruptive) mingling between the low-SiO ${ }_{2}$ rhyolite and volumetrically dominant high- $\mathrm{SiO}_{2}$ rhyolite. As indicated, only the composition of the lesser evolved population of glass is considered for mineral-melt equilibrium calculations for orthopyroxene and plagioclase from low- $\mathrm{SiO}_{2}$ rhyolite clasts. Uncertainties represent 2 standard deviations from analyses of the ATHO-G rhyolitic glass standard. 


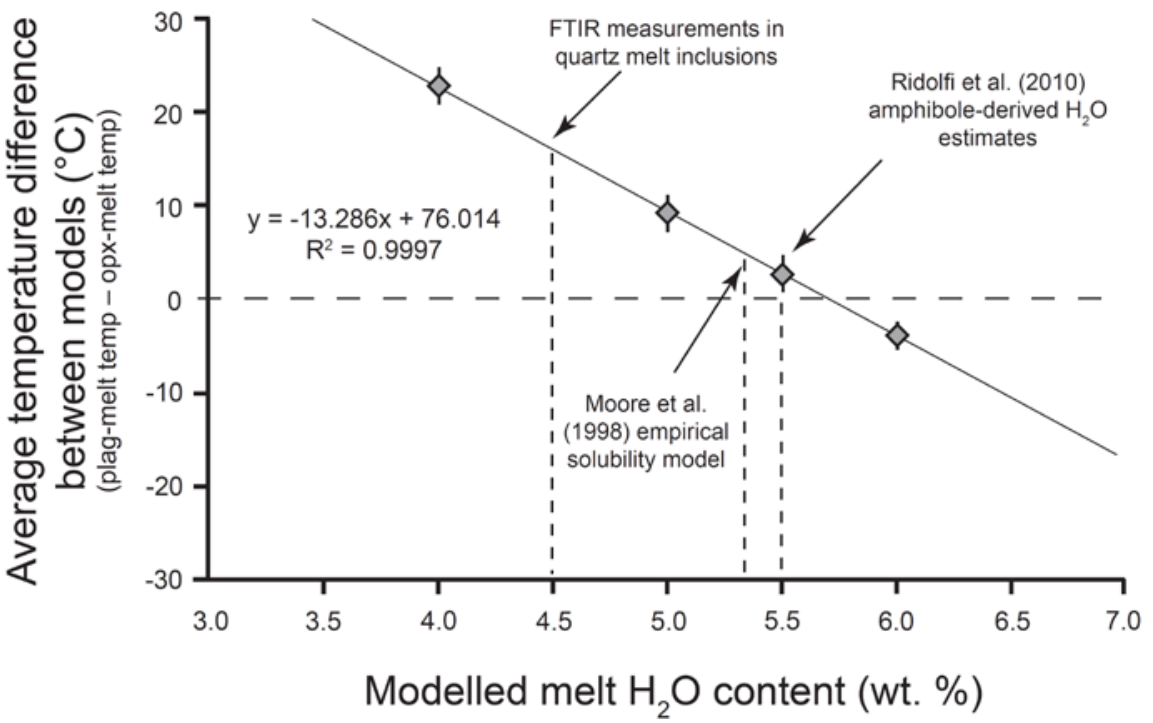

Figure 5.9 A plot showing the effect of the adopted melt- $\mathrm{H}_{2} \mathrm{O}$ content on the results of the plagioclasemelt and orthopyroxene-melt thermometers of Putirka (2008). Adopting a melt- $\mathrm{H}_{2} \mathrm{O}$ content of $5.5 \mathrm{wt} \%$ for the Oruanui high-SiO2 rhyolite, as indicated by the Ridolfi et al. (2010) model applied to the outermost amphibole rims, results in the best agreement between the two cryst-liquid equilibrium thermometers.

Both the 'plag-melt' and 'opx-melt' thermometers are sensitive to the value adopted for the water content of the melt, with lower input values of $\mathrm{H}_{2} \mathrm{O}$ resulting in hotter model temperatures. The plagioclase equations appear to be more sensitive to the adopted value of $\mathrm{H}_{2} \mathrm{O}$. Measured and modelled estimates of the mean $\mathrm{H}_{2} \mathrm{O}$ content of the HSR melt vary between 4.5 to $6.2 \mathrm{wt} \%$ (Table 5.3). The lower-bound values come from FTIR measurements from quartz-hosted melt inclusions (Liu et al. 2006). However, new quartz melt inclusion data presented and discussed in Chapter 4 (see also Liu et al. 2006) shows that most of the fully enclosed inclusions trapped different and more compositionally evolved melts than the final composition of the melt-dominant magma body, as represented by HSR pumice matrix glass and the glass shards in Oruanui fall deposits. This suggests that the measured values for the $\mathrm{H}_{2} \mathrm{O}$ in the quartz melt inclusions may not represent the final $\mathrm{H}_{2} \mathrm{O}$ content in the HSR magma body. Using an input of $5.5 \mathrm{wt} \%$, derived from the Ridolfi et al. (2010) melt- $\mathrm{H}_{2} \mathrm{O}$ formulation applied to the outermost HSR amphibole rims, generated temperature estimates that were consistent between the two phases (orthopyroxene and plagioclase) and amphibole and Fe-Ti oxide thermometers (Figure 5.1; Table 5.2). Using values of $\mathrm{H}_{2} \mathrm{O}<5.5 \mathrm{wt} \%$ results in a decoupling of the plagioclase and orthopyroxene derived temperatures, with the plagioclase-melt 
thermometer being more sensitive and shifted to higher temperatures (Figure 5.9). Using the same rationale, a melt $-\mathrm{H}_{2} \mathrm{O}$ content of $6.0 \mathrm{wt} \%$, derived from the outermost rims of amphiboles, was used for the LSR samples.

The outermost rim compositions of plagioclase and orthopyroxene from high- $\mathrm{SiO}_{2}$ rhyolite samples yield a mean final temperature for the melt-dominant magma body of 787 ${ }^{\circ} \mathrm{C}$ and $785^{\circ} \mathrm{C}$, respectively (Table 5.1). The comparatively small range of temperatures (< $20{ }^{\circ} \mathrm{C}$, Table 5.2) indicated by these models, despite the large number of determinations, results from the use of both a homogenous melt composition and a single value for melt$\mathrm{H}_{2} \mathrm{O}$ content. The former is considered valid because the matrix glass from HSR samples is approximately homogenous within analytical uncertainty (Figure 5.8; Table 5.4). The use of a single value for the melt $-\mathrm{H}_{2} \mathrm{O}$ content is less rigorously constrained as is discussed above. However, the application of these models under these constraints results in mean temperature determinations for the plagioclase and orthopyroxene rims that are consistent both with each other and with additional constraints from Fe-Ti oxide and amphibole thermometry (Figure 5.1b).

Application of Putirka's plagioclase- and orthopyroxene-melt thermometers to the outermost crystal rims from the LSR samples yields mean temperatures of $831^{\circ} \mathrm{C}$ and 839 ${ }^{\circ} \mathrm{C}$ for plagioclase and orthopyroxene, respectively. These mean temperatures are also in good agreement with the modal temperature estimates from Fe-Ti oxides and amphibole thermometry (Figure 5.1b).

The crystal-liquid formulations of Putirka (2008) also include equations that can be used to estimate the equilibrium pressure of crystallisation based on the co-existing crystal and melt compositions. However, these equations often yielded negative values for pressure, and are associated with large uncertainties $( \pm 300 \mathrm{MPa})$, much larger than the absolute values of what I consider to be accurate pressure estimates for the Oruanui rhyolites (Table 5.3, Figure 5.2). As such, these barometric formulations were not applied.

\subsubsection{Volatile saturation pressures}

Liu et al. (2006) measured volatile and trace element contents in quartz and quartz-hosted melt inclusions from the Oruanui HSR in order to estimate volatile saturation pressures (after Liu et al. 2005). Entrapment pressures were made on the basis on $\mathrm{H}_{2} \mathrm{O}$ and $\mathrm{CO}_{2}$ contents measured in trapped (fully enclosed) inclusions by FTIR, and based on the inference that the Oruanui melt-dominant magma body was gas saturated. This inference 
was made on basis of $\mathrm{CO}_{2}$ contents displaying positive trends with $\mathrm{Sr}$ as predicted by closed-system fractional crystallisation under gas saturated conditions (see also discussion in Wilson et al. 2012). When only data from the trapped inclusions are considered (i.e. excluding re-entrant and hourglass-shaped inclusions) the Liu et al. (2006) dataset gives a mean pressure of $138 \mathrm{MPa}$, ranging from 94 to $188 \mathrm{MPa}$. This range is consistent with the pressure range indicated by the amphibole-based barometer of Ridolfi et al. (2010).

\subsection{MODELS INVESTIGATED, BUT NOT RELIED ON}

\subsubsection{Plagioclase-hornblende thermometry}

The Holland and Blundy (1994) plagioclase-hornblende thermometer (their 'thermometer B') estimates an equilibrium temperature based on the co-crystallisation of amphibole and plagioclase and the reaction:

$$
\text { edenite }+ \text { albite }=\text { richerite }+ \text { anorthite. }
$$

For this thermometer to yield meaningful estimates requires the plagioclase and hornblende to have co-crystallised under equilibrium conditions. This requirement somewhat limits the extent to which the thermometer can be applied because, in general, it is difficult to demonstrate equilibrium relationships existed for any but the outermost rims of the crystals. In my application of this thermometer to the Oruanui HSR samples I paired together compositional data from the outermost rims of plagioclase and amphiboles, inferred to reflect the final stage of crystal growth in the melt-dominant magma body. These pairings resulted in a mean temperature estimate of $798^{\circ} \mathrm{C}(n=121$; $\left.\min =758^{\circ} \mathrm{C}, \max =858^{\circ} \mathrm{C}\right)$. These values are consistent with the earlier application of this thermometer to Oruanui HSR samples by Wilson et al. $\left(2006 ; \sim 800{ }^{\circ} \mathrm{C}\right)$.

This mean temperature is slightly higher than indicated by my preferred thermometers, although it is consistent within model uncertainties. Blundy and Cashman (2008) compared the performance of the Holland and Blundy (1994) thermometer to reproduce the temperatures of experimental amphiboles grown at controlled temperatures, but that were not used in the original calibration of the thermometer. Their results suggested an absolute average deviation (add) of $61{ }^{\circ} \mathrm{C}$ between the calculated and experimental temperatures. They also noted that the deviation was negatively correlated with the Mg\# of the amphibole, and urged caution when applying the thermometer to amphbioles with $\mathrm{Mg \#}$ $>0.7$. Application of this thermometer to the rims of LSR crystals yields a mean 
temperature of $837^{\circ} \mathrm{C}$ (ranging 774 to $880^{\circ} \mathrm{C}$ ). Although the results of the Holland and Blundy (1994) thermometer are in general agreement with the results of my preferred thermometers, I do not apply this thermometer extensively.

\subsubsection{Al-in-hornblende barometry}

The Anderson and Smith (1995) amphibole barometer estimates the equilibrium pressure of amphibole crystallisation on the basis of total $\mathrm{Al}$ content in the amphibole at a given temperature. Application of this barometer to rim compositions from amphiboles in the HSR clasts paired with the Ridolfi et al. (2010) modelled temperatures gives pressure estimates that are surprisingly consistent with the Ridolfi et al. derived pressure estimates $($ mean $=118 \mathrm{MPa}$, ranging 71 to $140 \mathrm{MPa})$. Application of the Anderson and Smith (1995) barometer to the LSR amphibole rims yields mean pressures of $103 \mathrm{MPa}$ (ranging 51 to $145 \mathrm{MPa}$ ) that are significantly lower than the Ridolfi et al. pressure estimates. The Anderson and Smith equations also imply a reverse thermal gradient (hottest temperatures corresponding to the shallowest depths, and vice versa) that is not consistent with evidence that the LSR crystals in general record derivation from both deeper and hotter regions than the HSR rims. For these reasons the Anderson and Smith (1995) barometer was not applied in this thesis.

\subsection{MODELS INVESTIGATED AND NOT TRUSTED}

\subsubsection{Ti-in-quartz}

During the earliest phases of this research I began investigating the different petrological models available for constraining magma intensive variables in the Oruanui system. It became apparent from an early stage that while consistency could be achieved between many different and independently calibrated models, the popular Ti-in-quartz thermobarometer (Wark and Watson 2006; Thomas et al. 2010) was problematic. The Thomas et al. (2010) experiments recalibrated the original TitaniQ model of Wark and Watson (2006) across pressures ranging from 500 to $2000 \mathrm{MPa}$. Their experiments, in which the presence of rutile was used to constrain the activity of $\mathrm{TiO}_{2}$ in the liquid phase at unity (i.e., $\mathrm{aTiO}_{2}=1$ ), determined that $\mathrm{Ti}$ solubility in quartz was both pressure and temperature dependent. Application of the resulting thermobarometer utilises three parameters - pressure, temperature and $\mathrm{aTiO}_{2}$. If two of these parameters are constrained 
then the third can, in principle, be calculated using a generalised formulation (equation 9 of Thomas et al. 2010), such that in general, for a given value of $\mathrm{aTiO}_{2}$, if temperatures are inferred to $\pm 20{ }^{\circ} \mathrm{C}$, pressure is constrained to $\pm 100 \mathrm{MPa}$ and vice versa.

As a result I became heavily involved in the publication of a Comment (Wilson et al. 2012) about the thermobarometric formulations of Thomas et al. (2010). The premise of our comment was that the results of the Thomas et al. (2010) formulations yielded estimates of pressure and temperature that were inconsistent with other models applied to quartz (and other mineral phases) used to infer these same parameters. If realistic values are given to any two of the three parameters then the value of the third is wholly unrealistic. The model yields growth temperatures at or below the granite solidus, pressures in the lower crust or upper mantle, or $\mathrm{TiO}_{2}$ activities inconsistent with the mineralogical and chemical compositions of the magmas. At the eventual conclusion of the comment-reply exchange, there was no agreement between the parties. I use this chapter to provide further comment on the workings presented by Thomas and Watson (2012).

The main rebuttal point of Thomas and Watson (2012) was that Wilson et al. (2012) used implausible input variables and therefore obtained implausible P-T estimates using the Thomas et al. (2010) calibration. The histograms presented in Figures 5.10 and 5.11, however, show that TitaniQ-derived pressures and temperatures for Oruanui quartz remain inconsistent and implausible even when Thomas and Watson's own preferred values for Oruanui $\mathrm{aTiO}_{2}(0.32)$ and temperature $\left(757^{\circ} \mathrm{C}\right)$ are used.

The histograms in Figure 5.10 summarise a number of temperature calculations using the TitaniQ formulations using two different values of $\mathrm{aTiO}_{2}$ and different pressures. Temperatures in panels (a) to (d) are calculated using the preferred $\mathrm{aTiO}_{2}$ of Wilson et al. (2012) whereas those in panels (e) to (h) use the preferred value of Thomas and Watson (2012). These model results show that the pressure-dependent TitaniQ model of Thomas et al. (2010) requires as input unrealistic, geologically improbable values for pressure (i.e., $800 \mathrm{MPa}$ for $\mathrm{aTiO}_{2}=0.52 ; 600 \mathrm{MPa}$ for $\mathrm{aTiO}_{2}=0.32$ ), in order to yield consistent results with the other methods used to infer temperature of the immediately pre-eruptive Oruanui magma body (i.e., $770-790{ }^{\circ} \mathrm{C}$; see Table 5.1). When the Thomas et al. (2010) model is run at lower pressures consistent with other constraints - i.e., 100 to $200 \mathrm{MPa}$ as inferred from volatile contents in quartz melt inclusions (Liu et al. 2006) and amphibole rim compositions (after Ridolfi et al. 2010) - the TitaniQ model temperatures are either on or below the water-saturated solidus. As the Oruanui quartz-hosted melt inclusions typically 

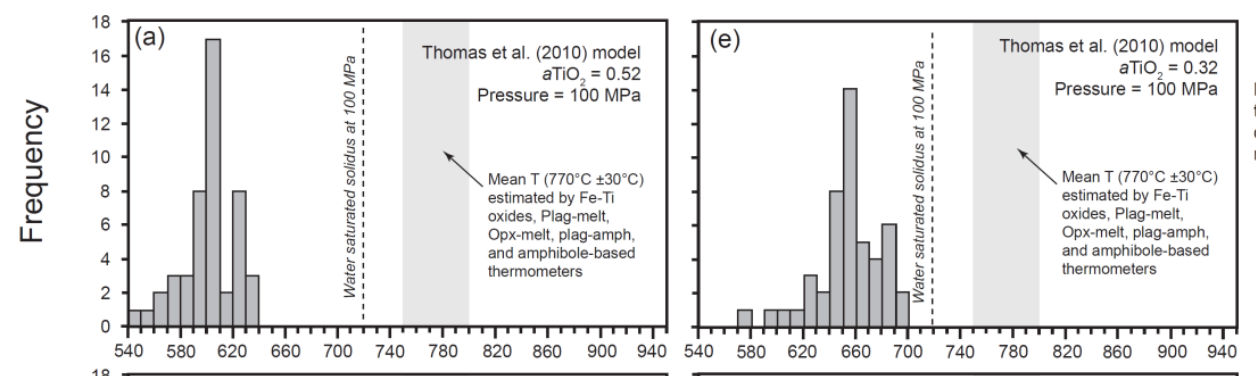

Models run at pressures that approximate the top of the melt dominant magma body.
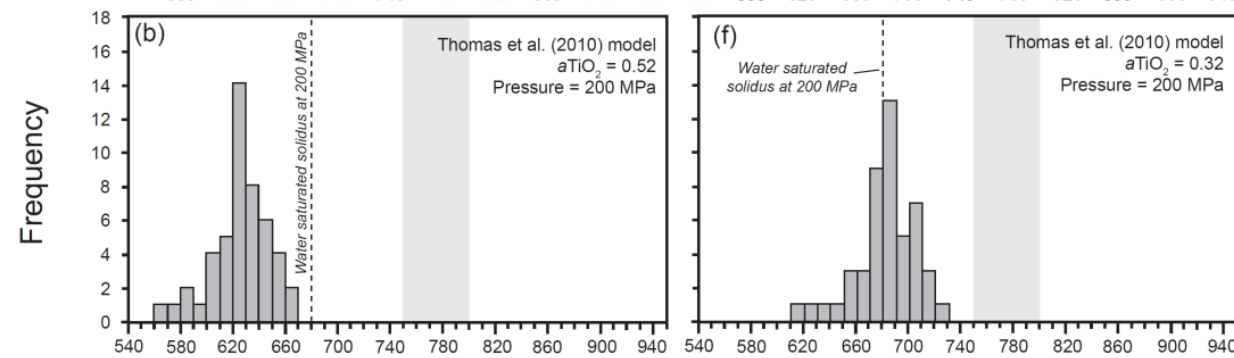

Models run at just above maximum pressures inferred from volatiles in quartz melt inclusions. Only low SiO2 rhyolites and the juvenile mafic clasts, quartz free, yield pressures equivalent to this.
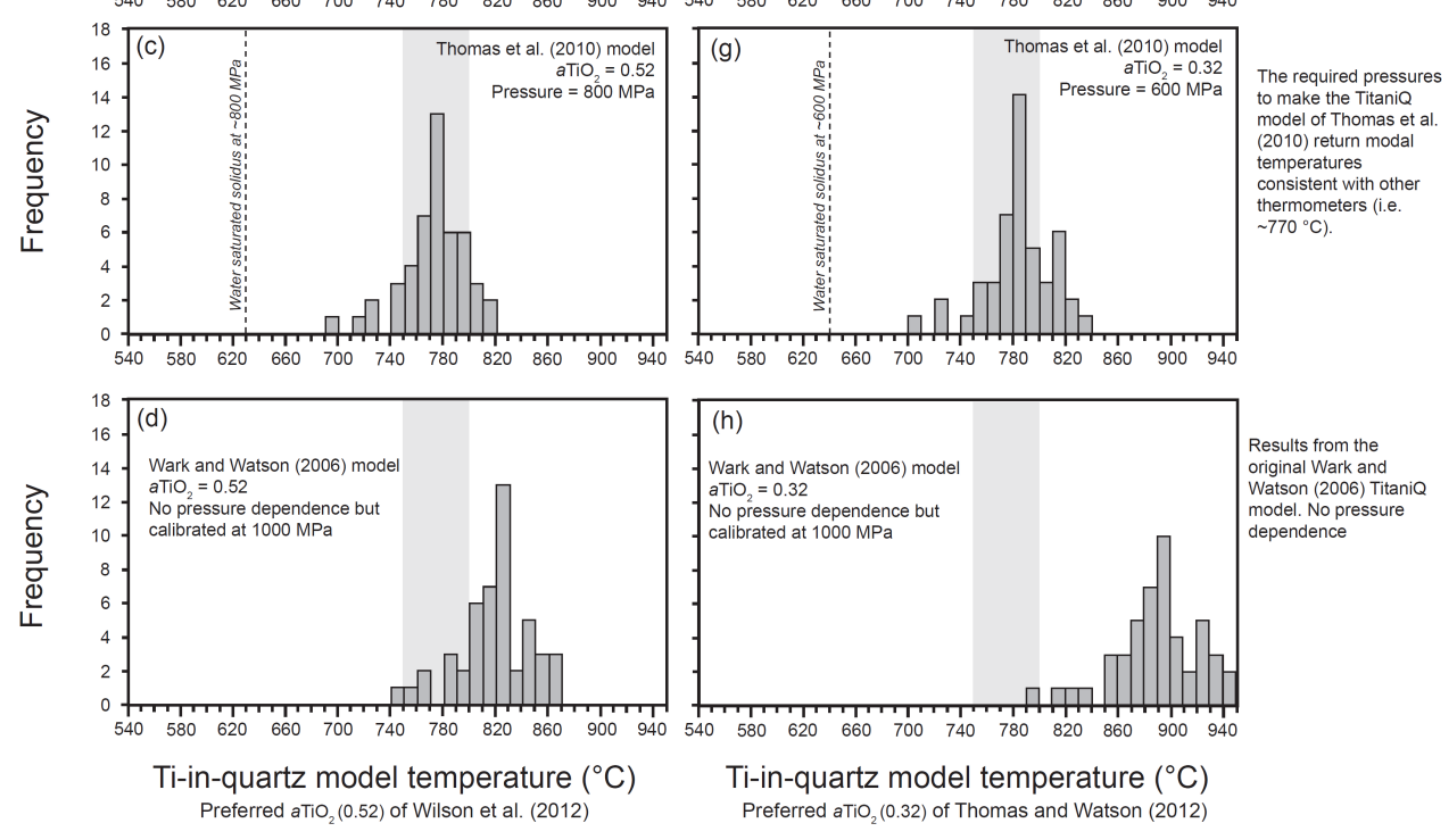

Figure 5.10 Iterations of Ti-in-quartz (TitaniQ) model temperatures of quartz from the Oruanui high$\mathrm{SiO}_{2}$ rhyolite. Data in panels (a-c) and (e-g) are generated using the pressure-dependant calibration of Thomas et al. (2010) whereas data in panels (d) and (h) were generated with the original Wark and Watson (2006) calcuation that has no pressure dependance. Ti concentrations in Oruanui quartz (ranging 47 to $128 \mathrm{ppm}, \mathrm{n}=48$ ) were taken from the online supplementary information of Liu et al. (2006), excluding analyses from quartz that had jagged cores under cathudoluminescence which were inferred by the authors to represent xenocrystic cores. Models on the left-hand side of the figure (a-d) use $\mathrm{aTiO}_{2}=0.52$, determined on the basis of co-existing Fe-Ti oxide equilibrium pairs and the preferred value of Wilson et al. (2012). Models of the right-hand side of the figure (e-h) use $\mathrm{aTiO}_{2}=$ 0.32 , a value derived from the MELTS algorithm, and the preferred value of Thomas and Watson (2012). The vertical dashed line (where shown) indicates the approximate temperature of the watersaturated solidus at the pressure indicated in the model. Temperatures to the left of the solidus indicate only solids should be present (i.e. no melt), and those to the right indicate the presence of both melt and crystals. The grey shaded bars highlight the temperature window of the immediately pre-eruptive melt-dominant magma body $\left(770 \pm 30^{\circ} \mathrm{C}\right)$ as inferred from Fe-Ti oxide, plag-melt, opx-melt, plagamph, and amphibole-based thermometry. For each of the two values of $\mathrm{aTiO}_{2}$ the data is modelled at a range of pressures $(100$ to $1000 \mathrm{MPa})$ to show that at no rational combination of pressure and temperature can be reached. That is, reasonable values of pressure (100 to $200 \mathrm{MPa}$ ) result very low temperatures compared to other methods (see Table 5.2), many of which are sub-solidus temperatures. In order for the Thomas et al. (2010) model to yeild temperatures consistent with my preferred thermometers (Fig 1), unreasonable pressures must be inferred. The original Wark and Watson (2006) TitaniQ formulation does not require an input for pressure, although the experiments were conducted at $1 \mathrm{GPa}(1000 \mathrm{MPa})$. 
contain between 80 and 200 ppm CO 2 (Liu et al. 2006), the activity of water is reduced $\left(\mathrm{aH}_{2} \mathrm{O}<1\right)$ which has the effect of raising the temperature of the solidus (Johannes and Holtz 1996) above that of the water-saturated solidus plotted.

The histogram in Figure 5.11 shows the results derived from the Thomas et al. (2010) TitaniQ barometer using the preferred temperature and $\mathrm{aTiO}_{2}$ inputs of Wilson et al. (2012) and Thomas and Watson (2012). The resultant pressures, from both sets of inputs, are inconsistent and irreconcilable with other lines of geological, petrological and geophysical evidence. The input values of Thomas and Watson (2012) yield pressures equivalent to depths at or below the base of the quartzo-feldspathic crust beneath the TVZ, at levels where quartz crystallisation is inherently unlikely. Using the input values of Wilson et al. (2012) yields pressure estimates equivalent to depths in the lower crust and upper mantle.

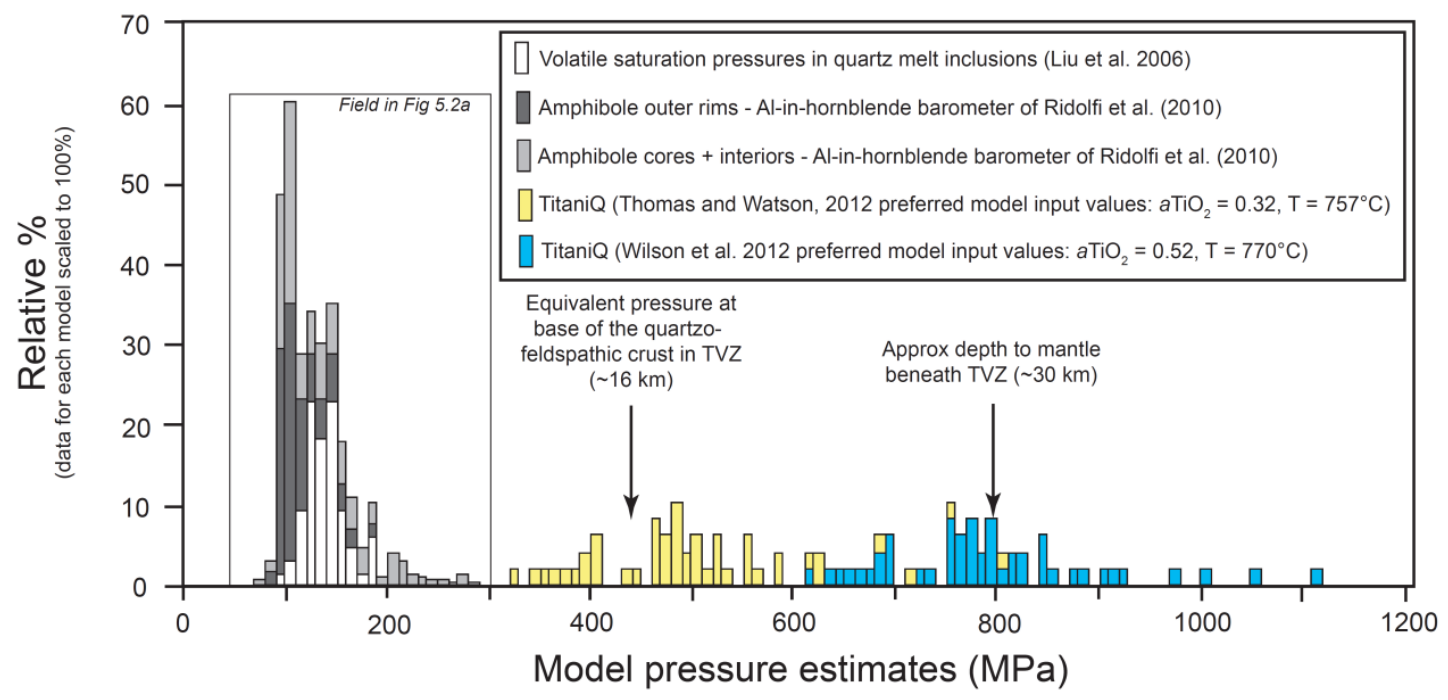

Figure 5.11 Model pressure estimates for the high- $\mathrm{SiO}_{2}$ rhyolite based on the Al-in-hornblende (Ridolfi et al. 2010), volatile saturation (Liu et al. 2006) and Ti-in-quartz (Thomas et al. 2010) barometers. Two sets of pressure estimates are shown for this dataset: one uses the preferred MELTS-derived model inputs for temperature and $\mathrm{aTiO}_{2}$ of Thomas and Watson (2012), and the other uses the Fe-Ti oxidederived values of Wilson et al. (2012). Using either combination of the model input values results in untenable pressure estimates from the Thomas et al. (2010) model.

Thomas and Watson (2012) also assert that the only accurate way to calculate $\mathrm{aTiO}_{2}$ in non-rutile bearing systems is by using one of two thermodynamic modelling software pckages, MELTS (Ghiorso and Sack 1995) or rhyolite MELTS (Gualda et al. 2012). 
However, many aspects of the rhyolite-MELTS modelling of Bishop Tuff compositions by Gualda et al. (2012) are, ironically, at odds with the assertions of Thomas and Watson (2012). For example, Thomas and Watson (2010) cite Ghiorso and Gualda (2013) to the effect that Fe-Ti oxides in the Bishop Tuff, and most likely Oruanui, were not in equilibrium with the melt and that the Fe-Ti oxide temperatures are too high. However, Gualda et al. (2012a,b) report that rhyolite-MELTS predicts a 'nearly invariant temperature of crystallisation' of $\sim 765-755^{\circ} \mathrm{C}$ for biotite, plagioclase, quartz, magnetite, ilmenite and sanidine in the Bishop magma, in contradiction to Thomas and Watson (2012). Thomas and Watson (2012) show plots of temperature versus pressure projected from a fixed value of $\mathrm{aTiO}_{2}$ (see their Figure 1) with isopleths of representative Ti-in-quartz concentrations, and state that quartz crystallisation could occur at any P-T along those isopleths. However, the rhyolite-MELTS derived temperature versus liquid-aTiO2 evolution path, shown in Figure 5.4 of Ghiorso and Gualda (2013), and based on the same Bishop Tuff quartz melt inclusion data, implies that significant changes in $\mathrm{aTiO}_{2}$ occur with decreasing temperature. Their trend shows a change from in $\mathrm{aTiO}_{2}$ from $\sim 0.25$ at $725^{\circ} \mathrm{C}$ to $\sim 0.45$ at $665^{\circ} \mathrm{C}$ (the temperature range in Thomas and Watson's Figure 5.1a). Using the 50 ppm Ti-in-quartz Bishop example and the above temperature and aTiO2 changes, the Thomas et al. TitaniQ model would indicate cooling from $725^{\circ} \mathrm{C}(\mathrm{aTiO} 20.25)$ to $665^{\circ} \mathrm{C}(0.45)$ was isobaric and occurred at a pressure of $\sim 500 \mathrm{MPa}$. All other data from the Bishop Tuff imply that these temperature and pressure estimates are both inconsistent and inaccurate. 


\section{Synthesis and conclusions}

\subsection{KEY FINDINGS}

This work illustrates the degrees of detail that can be obtained about the operations of a large silicic magmatic system by combining field-focussed information with an integrated study of stratigraphically and temporally controlled samples and investigation of all the mineral phases. My work in particular has focussed on the major mineral phases with the aim of comparing and contrasting the records available in single pumices or at single stratigraphic levels (i.e., points in time during the evacuation of the magma body) in order to address the key issues/questions raised in the Introduction. Here I summarise some of the key findings of this research highlighting how it extends our current understanding of the operation of large silicic magmatic systems. In drawing this thesis to a conclusion I call attention to some potential avenues for future research into the Oruanui system in particular and large volume, crystal-poor rhyolites in general.

\subsubsection{What determines the precise moment a large silicic eruption begins?}

Determining the factors that control the initiation and modulation of an eruption is a significant challenge. This is particularly so for pre-historic eruptions where such factors must be pieced together solely from information preserved in the geological record. The discovery of juvenile biotite-bearing rhyolite pumices among the volumetrically dominant (and biotite-free) HSR pumices proved to be a vital piece of evidence that enabled me to address the processes that initiated the Oruanui eruption. A number of lines of evidence were presented in Chapter 2 (published as Allan et al. 2012) that indicated the co-eruption of the biotite-bearing pumices with regular Oruanui magma, the onset of the eruption, and its progression during the earliest phases, were all intimately controlled by rifting-related processes. Key to establishing these findings was evidence that:

1. the biotite-bearing and biotite-free magmas only encountered each other syneruptively and, from the mixing relationships, only in the conduit,

2. the reconstructed pressure ranges for the two magmas indicated overlapping storage regions within the crust, yet strongly contrasting mineral compositions indicated the two pre-eruptive magma bodies must have been laterally separated, and 
3. crystal compositional characteristics that unambiguously tied the biotite-bearing rhyolite to the NE dome system, suggesting that the pre-eruptive lateral separation was approximately $10-15 \mathrm{~km}$, and broadly along the axis of regional extension.

The presence of the biotite-bearing pumice in minor quantities $(3 \%)$ in basal phase 1 deposits demonstrates that lateral transport of the biotite-bearing magma, and the opening up of the earliest vent for the Oruanui eruption were closely coincident. On the basis of these relationships it was inferred that a rifting-related event simultaneously triggered the onset of phase 1 of the Oruanui eruption, and caused propagation of a biotite-bearing rhyolite dike from the NE dome source system along a NE to SW trajectory towards Taupo where it intercepted the Oruanui magma in the conduit.

Paradoxically, the rifting-related processes that initiated the onset of the Oruanui eruption may have also led to the temporary shutdown of explosive activity at the conclusion of phase 1. Wilson (2001) reported field evidence that indicated a significant time-break, on the order of several weeks to months, between phase 1 and phase 2 activity. It is suggested that towards the end of phase 1, a tipping point was reached such that magmatic stresses temporarily were overcome by crustal containing stresses once more, prompting the cessation of phase 1 activity. Renewed rifting-related processes re-initiated explosive activity during phase 2 accompanied by a new influx of biotite-bearing rhyolite.

This new model goes some way towards explaining some of the established findings prior to embarking on this research, in particular the phase 1-2 time-break identified by Wilson (2001), that were, and still are, at odds with generalised notions for the triggering of large silicic eruptions. Traditional models which suggested eruption could be triggered as a result of volatile oversaturation (e.g. Blake 1984), are theoretically valid and applicable to many situations, but cannot adequately capture many key details from the Oruanui. For example, data published since Blake (1984) suggests that many large silicic magma bodies may be gas-saturated for much of their accumulation histories (e.g. Liu et al. 2006 and Wilson et al. 2012 for the Oruanui; Wallace et al. 1999 for Bishop Tuff). In addition, volatile oversaturation working in isolation as a trigger for an eruption can only work once. At the conclusion of phase 1 , less than $0.1 \%$ of the total erupted magma volume $\left(\sim 530 \mathrm{~km}^{3}\right)$ had been evacuated when activity shutdown for several weeks-to-months, despite the inference from volatile contents in quartz melt inclusions that the overall magma body was gassaturated (Liu et al. 2006). Volatile oversaturation alone cannot explain why the Oruanui underwent premature shutdown of explosive activity. 
In addition, several numerical and theoretical models have been developed for the containment and release of large magma bodies. One key criticism of such models when applied to the triggering of eruptions is that they largely consider the magma body in isolation, sitting in a medium that has no role to play in determining how the magma behaves (e.g. Jellinek and DePaolo 2003; Gregg et al. 2012). For example, while the Gregg et al. (2012) model incorporates and predicts a significant influence of extensional faults above the magma chamber that ultimately initiate eruption, these faults are imposed in the modelling by the growing magma chamber itself and do not relate to any inherent extensional processes within the containing crust related to the tectonic setting. In contrast, the Costa et al. (2011) work does address the influence of extensional tectonics on the unfolding of a large silicic eruption. Their model highlights the potential for moderate extension rates to greatly influence the tempo and vigour of an eruption and to sustain high eruption rates under favourable conditions. Such a model has some grounding in the Oruanui with the onset of phase 3 activity. Wilson (2001) showed that the onset of phase 3 coincided with the unzipping of elongate vent structures down the eastern margin of the caldera, the first involvement of significant volumes of magma from deeper, hotter and less evolved sources, and an overall escalation of the vigor of the eruption. The Costa et al. (2011) model is primarily concerned with the escalation of eruption rates in response to imposed tensile stresses; it cannot though, in itself, explain why the Oruanui event stopped and started several times.

The model put forth in Chapter 2 highlights a delicate interplay between external (tectonic) and internal (magmatic) processes during the earliest phases of the Oruanui eruption. It offers an explanation for some of the characteristics observed in the Oruanui that are not captured by most numerical and theoretical models of eruption triggering. A pertinent question is whether this sort of process can be demonstrated as applicable to other examples of large silicic eruptions, especially those occurring within extensional tectonic settings. The main complexity in assessing this lies in the difficulty of identifying how the rifting processes are manifested in the geological record. It is only the fortuitous involvement of a foreign magma, able to be chemically fingerprinted to a physically distinct source that allows this link to be made for the Oruanui. As was emphasised in Chapter 2, tectonic rupturing of shallow magma chambers (and even premature shutdown of explosive activity) may be commonplace in these settings, but it may just not be tangibly represented in the geological record. 


\subsubsection{Was the Oruanui magma extracted from a crystal-mush source?}

The antecedents to large-volume crystal-poor rhyolites are generally considered to be crystal-rich mushes (Hildreth 2004; Bachmann and Bergantz 2004). One of the major implications of this perspective is that crystal-melt segregation on an enormous scale must occur at some stage prior to the eruption. While many studies of crystal-rich ignimbrites identify 'up-temperature' signals in the rims of crystals that are used to invoke rejuvenation and/or remobilisation of the crystal mush through mafic recharge (e.g. Fish Canyon Tuff, Bachmann and Dungan 2002; Whakamaru, Matthews et al. 2012a), petrological studies of crystal-poor rhyolites have so far been unable to unambiguously establish a feature within the crystals that specifically represents the formation of the melt-dominant magma body. In Chapters 3 and 4, evidence is presented to show that processes of extraction of melt plus entrained crystals from the Oruanui crystal mush are physically recorded in orthopyroxenes and plagioclase from the high-silica rhyolite (HSR) pumices as prominent core-rim textural contrasts (summarised in Figs. 4.6 and 4.7). The formation of the relevant boundaries occurred following a temporary disequilibrium that caused significant partial dissolution and/or resorption of plagioclase and orthopyroxene, followed by a return to stability and growth of the rim zones. Orthopyroxene and plagioclase destabilisation followed by re-stabilisation behaviour is recognised in complementary chemical signatures in the amphiboles that continued equilibrium crystallisation throughout the changes in crystallisation setting. In-situ pressure determinations from the amphiboles show that these characteristic textures in the orthopyroxene and plagioclase crystals developed as the host magma underwent significant decompression from $\sim 270 \mathrm{MPa}$ to $\sim 140 \mathrm{MPa}(\sim 10 \mathrm{~km}$ to $\sim 6 \mathrm{~km}$ depth). The decompression event is interpreted to reflect the extraction of vast volumes of melt (plus some fraction of the crystals) from the Oruanui source mush, and accumulation of the melt-dominant magma body at shallower levels ( $90 \mathrm{MPa}$ to $140 \mathrm{MPa}$ or $\sim 3.5 \mathrm{~km}$ to $6 \mathrm{~km}$ depth).

These textural and chemical linkages between orthopyroxene, plagioclase and amphibole crystals of the HSR provide a unique perspective on the assembly of the Oruanui meltdominant magma body. They provide information on the diversity of sources that were drawn from, and the timescales over which the magma transitioned from a largely uneruptible mush into a highly eruptible, gas-saturated crystal-poor rhyolite body at shallow crustal levels. 


\subsubsection{Over what timescales did the Oruanui melt-dominant magma body accumulate?}

In Chapter 3 (published as Allan et al. 2013), the main core-rim boundary in the HSR orthopyroxenes were targeted for Fe-Mg diffusion modelling in order to quantify the timescales involved in the physical accumulation of the Oruanui melt-dominant magma body. After careful consideration of the source and magnitude of age uncertainties, the results indicated that the accumulation of the melt-dominant magma body only began $\sim 1600$ years before eruption with most of the accumulation apparently occurring in the final $\sim 500$ years. These diffusion based ages are in agreement with earlier constraints $(<3000$ years) based on contrasting zircon age spectra between the Oruanui zircons and those from the Okaia eruption that was vented only $\sim 3$ ka earlier from a vent subsequently engulfed by the Oruanui caldera (Wilson and Charlier 2009). The time constraints placed on the Oruanui melt-dominant magma body formation are currently unparalleled. At present, the closest comparison to the Oruanui study in Chapter 3 is the series of timescales reported by Gualda et al. (2012a) for the crystallisation of Bishop Tuff quartz. However, in contrast to the Oruanui, there is no specific, clear and widespread feature of the Bishop quartz that can be inferred to represent the formation of the Bishop melt dominant magma body. In addition, several aspects of the constraints applied by Gualda et al. (2012a, b) on the basis of rhyolite-MELTS modelling, require further scrutiny. For example, the assertion that Bishop magma underwent invariant crystallisation at $\sim 756{ }^{\circ} \mathrm{C}$, despite several lines of evidence that a thermal gradient of up to $\sim 100{ }^{\circ} \mathrm{C}$ persisted between early- and late-erupted samples (e.g., Bindeman and Valley 2002; Hildreth and Wilson 2007; Evans and Bachmann 2013; Katy Chamberlain, pers. comm. 2013).

\subsubsection{What are the controls on determining whether a magma body is zoned versus unzoned?}

Chapter 4 builds on the mush extraction model presented in Chapter 3, in order to explore how data from crystal-specific and whole-rock studies could be reconciled in a single unifying scenario for development of the Oruanui magma body. Textural and compositional analysis of HSR plagioclase showed that many crystals shared a very similar history to the orthopyroxene, involving dissolution and/or resorption during decompression, followed by restabilisation and crystallisation of prominent rim-zones in the melt-dominant magma body. Textural zonation of quartz viewed under CL imagery is 
more complex, however, and does not conform to a broad, consistent zonation pattern as seen in a significant proportion of the other major phases. In addition, the quartz cores contain trapped melt inclusions which were more evolved than the final melt dominant magma body, indicating derivation from more evolved sources (Chapter 4; Liu et al. 2006). These observations are in direct contrast with the majority of plagioclase, orthopyroxene and amphibole crystals, the evidence from which indicates derivation from deeper, hotter and less evolved sources prior to their incorporation in the melt dominant magma body.

In recognition of these additional complexities from quartz, a revised model was presented in Chapter 4. This model is summarised schematically in Figure 6.1. Wilson et al. (2006) found that there was no significant systematic zonation of the Oruanui rhyolite pumice compositions with respect to stratigraphic height. This led them to suggest that any stratification in the pre-eruptive magma body had been destroyed by vigorous stirring, presumed by them to have occurred due to interactions with mafic magma. The lack of zonation and indications of vigorus mixing are further confirmed here by comparing the rim compositions of crystals from early- versus late-erupted samples (Chapter 4).

From the revised model shown in Figure 6.1 the cores and interiors of HSR crystals record a huge diversity of compositions and inferred intensive variables because they were sourced from a thermally and compositionally stratified crystal mush body. Only the uppermost layer of the crystal mush is inferred to have been silica-saturated and hence quartz-bearing. Magma-assisted rifting processes are inferred to have repeatedly opened up channels within the mush that allowed large volumes of melt to ascend and pond at the top of the mush body, entraining crystals from all heights of the mush body and inducing partial decomposition of orthopyroxene and plagioclase during the associated decompression. The extraction and accumulation is inferred to have become selfpropogating, with large-scale collapse and compaction of areas of the mush drained of melt, and with sagging of the mush roof accommodating the growing melt dominant magma body.

Substantial heat-loss (accompanying crystallisation) in the melt dominant magma body is indicated by the consistent rimward down-temperature signals in the rim zones of orthopyroxenes (decreasing En) and plagioclase (decreasing An), and the model temperature estimates from the amphiboles. In Chapter 3 it was argued that the orthopyroxene core-rim boundaries, marking the arrival of individual orthopyroxene crystals into the accumulating melt dominant magma body, formed at $\sim 820{ }^{\circ} \mathrm{C}$ after which 
(a)

Prior to development of Oruanui melt-dominant magma body (i.e. $>1600$ years before eruption)

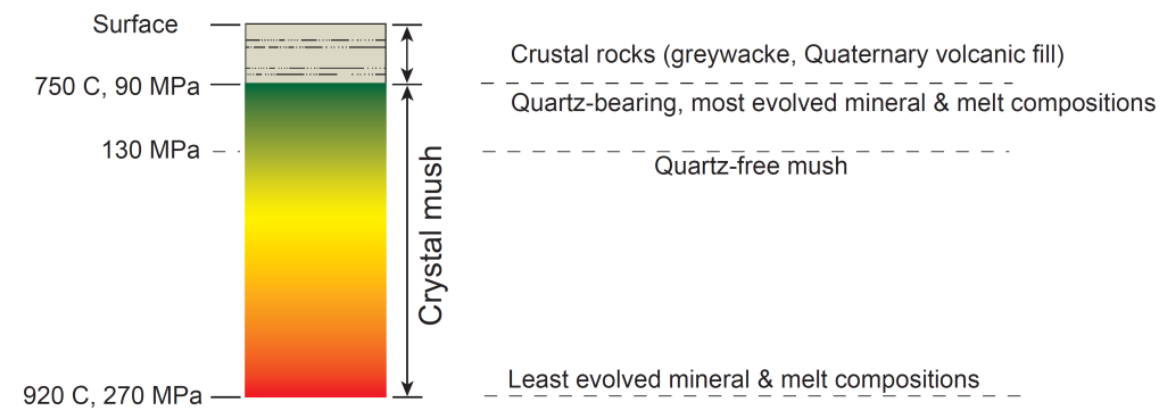

(b)

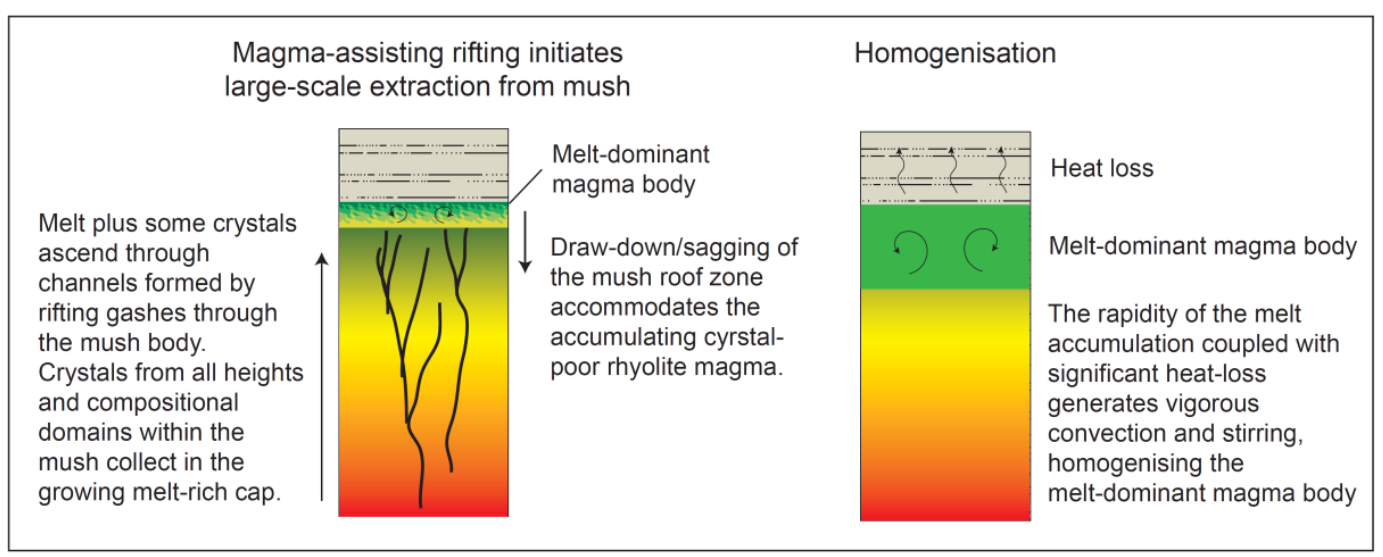

(c)

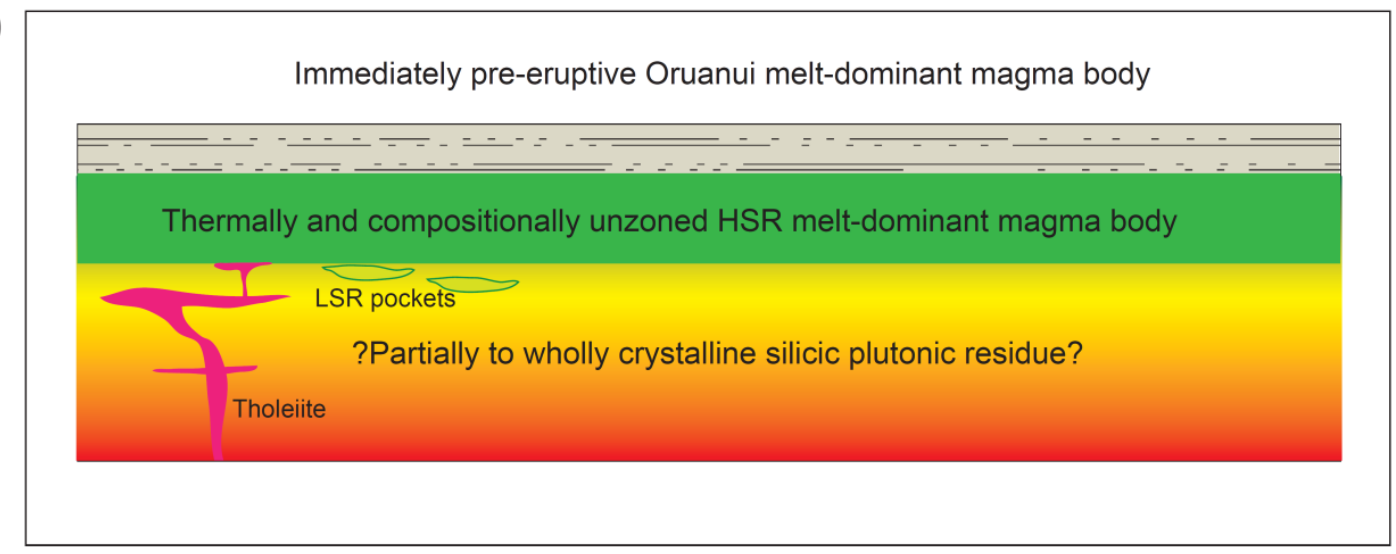

Figure 6.1. Schematic summary of the model for generation of the Oruanui melt-dominant magma body. (a) An initial thermally and compositionally zoned crystal mush with a quartz-bearing upper cap. (b) Magma-assisted rifting leads to the development of channelised flows of melt plus crystals to higher levels, and crystal-poor rhyolite begins to pond at the top of the mush. The roof of the mush sags with progressive extension and collapse of the crystal network as in becomes drain of melt. This accommodates the accumulating crystal-poor rhyolite. Substantial heat-loss generates chamber wide convection currents in the melt-dominant body, destroying any significant thermal and compositional gradients. (c) The immediately pre-eruptive Oruanui melt dominant magma body. 
Antecrysts inherited from mush

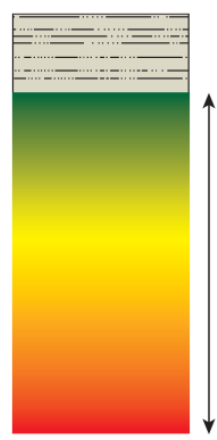

$\uparrow$ Quartz-bearing mush

Antecrystic cores and

interior domains of HSR

crystals (a) and (b)
Phenocrysts inherited from mush

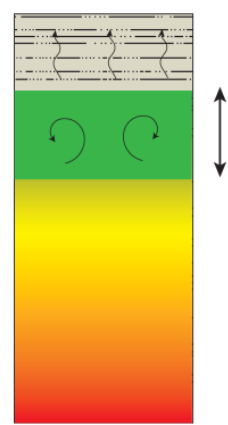

Phenocrystic rim-zones and outermost rims of crystals (c) and (d)
Orthopyroxene

Plagioclase

sieve textured resorbed

(d)
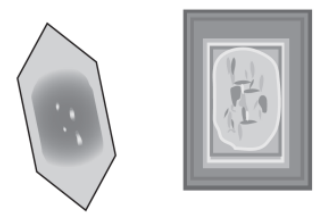

(c)
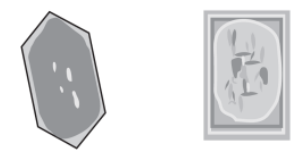

(b)
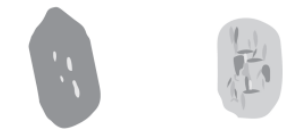

(a)
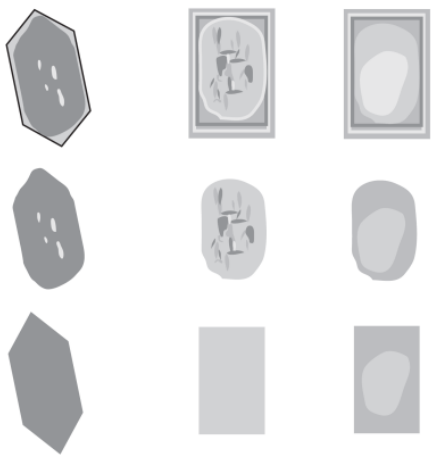

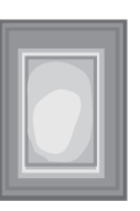

Amphibole

resorbed
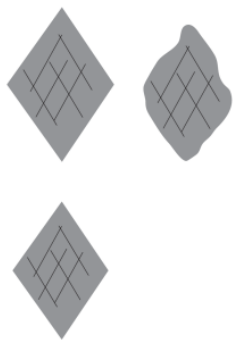

Phenocrystic

Crystallisation of rim-zones and maturation of textures in melt-dominant magma body
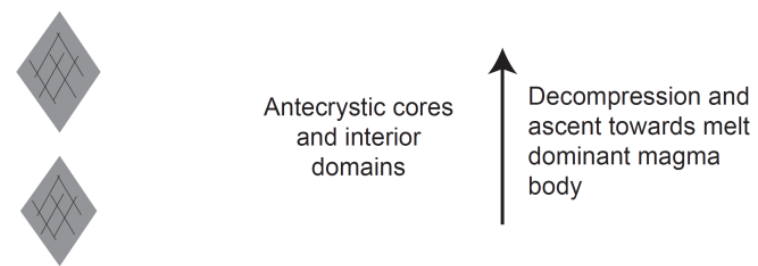

Quartz

Melt inclusion more evolved than HSR melt - derived from qtz-bearing mush

Fe-Ti oxides

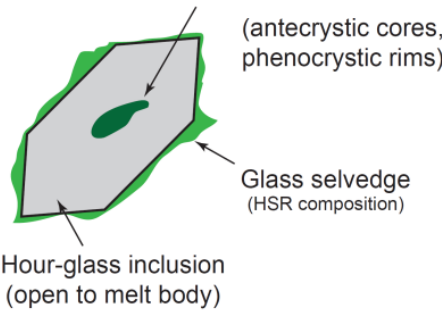

Derived from both mush and in-growth in melt-dominant magma body

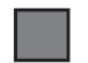

Rapid re-equilibration means they are considered phenocrystic

Figure 6.2. Schematic linkages between Oruanui HSR crystal phases, their zonation characteristics and their derivation from different parts of the system. 
point the crystals grew in a cooling evolving melt-dominant body that reached a final preeruptive temperature of $\sim 770{ }^{\circ} \mathrm{C}$. The $\sim 50{ }^{\circ} \mathrm{C}$ cooling that occurred within the meltdominant magma chamber, combined with the modelled timescales for the formation of the melt dominant magma body from Chapter 3 (i.e., $<1600$ years and peak extraction at $\sim 230$ years) allow first order estimates of the rate of heat loss to be established.

To a first order the heat loss due to the change in temperature of the magma in the growing melt dominant body from can be estimated from combining the overall body of the magma $\left(530 \mathrm{~km}^{3}\right)$ with the change in heat capacity of rhyolite glass over the appropriate temperature interval (Neuville et al. 1993). This approach neglects secondorder effects, such as loss of volatiles, and latent heat exchange associated with crystallisation or dissolution of the crystal phases. The total heat loss over $50{ }^{\circ} \mathrm{C}$ (i.e. 820 ${ }^{\circ} \mathrm{C}$ to $770{ }^{\circ} \mathrm{C}$ ) amounts to $\sim 250 \mathrm{~J} / \mathrm{g}$, or roughly $3 \times 10^{20} \mathrm{~J}$ for the whole magma body. If released evenly over 1600 years (the longest time estimate for development and cooling of the melt-dominant body: Chapter 3) this would average at just below 100 MW thermal release. Consideration of the geophysical consequences of this additional heat flow is beyond the scope of this thesis, but geothermal systems at modern Taupo and surrounding area release of the order of 200 MW (e.g. Horomatangi Reefs) to 400 MW (e.g. WairakeiTauhara; estimates from Bibby et al. 1995), so the thermal impact of the growing Oruanui magma body may have been similar to that of a typical TVZ geothermal system. These significant rates of heat loss combined with the rapidity of the physical extraction process would have generated vigorous convection in the melt dominant magma body that ultimately led to the homogenisation of any significant compositional or thermal gradient. The overarching model put forward here for the Oruanui magma body is similar to that suggested by Hildreth and Wilson (2007) for the compositionally and thermally zoned Bishop Tuff. The key difference between the Bishop and Oruanui systems, and what allowed the Bishop to sustain its stratification, is the overall sluggishness of the Bishop melt accumulation process and the lack of crystal-specific evidence for any significant rate of heat loss.

\subsubsection{To what extent are the Oruanui crystals inherited from older sources, versus grown in situ within the melt-dominant magma body?}


As has been addressed in the preceding sections, there is a large degree of inheritance in the Oruanui HSR (and low-silica rhyolite [LSR]) crystals. An interesting aspect of the Oruanui melt accumulation process is that it blurs the distinction between what crystals can be considered as phenocrysts versus antecrysts. This is schematically summarised in Figure 6.2. In the Oruanui HSR, a large proportion of all of the main crystal phases can be considered to have antecrystic cores and interiors that were derived from the stratified crystal mush source. Only the rim-zones of the crystals, that reflect growth in the cooling and evolving melt dominant magma in which they ultimately erupted, can be considered truly phenocrystic, that is, grown in the melt composition in which they were immersed on eruption. Identification of crystals that can be accurately called phenocrysts, i.e., that have no antecrystic component, are relatively uncommon and probably make up no more than $\sim 10 \%$ of the HSR crystals. Such crystals are those that either display no significant zoning (and are of the appropriate composition), or simple normal zoning out towards the same final compositional range at seen in the outermost rims of most phases.

\subsubsection{What information about magma intensive parameters can be reliably inferred?}

What seemed to be a straightforward question at the start of this thesis work soon became complex as a result of a series of publications that called into question the veracity of some of the most commonly used mineral thermobarometers. In particular, Ti-in-quartz (TitaniQ) and Fe-Ti oxide models have received much attention and controversy in recent times as outlined in Chapter 5 (i.e., Wilson et al. 2012 vs. Thomas and Watson 2012 and Ghiorso and Gualda 2013 vs. Evans and Bachmann 2013). Indeed, my own work from this research has contributed to the debate and I was heavily involved in the Comment-Reply series recently played out in Contributions to Mineralogy and Petrology questioning the veracity of the Ti-in-quartz thermobarometer (included in Appendix 2). These controversies and their implications for this research specifically are outlined and discussed during Chapter 6.

As a result of my work I have concluded that many of the thermometers available in the literature can generate reproducible, reliable and consistent results so long as care is taken as to what data is used as inputs. It is important to note that this requires taking care that a consistent reference point is used. For example, the outermost rims of crystals in HSR samples are inferred (Chapters 3 and 4) to represent the final stage of crystal growth within the melt-dominant magma body from which they erupted. The results from thermometry 
applied to the outermost rims can then be used to provide an informed perspective on the reliability and reproducibility of the results. Fe-Ti oxides are known to undergo rapid diffusive re-equilibration to equilibrium conditions while held at magmatic temperatures (e.g., Freer and Hauptman 1978; Venezky and Rutherford 1999). So long as equilibrium criteria for Fe-Ti oxides are met (i.e., Bacon and Hirschmann 1988), the Fe-Ti oxides should provide meaningful comparisons to the thermometric results derived from the outermost rims of the other silicate crystal phases.

As outlined in Chapters 4 and 5, the following thermometers were found to yield reasonable, consistent and reliable estimates for the final conditions of the Oruanui HSR melt-dominant magma body: plagioclase-melt (Putirka 2008), orthopyroxene-melt (Putirka 2008), Fe-Ti oxides (Ghiorso and Evans 2008 model), amphibole thermometry (Ridolfi et al. 2010). These models also yielded consistent temperature estimates for the final preeruptive conditions of the LSR.

Among these models the Ridolfi et al. (2010) formulations for amphiboles are unique in that they require compositional input from only one phase (amphibole). In theory this means that more meaningful thermobarometric estimates for the crystal interiors can be achieved in a manner that is not possible for the other phases. This may be ruled out for other phases because either their records of thermometric information do not extend beyond that of shortly pre-eruptive conditions (e.g. Fe-Ti oxides), or because the requisite proof of equilibrium relationships between two phases cannot be reasonably established from the available information (e.g. opx-melt, plag-melt, hornblende-plagioclase thermometry). Chapter 5 outlines that, so long as a careful analysis of the associated crystal textures is undertaken, then the Ridolfi et al. (2010) formulations can provide valuable P-T information from the amphibole cores and interiors.

\subsection{SUGGESTIONS FOR FUTURE STUDIES}

Many of the ideas and models put forth by this research lend themselves to further scrutiny and/or application.

An obvious question arising from this work is how applicable the mush extraction model is to the precursor Oruanui-type magmas, inferred from their zircon age spectra to have been 
earlier tappings from the Oruanui crystal mush (Charlier et al. 2005; Wilson and Charlier 2009). My own preliminary data (not presented in this thesis) suggests that orthopyroxene and plagioclase crystals in Okaia, 'New plinian' and Tihoi pumices exhibit the same sorts of textures (prominent cores and rim-zones) as observed in the Oruanui HSR. Preliminary amphibole thermobarometry suggests that although a similar extraction from mush process may have operated, far fewer crystals from deeper, hotter and more primitive levels of the crystal mush were incorporated into these pre-Oruanui magmas. This may be an indication that the magma-assisted rifting processes inferred to have driven or aided the near runaway accumulation of the Oruanui melt-dominant body, were not yet operating at the time these smaller eruptions were generated.

The research presented here has many implications for the study of other large silicic magmatic systems and their applicability to the conceptual mush model. Within the Oruanui case study my work has indicated that the intervention of an external force (extensional tectonism) imparted a significant influence in regulating not only the build-up and assembly of the melt-dominant magma body, but also the initiation and modulation of the tempo of the eruption. A current major limitation of numerical models for understanding the generation, storage and eruption of large silicic magmas is that such external roles are not considered, probably in part because they are not generic, but are specific to the setting of any particular magma body. In light of the findings presented here for the Oruanui system, there is potential to re-examine the crystal records for other magmatic systems to see whether a similar external/tectonic influence is apparent. Examples erupted from Okataina volcano, the other active caldera system within the TVZ, would be a natural starting point to compare and contrast with the Oruanui case study presented here.

The role of mafic magmas in remobilising and/or defrosting crystal mush bodies remains a valid conclusion for systems (e.g. Bachmann and Dungan 2002 and Bachmann et al. 2002 for the Fish Canyon Tuff). However, the Oruanui example presented here shows that the presence of significant volumes of mafic magma does not always translate to those magmas having played a driving role in initiating the melt accumulation process or triggering eruption; instead they appear to have been opportunistic. The nature and extent of mafic-felsic interactions in some systems may benefit from re-analysis to establish whether the presence of co-erupted mafic magmas is a causal factor in the eruption versus a consequence of more fundamental magma-assisted rifting processes that drive the 
system. Again, Okataina volcano would be a natural system to approach such investigations (cf. Leonard et al. 2002; Shane et al. 2007, 2008).

Many of the processes that operated during the lead-in to the Oruanui eruption did so across timescales short enough to be of considerable human interest (centuries to hours before eruption). A natural extension of these research findings would be to establish what the likely associated geophysical signals would be, and how operation of these processes at a volcano might be identified by geophysical monitoring techniques currently in use. 


\section{References}

Allan ASR, Baker JA, Carter L, Wysoczanski RJ (2008) Reconstructing the Quaternary evolution of the world's most active silicic volcanic system: insights from an $\sim 1.65$ Ma deep ocean tephra record sourced from Taupo Volcanic Zone, New Zealand. Quat Sci Rev 27:2341-2360

Allan ASR, Wilson CJN, Millet M-A, Wysoczanski RJ (2012) The invisible hand: tectonic triggering and modulation of a rhyolitic supereruption. Geology 40:563-566 (Chapter 2 of this thesis)

Allan ASR, Morgan DJ, Wilson CJN, Millet M-A (2013) From mush to eruption in centuries: assembly of the super-sized Oruanui magma body. Contrib Mineral Petrol DOI 10.1007/s00410-013-0869-2 (Chapter 3 of this thesis)

Allmann BP, Shearer PM (2009) Global variations of stress drop for moderate to large earthquakes. J Geophys Res 114:B01310

Alloway BV, Pillans BJ, Carter L, Naish TR, Westgate JA (2005) Onshore-offshore correlation of Pleistocene rhyolitic eruptions from New Zealand: implications for TVZ eruptive history and paleoenvironmental construction. Quat Sci Rev 24:16011622

Anderson JL, Smith DR (1995) The effects of temperature and $f \mathrm{O}_{2}$ on the Al-inhornblende barometer. Am Mineral 80:549-559

Anderson AT, Davis AM, Lu F (2000) Evolution of Bishop Tuff rhyolitic magma system based on melt and magnetite inclusions and zoned phenocrysts. J Petrol 41:449-473

Annen C (2009) From plutons to magma chambers: thermal constraints on the accumulation of eruptible silicic magma in the upper crust. Earth Planet Sci Lett 284:409-416

Bachmann O, Bergantz GW (2003) Rejuvenation of the Fish Canyon magma body: a window into the evolution of large-volume silicic magma systems. Geology 31: 789-792

Bachmann O, Bergantz GW (2004) On the origin of crystal-poor rhyolites: extracted from batholithic crystal mushes. J Petrol 45:1565-1582

Bachmann O, Bergantz GW (2006) Gas percolation in upper-crustal silicic crystal mushes as a mechanism for upward heat advection and rejuvenation of near-solidus magma bodies. J Volcanol Geotherm Res 149:85-102

Bachmann O, Bergantz GW (2008a) Rhyolites and their source mushes across tectonic settings. J Petrol 49:2277-2285

Bachmann, O., Bergantz, G., 2008b. The magma reservoirs that feed supereruptions. Elements 4, 17-21. 
Bachmann O, Dungan MA (2002) Temperature-induced Al-zoning in hornblendes of the Fish Canyon magma, Colorado. Am Mineral 87:1062-1076

Bachmann O, Dungan MA, Lipman PW (2002) The Fish Canyon magma body, San Juan volcanic field, Colorado: rejuvenation and eruption of an upper-crustal batholith. J Petrol 43:1469-1503

Bachmann O, Miller CF, de Silva SL (2007a) The volcanic-plutonic connection as a stage for understanding crustal magmatism. J Volcanol Geotherm Res 167:1-23

Bachmann O, Oberli F, Dungan MA, Meier M, Mundil R, Fischer H (2007b) ${ }^{40} \mathrm{Ar} /{ }^{39} \mathrm{Ar}$ and $\mathrm{U}-\mathrm{Pb}$ dating of the Fish Canyon magmatic system, San Juan volcanic field, Colorado: evidence for an extended crystallization history. Chem Geol 236:134-166

Bacon CR, Hirschmann MM (1988) Mg/Mn partitioning as a test for equilibrium between coexisting Fe-Ti oxides. Am Mineral:73:57-61

Bacon CR, Druitt TH (1988) Compositional evolution of the zoned calcalkaline magma chamber of Mount Mazama, Crater Lake, Oregon. Contrib Mineral Petrol 98:224256

Bain AA, Jellinek AM, Wiebe RA (2013) Quantitative field constraints on the dynamics of silicic magma chamber rejuvenation and overturn. Contrib Mineral Petrol DOI 10.1007/s00410-013-0858-5

Belachew M, Ebinger C, Coté D, Keir D, Rowland JV, Hammond JOS, Ayele A (2011) Comparison of dike intrusions in an incipient seafloor-spreading segment in Afar, Ethiopia: Seismicity perspectives. J Geophys Res 116:B06405

Besancon JR (1981) Rate of cation ordering in orthopyroxenes. Am Mineral 66:965-973

Bibby HM, Caldwell TG, Davey FJ, Webb TH (1995) Geophysical evidence on the structure of the Taupo Volcanic Zone and its hydrothermal circulation. J Volcanol Geotherm Res 68:29-58

Bindeman IN, Valley JW, Wooden JL, Persing HM (2001) Post-caldera volcanism: in situ measurement of $\mathrm{U}-\mathrm{Pb}$ age and oxygen isotope ratio in Pleistocene zircons from Yellowstone caldera. Earth Planet Sci Lett 189:197-206

Bindeman IN, Valley JW (2002) Oxygen isotope study of the Long Valley magma system, California: isotope thermometry and convection in large silicic magma bodies. Contrib Mineral Petrol 144:185-205

Blake S (1984) Volatile oversaturation during the evolution of silicic magma chambers as an eruption trigger. J Geophys Res 89:8237-8244

Blundy J, Cashman K (2008) Petrological reconstruction of magmatic system variables and processes. Rev Mineral Geochem 69:179-239

Brey GP, Köhler T (1990) Geothermobarometry in four-phase lherzolites II. new thermobarometers, and practical assessment of existing thermobarometers. J Petrol 31:1353-1378 
Brophy JG (1991) Composition gaps, critical crystallinity, and fractional crystallization in orogenic (calc-alkaline) magmatic systems. Contrib Mineral Petrol 109:173-182

Brooker MR, Houghton BF, Wilson CJN, Gamble JA (1993) Pyroclastic phases of a rhyolitic dome-building eruption: Puketarata tuff ring, Taupo Volcanic Zone, New Zealand. Bull Volc 55:395-406

Brown SJA (1994) Geology and geochemistry of the Whakamaru group ignimbrites, and associated rhyolite domes, Taupo Volcanic Zone, New Zealand. Unpublished PhD thesis, University of Canterbury, Christchurch, New Zealand

Brown SJA, Fletcher IR (1999) SHRIMP U-Pb dating of the pre-eruption growth history of zircons from the $340 \mathrm{ka}$ Whakamaru Ignimbrite, New Zealand: Evidence for $>250$ k.y. magma residence times. Geology 27:1035-1038

Burgisser A Bergantz GW (2011) A rapid mechanism to remobilize and homogenize highly crystalline magma bodies. Nature 471:212-217

Bursik M, Renshaw C, McCaplin J, Berry M (2003) A volcanotectonic cascade: Activation of range front faulting and eruptions by dike intrusion, Mono Basin-Long Valley Caldera, California: J Geophys Res 108:2393-2406

Cameron KL (1984) Bishop Tuff revisited: new rare earth element data consistent with crystal fractionation. Science 224:1338-1340

Charlier BLA, Wilson CJN, Lowenstern JB, Blake S, van Calsteren PW, Davidson JP (2005) Magma generation at a large, hyperactive silicic volcano (Taupo, New Zealand) revealed by U-Th and U-Pb systematics in zircons. J Petrol 46:3-32

Charlier BLA, Wilson CJN, Davidson JP (2008) Rapid open-system assembly of a large silicic magma body: time-resolved evidence from cored plagioclase crystals in the Oruanui eruption deposits, New Zealand. Contrib Mineral Petrol 156:799-813

Charlier BLA, Wilson CJN, Mortimer N (2010) Evidence from zircon U-Pb age spectra for crustal structure and felsic magma genesis at Taupo volcano, New Zealand. Geology 38:915-918

Charlier BLA, Morgan DJ, Wilson CJN, Wooden JL, Allan ASR, Baker JA (2012) Lithium concentration gradients in feldspar and quartz record the final minutes of magma ascent in an explosive supereruption. Earth Planet Sci Lett 319-320:218-227

Chakraborty S (2008) Diffusion in solid silicates: A tool to track timescales of processes comes of age. Annu Rev Earth Planet Sci 36: 153-190

Cherniak DJ, Dimanov A (2010) Diffusion in pyroxene, mica and amphibole. Rev Mineral Geochem 72:641-690

Christiansen EH (2005) Contrasting processes in silicic magma chambers: evidence from very large volume ignimbrites. Geol Mag 142:669-681

Cole JW (1990) Structural control and origin of volcanism in the Taupo Volcanic Zone, New Zealand. Bull Volcanol 52:445-459 
Cole JW, Lewis KB (1981) Evolution of the Taupo-Hikurangi subduction system. Tectonophysics 72:1-21

Cole JW, Darby DJ, Stern TA (1995) Taupo Volcanic Zone and Central Volcanic Region: backarc structures of North Island, New Zealand. In: Taylor B (ed) Backarc Basins: Tectonics and Magmatism. Plenum Press, New York, 1-27

Cooper GF, Wilson CJN, Millet M-A, Baker JA, Smith EGC (2012) Systematic tapping of independent magma chambers during the $1.0 \mathrm{Ma}$ Kidnappers supereruption. Earth Planet Sci Lett 313-314:23-33

Costa A, Gottsmann J, Melnik O, Sparks RSJ (2011) A stress-controlled mechanism for the intensity of very large magnitude explosive eruptions. Earth Planet Sci Lett 310:161166

Costa F. Morgan D (2010) Time constraints from chemical equilibration in magmatic crystals". In: Dosseto A, Turner SP, Van Orman JA (eds) Timescales of magmatic processes: from core to atmosphere. John Wiley \& Sons, Chichester, UK. doi: 10.1002/9781444328509.ch7

Costa F, Dohmen R, Chakraborty S (2008) Timescales of magmatic processes from modelling the zoning patterns of crystals. Rev Mineral Geochem 69:545-594

Dall'Agnol R, Scaillet B, Pichavant M (1999) An experimental study of lower Proterozoic A-type granite from the eastern Amazonian craton, Brazil. J Petrol 40:1673-1698

Davidson JP, Hora, JM, Garrison, JM, Dungan, MA (2005) Crustal forensics in arc magmas. Journal of Volcanology and Geothermal Research 140: 157-170

Davidson JP, Morgan DJ, Charlier BLA, Harlou R, Hora JM (2007) Microsampling and isotopic analysis of igneous rocks: implications for the study of magmatic systems. Annu Rev Earth Planet Sci 35:273-311

Devine JD, Rutherford MJ, Norton GE, Young SR (2003) Magma storage region processes inferred from geochemistry of Fe-Ti oxides in andesitic magma, Soufrière Hills Volcano, Montserrat, WI. J Petrol 44:1375-1400

Dohmen R, Becker H-W, Chakraborty S (2007) Fe-Mg diffusion in olivine I: Experimental determination between 700 and $1,200^{\circ} \mathrm{C}$ as a function of composition, crystal orientation and oxygen fugacity. Phys Chem Miner 34:389-407

Dungan MA, Davidson J (2004) Partial assimilative recycling of the mafic plutonic roots of arc volcanoes: an example from the Chilean Andes. Geology 32:773-776

Eichelberger JC (1978) Andesitic volcanism and crustal evolution. Nature 275:21-27

Ernst WG, Liu J (1998) Experimental phase-equilibrium study of Al- and Ti-contents of calcic amphibole in MORB - A semiquantitative thermobarometer. Am Mineral 83:952-969

Evans BW, Bachmann O (2013) Implications of equilibrium and disequilibrium among crystal phases in the Bishop Tuff. Am Mineral 98:271-274 
Ferry JM, Watson EB (2007) New thermodynamic models and revised calibrations for the Ti-in-zircon and Zr-in-rutile thermometers. Contrib Mineral Petrol 154:429-437

Folkes CB, de Silva SL, Schmitt AK, Cas RAF (2011) A reconnaissance of U-Pb zircon ages in the Cerro Galán system, NW Argentina: prolonged magma residence, crystal recycling, and crustal assimilation. J Volcanol Geotherm Res 206:136-147

Foroozan F, Elsworth D, Voight B, Mattioli GS (2011) Magmatic-metering controls the stopping and restarting of eruptions. Geophys Res Lett 38:L05306

Freer R, Hauptman Z (1978) Experimental study of magnetite-titanomagnetite interdiffusion. Phys Earth Planet Int 16:223-231

Gamble J, Woodhead J, Wright I, Smith IEM (1996), Basalt and sediment geochemistry and magma petrogenesis in a transect from oceanic island arc to rifted continental margin arc: the Kermadec-Hikurangi Margin, SW Pacific, J Petrol 37:1523-1546

Gamble JA, Wood CP, Price RC, Smith IEM, Stewart RB, Waight T (1999) A fifty year perspective of magmatic evolution on Ruapehu Volcano, New Zealand: verification of open system behaviour in an arc volcano. Earth Planet Sci Lett 170:301-314

Ganguly J, Tazzoli V (1994) $\mathrm{Fe}^{2+}-\mathrm{Mg}$ interdiffusion in orthopyroxene: Retrieval from the data on intracrystalline exchange reaction. Am Mineral 79:930-937

Ghiorso MS, Sack RO (1995) Chemical mass transfer in magmatic processes IV. A revised and internally consistent thermodynamic model for the interpolation and extrapolation of liquid-solid equilibria in magmatic systems at elevated temperatures and pressures. Contrib Mineral Petrol 119:197-212

Ghiorso MS, Evans BW (2008) Thermodynamics of rhombohedral oxide solid solutions and a revision of the Fe-Ti two-oxide geothermometer and oxygen-barometer. Am J Sci 308:957-1039

Ghiorso MS, Gualda GAR (2013) A method for estimating the activity of titania in magmatic liquids from the compositions of coexisting rhombohedral and cubic iron-titanium oxides. Contrib Mineral Petrol 165:73-81

GNS Science (2013) GNS Science Active Fault Database. Unpublished data available from the Institute of Geological and Nuclear Sciences. http://data.gns.cri.nz/af/

Götze J, Plotze M, Habermann D (2001) Origin, spectral characteristics and practical applications of the cathodoluminescence (CL) of quartz - a review. Miner Petrol $71: 225-250$

Gravley DM,Wilson CJN, Leonard GS, Cole JW (2007) Double trouble: paired ignimbrite eruptions and collateral subsidence in the Taupo Volcanic Zone, New Zealand. Geol Soc Am Bull 119:18-30

Gregg PM, de Silva SL, Grosfils EB, Parmigiani JP (2012) Catastrophic caldera-forming eruptions: thermomechanics and implications for eruption triggering and maximum caldera dimensions on Earth. J Volcanol Geotherm Res 241:1-12 
Gualda GAR, Pamukcu AS, Ghiorso MS, Anderson AT, Sutton SR, Rivers ML (2012a) Timescales of quartz crystallization and the longevity of the Bishop giant magma body. PLoS ONE 7:e37492

Gualda GAR, Ghiorso MS, Lemons RV, Carley TL (2012b) Rhyolite-MELTS: A modified calibration of MELTS optimized for silica-rich, fluid-bearing magmatic systems. J Petrol 53:875-890

Hammond PA, Taylor LA (1982) The ilmenite titano-magnetite assemblage - kinetics of reequilibration. Earth Planet Sci Lett 61:143-150

Harrison AJ, White RS (2004) Crustal structure of the Taupo Volcanic Zone, New Zealand: stretching and igneous intrusion. Geophys Res Lett 31 doi:10.1029/2004GL019885.

Harrison A, White RS (2006) Lithospheric structure of an active backarc basin: the Taupo Volcanic Zone, New Zealand. Geophys J Int 167:968-990

Hammond PA, Taylor LA (1982) The ilmenite titano-magnetite assemblage - kinetics of reequilibration. Earth Planet Sci Lett 61:143-150

Hellstrom J, Paton C, Woodhead JD, Hergt JM (2008) Iolite: software for spatially resolved LA-(quad and MC) ICPMS analysis. In Laser Ablation ICP-MS in the Earth Sciences: Current Practices and Outstanding Issues (P. Sylvester, ed). Min Assoc Canada Short Course Ser 40:343-348

Hiess J, Cole JW, Spinks KD (2007) Influence of the crust and crustal structure on the location and composition of high-alumina basalts of the Taupo Volcanic Zone, New Zealand. NZ J Geol Geophys 50:327-342

Hildreth EW (1977) The magma chamber of the Bishop Tuff: gradients in temperature, pressure and composition. PhD thesis University of California, Berkeley, p 328

Hildreth W (1979) The Bishop Tuff: evidence for the origin of compositional zonation in silicic magma chambers. Geol Soc Am Spec Pap 180:43-75

Hildreth W (1981) Gradients in silicic magma chambers: implications for lithospheric magmatism. J Geophys Res 86:10153-10192

Hildreth W, Michael PJ (1983) Comment and Reply on 'Chemical differentiation of the Bishop Tuff and other high-silica magmas through crystallization processes'. Geology 11:622-624

Hildreth W (2004) Volcanological perspectives on Long Valley, Mammoth Mountain, and Mono Craters: several contiguous but discrete systems. J Volcanol Geotherm Res 136:169-198

Hildreth W, Wilson CJN (2007) Compositional zoning of the Bishop Tuff. J Petrol 48:951999

Holland T, Blundy J (1994) Non-ideal interactions in calcic amphiboles and their bearing on amphibole-plagioclase thermometry. Contrib Mineral Petrol 116:433-447 
Hochstein MP (1995) Crustal heat transfer in the Taupo Volcanic Zone (New Zealand): comparison with other volcanic arcs and explanatory heat source models. J Volcanol Geotherm Res 68:117-151

Houghton BF, Wilson CJN (1989) A vesicularity index for pyroclastic rocks. Bull Volc 51:451-462

Houghton BF, Lloyd EF, Wilson CJN, Lanphere MA (1991) K-Ar ages from Western Dome Belt and associated rhyolite lavas in the Maroa-taupo area, Taupo Volcanic Zone, New Zealand. NZ J Geol Geophys 34:99-101

Houghton BF, Wilson CJN, McWilliams MO, Lanphere MA, Weaver SD, Briggs RM, Pringle MS (1995) Chronology and dynamics of a large silicic magmatic system: Central Taupo Volcanic Zone, New Zealand. Geology 23:13-16

Housh TB, Luhr JF (1991) Plagioclase-melt equilibria in hydrous systems. Am Mineral $76: 477-492$

Huber C, Bachmann O, Manga M (2010) Two competing effects of volatiles on heat transfer in crystal-rich magmas: thermal insulation vs defrosting. J Petrol 51:847-867

Huber C, Bachmann O, Dufek J (2011) Thermo-mechanical reactivation of locked crystal mushes: melting-induced internal fracturing and assimilation processes in magmas. Earth Planet Sci Lett 304:443-454

Huber C, Bachmann O, Vigneresse JL, Dufek J, Parmigiani A (2012) A physical model for melt extraction and transport in shallow magmatic systems. Geochem Geophys Geosyst 13:Q08003

Jellinek AM, DePaolo DJ (2003) A model for the origin of large silicic magma chambers: precursors of caldera-forming eruptions. Bull Volcanol 65:363-381

Jochum KP, Weis U, Stoll B, Kuzmin D, Yang Q, Raczek I, Jacob D, Stracke A, Birbaum K, Frick D, Gunther D, Enzweiler J (2011) Determination of reference values for NIST SRM 610-617 glasses following ISO guidelines. Geostand Geoanal Res $35: 397-429$

Johannes W, Holtz F (1996) Petrogenesis and experimental petrology of granitic rocks. Springer, Berlin, p 335

Johnson MC, Rutherford MJ (1989) Experimental calibration of the aluminum-inhornblende geobarometer with application to Long Valley caldera (California) volcanic rocks. Geology 17:837-841

Kahl M, Chakraborty S, Costa F, Pompilio M, (2011) Dynamic plumbing system beneath volcanoes revealed by kinetic modeling, and the connection to monitoring data: An example from Mt. Etna. Earth Planet Sci Lett 308:11-22

Karlstrom L, Dufek J, Manga M (2010) Magma chamber stability in arc and continental crust. J Volcanol Geotherm Res 190:249-270 
Klimm K, Holtz F, Johannes W, King PL (2003) Fractionation of metaluminous A-type granites: an experimental study of the Wangrah Suite, Lachlan Fold Belt, Australia. Precamb Res 124:327-341

Klügel A (2001) Prolonged reactions between harzburgite xenoliths and silicaundersaturated melt: Implications for dissolution and Fe-Mg interdiffusion rates of orthopyroxene. Contrib Mineral Petrol 141:1-14

Leonard GS (2003) The evolution of Maroa Volcanic Centre, Taupo Volcanic Zone, New Zealand. Unpublished $\mathrm{PhD}$ thesis, University of Canterbury, Christchurch, New Zealand

Leonard GS, Cole JW, Nairn IA, Self S (2002) Basalt triggering of the c. AD 1305 Kaharoa rhyolite eruption, Tarawera Volcanic Complex, New Zealand. J Volcanol Geotherm Res 115:461-486

Leonard GS, Begg JG, Wilson CJN (2010) Geology of the Rotorua area: scale 1:250,000. Lower Hutt: GNS Science. Institute of Geological \& Nuclear Sciences 1:250,000 geological map 5. 102 p. +1 folded map

Lindsay JM, Schmidt AK, Trumbull RB, De Silva SL, Siebel W, Emmermann R (2001) Magmatic evolution of the La Pacana Caldera system, Central Andes, Chile: compositional variation of two cogenetic, large-volume felsic ignimbrites. J Petrol 42:459-486

Liu Y, Zhang Y, Behrens $\mathrm{H}$ (2005) Solubility of $\mathrm{H}_{2} \mathrm{O}$ in rhyolitic melts at low pressures and a new empirical model for mixed $\mathrm{H}_{2} \mathrm{O}-\mathrm{CO}_{2}$ solubility in rhyolitic melts. J Volcanol Geotherm Res 143:219-235

Liu Y, Anderson AT, Wilson CJN, Davis AM, Steele IM (2006) Mixing and differentiation in the Oruanui rhyolitic magma, Taupo, New Zealand: evidence from volatiles and trace elements in melt inclusions. Contrib Mineral Petrol 151:71-87

Liu Y, Anderson AT, Wilson CJN (2007) Melt pockets in phenocrysts and ascent rates of silicic magmas. J Geophys Res 112:B06204

Lister JR (1990) Buoyancy-driven fluid fracture: similarity solutions for the horizontal and vertical propagation of fluid-filled cracks. J Fluid Mech 217:213-239

Lowe DJ, Shane PAR, Alloway BV, Newnham RM (2008) Fingerprints and age models for widespread New Zealand tephra marker beds erupted since 30,000 years ago: a framework for NZ-INTIMATE. Quat Sci Rev 27:95-126

Lowe DJ, Blaauw M, Hogg AG, Newnham RM (2013) Ages of 24 widespread tephras erupted since 30,000 years ago in New Zealand, with re-evaluation of the timing and palaeoclimatic implications of the late-glacial cool episode at Kaipo bog. Quat Sci Rev doi:10/10.16/j.quascirev.2012.11.022

Manga M, Brodsky E (2006) Seismic triggering of eruptions in the far field: volcanoes and geysers. Annu Rev Earth Planet Sci 34:263-291 
Mason BG, Pyle DM, Oppenheimer C (2004) The size and frequency of the largest explosive eruptions on Earth. Bull Volc 66:735-748

Marsh BD (1981) On the crystallinity, probability of occurrence, and rheology of lava and magma. Contrib Mineral Petrol 78:85-98

Martin VM, Morgan DJ, Jerram DA, Caddick MJ, Prior DJ, Davidson JP (2008) Bang! Month-scale eruption triggering at Santorini Volcano. Science 321:1178

Matthews NE, Pyle DM, Smith VC, Wilson CJN, Huber C, van Hinsberg V (2012a) Quartz zoning and the pre-eruptive evolution of the $\sim 340$-ka Whakamaru magma systems, New Zealand. Contrib Mineral Petrol 163:87-107

Matthews NE, Huber C, Pyle DM, Smith VC (2012b) Timescales of magma recharge and reactivation of large silicic systems from Ti diffusion in quartz. J Petrol 53:1385-1416

Metz JM, Mahood GA (1985) Precursors to the Bishop Tuff eruption: Glass Mountain, Long Valley, California. J Geophys Res 90:11121-11126

Metz JM, Mahood GA (1991) Development of the Long Valley, California, magma chamber recorded in precaldera rhyolite lavas of Glass Mountain. Contrib Mineral Petrol 106:379-397

Michael PJ (1983) Chemical differentiation of the Bishop Tuff and other high-SiO magmas through crystallization processes. Geology 11:31-34

Miller CF, Mittlefehldt DW (1984) Extreme fractionation in felsic magma chambers: a product of liquid-state diffusion or fractional crystallization? Earth Planet Sci Lett 68:151-158

Miller CF, Wark DA (2008) Supervolcanoes and their explosive supereruptions. Elements 4:11-16

Miyashiro A (1974) Volcanic rock series in island arcs and active continental margins. Am J Sci 274:321-355

Moore G, Vennemann T, Carmichael ISE (1998) An empirical model for the solubility of $\mathrm{H}_{2} \mathrm{O}$ in magmas to 3 kilobars. Am Mineral 83:36-42

Murphy MD, Sparks RSJ, Barclay J, Carroll MR, Lejeune A-M, Brewer TS, Macdonald R, Black S, Young SR (1998) The role of magma mixing in triggering the current eruption at the Soufrière Hills volcano, Montserrat, West Indies. Geophys Res Lett 25:3433-3436

Nakamura M (1995) Continuous mixing of crystal mush and replenished magma in the ongoing Unzen eruption. Geology 23:807-810

Nelson ST, Montana A (1992) Sieve-textured plagioclase in volcanic rocks produced by rapid decompression. Am Mineral 77:1242-1249

Neuville DR, Courtial P, Dingwell DB, Richet P (1993) Thermodynamic and rheological properties of andesite and rhyolite melts. Contrib Mineral Petrol 113:572-581 
Pallister JS, Hoblitt RP, Reyes AG (1992) A basalt trigger for the 1992 eruptions of Pinatubo volcano. Nature 356:426-428

Palme H, Beer H (1993) Abundances of the elements in the solar system. In LandoltBörnstein, Group VI: Astronomy and Astrophysics: Instruments; Methods; Solar System (ed. H. H. Voigt). Springer, Berlin, vol. 3(a), pp. 196-221

Pearce, N.J.G., Westgate, J.A., Perkins, W.T., 1996. Developments in the analysis of volcanic glass shards by laser ablation ICP-MS: quantitative and single internal standard multi-element methods. Quaternary International 34-36, 213-227.

Pearce NJ, Denton JS, Perkins WT, Westgate JA, Alloway BV (2007) Correlation and characterization of individual glass shards from tephra deposits using trace element laser ablation ICP-MS analyses: current status and future potential. J Quat Sci 22:721-736

Peppard BT, Steele IM, Davis AM, Wallace PJ, Anderson AT (2001) Zoned quartz phenocrysts from the rhyolitic Bishop Tuff. Am Mineral 86:1034-1052

Perkins WT, Pearce NJG. 1995. Mineral microanalysis by laserprobe inductively coupled plasma mass spectrometry. In Microprobe Techniques in the Earth Sciences, Potts PJ, Bowles JFW, Reed SJB, Cave MR (eds). The Mineralogical Society: London.

Pistone M, Caricchi L, Ulmer P, Reusser E, Ardeia P (2013) Rheology of volatile-bearing crystal mushes: mobilization vs. viscous death. Chem Geol 345:16-39

Putirka KD (2008) Thermometers and barometers for volcanic systems. Rev Mineral Geochem 69:61-120

Rampino MR, Self S (1992) Climate-volcanism feedback and the Toba eruption of $\sim 74,000$ years age. Quat Res 40:269-280

Reches Z, Fink J (1988) The mechanism of intrusion of the Inyo dike, Long Valley caldera, California. J Geophys Res 93:4321-4334

Reid MR (2008) How long does it take to supersize an eruption? Elements 4:23-28

Reid MR, Vazquez JA, Schmitt AK (2011) Zircon-scale insights into the history of a supervolcano, Bishop Tuff, Long Valley, California, with implications for the Ti-inzircon geothermometer. Contrib Mineral Petrol 161:293-311

Reyners M (2013) The central role of the Hikurangi Plateau in the Cenozoic tectonics of New Zealand and the Southwest Pacific. Earth Planet Sci Lett 361:460-468

Ridolfi F, Renzulli A, Puerini M (2010) Stability and chemical equilibrium of amphibole in calc-alkaline magmas: an overview, new thermobarometric formulations and application to subduction-related volcanoes. Contrib Mineral Petrol 160:45-66

Robinson R, Smith EGC, Latter JH (1981) Seismic studies of the crust under the hydrothermal areas of the Taupo Volcanic Zone, New Zealand. J Volcanol Geotherm Res 9:253-267 
Rowe MC, Wolff JA, Gardner JN, Ramos FC, Teasdale R, Heikoop CE (2007)

Development of a continental volcanic field: petrogenesis of pre-caldera intermediate and silicic rocks and origin of the Bandelier magmas, Jemez Mountains (New Mexico, USA). J Petrol 48:2063-2091

Rowland JV, Wilson CJN, Gravley DM (2010) Spatial and temporal variations in magmaassisted rifting, Taupo Volcanic Zone, New Zealand. J Volcanol Geotherm Res 190:89-108

Sable JE, Houghton BF, Wilson CJN, Carey RJ (2009) Eruption mechanisms during the climax of the Tarawera 1886 basaltic Plinian eruption inferred from microtextural characteristics of the deposits. In: Thordarson T, Self S, Larsen G, Rowland SK, Hoskuldsson A (eds) Studies in Volcanology: The Legacy of George Walker. Spec Publ IAVCEI 2:129-154

Sampson DE, Cameron KL (1987) The geochemistry of the Inyo volcanic chain: multiple magma systems in the Long Valley region, eastern California. J Geophys Res 92:10403-10421

Sauerzapf U, Lattard D, Burchard M, Engelman R (2008) The titanomagnetite-ilmenite equilibrium: new experimental data and thermo-oxybarometric application to the crystallization of basic to intermediate rocks. J Petrol 49:1161-1185

Saunders K, Blundy J, Dohmen R, Cashman K (2012) Linking petrology and seismology at an active volcano. Science 336:1023-1027

Schmidt MW (1992) Amphibole composition in tonalite as a function of pressure: an experimental calibration of the Al-in-hornblende barometer. Contrib Mineral Petrol 110:304-310

Schwandt CS, Cygan RT, Westrich HR (1998) Magnesium self-diffusion in orthenstatite. Contrib Mineral Petrol 130:390-396

Self S, Healy J (1987) Wairakei Formation, New Zealand: stratigraphy and correlation. NZ J Geol Geophys 30:73-86

Self S (1983) Large-scale phreatomagmatic silicic volcanism: a case study from New Zealand. J Volcanol Geotherm Res 17:433-469

Self S (2006) The effects and consequences of very large explosive volcanic eruptions. Phil Trans R Soc Lond A364:2073-2097

Self S, Sparks RSJ (1978) Characteristics of widespread pyroclastic deposits formed by the interaction of silicic magma and water. Bull Volc 41:196-212

Shane P, Martin SB, Smith VC, Beggs KF, Darragh MB, Cole JW, Nairn IA (2007)

Multiple rhyolite magmas and basalt injection in the 17.7 ka Rerewhakaaitu eruption episode from Tarawera volcanic complex, New Zealand. J Volcanol Geotherm Res $164: 1-26$ 
Shane P, Nairn IA, Smith VC, Darragh M, Beggs KF, Cole JW (2008) Silicic recharge of multiple rhyolite magmas by basaltic intrusion during the $22.6 \mathrm{ka}$ Okareka eruption episode, New Zealand. Lithos 103:527-549

Shane P, Smith VC (2013) Using amphibole crystals to reconstruct magma storage temperatures and pressures for the post-caldera collapse volcanism at Okataina volcano. Lithos 156-159:159-170

Shaw, HR (1965) Comments on viscosity, crystal settling and convection in granitic magmas. American Journal of Science 263:120-152

Shaw HR (1985) Links between magma-tectonic rate balances, plutonism, and volcanism. J Geophys Res 90:11275-11288

Shulmeister J, Shane P, Lian OB, Okuda M, Carter JA, Harper M, Dickinson W, Augustinus P, Heijnis H (2001) A long late-Quaternary record from Lake Poukawa, Hawke's Bay, New Zealand. Palaeogeogr Palaeoclimatol Palaeoecol 176:81-107

Simon JI, Reid MR (2005) The pace of rhyolite differentiation and storage in an 'archetypical' silicic magma system, Long Valley, California. Earth Planet Sci Lett 235:123-140

Smith RL (1979) Ash-flow magmatism. Geol Soc Am Spec Pap 180:5-27

Smith D, Barron BR (1991) Pyroxene-garnet equilibration during cooling in the mantle. Am Mineral 76:1950-1963

Snyder D (2000) Thermal effects of the intrusion of basaltic magma into a more silicic magma chamber and implications for eruption triggering. Earth Planet Sci Lett $175: 257-273$

Sparks RSJ, Sigurdsson H, Wilson L (1977) Magma mixing: a mechanism for triggering acid explosive eruptions. Nature Lond 267:315-318

Sparks RSJ, Self S, Grattan JP, Oppenheimer C, Pyle DM, Rymer H (2005) Supereruptions: global effects and future threats. Report of a Geological Society of London Working Group, The Geological Society, London, 24 pp.

Stimpfl M, Ganguly J, Molin G (2005) Kinetics of $\mathrm{Fe}^{2+}-\mathrm{Mg}$ order-disorder in orthopyroxene; experimental studies and applications to cooling rates of rocks. Contrib Mineral Petrol 150:319-334

Stix J, Goff F, Gorton MP, Heiken G, Garcia SR (1988) Restoration of compositional zonation in the Bandelier silicic magma chamber between two caldera-forming eruptions: geochemistry and origin of the Cerro Toledo Rhyolite, Jemez Mountains, New Mexico. J Geophys Res 93:6129-6147

Sutton AN (1995) Evolution of a large silicic magma system: Taupo volcanic centre, New Zealand. Unpub PhD thesis, The Open University, Milton Keynes, UK.

Sutton AN, Blake S, Wilson CJN (1995) An outline geochemistry of rhyolite eruptives from Taupo volcanic centre, New Zealand. J Volcanol Geotherm Res 68:153-175 
Sutton AN, Blake S, Wilson CJN, Charlier BLA (2000) Late Quaternary evolution of a hyperactive rhyolite magmatic system: Taupo volcanic centre, New Zealand. J Geol Soc Lond 157:537-552

Suzuki Y, Yasuda A, Hokanishi N, Kaneko T, Nakada S Fujii T (in press) Syneruptive deep magma transfer and shallow magma remobilization during the 2011 eruption of Shinmoe-dake, Japan: Constraints from melt inclusions and phase equilibria experiments. J Volcanol Geotherm Res DOI: 10.1016/j.volgeores.2013.03.017

ter Heege JH, Dohmen R, Becker H, Chakraborty S (2006) Experimental determination of $\mathrm{Fe}-\mathrm{Mg}$ interdiffusion coefficients in orthopyroxene using pulsed laser ablation and nanoscale thin films. AGU Fall Meeting, San Francisco, CA, abstract MR21A-0004

Tiepolo M, Oberti R, Zanetti A, Vannucci R, Foley SF (2007) Trace-element partitioning between amphibole and silicate melt. Rev Mineral Geochem 67:417-452

Thomas JB, Watson EB (2012) Application of the Ti-in-quartz thermobarometer to rutilefree systems. Reply to: A comment on: 'TitaniQ under pressure: the effect of pressure and temperature on the solubility of 'Ti in quartz' by Thomas et al. Contrib Mineral Petrol 164:369-374

Thomas JB, Watson EB, Spear FS, Shemella PT, Navak SK, Lanzirotti A (2010) TitaniQ under pressure: the effect of pressure and temperature on the solubility of Ti in quartz. Contrib Mineral Petrol 160:743-759

Tomiya A, Takahashi E (2005) Evolution of the magma chamber beneath Usu Volcano since 1663: a natural laboratory for observing changing phenocryst compositions and textures. J Petrol 46:2395-2426

Vandergoes MJ, Hogg AG, Lowe DJ, Newnham RM, Denton GH, Southon J, Barrell DJA, Wilson CJN, McGlone MS, Allan ASR, Almond PC, Petchey F, Dabell K, Dieffenbacher-Krall AC, Blaauw M (2013) A revised age for the Kawakawa/Oruanui tephra, a key marker for the last Glacial Maximum in New Zealand. Quat Sci Rev doi:10:1016/j.quascirev.2012.11.006

Vazquez JA, Reid MR (2004) Probing the accumulation history of the voluminous Toba magma. Science 305:991-994

Venezky DY, Rutherford MJ (1999) Petrology and Fe-Ti oxide reequilibration of the 1991 Mount Unzen mixed magma. J Volcanol Geotherm Res 89:213-230

Vucetich CG, Howorth R (1976) Late Pleistocene tephrostratigraphy in the Taupo District, New Zealand. NZ J Geol Geophys 19:51-69

Wallace PJ, Anderson AT, Davis AM (1999) Gradients in H2O, CO2, and exsolved gas in a large-volumes silicic magma system: interpreting the record preserved in melt inclusions from the Bishop Tuff. J Geophys Res 104:20097-20122

Wark D, Watson EB (2006) TitaniQ: a titanium-in-quartz geothermometer. Contrib Mineral Petrol 152:743-754 
Wark DA, Hildreth W, Spear FS, Cherniak DJ, Watson EB (2007) Pre-eruption recharge of the Bishop magma system. Geology 35:235-238

Wilson CJN (2001) The 26.5 ka Oruanui eruption, New Zealand: an introduction and overview. J Volcanol Geotherm Res 112:133-174

Wilson, C.J.N., 2008, Supereruptions and supervolcanoes: Processes and products: Elements 4:29-34

Wilson CJN, Charlier BLA (2009) Rapid rates of magma generation at contemporaneous magma systems, Taupo volcano, New Zealand: Insights from U-Th model-age spectra in zircons. J Petrol 50:875-907

Wilson CJN, Houghton BF, Lloyd EF (1986) Volcanic history and evolution of the MaroaTaupo area, central North Island. In: I.E.M. Smith (Editor), Late Cenozoic Volcanism in New Zealand. Royal Society of New Zealand Bulletin 23:194-223

Wilson CJN, Houghton BF, McWilliams MO, Lanphere MA, Weaver SD, Briggs RM (1995) Volcanic and structural evolution of Taupo Volcanic Zone, New Zealand: a review. J Volcanol Geotherm Res 68:1-28

Wilson CJN, Blake S, Charlier BLA, Sutton AN (2006) The 26.5 ka Oruanui eruption, Taupo volcano, New Zealand: development, characteristics and evacuation of a large rhyolitic magma body. J Petrol 47:35-69

Wilson CJN, Seward TM, Allan ASR, Charlier BLA, Bello L (2012) A comment on: 'TitaniQ under pressure: the effect of pressure and temperature on the solubility of Ti in quartz', by Jay B. Thomas, E. Bruce Watson, Frank S. Spear, Philip T. Shemella, Saroj K. Nayak and Antonio Lanzirotti. Contrib Mineral Petrol 164:359368

Wolff JA, Ramos FC (2003) Pb isotope variations among Bandelier Tuff feldspars: no evidence for a long-lived silicic magma chamber. Geology 31:533-536 


\section{Appendix 1: Analytical Techniques}

\subsection{SAMPLE PREPARATION}

The samples used in this study were fresh, glassy pumice and/or lava. Following collection all clasts were rinsed with tap water and scrubbed with a stiff brush to remove adhering material and then dried in a fan-forced oven at $110{ }^{\circ} \mathrm{C}$ for $24-48$ hours. Clasts that were selected for crystal-specific analytical work were then split in two pieces with one portion used for crystal separation and the other used for whole rock analytical characterisation. The dried clasts were then soaked for a further 24 hours in deionised water followed by another 24-48 hours oven drying.

\subsubsection{Crystal separation}

Crystals were liberated from pumices by gently crushing the clasts with an agate mortar and pestle. The rough crush was then poured into a $600 \mathrm{~mL}$ glass beaker and filled with tap water to float off and remove buoyant pumice fragments. The crystals, which are denser than glass and water, were concentrated by swilling water in the crystal-glass residue in the bottom of the beaker and pouring off the glass-richer component which rose to the top. After $\sim 5$ minutes of this technique, a crystal concentrate comprising approximately 90 95\% crystals could be routinely achieved. The crystal concentrate was rinsed three times in deionised water before being left to dry in a fan forced oven at $50-80{ }^{\circ} \mathrm{C}$.

\subsubsection{Mounting of crystals and glass}

Crystals and glass were mounted in epoxy resin blocks for in-situ major and trace element characterisation by electron probe microanalysis (EPMA) and laser ablation (LA) ICP-MS, respectively. Orthopyroxene, amphibole and quartz crystals, wherever possible, were oriented so that their crystallographic $c$-axis would be perpendicular to the polished surface. Plagioclase crystals were mounted on the tabular surface perpendicular to the crystallographic $b$-axis. Glass shards were funnelled into pre-drilled holes of $\sim 5 \mathrm{~mm}$ 
diameter in pre-made $25 \mathrm{~mm}$ epoxy resin mounts, and then back-filled with epoxy. After the epoxy had cured overnight the crystals/glass were exposed by grinding with 400-2400 grit silicon carbide paper, and then polished to a high finish using $1 \mu \mathrm{m}$ liquid diamond suspension. A $\sim 25 \mathrm{~nm}$ carbon coating was applied to each mount to ensure a conductive surface for EPMA. This coating was removed using AR grade methanol and MQ water prior to LA-ICP-MS analysis.

\subsubsection{Rock powdering}

The preferred option for powdering samples was to use an agate mill, as the use of a tungsten carbide (WC) mill results in contamination of the powder for several elements that were targeted for analysis using the ICP-MS (particularly W, but also Nb, Ta, and some of the transition metals). Only 10 of the 67 samples analysed by ICP-MS were powdered in WC, with all others being milled in agate. Two separate pieces of a single pumice were milled in both agate and WC and analysed by ICP-MS to see which trace elements were compromised by the $\mathrm{WC}$ milling. It was found that $\mathrm{W}, \mathrm{Ni}, \mathrm{Co}, \mathrm{Nb}$ and $\mathrm{Ta}$ were the only elements that failed to reproduce values from the agate milled sample. Data for these elements are thus discarded for all samples that were milled in WC.

\subsection{WHOLE ROCK MAJOR ELEMENT TECHNIQUE - X-RAY FLUORESCENCE (XRF)}

The whole rock major element analyses were conducted by Spectrachem Analytical (CRL Energy Ltd), Wellington, New Zealand. The powders were held at $1000^{\circ} \mathrm{C}$ for 1 hour and weighed to determine loss on ignition (LOI). Data for international rock standards (JR-1, rhyolite; BCR-2, basalt; BHVO-2, basalt) collected during the same sessions as samples are reported in Table A1 and Figure A1. On the basis of repeat measurements of these rock standards I estimate the average relative precision $(\% 2 \mathrm{sd}=2 \mathrm{sd} /$ mean $\times 100)$ of the XRF data is as follows; $\mathrm{SiO}_{2}, \mathrm{Al}_{2} \mathrm{O}_{3}$ and $\mathrm{Fe}_{2} \mathrm{O}_{3}-<1 \%$; $\mathrm{MnO}, \mathrm{MgO}, \mathrm{CaO}, \mathrm{Na}_{2} \mathrm{O}$ and $\mathrm{P}_{2} \mathrm{O}_{5}-1$ $2 \% ; \mathrm{K}_{2} \mathrm{O}, \mathrm{TiO}_{2}$ and $\mathrm{LOI}-3-5 \%$. The measured values are in excellent agreement with the preferred values for these standards in the GeoReM online database (http://georem.mpchmainz.gwdg.de/sample_query_pref.asp - also see Table A1). 

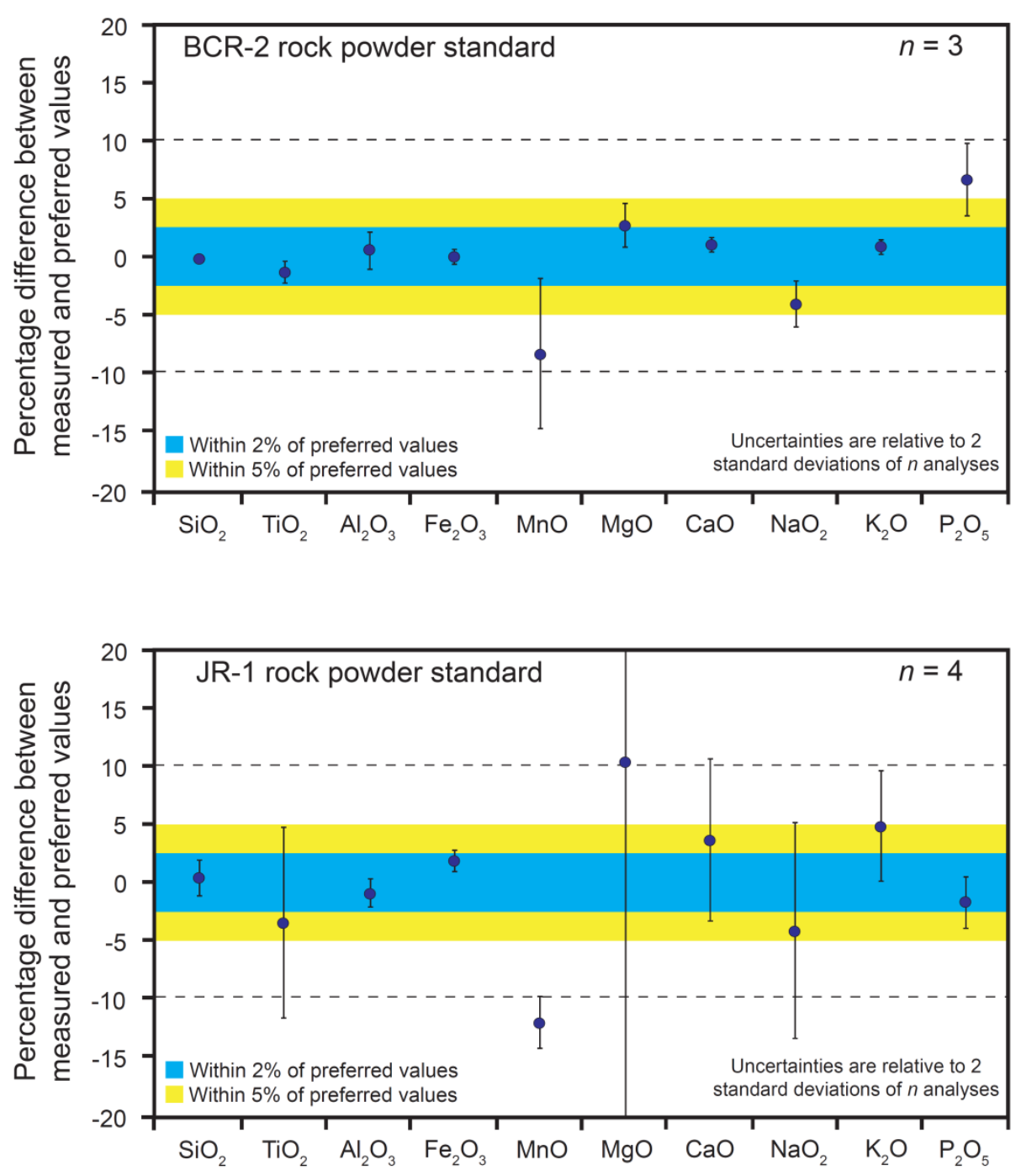

Figure A1. Summary of XRF data for the BCR-2 and JR-1 rock standards. 
Table A1. Summary of XRF data for the JR-1, BCR-2 and BHVO-2 rock standards.

\begin{tabular}{|c|c|c|c|c|c|c|c|c|c|c|c|c|c|c|c|}
\hline & \multicolumn{5}{|c|}{$\begin{array}{c}\text { JR-1 (Rhyolite, JGS) } \\
n=3\end{array}$} & \multicolumn{5}{|c|}{$\begin{array}{c}\text { BCR-2 (Basalt, USGS) } \\
n=2\end{array}$} & \multicolumn{5}{|c|}{$\begin{array}{l}\text { BHVO-2 (Bas alt, USGS) } \\
n=1\end{array}$} \\
\hline & Mean & $2 \mathrm{sd}$ & $\% 2$ sd & Preferred* & $\%$ diff & Mean & $2 \mathrm{sd}$ & $\% 2$ sd & Preferred ${ }^{\star *}$ & $\%$ diff & & $2 \mathrm{sd}$ & $\% 2$ sd & Preferred ${ }^{* *}$ & $\%$ diff \\
\hline $\mathrm{SiO}_{2}(\mathrm{wt} \%)$ & 76.1 & 1.29 & 1.7 & 75.5 & 0.7 & 54.0 & 0.13 & 0.2 & 54.1 & -0.2 & 49.7 & - & - & 49.9 & -0.4 \\
\hline $\mathrm{TiO}_{2}$ & 0.11 & 0.01 & 9.8 & 0.11 & -3.7 & 2.22 & 0.00 & 0.0 & 2.26 & -1.8 & 2.70 & - & - & 2.73 & -1.1 \\
\hline $\mathrm{Al}_{2} \mathrm{O}_{3}$ & 12.9 & 0.20 & 1.5 & 13.0 & -0.8 & 13.5 & 0.03 & 0.2 & 13.5 & -0.2 & 13.5 & - & - & 13.5 & 0.2 \\
\hline $\mathrm{Fe}_{2} \mathrm{O}_{3}$ & 0.88 & 0.01 & 0.9 & 0.87 & 1.9 & 13.8 & 0.03 & 0.2 & 13.8 & -0.3 & 12.4 & - & - & 12.3 & 0.7 \\
\hline $\mathrm{MnO}$ & 0.09 & 0.00 & 2.2 & 0.10 & -12 & 0.18 & 0.00 & 0.0 & 0.20 & -10 & 0.15 & - & - & 0.17 & -12 \\
\hline $\mathrm{MgO}$ & 0.13 & 0.00 & 2.2 & 0.11 & 23 & 3.65 & 0.00 & 0.0 & 3.59 & 1.7 & 7.37 & - & - & 7.23 & 1.9 \\
\hline $\mathrm{CaO}$ & 0.71 & 0.02 & 3.4 & 0.70 & 2.2 & 7.16 & 0.03 & 0.4 & 7.12 & 0.6 & 11.50 & - & - & 11.4 & 0.9 \\
\hline $\mathrm{Na}_{2} \mathrm{O}$ & 3.95 & 0.12 & 2.9 & 4.02 & -1.8 & 3.08 & 0.03 & 0.9 & 3.16 & -2.5 & 2.18 & - & - & 2.22 & -1.8 \\
\hline $\mathrm{K}_{2} \mathrm{O}$ & 4.62 & 0.25 & 5.5 & 4.39 & 5.4 & 1.80 & 0.03 & 1.6 & 1.79 & 0.6 & 0.51 & - & - & 0.52 & -1.9 \\
\hline $\mathrm{P}_{2} \mathrm{O}_{5}$ & 0.02 & 0.00 & 2.2 & 0.02 & -1.1 & 0.37 & 0.00 & 0.0 & 0.35 & 5.7 & 0.30 & - & - & 0.27 & 11 \\
\hline LOI & 1.34 & 0.05 & 3.9 & 1.59 & -16 & 0.00 & - & - & - & - & 0.00 & - & - & - & - \\
\hline Original total & 99.50 & 1.99 & 2.0 & 98.84 & 0.7 & 99.66 & 0.27 & 0.3 & 99.87 & -0.2 & 100.30 & - & - & 100.24 & 0.1 \\
\hline
\end{tabular}

*Values complied from data in the GeoReM database and published in Supplementary Table S4 of Allan et al. (2012) Geology 40, 563-566, reproduced here as Table A1.

** GeoReM preferred values as of July 2010 


\subsection{WHOLE ROCK TRACE ELEMENT TECHNIQUE - SOLUTION ICP-MS}

\subsubsection{Sample digestion}

Powdered samples were digested using standard hydrofluoric acid (HF) and nitric acid $\left(\mathrm{HNO}_{3}\right)$ digestion methods inside $23 \mathrm{~mL}$ Teflon beakers. The beakers were subjected to a rigorous cleaning process consisting of:

1) 24 hours submerged in Analytical Grade 6-7 $\mathrm{M}$ hydrochloric acid $(\mathrm{HCl})$ at $80{ }^{\circ} \mathrm{C}$,

2) 24 hours submerged in Analytical Grade 6-7 $\mathrm{M} \mathrm{HNO}_{3}$ at $80{ }^{\circ} \mathrm{C}$,

3) 12-24 hours refluxing in Sub-Boiled (SB) 6-7 $\mathrm{M} \mathrm{HNO}_{3}$ on a hotplate at $120{ }^{\circ} \mathrm{C}$,

4) 12-24 hours refluxing in Optima grade (ultra pure) 6-7 $\mathrm{M} \mathrm{HNO}_{3}+2$ drops of concentrated HF (Optima Grade) on a hotplate at $120^{\circ} \mathrm{C}$.

In between each stage of acid cleaning the beakers were rinsed three times with ultra clean (>18 M $\Omega$ ) milli-Q (MQ) water, and following steps 2-4 the beakers were fully dried on a hotplate at $120^{\circ} \mathrm{C}$ in a laminar flow hood before proceeding to the next stage.

$50 \pm 4 \mathrm{mg}$ of powdered sample and rock powder standards were placed into the acid cleaned Savillex Teflon beakers ready for digestion. The digestion method is summarised below. Note: all acids used during digestion and dilution stages are Optima grade (ultra pure).

- To each of the pre-cleaned beakers containing powder add 30-50 drops of conc. $\mathrm{HF}$ and 10-15 drops of conc. $\mathrm{HNO}_{3}$.

- Cap beakers and leave on the hotplate $\left(120^{\circ} \mathrm{C}\right)$ for $2-3$ days.

- Remove from hotplate and allow to cool.

- Remove caps and return to the hotplate to evaporate acid to incipient dryness. Over-drying at this stage will result in the formation of fluorides which are extremely difficult to get into solution.

- When incipient dryness is reached (after approximately 1.5 to 2 hours), remove beakers from the hotplate to allow to cool. Over drying at this stage can result in the formation of fluoride compounds that are extremely difficult to get back into solution.

- To each beaker add 30-40 drops of conc. $\mathrm{HNO}_{3}$ (or enough to bathe the entire sample in acid), re-cap the beakers and place on the hotplate for a further 20 minutes. 
- Remove the caps and evaporate the acid - as the HF will have completely evaporated by this time, the samples can be thoroughly dried out without the risk of forming fluorides.

- Once dry, add another 30-40 drops of conc. $\mathrm{HNO}_{3}$, cap, place on the hotplate for 20 minutes before removing the caps and allowing acid to evaporate until sample residue is dry.

- Remove beakers from the hotplate and allow to cool.

- To each beaker add $5 \mathrm{~mL}$ of 6-7 $\mathrm{M} \mathrm{HCl}$, cap the beakers and place on the hotplate at $120{ }^{\circ} \mathrm{C}$ for 24 hours.

- After 24 hours check to ensure that the solution is translucent (if not, repeat HF and $\mathrm{HNO}_{3}$ steps).

- Uncap the beakers and return to the hotplate to evaporate acid (overnight)

- To the dry sample residue add 30 drops of conc. $\mathrm{HNO}_{3}$ and place uncapped beaker on the hotplate to evaporate.

- To each beaker add $9 \mathrm{~mL}$ of $1 \mathrm{M} \mathrm{HNO}_{3}$, cap the beakers and place on the hotplate for 24 hours to bring the samples into solution.

The $9 \mathrm{~mL}$ solutions were then pipetted into labelled $10 \mathrm{~mL}$ centrifuge tubes that had been pre-cleaned with $\mathrm{HNO}_{3}$ and MQ. Dilutions for analysis by ICP-MS were made by adding a $60 \mu \mathrm{L}$ aliquot of the sample solutions to $6 \mathrm{~mL}$ of $1 \mathrm{wt} \% \mathrm{HNO}_{3}$ acid. The centrifuge tubes (both those containing the undiluted sample solutions and those containing the aliquot/diluted solutions for analysis) were precisely weighed when empty and after the addition of any solutions or acids, meaning that any loss of sample could be detected.

\subsubsection{Analysis by ICP-MS}

All solution trace element analyses were conducted on an Agilent 7500 CS ICP-MS at Victoria University of Wellington, New Zealand. Sample and standard solutions were introduced to the ICP-MS by free aspiration through a wet spray chamber. The ICP-MS was tuned using a $10 \mathrm{ppb}$ dilution of the Agilent tuning solution to optimise relative standard deviations (RSDs) of the isotopes in that standard $\left({ }^{7} \mathrm{Li},{ }^{59} \mathrm{Co},{ }^{89} \mathrm{Y},{ }^{140} \mathrm{Ce},{ }^{205} \mathrm{Tl}\right)$ and the plasma torch was tuned so that the production of oxides, as monitored by $\mathrm{CeO}^{+} / \mathrm{Ce}^{+}$, was $<1.5 \%$. In addition, the solutions of the BHVO-2 and BCR-2 standards and the mostand least-evolved samples were briefly monitored in tuning mode in order to access the 
RSDs across the targeted mass range $\left({ }^{7} \mathrm{Li}\right.$ to $\left.{ }^{238} \mathrm{U}\right)$ and to allow the calculation of P/A factors. P/A factors are necessary to ensure that the ICP-MS correctly switches between 'pulse' and 'analogue' counting mode when measuring for masses that yield count rates in excess of 1 million counts per second (cps). Washouts were conducted for 120 seconds (30 seconds of MQ followed by 90 seconds of $1 \mathrm{wt} \% \mathrm{HNO}_{3}$ (Optima)). Following washouts, 30 seconds of backgrounds (analytical blanks) were collected before introduction of the sample solution. Data for samples and standards were collected for 120 seconds.

After correction for backgrounds, the trace element concentrations of standards (BCR-2, JR-1) and samples were calculated relative to bracketed analyses of the BHVO-2 standard, employing ${ }^{43} \mathrm{Ca}$ as an internal standard and applying corrections to the known $\mathrm{CaO}$ content that was either known from previous XRF analyses (samples) or from reference values (standards). A summary of the values adopted for these standards and data acquired for during the same sessions as the samples from this research is presented in Tables A2 and A3. In contrast to BHVO-2 and BCR-2, the trace element concentrations of the JR-1 standard are not very well constrained and Table A4 provides a summary of what I have compiled as my preferred values for this standard based on the available data from the GeoReM database. These were typically the mean of published ICP-MS data with preference given to values determined by precise isotope dilution (ID) methods where available. A visual display of the precision and accuracy of each element measured for these standards is illustrated in Figure A2.

\subsection{IN-SITU MAJOR ELEMENT TECHNIQUE - ELECTRON PROBE MICROANALYSIS (EPMA)}

All in-situ major element analyses were determined using a JEOL JXA-8230 EPMA equipped with 5 wavelength dispersive spectrometers at Victoria University of Wellington. Mineral analyses were conducted at $15 \mathrm{kV}$ and $12 \mathrm{nA}$ under a focused $(\sim 1 \mu \mathrm{m})$ electron beam, with the current reduced to $8 \mathrm{nA}$ and beam de-focused to 10-15 $\mu \mathrm{m}$ diameter for glass analyses. Standardisation of element oxide concentrations and count rates was achieved using a combination of natural and synthetic standards and concentrations of the unknowns calculated using the ZAF correction method. In addition to the reduced current and de-focused electron beam, the severity of alkali loss during the analysis of rhyolitic 
glasses was reduced by including $\mathrm{Na}_{2} \mathrm{O}$ and $\mathrm{K}_{2} \mathrm{O}$ in the first analytical scan (of 2) and by having shorter count times $\left(10\right.$ seconds for $\left.\mathrm{Na}_{2} \mathrm{O}\right)$. Analyses of mineral and glass standards

Table A2. Elemental compositions of the rock powder standards utilised during solution ICP-MS sessions

\begin{tabular}{|c|c|c|c|}
\hline & $\begin{array}{c}\text { BCR-2 } \\
\text { GeoReM preferred* }\end{array}$ & $\begin{array}{c}\text { BHVO-2 } \\
\text { GeoReM preferred* }\end{array}$ & $\begin{array}{c}\text { JR-1 } \\
\text { Complied values }^{* *}\end{array}$ \\
\hline Li (ppm) & 9.00 & 4.80 & 63.0 \\
\hline $\mathrm{MgO}($ w t \%) & 3.59 & 7.23 & 0.11 \\
\hline Sc (ppm) & 33.0 & 32.0 & 5.14 \\
\hline Ti & 13500 & 16300 & 658 \\
\hline V & 416 & 317 & 7.89 \\
\hline $\mathrm{Cr}$ & 18.0 & 280 & 2.49 \\
\hline $\mathrm{MnO}$ & 0.20 & 0.17 & 0.10 \\
\hline $\mathrm{Cu}$ & 21.0 & 127 & 1.50 \\
\hline $\mathrm{Zn}$ & 127 & 103.0 & 28.7 \\
\hline $\mathrm{Ga}$ & 23.0 & 22.0 & 17.3 \\
\hline $\mathrm{Rb}$ & 46.9 & 9.11 & 257 \\
\hline $\mathrm{Sr}$ & 340 & 396 & 29.0 \\
\hline Y & 37.0 & 26.0 & 44.3 \\
\hline $\mathrm{Zr}$ & 184 & 172 & 99.6 \\
\hline $\mathrm{Nb}$ & 12.6 & 18.1 & 15.7 \\
\hline Mo & 250 & 4.00 & \\
\hline Cs & 1.10 & 0.10 & 20.2 \\
\hline $\mathrm{Ba}$ & 677 & 131 & 44.7 \\
\hline La & 24.9 & 15.2 & 19.3 \\
\hline $\mathrm{Ce}$ & 52.9 & 37.5 & 46.9 \\
\hline $\operatorname{Pr}$ & 6.70 & 5.35 & 5.83 \\
\hline $\mathrm{Nd}$ & 28.7 & 24.5 & 23.2 \\
\hline Sm & 6.58 & 6.07 & 5.75 \\
\hline $\mathrm{Eu}$ & 1.96 & 2.07 & 0.26 \\
\hline $\mathrm{Gd}$ & 6.75 & 6.24 & 5.41 \\
\hline $\mathrm{Tb}$ & 1.07 & 0.92 & 1.02 \\
\hline Dy & 6.41 & 5.31 & 6.05 \\
\hline Ho & 1.28 & 0.98 & 1.24 \\
\hline Er & 3.66 & 2.54 & 3.93 \\
\hline $\mathrm{Tm}$ & 0.54 & 0.33 & 0.67 \\
\hline $\mathrm{Yb}$ & 3.38 & 2.00 & 4.53 \\
\hline Lu & 0.50 & 0.27 & 0.69 \\
\hline $\mathrm{Hf}$ & 4.90 & 4.36 & 4.81 \\
\hline $\mathrm{Pb}$ & 11.0 & 1.60 & 19.0 \\
\hline Th & 5.70 & 1.22 & 25.8 \\
\hline$U$ & 1.69 & 0.40 & 8.69 \\
\hline
\end{tabular}

* GeoReM preferred values as at July 2010.

** Values compiled from data in the GeoReM database and published in the Supplementary Table S4 of Allan et al. (2012 - Geology 40, 563-566).

were interspersed among analyses of sample crystals and glasses and, if necessary, were used to correct for spectrometer drift. In particular, the NMNH 115900 plagioclase, Engels' amphibole, Johnstown Hypersthene, and ATHO-G standards were routinely analysed, and data for these standards are summarised in Table A5. 
Table A3. Summary of ICP-MS data acquired for international rock powder standards.

\begin{tabular}{|c|c|c|c|c|c|c|c|c|c|c|c|c|c|c|c|c|}
\hline \multirow{2}{*}{$\begin{array}{c}\text { Mass } \\
\text { monitored }\end{array}$} & \multirow{2}{*}{ Element } & \multirow{2}{*}{\multicolumn{5}{|c|}{$\begin{array}{c}\text { BHVO-2 rock pow der standard } \\
n=5\end{array}$}} & \multirow{2}{*}{\multicolumn{5}{|c|}{$\begin{array}{l}\text { BCR-2 rock pow der standard } \\
n=15\end{array}$}} & \multirow{2}{*}{\multicolumn{5}{|c|}{$\begin{array}{c}\text { JR-1 rock pow der standard } \\
n=7\end{array}$}} \\
\hline & & & & & & & & & & & & & & & & \\
\hline 7 & $\mathrm{Li}$ & 4.83 & 0.22 & 4.6 & 4.8 & 0.7 & 9.74 & 0.52 & 5.3 & 9.00 & 8.2 & 51.4 & 12.1 & 23.5 & 63.0 & -18.3 \\
\hline 11 & B & 2.29 & 1.09 & 48 & - & - & 2.42 & 1.56 & 64 & - & - & - & - & - & - & - \\
\hline 25 & $\mathrm{MgO}(\mathrm{wt} \%)$ & 7.30 & 0.19 & 2.5 & 7.23 & 1.0 & 3.59 & 0.09 & 2.5 & 3.59 & 0.0 & 0.12 & 0.00 & 3.6 & 0.11 & 13.7 \\
\hline 45 & Sc & 32.46 & 0.64 & 2.0 & 32 & 1.4 & 33.5 & 1.19 & 3.6 & 33 & 1.6 & 5.86 & 1.99 & 34.0 & 5.14 & 13.9 \\
\hline 47 & $\mathrm{Ti}$ & 16459 & 149.26 & 0.9 & 16300 & 1.0 & 13428 & 304 & 2.3 & 13500 & -0.5 & 601 & 32.2 & 5.4 & 658 & -8.6 \\
\hline 51 & $v$ & 319 & 10.31 & 3.2 & 317 & 0.6 & 416 & 9.72 & 2.3 & 416 & 0.0 & 5.59 & 0.32 & 5.7 & 7.89 & -29.2 \\
\hline 53 & $\mathrm{Cr}$ & 282 & 6.52 & 2.3 & 280 & 0.8 & 15.5 & 3.06 & 20 & 18 & -14 & 1.50 & 1.24 & 82.7 & 2.49 & -39.8 \\
\hline 55 & $\mathrm{MnO}(\mathrm{wt} \%)$ & 0.17 & 0.01 & 3.2 & 0.17 & 0.1 & - & - & - & - & - & 0.10 & 0.01 & 5.8 & 0.10 & -3.0 \\
\hline 59 & Co & 45.0 & 1.29 & 2.9 & 45 & 0.1 & 38.0 & 1.36 & 3.6 & 37 & 2.6 & - & - & - & - & - \\
\hline 60 & $\mathrm{Ni}$ & 120 & 2.70 & 2.3 & 119 & 0.6 & 11.8 & 2.03 & 17 & 18 & -34 & - & - & - & - & - \\
\hline 63 & $\mathrm{Cu}$ & 128 & 3.34 & 2.6 & 127 & 1.1 & 19.5 & 1.83 & 9.4 & 21 & -7.2 & 3.77 & 0.59 & 15.6 & 1.50 & 151.2 \\
\hline 66 & $\mathrm{Zn}$ & 102 & 13.89 & 14 & 103 & -0.7 & 129 & 12.86 & 10 & 127 & 1.6 & 51.1 & 16.0 & 31.3 & 28.7 & 78.0 \\
\hline 71 & Ga & 22.2 & 0.50 & 2.3 & 22 & 1.1 & 23.0 & 0.51 & 2.2 & 23 & -0.1 & 17.7 & 0.86 & 4.9 & 17.3 & 2.1 \\
\hline 85 & $\mathrm{Rb}$ & 9.16 & 0.15 & 1.7 & 9.11 & 0.6 & 47.1 & 1.08 & 2.3 & 46.9 & 0.4 & 248 & 11.9 & 4.8 & 257 & -3.8 \\
\hline 88 & $\mathrm{Sr}$ & 398 & 7.24 & 1.8 & 396 & 0.5 & 341 & 8.22 & 2.4 & 340 & 0.3 & 27.9 & 1.42 & 5.1 & 29.0 & -3.8 \\
\hline 89 & $\mathrm{Y}$ & 26.1 & 0.40 & 1.5 & 26 & 0.4 & 36.1 & 0.94 & 2.6 & 37 & -2.6 & 42.8 & 2.21 & 5.2 & 44.3 & -3.3 \\
\hline 90 & $\mathrm{Zr}$ & 173 & 2.45 & 1.4 & 172 & 0.5 & 188 & 5.16 & 2.7 & 184 & 2.4 & 92.0 & 4.65 & 5.1 & 99.6 & -7.7 \\
\hline 93 & $\mathrm{Nb}$ & 18.1 & 0.64 & 3.5 & 18.1 & 0.2 & 12.4 & 0.45 & 3.6 & 12.6 & -1.5 & 15.2 & 0.35 & 2.3 & - & - \\
\hline 95 & Mo & 4.14 & 0.47 & 11 & 4 & 3.6 & 264 & 111 & 42 & 250 & 5.4 & 3.98 & 0.75 & 18.8 & 15.7 & -74.6 \\
\hline 133 & Cs & 0.10 & 0.00 & 4.7 & 0.1 & 0.2 & 1.09 & 0.28 & 25 & 1.1 & -1.1 & 20.5 & 3.92 & 19.2 & 20.2 & 1.2 \\
\hline 137 & $\mathrm{Ba}$ & 131 & 2.24 & 1.7 & 131 & 0.2 & 678 & 41.39 & 6.1 & 677 & 0.2 & 46.7 & 2.33 & 5.0 & 44.7 & 4.6 \\
\hline 139 & La & 15.4 & 0.41 & 2.7 & 15.2 & 1.5 & 25.1 & 0.94 & 3.8 & 24.9 & 0.8 & 19.7 & 0.90 & 4.6 & 19.3 & 2.0 \\
\hline 140 & $\mathrm{Ce}$ & 37.6 & 0.45 & 1.2 & 37.5 & 0.3 & 53.4 & 1.93 & 3.6 & 52.9 & 1.0 & 47.0 & 2.17 & 4.6 & 46.9 & 0.2 \\
\hline 141 & $\mathrm{Pr}$ & 5.41 & 0.17 & 3.1 & 5.35 & 1.2 & 6.88 & 0.23 & 3.3 & 6.7 & 2.7 & 6.04 & 0.26 & 4.3 & 5.83 & 3.5 \\
\hline 146 & $\mathrm{Nd}$ & 24.7 & 0.63 & 2.5 & 24.5 & 0.8 & 28.9 & 0.85 & 2.9 & 28.7 & 0.6 & 23.7 & 1.30 & 5.5 & 23.2 & 2.3 \\
\hline 147 & $\mathrm{Sm}$ & 6.10 & 0.25 & 4.0 & 6.07 & 0.5 & 6.60 & 0.24 & 3.7 & 6.58 & 0.4 & 5.81 & 0.37 & 6.4 & 5.75 & 1.0 \\
\hline 153 & Eu & 2.09 & 0.06 & 2.6 & 2.07 & 1.0 & 2.04 & 0.06 & 3.1 & 1.96 & 4.3 & 0.28 & 0.02 & 5.6 & 0.26 & 5.1 \\
\hline 157 & $G d$ & 6.30 & 0.10 & 1.6 & 6.24 & 1.0 & 6.89 & 0.18 & 2.7 & 6.75 & 2.1 & 5.87 & 0.35 & 5.9 & 5.41 & 8.6 \\
\hline 159 & $\mathrm{~Tb}$ & 0.93 & 0.02 & 2.0 & 0.92 & 0.9 & 1.04 & 0.03 & 2.5 & 1.07 & -2.5 & 0.98 & 0.06 & 6.0 & 1.02 & -4.1 \\
\hline 163 & Dy & 5.36 & 0.11 & 2.1 & 5.31 & 0.9 & 6.44 & 0.19 & 3.0 & 6.41 & 0.5 & 6.38 & 0.32 & 5.1 & 6.05 & 5.6 \\
\hline 165 & Ho & 0.99 & 0.03 & 2.7 & 0.98 & 1.1 & 1.30 & 0.04 & 3.0 & 1.28 & 1.6 & 1.35 & 0.08 & 5.8 & 1.24 & 9.2 \\
\hline 166 & $\mathrm{Er}$ & 2.56 & 0.09 & 3.4 & 2.54 & 0.7 & 3.69 & 0.14 & 3.9 & 3.66 & 0.7 & 4.19 & 0.22 & 5.1 & 3.93 & 6.6 \\
\hline 169 & $\mathrm{Tm}$ & 0.33 & 0.01 & 2.5 & 0.33 & 1.2 & 0.52 & 0.02 & 3.1 & 0.554 & -5.5 & 0.67 & 0.04 & 6.2 & 0.67 & -0.9 \\
\hline 172 & $\mathrm{Yb}$ & 2.02 & 0.08 & 3.8 & 2 & 1.0 & 3.40 & 0.10 & 3.0 & 3.38 & 0.7 & 4.76 & 0.25 & 5.2 & 4.53 & 5.2 \\
\hline 175 & Lu & 0.28 & 0.01 & 3.5 & 0.27 & 3.0 & 0.50 & 0.01 & 2.7 & 0.5 & -0.4 & 0.71 & 0.03 & 4.6 & 0.69 & 3.3 \\
\hline 178 & $\mathrm{Hf}$ & 4.40 & 0.10 & 2.3 & 4.36 & 1.0 & 4.85 & 0.14 & 2.9 & 4.9 & -1.0 & 4.66 & 0.22 & 4.8 & 4.81 & -3.0 \\
\hline 181 & $\mathrm{Ta}$ & 1.11 & 0.11 & 9.7 & 1.14 & -2.6 & 0.78 & 0.12 & 15 & 0.74 & 5.9 & - & - & - & - & - \\
\hline 182 & w & 0.15 & 0.18 & 122 & 0.21 & -29.1 & 0.29 & 0.19 & 67 & - & - & - & - & - & - & - \\
\hline 205 & TI & 0.04 & 0.03 & 69 & - & - & 0.31 & 0.32 & 104 & - & - & - & - & - & - & - \\
\hline 208 & $\mathrm{~Pb}$ & 1.62 & 0.06 & 3.4 & 1.6 & 1.1 & 9.57 & 0.81 & 8.5 & 11 & -13 & 18.1 & 0.91 & 5.0 & 19.0 & -4.6 \\
\hline 232 & Th & 1.23 & 0.02 & 1.8 & 1.22 & 0.6 & 5.98 & 0.18 & 3.0 & 5.7 & 4.8 & 27.1 & 1.31 & 4.8 & 25.8 & 4.8 \\
\hline 248 & u & 0.41 & 0.01 & 3.2 & 0.4 & 1.7 & 1.63 & 0.06 & 3.4 & 1.69 & -3.3 & 8.52 & 0.52 & 6.1 & 8.69 & -1.9 \\
\hline
\end{tabular}


Table A4. My preferred values for the JR-1 (JGS, rhyolite) reference material compiled from the GeoReM online database.

\begin{tabular}{|c|c|c|c|c|c|c|}
\hline & $\begin{array}{l}\text { Compiled } \\
\text { values (wt } \%)\end{array}$ & $\begin{array}{l}2 \text { sd of } \\
\text { compiled } \\
\text { values }\end{array}$ & $\begin{array}{l}\text { Precision of } \\
\text { the compiled } \\
\text { values } \\
(\% 2 \mathrm{sd})\end{array}$ & $\begin{array}{c}\text { Precision of } \\
\text { measured } \\
\text { values } \\
(\% 2 \mathrm{sd})\end{array}$ & Method & GeoReM references ${ }^{\star}$ \\
\hline $\mathrm{SiO}_{2}$ & 75.5 & 0.53 & 0.7 & 1.7 & XRF (excluding outliers) & compiled from 14, 1585, 1784, 2923, 345, 3734, 808, 92 \\
\hline $\mathrm{TiO}_{2}^{2}$ & 0.11 & 0.01 & 7.4 & 9.8 & XRF (excluding outliers) & compiled from $14,1585,1784,2923,345,3734,808,92$ \\
\hline $\mathrm{Al}_{2} \mathrm{O}_{3}$ & 13.0 & 0.31 & 2.4 & 1.5 & XRF (excluding outliers) & compiled from $14,1585,1784,2923,345,3734,808,92$ \\
\hline $\mathrm{Fe}_{2} \mathrm{O}_{3}(\mathrm{t})$ & 0.87 & 0.15 & 17 & 0.9 & XRF (excluding outliers) & compiled from $14,1585,1784,2923,345,3734,808,92$ \\
\hline MnO & 0.10 & 0.01 & 7.5 & 2.2 & XRF (excluding outliers) & compiled from $14,1585,1784,2923,345,3734,808,92$ \\
\hline MgO & 0.11 & 0.03 & 29 & 2.2 & XRF (excluding outliers) & compiled from $14,1585,1784,2923,345,3734,808,92$ \\
\hline $\mathrm{CaO}$ & 0.70 & 0.07 & 10 & 3.4 & XRF (excluding outliers) & compiled from $14,1585,1784,2923,345,3734,808,92$ \\
\hline $\mathrm{Na}_{2} \mathrm{O}$ & 4.02 & 0.17 & 4.2 & 2.9 & XRF (excluding outliers) & compiled from $14,1585,1784,2923,345,3734,808,92$ \\
\hline $\mathrm{K}_{2} \mathrm{O}$ & 4.39 & 0.17 & 4.0 & 5.5 & XRF (excluding outliers) & compiled from $14,1585,1784,2923,345,3734,808,92$ \\
\hline $\mathrm{P}_{2}^{2} \mathrm{O}_{5}$ & 0.02 & 0.01 & 30 & 2.2 & XRF (excluding outliers) & compiled from $14,1585,1784,2923,345,3734,808,92$ \\
\hline LoI & 1.59 & & & 3.9 & XRF & only GeoReM data for LOI, 640 \\
\hline \multirow[t]{2}{*}{ SuM } & 98.84 & & & 2.0 & & \\
\hline & ppm & $2 \mathrm{sd}$ & $\% 2 s d$ & & & GeoReM references \\
\hline $\mathrm{Li}$ & 63.0 & 1.56 & 2.5 & 23 & ID-TIMS, ID-ICP-MS & 283 \\
\hline $\mathrm{MgO}(\mathrm{wt} \%)$ & 0.11 & 0.03 & 29 & 3.6 & XRF (excluding outliers) & compiled from $14,1585,1784,2923,345,3734,808,92$ \\
\hline Sc & 5.14 & 0.87 & 17 & 34 & ICP-MS, INAA & $14,2388,305,345,4028,4211,640,657,736,97$ \\
\hline v & 7.89 & 2.61 & 33 & 5.7 & Mean ICP-MS & $2388,305,92$ \\
\hline $\mathrm{Cr}$ & 2.49 & 0.61 & 24 & 83 & ICP-MS & $2388,305,4211,97$ \\
\hline $\mathrm{MnO}(\mathrm{wt} \%)$ & 0.10 & 0.01 & 7.5 & 5.8 & XRF (excluding outliers) & compiled from 14, 1585, 1784, 2923, 345, 3734, 808, 92 \\
\hline $\mathrm{Cu}$ & 1.50 & 0.19 & 13 & 16 & Mean ICP-MS & $2388,305,4211$ \\
\hline $\mathrm{Zn}$ & 28.7 & 5.30 & 18 & 31 & Mean ICP-MS, INAA & $2388,305,4211,640,97$ \\
\hline Ga & 17.3 & 2.42 & 14 & 4.9 & ICP-MS, XRF & $14,1585,215,2388,305,345,4211,736,92,97$ \\
\hline $\mathrm{Rb}$ & 257 & 1.86 & 0.7 & 4.8 & Mean ICP-MS & $24,305,4028,4211,79,97$ \\
\hline $\mathrm{Sr}$ & 29.0 & 3.37 & 12 & 5.1 & Mean ICP-MS & $2388,24,305,4208,4211,736,79,97$ \\
\hline $\mathbf{Y}$ & 44.3 & 4.53 & 10 & 5.2 & Mean ICP-MS & $24,305,4208,4211,736,79,97$ \\
\hline $\mathrm{Zr}$ & 99.6 & 8.22 & 8.3 & 5.1 & Mean ICP-MS & $2388,24,305,4208,4211,736,79,97$ \\
\hline $\mathrm{Nb}$ & 15.7 & 1.52 & 9.7 & 2.3 & Mean ICP-MS & $2388,24,305,4208,4211,736,97$ \\
\hline Cs & 20.2 & 0.71 & 3.5 & 19 & Mean ICP-MS & $2388,24,305,4208,4211,736,79,97$ \\
\hline $\mathrm{Ba}$ & 44.7 & 5.92 & 13 & 5.0 & Mean ICP-MS & $2388,24,305,4208,4211,736,79,97$ \\
\hline La & 19.3 & 1.05 & 5.4 & 4.6 & Mean ICP-MS & $2388,24,305,4208,4211,643,736,79,97$ \\
\hline $\mathrm{Ce}$ & 46.9 & 3.32 & 7.1 & 4.6 & Mean ICP-MS & $2388,24,305,4208,4211,643,736,79,97$ \\
\hline $\mathrm{Pr}$ & 5.83 & 0.37 & 6.4 & 4.3 & Mean ICP-MS & $2388,24,305,4208,4211,643,736,79,97$ \\
\hline Nd & 23.2 & 1.87 & 8.0 & 5.5 & Mean ICP-MS & $2388,24,305,4208,4211,643,736,79,97$ \\
\hline Sm & 5.75 & 0.44 & 7.7 & 6.4 & Mean ICP-MS & $2388,24,305,4208,4211,643,736,79,97$ \\
\hline Eu & 0.26 & 0.06 & 25 & 5.6 & Mean ICP-MS & $2388,24,305,4208,4211,643,736,79,97$ \\
\hline Gd & 5.41 & 0.90 & 17 & 5.9 & Mean ICP-MS & $2388,24,305,4208,4211,643,736,79,97$ \\
\hline Tb & 1.02 & 0.20 & 19 & 6.0 & Mean ICP-MS & $2388,24,305,4208,4211,643,736,79,97$ \\
\hline Dy & 6.05 & 0.59 & 9.8 & 5.1 & Mean ICP-MS & $2388,24,305,4208,4211,643,736,79,97$ \\
\hline Ho & 1.24 & 0.24 & 19 & 5.8 & Mean ICP-MS & $2388,24,305,4208,4211,643,736,79,97$ \\
\hline Er & 3.93 & 0.33 & 8.4 & 5.1 & Mean ICP-MS & $2388,24,305,4208,4211,643,736,79,97$ \\
\hline $\mathrm{Tm}$ & 0.67 & 0.13 & 19 & 6.2 & Mean ICP-MS & $2388,24,4208,4211,736,79,97$ \\
\hline $\mathrm{Yb}$ & 4.53 & 0.30 & 6.7 & 5.2 & Mean ICP-MS & $2388,24,305,4208,4211,643,736,79,97$ \\
\hline Lu & 0.69 & 0.10 & 14 & 4.6 & Mean ICP-MS & $2388,24,305,4208,4211,643,736,79,97$ \\
\hline Hf & 4.81 & 0.63 & 13 & 4.8 & Mean ICP-MS & $2388,24,305,4208,4211,736,79,97,2056$ \\
\hline $\mathrm{Pb}$ & 19.0 & 1.48 & 7.8 & 5.0 & Mean ICP-MS & $2388,24,305,321,4208,736,79,97$ \\
\hline Th & 25.8 & 2.49 & 9.6 & 4.8 & Mean ICP-MS & $2388,24,305,4208,4211,736,79,97$ \\
\hline u & 8.69 & 1.16 & 13 & 6.1 & Mean ICP-MS & $2388,24,25,305,4208,4211,736,79,97$ \\
\hline
\end{tabular}


Table A5. Summary of EPMA data for glass and mineral standards analysed routinely throughout this study.

\begin{tabular}{|c|c|c|c|c|c|c|c|c|c|c|}
\hline & \multicolumn{5}{|c|}{ ATHO-G (rhyolitic glass) } & \multicolumn{5}{|c|}{ Engels' Amphibole } \\
\hline & & & $n=95$ & & & & & $n=23$ & & \\
\hline & Mean & $2 \mathrm{sd}$ & $\% 2$ sd & Certified & $\%$ diff & Mean & $2 \mathrm{sd}$ & $\% 2$ sd & Pref* & $\%$ diff \\
\hline $\mathrm{SiO}_{2}$ & 75.56 & 0.75 & 1.0 & 75.6 & -0.1 & 42.30 & 0.45 & 1.1 & 42.14 & 0.4 \\
\hline $\mathrm{TiO}_{2}$ & 0.24 & 0.03 & 13 & 0.255 & -5.3 & 0.91 & 0.05 & 5.9 & 0.94 & -2.7 \\
\hline $\mathrm{Al}_{2} \mathrm{O}_{3}$ & 12.22 & 0.28 & 2.3 & 12.2 & 0.1 & 12.04 & 0.16 & 1.3 & 12.09 & -0.4 \\
\hline $\mathrm{FeO}$ & 3.21 & 0.21 & 6.6 & 3.27 & -2.0 & 18.98 & 0.50 & 2.7 & 19.05 & -0.4 \\
\hline MnO & 0.10 & 0.03 & 27 & 0.106 & -2.6 & 0.65 & 0.16 & 25 & 0.63 & 3.2 \\
\hline $\mathrm{MgO}$ & 0.10 & 0.02 & 23 & 0.103 & -4.8 & 8.69 & 0.13 & 1.5 & 8.67 & 0.2 \\
\hline $\mathrm{CaO}$ & 1.70 & 0.06 & 3.6 & 1.7 & 0.1 & 11.57 & 0.08 & 0.7 & 11.56 & 0.1 \\
\hline $\mathrm{Na}_{2} \mathrm{O}$ & 3.83 & 0.21 & 5.4 & 3.75 & 2.1 & 1.65 & 0.07 & 4.3 & 1.63 & 1.0 \\
\hline $\mathrm{K}_{2} \mathrm{O}$ & 2.57 & 0.16 & 6.4 & 2.64 & -2.5 & 0.92 & 0.04 & 4.2 & 0.91 & 0.9 \\
\hline \multicolumn{11}{|l|}{$\mathrm{Cr}_{2} \mathrm{O}_{3}$} \\
\hline \multirow[t]{4}{*}{ Total } & 99.53 & & & 99.62 & & 97.65 & 0.70 & 0.7 & 97.62 & 0.0 \\
\hline & \multirow{2}{*}{\multicolumn{5}{|c|}{$\begin{array}{c}\text { Johnstw on hypers thene } \\
n=42\end{array}$}} & \multicolumn{5}{|c|}{ NM NH 115900 plagioclase } \\
\hline & & & & & & \multicolumn{5}{|c|}{$n=30$} \\
\hline & Mean & $2 s d$ & $\% 2$ sd & Pref $f^{\star \star}$ & $\%$ diff & Mean & $2 \mathrm{sd}$ & $\% 2$ sd & Pref ${ }^{\star \star}$ & $\%$ diff \\
\hline $\mathrm{SiO}_{2}$ & 54.36 & 0.40 & 0.7 & 54.09 & 0.5 & 51.11 & 0.61 & 1.2 & 51.25 & -0.3 \\
\hline $\mathrm{TiO}_{2}$ & 0.07 & 0.02 & 31 & 0.16 & -57 & 0.02 & 0.02 & 77 & 0.05 & -50 \\
\hline $\mathrm{Al}_{2} \mathrm{O}_{3}$ & 1.23 & 0.07 & 5.8 & 1.23 & 0.3 & 30.90 & 0.44 & 1.4 & 30.91 & 0.0 \\
\hline $\mathrm{FeO}$ & 15.38 & 0.28 & 1.8 & 15.22 & 1.0 & 0.45 & 0.07 & 16 & 0.46 & -2.9 \\
\hline MnO & 0.49 & 0.07 & 14 & 0.49 & -0.6 & & & & & \\
\hline $\mathrm{MgO}$ & 26.99 & 0.33 & 1.2 & 26.79 & 0.8 & 0.14 & 0.02 & 17 & 0.14 & 1.8 \\
\hline $\mathrm{CaO}$ & 1.53 & 0.06 & 4.2 & 1.52 & 0.7 & 13.67 & 0.20 & 1.4 & 13.64 & 0.2 \\
\hline $\mathrm{Na}_{2} \mathrm{O}$ & 0.02 & 0.02 & 97 & $<0.05$ & & 3.42 & 0.14 & 4.0 & 3.45 & -0.9 \\
\hline $\mathrm{K}_{2} \mathrm{O}$ & & & & & & 0.13 & 0.02 & 17 & 0.18 & -30 \\
\hline $\mathrm{Cr}_{2} \mathrm{O}_{3}$ & 0.71 & 0.11 & 15 & 0.75 & -5.8 & & & & & \\
\hline Total & 100.78 & & & 100.25 & & & & & 100.08 & \\
\hline
\end{tabular}

*Preferred values from Ingamells (1980) Geostandards New sletter 4 (1), 139

** Preferred values from Jarosew ich et al. (1980, Geostandards New sletter 4, 43-47) 

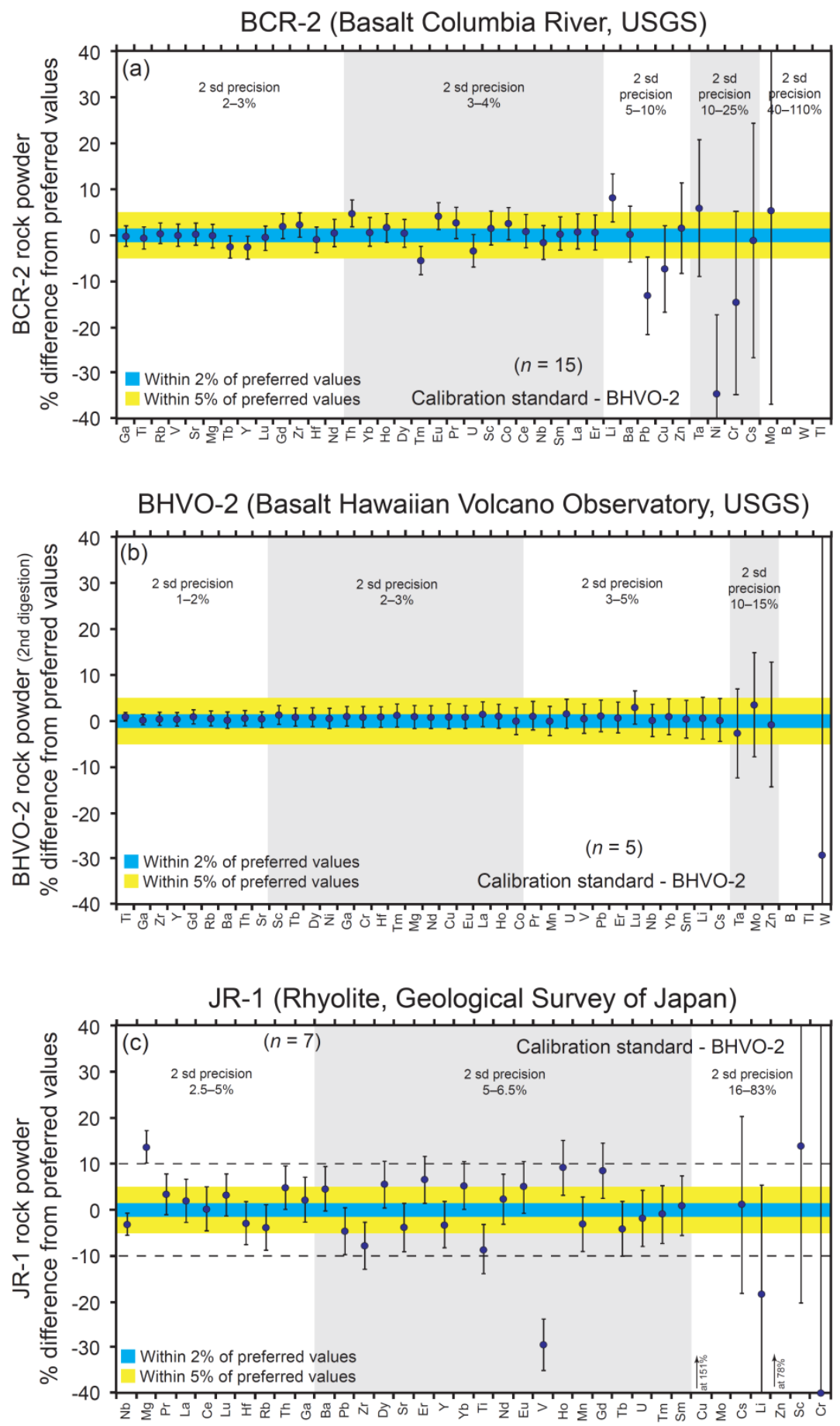

Figure A2. Summary of the ICP-MS data for the international rock standards analysed during this study. For each standard the elements are listed from left-to-right in order of the most precise to least precise measurements. The uncertainties shown are based 2 standard deviations from the mean measured values expressed as a percentage. 


\subsection{IN-SITU TRACE ELEMENT TECHNIQUE - LASER ABLATION (LA) ICP-MS}

All laser ablation ICP-MS analyses were conducted at the Victoria University of Wellington using a New Wave $193 \mathrm{~nm}$ solid state laser ablation system coupled to the Agilent 7500CS ICP-MS. Trace element concentrations were calculated from raw LA-ICP-MS data using the Iolite software package and the internal standard data reduction scheme of Hellstrom et al. (2008). The internal standard isotope technique, developed by Perkins and Pearce (1995) and Pearce et al. (1996), requires knowledge of the concentration of at least one element in the unknown (the 'internal standard'). For the analysis of silicate minerals and melts this is usually a major element oxide, typically $\mathrm{SiO}_{2}$ or $\mathrm{CaO}$ for which the concentrations have been previously determined by EPMA. A minor isotope of the major element (e.g. ${ }^{29} \mathrm{Si}$ or ${ }^{43} \mathrm{Ca}$ ) is then included in the ICP-MS analytical scan so that, after correction for backgrounds, the trace element concentrations of the unknown can then be calculated by reference to count rates on the internal standard and other isotopes in a homogenous well characterised reference material (aka the 'calibration standard'), following the relationship:

$$
\begin{aligned}
& C_{\mathrm{unk}}^{\mathrm{el}}=C_{\mathrm{rm}}^{\mathrm{el}}\left(C P S_{\mathrm{rm}}^{\mathrm{el}} / C P S_{\mathrm{rm}}^{\mathrm{I} . \mathrm{S}}\right) \times\left(C P S_{\text {unk }}^{\mathrm{el}} / C P S_{\text {unk }}^{\mathrm{I} . \mathrm{S}_{\mathrm{i}}}\right) \\
& \times\left(C_{\text {unk }}^{\text {l.S. }} / C_{\mathrm{rm}}^{\mathrm{l} . \mathrm{S}_{\mathrm{m}}}\right)
\end{aligned}
$$

where $\mathrm{C}=$ concentration, $\mathrm{el}=$ analyte element, I.S. $=$ element used as internal standard, $\mathrm{rm}$ $=$ in the reference material, unk $=$ in the sample being analysed and CPS $=$ counts per second (Pearce et al., 2007). The isotopes ${ }^{29} \mathrm{Si}$ (for orthopyroxene, plagioclase, olivine, glass), ${ }^{43} \mathrm{Ca}$ (for amphibole), and ${ }^{47} \mathrm{Ti}$ (for ilmenite and magnetite) were employed as an internal standards for the respective crystal phases with the oxide concentrations of these elements having previously been determined by EPMA.

Calculation of trace element concentrations also requires accompanying analyses of a well characterised, and preferably matrix matched, reference material (i.e. the calibration standard). Because there are no widely available, well characterised trace element standards for the mineral phases investigated here I used a selection of homogenous glass standards. The basaltic glass BHVO-2G (basaltic, USGS) was employed as the calibration standard for analyses of orthopyroxene, amphibole, olivine and Fe-Ti oxides while the synthetic glass standard NIST 612 was used to calibrate analyses of rhyolitic matrix glass, melt inclusions, and plagioclase crystals. The glass standards BCR-2G (USGS, basaltic) and ATHO-G (MPI-DING, rhyolitic) were employed as secondary standards to monitor and 
Table A6. Preferred values for the reference materials used as secondary- and calibration-standards during LA-ICPMS analytical work.

\begin{tabular}{|c|c|c|c|c|}
\hline & $\begin{array}{c}\text { NIST612 } \\
\text { GeoReM preferred* }\end{array}$ & $\begin{array}{c}\text { ATHO-G } \\
\text { Jochum et al. } 2006\end{array}$ & $\begin{array}{c}\text { BHVO-2G } \\
\text { GeoReM preferred** }^{*}\end{array}$ & $\begin{array}{c}\text { BCR2-G } \\
\text { GeoReM preferred }^{\star *}\end{array}$ \\
\hline Li & 42 & 28.6 & 4.4 & 9 \\
\hline B & 35 & 5.7 & & \\
\hline $\mathrm{Mg}$ & 77 & 621 & 43001 & 3.56 \\
\hline Si & 336061 & 353336 & 230428 & 254270 \\
\hline $\mathrm{Ca}$ & 85002 & 12150 & 81430 & 50458 \\
\hline Sc & 41 & 5 & 33 & 33 \\
\hline $\mathrm{Ti}$ & 44 & 1529 & 16300 & 2.27 \\
\hline V & 39 & 3.91 & 308 & 425 \\
\hline $\mathrm{Cr}$ & 36 & 6.1 & 293 & 17 \\
\hline$M n$ & 38 & 821 & 0.17 & 1472 \\
\hline Co & 35 & 2.13 & 44 & 38 \\
\hline $\mathrm{Ni}$ & 38.8 & 13 & 116 & 13 \\
\hline $\mathrm{Cu}$ & 37 & 18.6 & 127 & 21 \\
\hline $\mathrm{Zn}$ & 38 & 141 & 102 & 125 \\
\hline $\mathrm{Ga}$ & 36 & 25.3 & 6.16 & 23 \\
\hline $\mathrm{Rb}$ & 31.4 & 65.3 & 9.20 & 47 \\
\hline $\mathrm{Sr}$ & 78.4 & 94.1 & 396 & 342 \\
\hline $\mathbf{Y}$ & 38 & 94.5 & 26.0 & 35 \\
\hline $\mathrm{Zr}$ & 38 & 512 & 170 & 184 \\
\hline $\mathrm{Nb}$ & 40 & 62.4 & 18.3 & 12.5 \\
\hline Cs & 42 & 1.08 & 0.10 & 1.16 \\
\hline $\mathrm{Ba}$ & 39.7 & 547 & 131 & 683 \\
\hline La & 35.8 & 55.6 & 15.2 & 24.7 \\
\hline $\mathrm{Ce}$ & 38.7 & 121 & 37.6 & 53.3 \\
\hline $\mathrm{Pr}$ & 37.2 & 14.6 & 5.35 & 6.7 \\
\hline Nd & 35.9 & 60.9 & 24.5 & 28.9 \\
\hline Sm & 38.1 & 14.2 & 6.10 & 6.59 \\
\hline $\mathrm{Eu}$ & 35 & 2.76 & 2.07 & 1.97 \\
\hline Gd & 36.7 & 15.3 & 6.16 & 6.71 \\
\hline Tb & 36 & 2.51 & 0.92 & 1.02 \\
\hline Dy & 36 & 16.2 & 5.28 & 6.44 \\
\hline Ho & 38 & 3.43 & 0.98 & 1.27 \\
\hline Er & 38 & 10.3 & 2.56 & 3.7 \\
\hline $\mathrm{Tm}$ & 38 & 1.52 & 0.34 & 0.51 \\
\hline $\mathrm{Yb}$ & 39.2 & 10.5 & 2.01 & 3.39 \\
\hline Lu & 36.9 & 1.54 & 0.28 & 0.503 \\
\hline $\mathrm{Hf}$ & 35 & 13.7 & 4.32 & 4.84 \\
\hline $\mathrm{Ta}$ & 40 & 3.9 & 1.15 & 0.78 \\
\hline W & 40 & 9.3 & 0.23 & 0.50 \\
\hline $\mathrm{Pb}$ & 38.57 & 5.67 & 1.70 & 11 \\
\hline Th & 37.79 & 7.4 & 1.22 & 5.90 \\
\hline $\mathbf{U}$ & 37.38 & 2.37 & 0.40 & 1.69 \\
\hline
\end{tabular}

* These are the GeoReM preferred values for the NIST612 standard between November 2006 and June2011. The preferred values have now been up dated since the publication of Jochum et al. (2011) in Geostandards and Geoanalytical Research 35, 397-429.

** GeoReM preferred values since January 2009.

inform estimates of precision and accuracy. The values adopted for each of the reference materials are given in Table A6 and are the preferred values from the GeoReM database (see table footnotes for dates of retrieval). A visual representation of the precision and accuracy of data for the BCR-2G and ATHO-G standards is presented in Fig A3. 
Tuning and optimisation of signal sensitivity and stability was achieved by rastering across the BHVO-2G (or NIST612) standard and adjusting the inflow of ultra-pure He gas. Data were acquired using $60 \mathrm{~s}$ acquisitions (+ $60 \mathrm{~s}$ backgrounds) (Figure A4) under a static, circular laser beam of 25 or $35 \mu \mathrm{m}$ diameter pulsed at $5 \mathrm{~Hz}$.

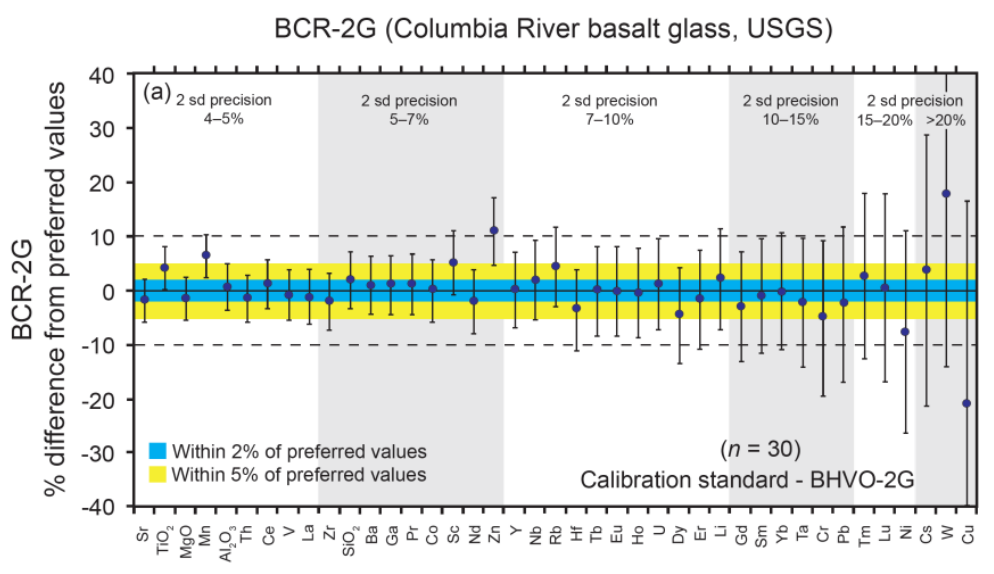

BHVO-2G (Hawaiian Volcano Observatory, basaltic glass, USGS)
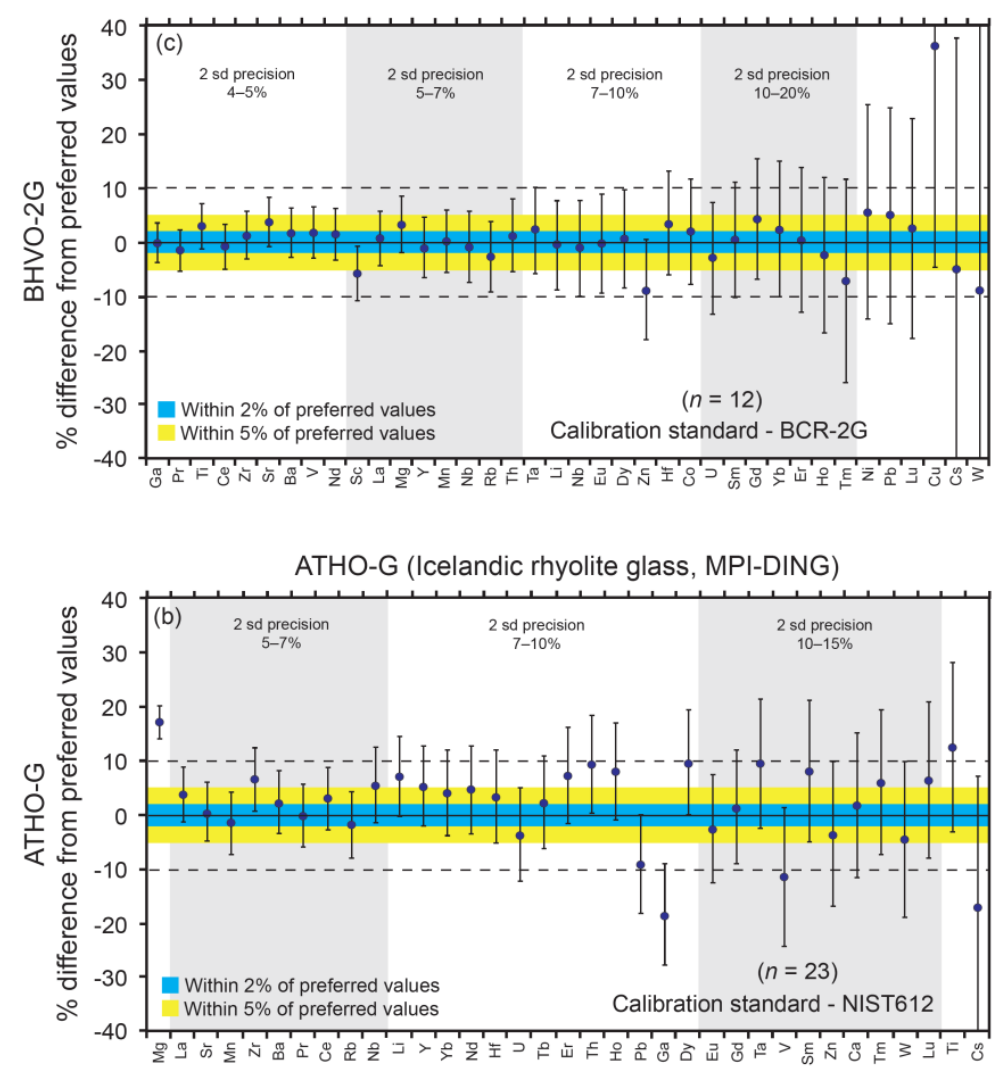

Figure A3. Summary of LA-ICP-MS data for the BHVO-2G, BCR-2G, and ATHO-G glass standards. 


\subsubsection{Processing of raw LA-ICP-MS data}

During processing of LA-ICP-MS data the time-resolved signals across several masses were monitored during each analysis to identify and remove any data compromised by the incidental ablation of inclusions beneath the polished surface. This process is essential to ensure that the data for a given analysis corresponds solely to the phase of interest. Figure A5 shows four examples where a contaminant phase was (unintentionally) ablated during part of an analysis. In all instances, had the contamination not been identified and removed, then the calculated trace element composition for the analysis would have been significantly compromised. In some cases it may be possible to learn more about what the contaminant phase by comparing the calculated trace element composition of a compromised analysis to those unaffected by contamination. An example of this is shown in Figure A6 showing data for 11 orthopyroxene analyses from the Oruanui high- $\mathrm{SiO}_{2}$ rhyolite that gave notably higher REE abundances, especially the LREE. By dividing the chondrite normalised REE values of these anomalous analyses against the average REE values of unaffected analyses, the shape of the chondrite normalised REE pattern of the contaminant phase was able to be resolved (Figure A6b). In the case of the data presented in Figure A6, and on the basis of very slightly elevated levels of Th and Sr, it seems likely that the anomalous orthopyroxene analyses represent analyses during which nanoinclusions of a LREE-enriched mineral phase, probably monazite, were incorporated. The following elements were found to be useful for monitoring the time-resolved signal and used identify the incidental ablation of mineral and melt inclusions:

- glass - elevated incompatible elements, especially Rb, Cs, Ba and Si (unless the host is quartz), $\mathrm{Al}$

- opx - elevated Mg, Mn, Zn

- ilmenite - elevated Ti, V, Mn, Nb, decreased Si

- magnetite - elevated $\mathrm{Ti}, \mathrm{Cr}$, decreased $\mathrm{Si}$

- olivine - elevated $\mathrm{Mg}, \mathrm{Ni}, \mathrm{Co}$

- plagioclase - elevated $\mathrm{Sr}, \mathrm{Al}, \mathrm{Ca}$

- amphibole - elevated levels of many trace elements but especially MREE, Y

- $\quad$ zircon - elevated Zr, Hf, HREE, Y

- monazite - almost exclusively results in strongly elevated LREE and Th

- quartz - elevated Si, a drop in all other elements 
Table A7. Summary of the LA-ICP-MS data acquired for glass standards throughout the course of this research.

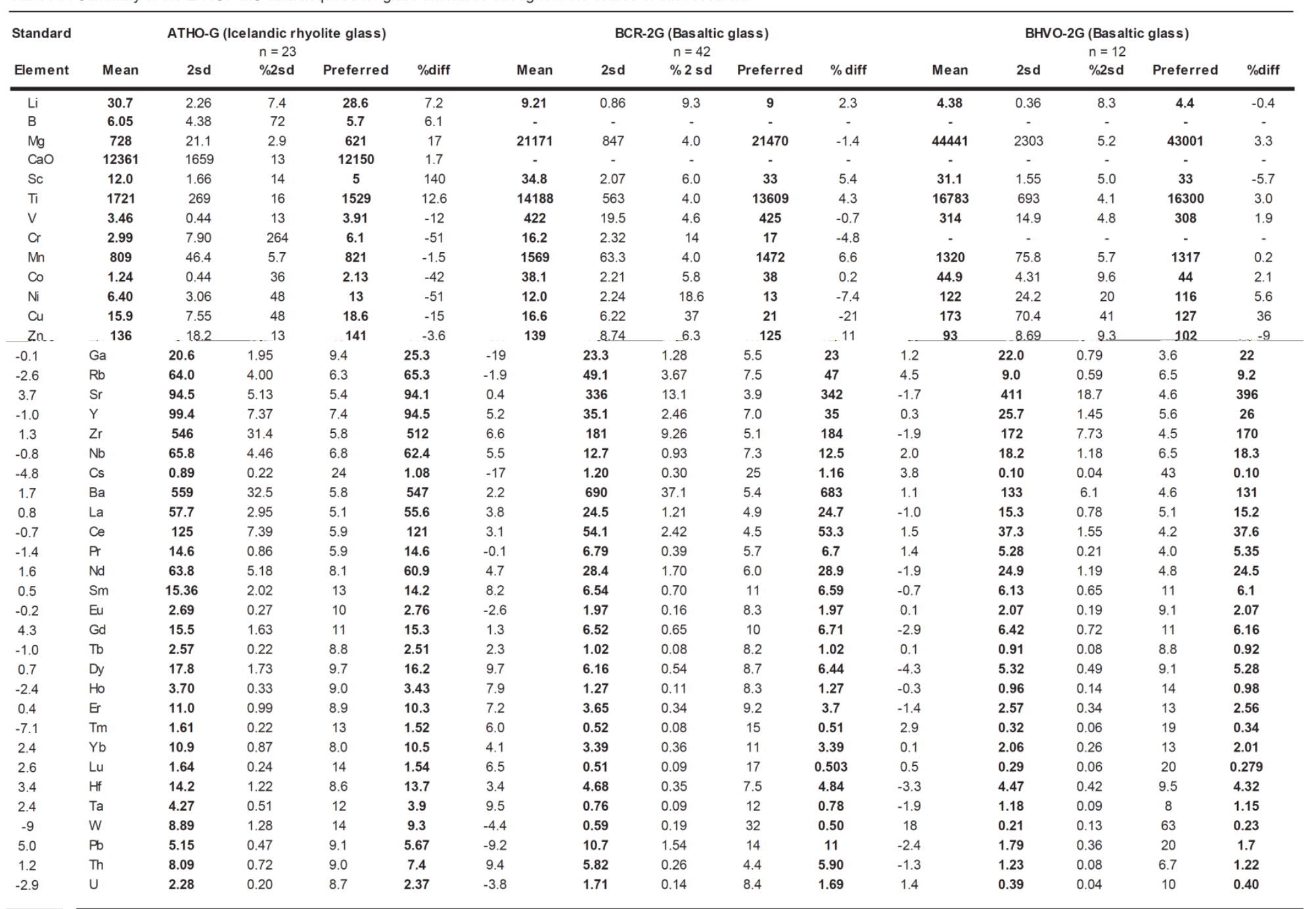




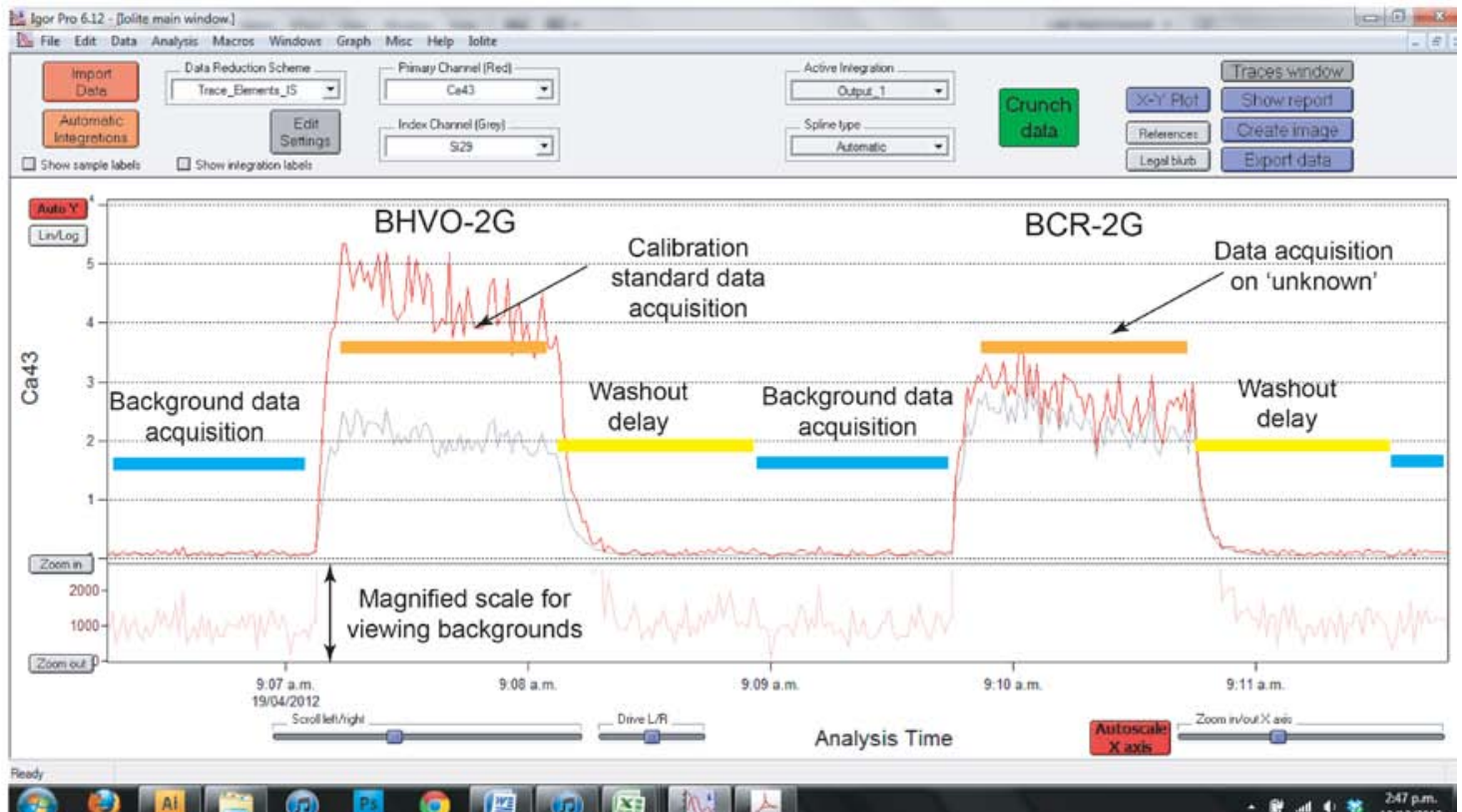

Figure A4. Annotated screen-shot of the Iolite data reduction software showing acquisition intervals for backgrounds, calibration standards and unknowns.

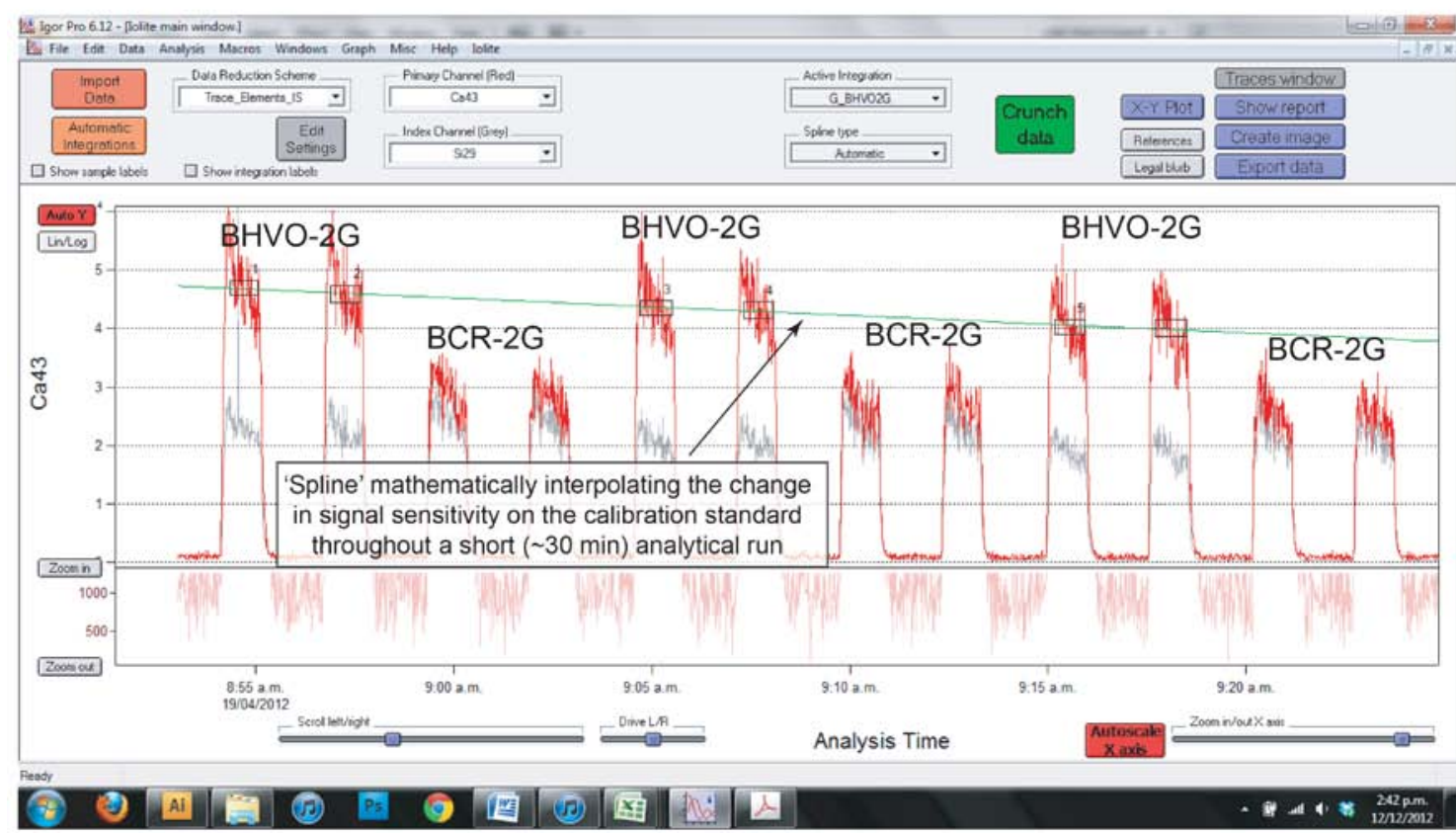

Figure A5. Annotated screen-shot the Iolite data reduction software illustrating how the 'spline' functions to mathematically account for fluctuations in the signal sensitivity during the course of a run. 
(a)

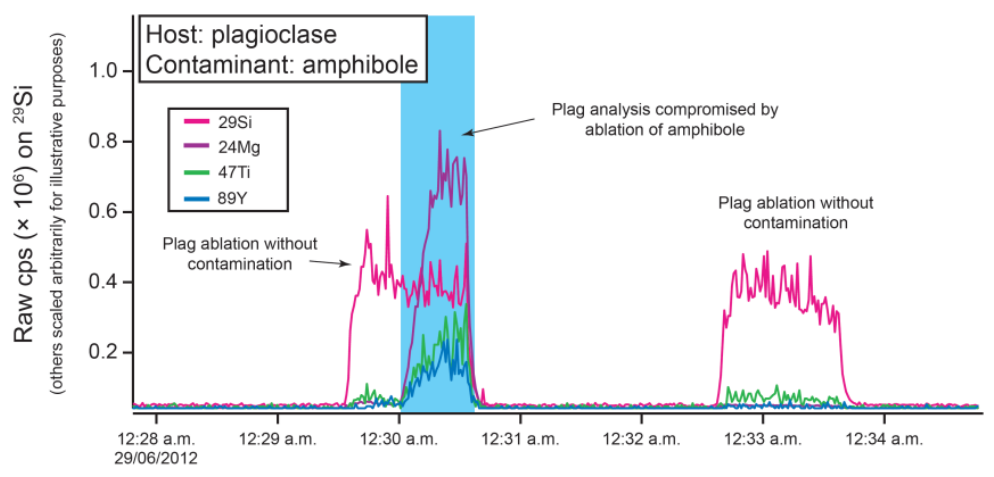

(b)

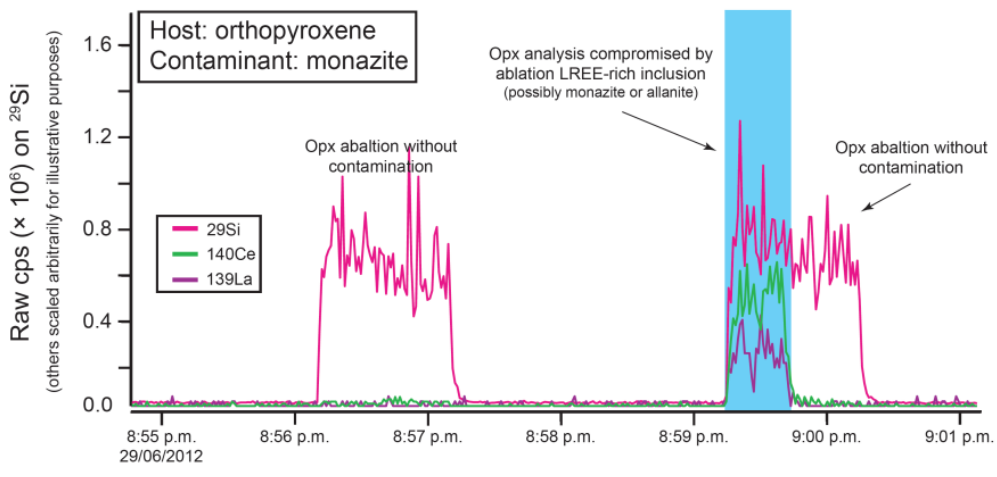

(c)

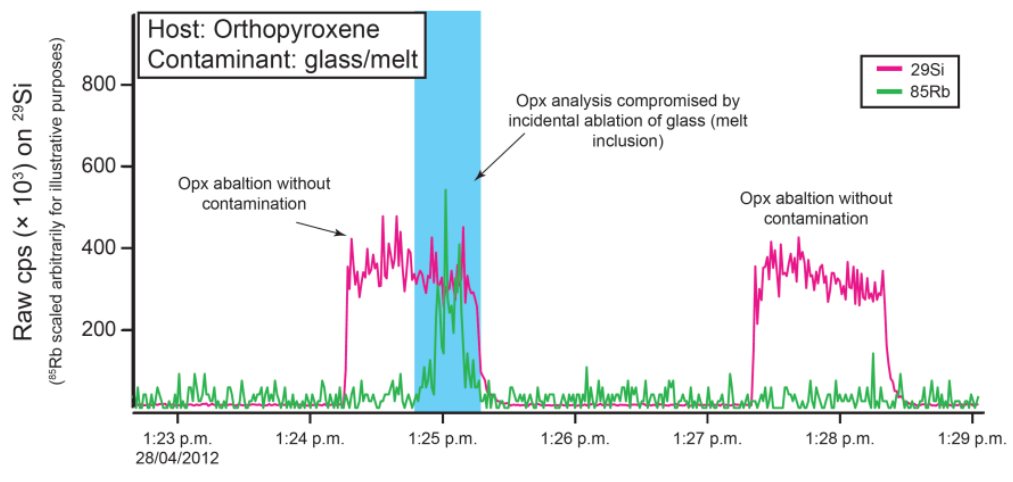

(d)

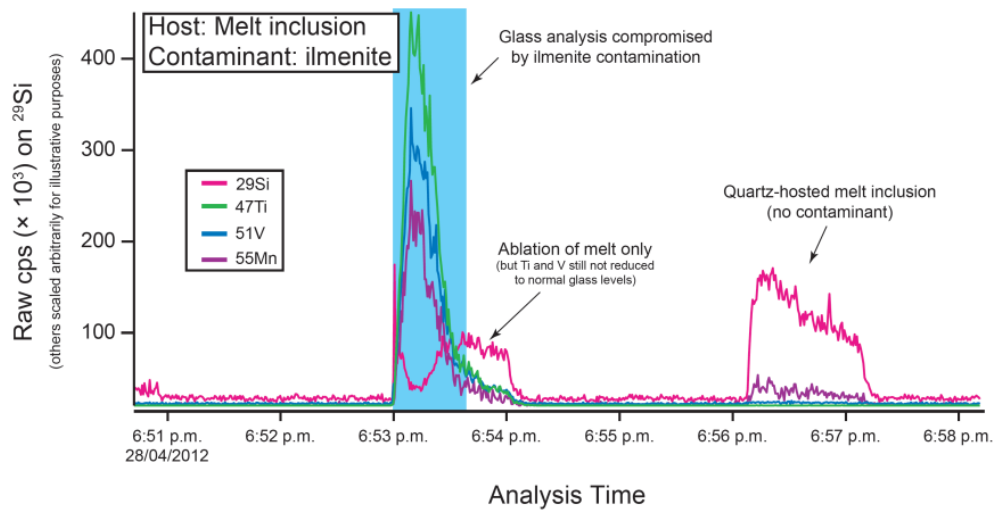

Figure A6. Selected examples showing how the raw, time-resolved signal from laser ablation analyses can be used to ascertain the accidental ablation of a contaminant (non-targeted) phase. 

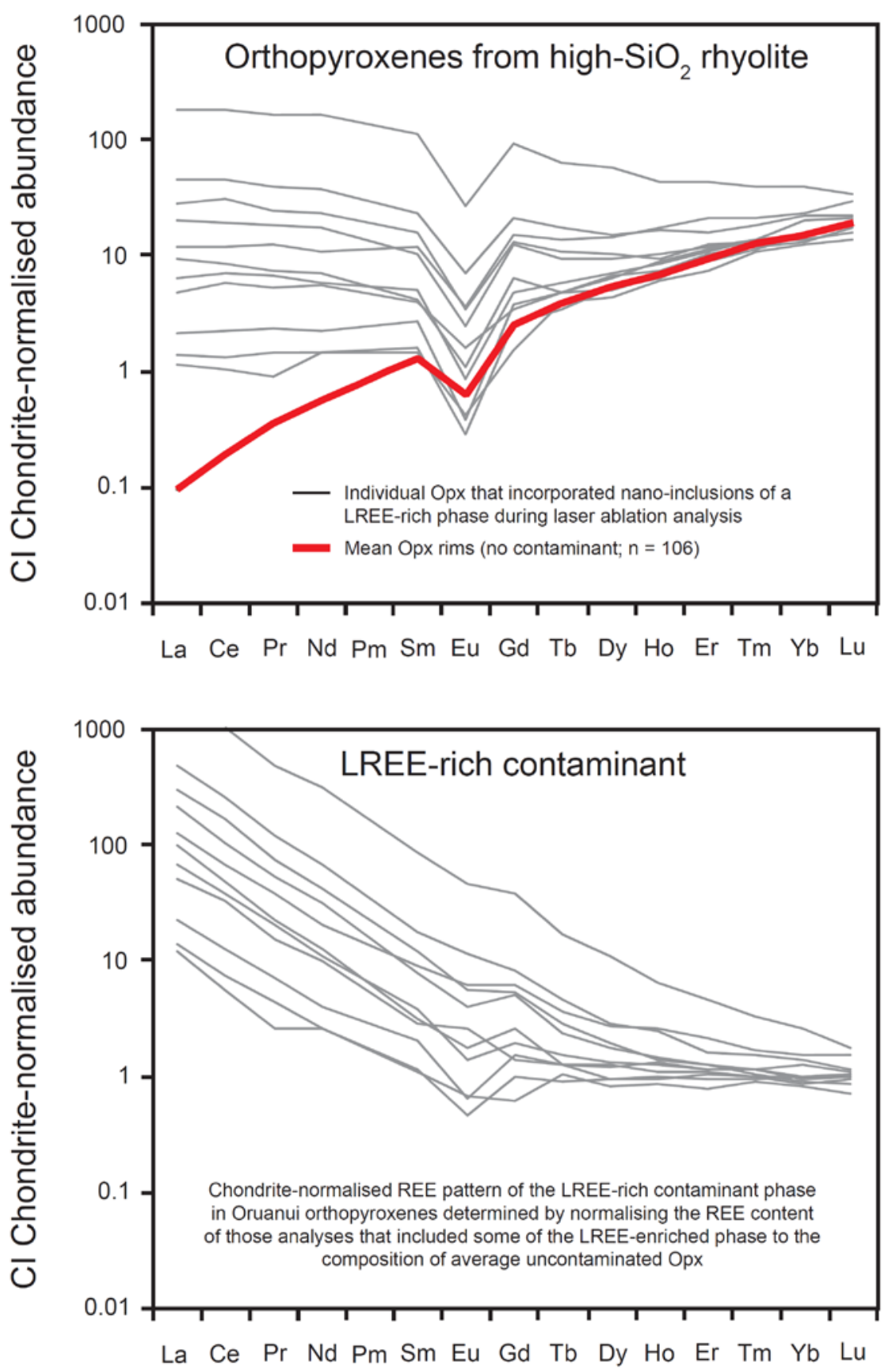

Figure A7. Chondrite normalised rare earth element (REE) data for orthopyroxenes from the Oruanui high-SiO${ }_{2}$ rhyolite. The black lines in the top plot are for orthopyroxene analyses that had noticeably higher LREE concentrations than normal, implying the incorporation of a LREE-rich contaminant phase. By normalising each of the contaminated analyses against the mean uncontaminated data, the REE pattern of the contaminant phase can be approximated (lower plot). 